TESIS DOCTORAL

\title{
PRÁCTICAS DE CLASE CON TIC EN EL SEGUNDO CICLO DE EDUCACIÓN INFANTIL. ESTUDIO DE CASOS.
}

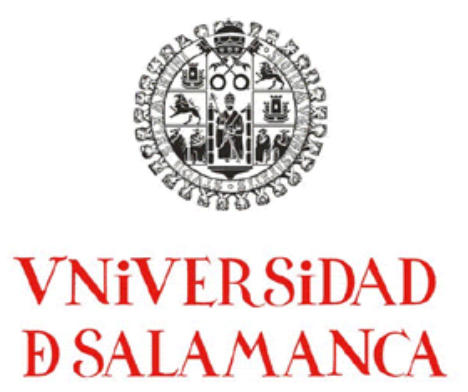

\author{
AUTOR \\ JORGE MARTÍN DOMÍNGUEZ \\ DIRECTORA \\ ELENA RAMÍREZ ORELLANA
}

SALAMANCA

2014 

Departamento de Didáctica, Organización y Métodos de Investigación.

Dra. Elena Ramírez Orellana, Profesora Titular de Universidad de Didáctica y Organización Escolar, en el Departamento de Didáctica, Organización y Métodos de Investigación de la Universidad de Salamanca, en calidad de directora del trabajo de Tesis Doctoral titulado "Prácticas de clase con TIC en el segundo ciclo de Educación Infantil. Estudio de casos.", realizado por Jorge Martín Domínguez,

\section{HACE CONSTAR que,}

dicho trabajo cumple, bajo su punto de vista, todos los requisitos científicos y formales para su presentación y defensa pública. La investigación trata de buscar respuestas a un tema relevante en el proceso de enseñanza con recursos digitales aplicando para ello un enfoque teórico riguroso y contrastado. La metodología de investigación, acorde con los objetivos planteados y la naturaleza del objeto de estudio, ha permitido el análisis y la interpretación de los datos atendiendo al marco teórico que fundamenta la investigación. Las conclusiones obtenidas contribuyen a enriquecer el corpus científico en torno el tema de especialización y abren nuevas líneas de indagación para el futuro.

Por todo ello, manifiesto mi conformidad para que se autorice la presentación y defensa del trabajo referido. 



\section{Agradecimientos:}

En primer lugar, y como no podía ser de otra forma, gracias Elena Ramírez porque me has brindado la oportunidad no sólo de poder realizar este trabajo bajo tu dirección sino también de crecer profesional y personalmente en estos años.

Gracias sobre todo por tu infinita paciencia (desde el primer día hasta la actualidad), tu profesionalidad y tu constancia en lo que a la Educación y la investigación se refiere, así como tu nobleza en todos los aspectos de la vida. Gratitud también por enseñarme que el trabajo bien hecho da sus frutos y apoyarme para seguir hacia delante, valorando mi labor y siendo siempre crítica y directa tanto en los aciertos como los fallos.

Gracias por último (aunque sé que son muchos más los que podría seguir escribiendo tanto a nivel personal como profesional) por hacerme sentir uno más, por escuchar, explicar y reflexionar sobre mis dudas, por compartir tu conocimiento (que es mucho), por trabajar tanto en todos los aspectos de elaboración de este trabajo (viajes, grabaciones, categorizaciones, tutorías, correcciones,...), y por todas aquellas cosas que, a buen seguro, tendré que agradecerte en el futuro. Por todo ello

\section{GRACIAS ELENA}

Gracias maestros de infantil, por dejarme entrar en vuestras aulas, por compartir vuestra experiencia, por responder a mis dudas, por contarme vuestras preocupaciones, por enseñarme tantas cosas para mí desconocidas y sobre todo por trabajar como trabajáis, por vuestra profesionalidad, por vuestro cariño a los niños, por vuestra infinita paciencia y respeto por la Educación

Gracias María Clemente por confiar siempre en mis posibilidades y ver que yo podría aportar algo, aunque sea poco, al mundo de la Educación, por estar siempre ahí, por compartir y por darme consejos que a día de hoy (y en el futuro) están (y estarán) muy presentes en mi profesión y mi vida.

Gracias Begoña Orgaz e Isabel Cañedo, que junto a María, Elena y Jesús (que más tarde le daré mi agradecimiento) formasteis parte del equipo de investigación del proyecto del cual surge esta tesis y porque con vuestro apoyo metodológico y teórico he contado siempre que lo he necesitado.

Gracias compañeros de departamento, en especial a Adriana Recamán, por tu apoyo brindado siempre en los momentos buenos y en los malos, teniendo como sabes, además de mi amistad, toda mi admiración profesional y la seguridad de en un futuro muy próximo trabajaremos juntos. A Carlos González, por creer como crees en la Educación, por romper esquemas y por reflexionar y aprender juntos. A Luis González, por esas horas intempestivas en las que te encuentras trabajando en el despacho y sacas un hueco para charlar conmigo. A Inés Rodríguez, por demostrar que sabes bien que hay que trabajar duro para conseguir las cosas y sigues adelante, y por tus consejos en las lecturas ociosas. A Dionisio de Castro, por soportarme como vecino de despacho y por la ayuda que me has ofrecido siempre. 
A Marisa García, porque siempre estás dispuesta ayudarme y por todo lo que aprendo de la Educación Infantil cuando hablamos. A Isabel Calvo, Ángel Morín y Ana Belén Sánchez por esas charlas en la que siempre le damos una vuelta a la situación de la Educación y sus problemas. A Fernando Martínez, por tu estudio en los aspectos metodológicos y por hacer que el tamaño del efecto fuese menos desconocido para mí. A Antonio, Juan Pablo, Patricia, Eva, Juanjo, Susana,... a todos.

Gracias Ángel San Martín, por tu hospitalidad, por tu nobleza y porque me enseñaste e hiciste que pensara, entre otras miles de cosas, en lo que hay entre los bastidores de todo esto que se hace llamar transferencia tecnológica en la Educación. Y también a Pepe Peirats y Jaume Martínez, que junto con Ángel, me adoptasteis en tierras valencianas y pude ver la labor que desempeñáis allí de la que tanto aprendí.

Gracias por la doble acogida amigo Rodrigo Pavez, primero en el Mediterráneo y luego en el Pacífico, donde hemos pasado ratos buenos y no tan buenos juntos, y porque desde tu visión de filósofo y educador has hecho que amplíe mi conocimiento y cultura.

Gracias Lucía Echeverría, por lo luchadora que eres en la vida y porque me diste una visión más amplia de lo que es la Educación acercándome la música y su didáctica. Ya nunca olvidaré a Suzuki y a Roland.

Aunque los anteriores agradecimientos también tienen en muchos casos un componente emocional y personal, los que escribo a continuación van destinados a aquellas personas que han influido en que hoy sea lo que soy, sobre todo como persona:

Gracias en especial a mi abuelo César, que aunque ya no te encuentres entre nosotros, sé que estás orgulloso de mí. Marcaste mi vida, me has hecho ser mejor persona, creer en la bondad de los demás y respetar a todos en su diversidad, eso sería el mejor legado que podría dar a la Educación.

Gracias a mis padres y mi hermano por compartir vuestra vida conmigo. A mi madre, por cuidarme y preocuparte de forma incondicional, por tu insistencia en la continuación de mis estudios que me han hecho llegar hasta aquí, por todo el cariño que siempre me has dado, por la paciencia que has tenido durante todos estos años conmigo (y que tendrás que seguir teniendo) y por los valores que me has transmitido. A mi padre, por la confianza que en mí demostraste pese a lo que pareciera, por hablarme claro y razonar conmigo, por esos cachetes que tanto me merecía cuando ya no razonaba, por la parte de maestro que gracias a ti llevo dentro, por el cariño, la comprensión y por demostrar lo orgulloso que estás de mí. A mi hermano César, por haber tenido la paciencia de crecer a mi lado, por compartir penas y alegrías, por abrirme el camino de la pedagogía, por esas charlas de las que tanto aprendí, aprendo y aprenderé y por hacerme tío. 
Gracias Nabi, por estos casi siete años que llevas a mi lado soportando todas esas horas que yo pasaba trabajando, por recibirme siempre en casa con una sonrisa, por darme palabras de ánimo y de cariño que tanto necesitaba, por todos esos momentos duros que me has ayudado a superar, por enseñarme tanto del valor y la lucha en la vida y sobre todo por ser tú.

Gracias José Ramón, porque tendiste esa mano cuando me caía y supiste ayudarme y comprenderme, por tu amistad y confianza depositada durante tantos años, y tu seguridad (más que nadie) en que este momento llegaría.

Gracias Pepe Casanueva, que me ayudaste en esos momentos en los que yo no entendía la Educación, pero me mostraste con tu labor lo que debería de ser, por ese gesto sigo y creo en ella.

Gracias Jesús Jiménez, por tu labor de apoyo y compresión a los alumnos entre los que tuve la suerte de tenerte como maestro, espero puedas con tu filosofía seguir rescatando esas personas que otros prejuician.

Gracias al resto de mi familia, porque ellos siempre me han apoyado cuando todo era incierto y se han alegrado cuando se hizo realidad. A mis abuelos, Vicente, Jesusa y $\mathrm{M}^{\mathrm{a}}$ Luisa. A mis tíos, Esther, Jesús, Lourdes, Chuchi, Mari Luz, Alicio, Ernesto, Montse, Elena, Julio, Coro, Malusa, Chani, Abraham, Carmen, Pruden, Daniel, Beli y Ankie. A mis primos, Rebeca, Elisa, Ítaca, Lydia, Alberto, Pablo, Zaira, Corona, David, Javier, Jacob, Silvia, Carlos, Vicky, Álvaro y Helena.

Gracias a mis amigos, los cuáles se dividen en los que pensaban que este día no iba a llegar, los que pensaban que podía llegar y los que no pensaban en este día. De forma especial lo agradezco a Rober (Pere), Manolo, Juancar, Araceli, Pablito, Watta, Rober, Kike, Mangas, Pinone, Dani, Noemí, Sergi, Óscar, Carlos, Gómez y David.

Son muchos más los agradecimientos que debería poner, siendo tanta gente la que ha estado ahí, tanto en lo profesional como en lo personal. Así que pido disculpas a todos aquellos que no haya nombrado y que indudablemente han aportado para que esto sea lo que es y yo sea lo que soy.

A TODOS ELLOS, GRACIAS

La realización de este trabajo no habría sido posible sin la financiación, apoyo y colaboración de:

- Las Ayudas destinadas a financiar la contratación de personal investigador de reciente titulación universitaria en el marco de la Estrategia Regional de Investigación Científica, Desarrollo Tecnológico e Innovación 2007-2013 cofinanciadas por el Fondo Social Europeo (Orden EDU/1933/2008, de 11 de noviembre, B.O.C. y L. n. ${ }^{\text {o } 220)}$ de la Junta de Castilla y León.

- La financiación del Proyecto de I+D (nº de referencia EDU 2009-11295) del Ministerio de Ciencia e Innovación.

- El apoyo y colaboración del Centro Internacional de Tecnologías Avanzadas en el Medio Rural de la Fundación Germán Sánchez-Ruipérez. 



\section{INDICE}

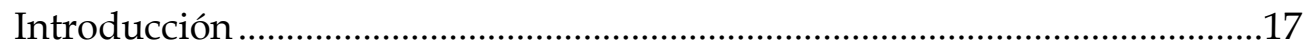

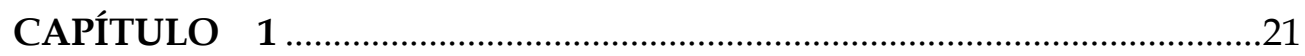

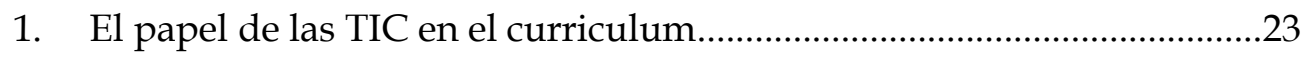

1.1. El curriculum. ¿Qué es el curriculum? ................................................23

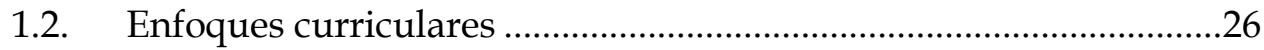

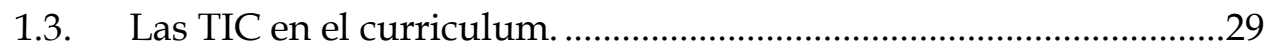

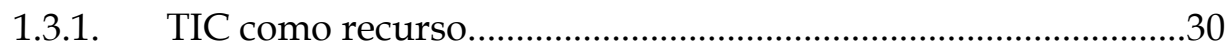

1.3.2. Las TIC como contenido: Alfabetización Digital ........................36

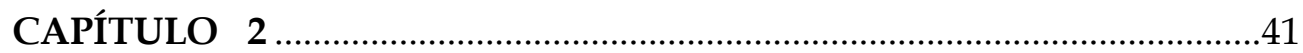

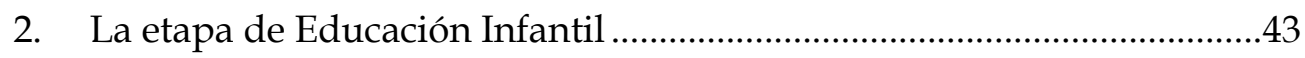

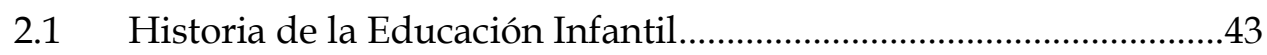

2.1.1. Los primeros referentes teóricos. .................................................43

2.1.2. Referentes teóricos en el siglo XX: desde la práctica a la

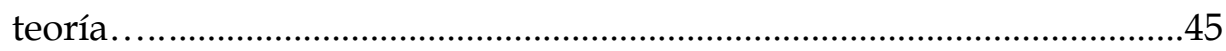

2.1.3. Evolución de la Educación Infantil en España. Marco

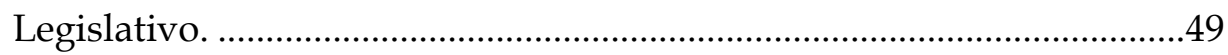

2.2. La legislación actual en Educación Infantil........................................52

2.2.1. Ley Orgánica 2/ 2006 de Educación ..............................................52

2.2.2. Decreto 122/2007, de 27 de diciembre, Consejería de Educación, Castilla y León...........................................................................54

2.3. La Etapa de Educación Infantil en el contexto español......................54

2.3.1. Características Psicológicas de la Edad ........................................55

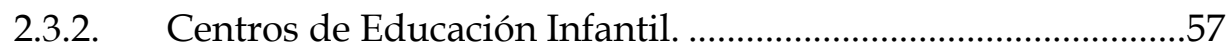

2.3.3. Aspectos organizativos y metodológicos de la etapa...............58

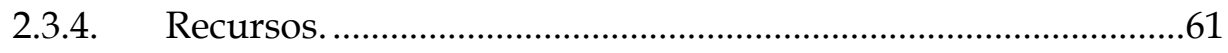




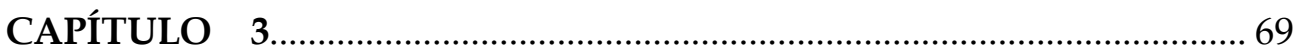

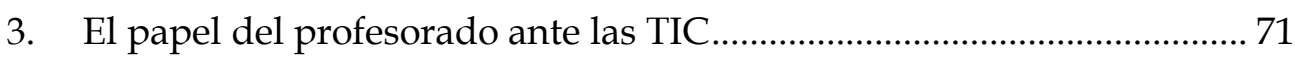

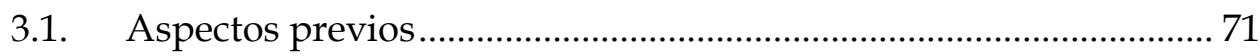

3.2. El conocimiento profesional del docente y las TIC ........................... 72

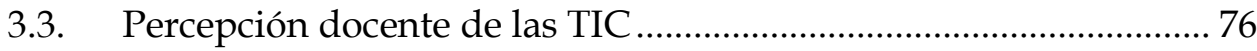

3.4. El docente y sus capacidades ante las TIC .......................................... 80

3.5. Profesor, TIC y Educación Infantil ........................................................ 84

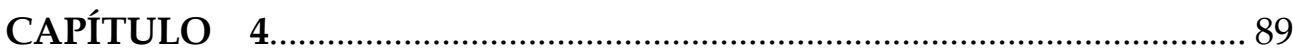

4. Prácticas de aula y sistemas de análisis......................................................... 91

4.1. La planificación: antes de la práctica. ................................................. 93

4.2. Estructura y desarrollo: las actividades y los esquemas de acción.95

4.3. El profesor. Situación privilegiada ante el estudio de la práctica de

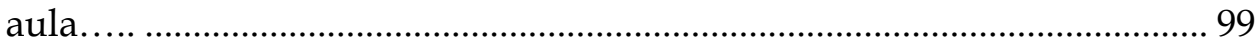

4.4. Sistemas de análisis. Planificación, observación, análisis e

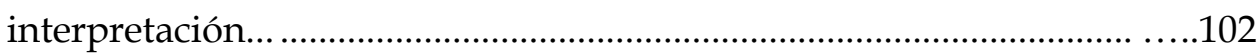

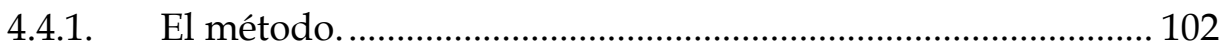

4.4.2. La construcción de la herramienta de análisis de las

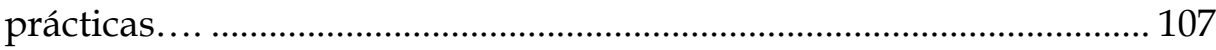

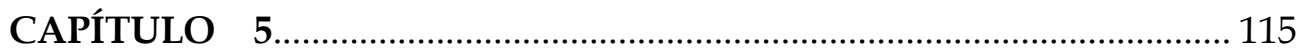

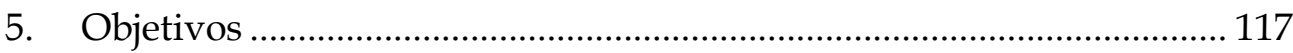

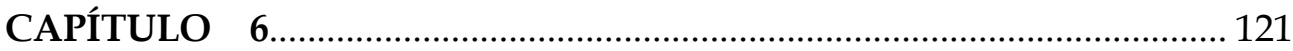

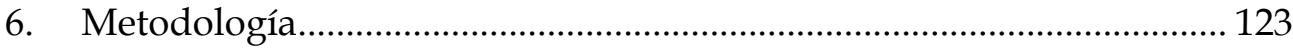

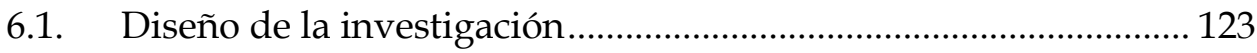

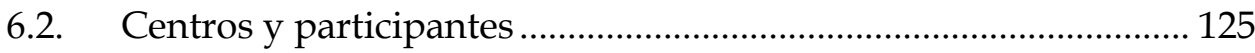

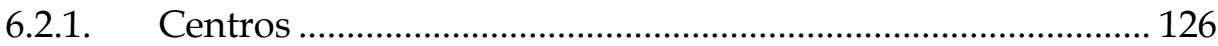

6.2.2. Datos comparativos: Centros................................................... 160

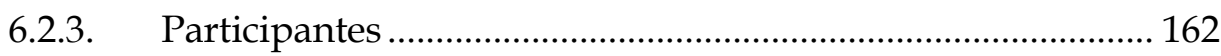

6.2.4. Datos comparativos: Profesores. ………………………….... 177

6.3. Sistema de análisis. Procedimiento de análisis de las clases........ 180 
7. Resultados

7.1. Datos descriptivos por ATAs: Cómo se configura cada patrón de actividad en el transcurso de las clases.

7.1.1. Planificación/organización de tareas ........................................192

7.1.2. Organización para salida al recreo............................................194

7.1.3. Visionado de película con recurso TIC.......................................195

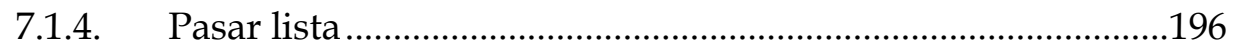

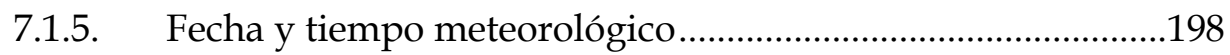

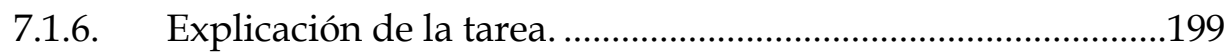

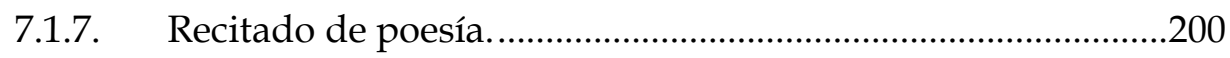

7.1.8. Realización de tareas por rincones..........................................202

7.1.9. Realización de tareas con y sin TIC relacionadas. ...................203

7.1.10. Realización de tareas con y sin TIC independiente................204

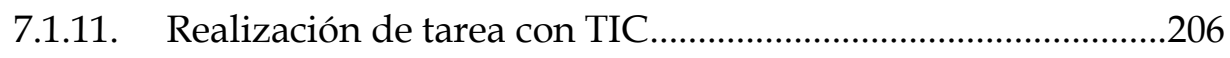

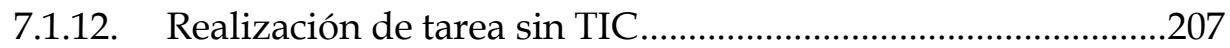

7.1.13. Corrección de trabajos en clase.....................................................209

7.1.14. Organización de vuelta del recreo. ..........................................210

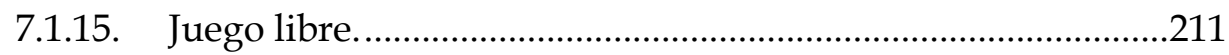

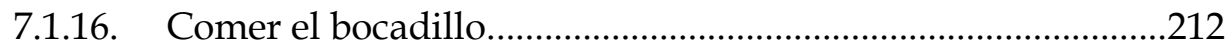

7.1.17. Lectura de imágenes con recurso no TIC..................................214

7.1.18. Lectura de imágenes con recurso TIC.........................................215

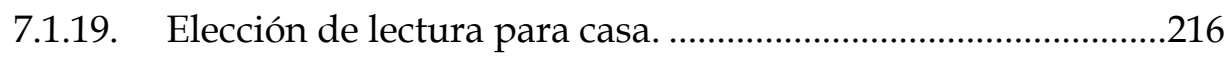

7.1.20. Síntesis comparativa de los datos descriptivos de las diferentes ATAs. 218

7.2. Datos descriptivos por profesores: Cómo desarrolla las prácticas

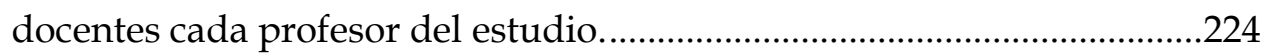

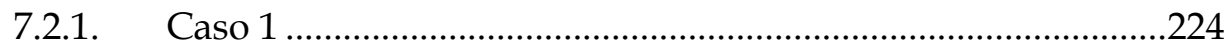

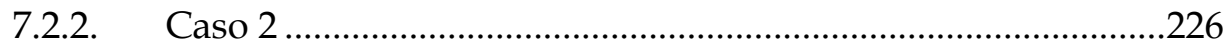




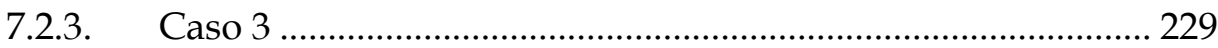

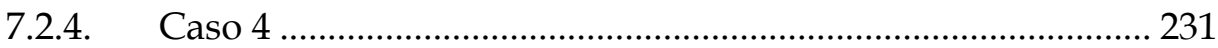

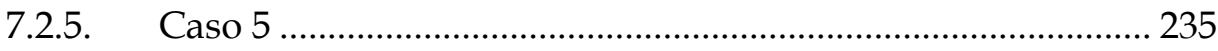

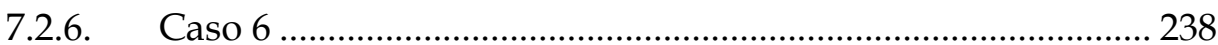

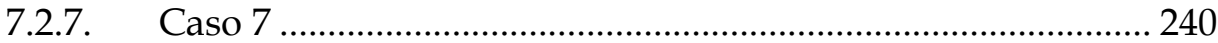

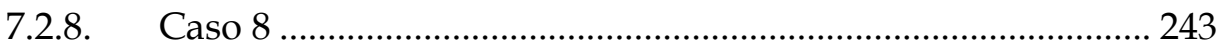

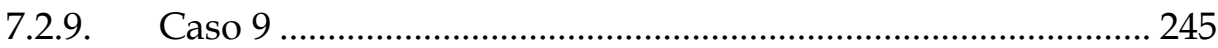

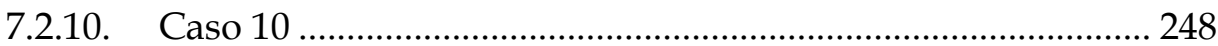

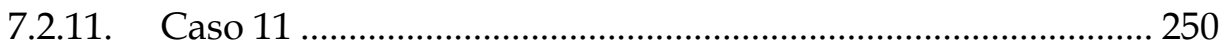

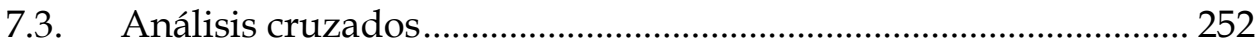

7.3.1. Análisis de las relaciones entre ATAs y curso de Educación

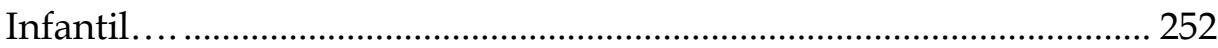

7.3.2. Análisis de las diferencias entre profesores y tipos de

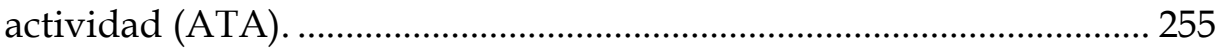

7.3.3. Análisis de las diferencias entre los tipos de actividad que desarrollan los profesores en los distintos cursos................................. 257

7.3.4. Análisis de la relación entre acciones instructivas y elementos

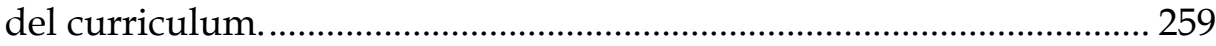

7.3.5. Análisis de la relación entre acciones instructivas y elementos del curriculum en los diferentes cursos................................................... 261

7.3.6. Análisis de la relación entre elementos del curriculum

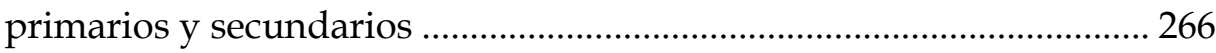

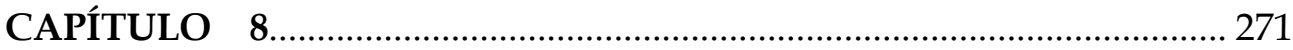

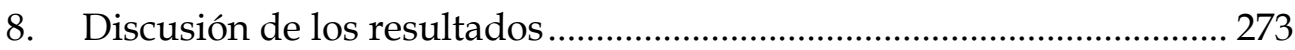

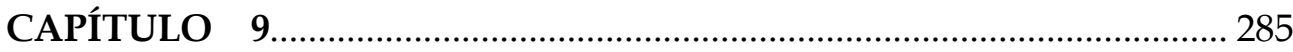

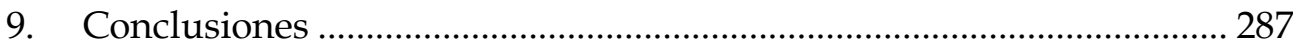

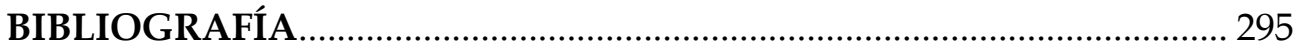

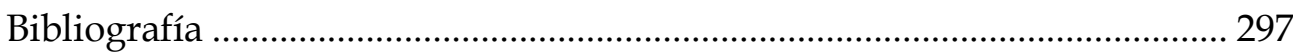

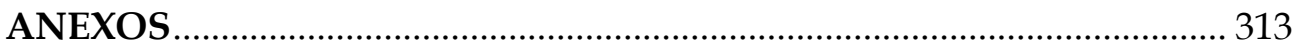




Dedicado a todos los docentes que día a día tanto hacen por la Educación.

"El que lo sabe hace, el que lo entiende enseña"

Lee S. Shulman 



\section{Introducción}

La irrupción de las TIC en todos los órdenes de la vida social y económica está provocando cambios que afectan a cuestiones personales, a los intercambios comunicativos, a las instituciones, a la producción de bienes y servicios... La educación es uno de los ámbitos que está siendo afectada por la incorporación de tecnologías y el efecto se puede apreciar, entre otros aspectos, en cuestiones claves como la evolución de lo que se entiende por "sujeto alfabetizado", la aparición de nuevos filtros y criterios para seleccionar la información que se considera valiosa para ser enseñada, el surgimiento de nuevos agentes de creación de contenidos o el desarrollo de nuevos recursos en la práctica de enseñanza. Este estado de cosas lleva consigo en el ámbito académico y, más en concreto, en la investigación un incremento notable del interés por explicar el efecto que los recursos TIC puedan ejercer sobre múltiples elementos implicados en los procesos de enseñanza-aprendizaje.

Inscrito en ese interés registramos el trabajo que se presenta en esta ocasión. De hecho, esta investigación forma parte de un proyecto más amplio dirigido a estudiar la incorporación de un recurso de aprendizaje basado en las TIC en la etapa de Educación Infantil. En dicho proyecto se abordan aspectos relativos al conocimiento pedagógico relacionado con las TIC que tienen los profesores de la etapa, atendiendo no sólo a sus pensamientos y creencias sino también a sus prácticas de aula. Asimismo, se estudia la repercusión que las prácticas de aula con las TIC tienen en lo que aprenden los alumnos de infantil del estudio. Como parte de ese proyecto genérico, en este trabajo se abordan de forma específica el análisis de las prácticas de aula con el recurso digital, profundizando en lo que a nuestro modo de ver constituye el núcleo clave para explicar los procesos de enseñanza y sus cambios, si es que se producen: el desarrollo del currículum en la propia práctica del aula.

El marco teórico del que partimos para explicar cómo los profesores incorporan el recurso TIC en las tareas de desarrollo del currículum en las prácticas de aula se apoya en una serie de ejes que constituyen los pilares sobre los que se asienta la explicación del fenómeno de la integración de las TIC, desde nuestro punto de vista. Por un lado, entendidos como materiales curriculares, los recursos TIC pueden desempeñar distintos papeles en el desarrollo del currículum en el aula dependiendo del concepto o modelo de 
currículum al que sirven. Para comprender el sentido de los recursos es preciso entender su funcionamiento en el marco de las distintas concepciones sobre el currículum que van asociadas a enfoques diversos de la práctica curricular. Los aspectos relacionados con este elemento se explican en el primer capítulo del marco teórico. Pero, el desarrollo del currículum y el papel de los recursos curriculares en la práctica viene definido en buena medida por las peculiaridades, sobre todo de orden metodológico y organizativo, que caracterizan a las distintas etapas educativas. De ahí que en el capítulo 2 de la fundamentación teórica se incluyan aspectos didácticos relativos a la etapa de Educación Infantil, para entender con mayor rigor lo que constituirían las particularidades curriculares de la etapa. Otro de los ejes básicos del marco teórico de este trabajo lo constituye la idea denominada "conocimiento profesional del docente". A partir de dicho constructo, tratamos de explicar cómo los profesores utilizan los recursos y cómo los integran en sus prácticas de clase. En definitiva, cómo les dan sentido en su práctica profesional. Este aspecto aparece ampliamente desarrollado en el capítulo 3 del marco teórico del trabajo. Por último, en el capítulo 4 de dicha fundamentación teórica, se retoman ideas previas en relación a la planificación del currículum, la estructura de las actividades en el desarrollo del currículum y el papel del docente en la materialización de la acción en el aula para explicar y justificar cómo la práctica se constituye en la dimensión protagonista del análisis de nuestro estudio y cómo el sistema de análisis de la práctica refleja no sólo lo que entendemos por las dimensiones más características de la actuación de los profesores en los contextos reales, sino también, las dimensiones referidas a la gestión de los elementos del currículum en la acción directa del aula por parte del docente.

Desde la fundamentación teórica se plantea el objetivo general de la investigación que en su formulación más genérica se enfoca hacia el análisis de cómo los docentes de Educación Infantil configuran sus prácticas de aula cuando introducen recursos TIC en el desarrollo del currículum.

Para conseguir ese objetivo se tomaron decisiones metodológicas especificas para el estudio, tanto en el diseño elegido como en el registro de los datos más adecuado a fin de conseguir el mayor rigor y precisión posible. Todos estos aspectos se desarrollan extensamente en el capítulo 6, capítulo que se considera fundamental para poder comprender el alcance, las posibilidades y las limitaciones de la investigación desde un punto de vista empírico y metodológico. A partir de este capítulo 6 se presentan los resultados obtenidos organizados en torno a tres niveles: el primero de ellos permite determinar el 
orden y el tipo de actividades que se concatenan en las prácticas de clase; el segundo nivel, nos indica cuáles son las acciones que los docentes realizan en cada una de las actividades; y el tercer nivel permite establecer cuáles son los elementos del currículum sobre los que recaen las actuaciones del profesor y simultáneamente su distribución en las actividades. Todos estos datos se han analizado a través del programa estadístico SPSS han permitido analizar y discutir cómo se secuencian las actividades en las sesiones de clase, cómo se distribuyen las acciones del profesor tanto en su conjunto como en cada actividad, y cómo estas acciones se ejecutan y afectan a los distintos elementos del currículum, entre los que se encuentran las TIC.

Estos resultados finales, explicados en la discusión y las conclusiones, vienen a ratificar los presupuestos teóricos explicados en el marco teórico en relación al conocimiento profesional docente y a la integración de las TIC en el currículum. Se concluye cómo cada profesor incorpora el recurso digital ajustándolo a su estilo docente o su enfoque de gestión de la práctica. Cada uno de esos enfoques se refleja en los distintos patrones de actividades vinculados de forma más característica a cada profesor que a otras variables como el nivel del curso o la naturaleza de la propia actividad. Asimismo los resultados demuestran que, aunque el uso de las TIC es habitual en las aulas del estudio, para ninguno de los docentes juegan un papel protagonista en el proceso de enseñanza-aprendizaje. De ahí que la idea de las TIC como recurso curricular dentro del desarrollo de la clase se perfile como una de las conclusiones destacadas. Sin embargo, pese a estas diferencias en la forma de estructurar las clases, también se han puesto de relieve tendencias similares en el conjunto de los profesores. Por ejemplo, el predominio de actuaciones de supervisión del trabajo del alumno y de puntualizaciones breves sobre el mismo, durante el discurrir de la clase. En este mismo sentido, el desarrollo del currículum en el aula por parte del conjunto de los maestros subraya la importancia de las tareas en el trabajo que alumnos y docentes llevan a cabo en colaboración en las sesiones de clase. Estos dos resultados son plenamente coherentes con las peculiaridades metodológicas de la etapa explicadas en el marco teórico.

Lo mostrado en este trabajo viene a aportar una perspectiva anclada en los contextos reales de integración de las TIC en la etapa de Educación Infantil, convirtiendo a la práctica docente en el núcleo central de la investigación y abriendo nuevas líneas de indagación ligadas a este campo y a esta etapa. Asimismo se ha puesto de relieve que el sistema de categorías que hemos 
utilizado permite de forma ajustada categorizar e interpretar la realidad de lo que sucede en las aulas, ofreciendo su utilidad para futuras investigaciones. 


\section{CAPÍTULO 1}

El papel de las TIC en el curriculum 



\section{El papel de las TIC en el curriculum}

\subsection{El curriculum. ¿Qué es el curriculum?}

Definir lo que se entiende por el término curriculum resulta una tarea realmente complicada por razones bien diversas. Una de las razones más convincentes para explicar esa dificultad se deriva, como señala Contreras (1990), de que al hacerlo quizás debamos elegir entre definir el curriculum por lo que pretende, por lo que hace o por lo que consigue. Si acudimos a la teoría del curriculum como cuerpo de conocimiento donde encontrar acuerdos en torno al concepto, surge una cierta confusión en el sentido de que dicha teoría no pretende únicamente explicar, sino que también busca proyectar el curriculum. De esta forma, la reflexión sobre el curriculum ha ido moviéndose simultáneamente entre, por un lado, una pretensión teórica y reflexiva sobre la naturaleza y el papel de la enseñanza y, por otro lado, la aspiración de elaborar una serie de enunciados que den cuenta de las decisiones que hay que tomar, cómo hay que hacerlo y cuál es el fundamento empírico de las mismas (Carr y Kemmis, 1983). A este panorama, hay que sumar además la relativa novedad del concepto en la tradición académica de nuestro país. Sólo recientemente, a partir de las reformas educativas de los años 80 , se ha generalizado el término en el vocabulario educativo de nuestro ámbito geográfico, importado desde la tradición anglosajona.

Sin embargo, al intentar precisar el concepto de curriculum y teniendo en cuenta las particularidades señaladas en el párrafo anterior, nos encontramos con que definir dicho concepto significa circunscribirlo en relación a las intencionalidades que se consideran valiosas para la enseñanza. Algunas de las preguntas cuyas posibles respuestas dan lugar a diferentes concepciones o definiciones sobre el curriculum serían: ¿el curriculum debe proponer lo que debe enseñarse o lo que los alumnos deben aprender?; ¿el curriculum es lo que se debe enseñar o aprender o lo que realmente se enseña y se aprende?; ¿el curriculum es lo que se debe enseñar o aprender, o incluye también el cómo, las estrategias, métodos y procesos de enseñanza?; ¿el curriculum es algo especificado, delimitado y acabado que luego se aplica, o es algo abierto, que se delimita en el propio proceso de aplicación? (Contreras, 1990, pp. 177-179). Dependiendo de la definición por la que se opte, se responde en un sentido u otro a las preguntas anteriores delimitando el concepto de lo que se entiende por curriculum y la forma en que se concibe y se construye la enseñanza.

Por otra parte, si nos atenemos a su evolución dentro del marco anglosajón, donde sin duda ha sido utilizado ampliamente, encontramos tres acepciones de currículo, que han tenido una cierta secuencia temporal (Angulo 
y Blanco, 1994). El curriculum fue entendido en su origen como los contenidos curriculares, o lo que es lo mismo la cultura que debe ser transmitida a través de la educación. La segunda acepción es la que identifica el concepto de currículo con planificación, con la representación de lo que se quiere conseguir y se va a realizar, es el curriculum entendido como diseño, currículo es lo mismo que diseño curricular. Esta acepción es la que surge y se mantiene por el modelo tecnológico, desde cuya posición, como describiremos después, lo importante para mejorar la educación es disponer de un buen diseño.

En los años setenta, surge una nueva forma de entender el currículo que pone todo el énfasis en la práctica, lo que importa es lo que se lleva a cabo en la aulas. Es por tanto, que el concepto de curriculum se identifica con el de desarrollo, desarrollo curricular.

Hoy las posiciones son más bien integradoras. Podemos decir que el currículo es la cultura que seleccionamos, pero también es el diseño del mismo y el desarrollo en la práctica.

En definitiva lo que tratamos de poner de relieve son dos asuntos que nos interesan de forma particular en este capítulo: por un lado, subrayar la complejidad de lo que se entiende por el término curriculum y por otro lado, hacer hincapié en la estrecha relación entre la reflexión teórica sobre el curriculum y el diseño y desarrollo del curriculum. Y la razón última estriba en que para entender el papel de las TIC en el curriculum, lo plantearemos atendiendo a las diversas concepciones sobre el tema fruto de los distintos enfoques teóricos sobre el curriculum y las propuestas de acción derivadas de cada uno de ellos que van a otorgar distinto protagonismo a los recursos TIC.

Como ilustración de lo que estamos tratando de explicar podemos analizar el ejemplo de la definición de curriculum de Gimeno (2010, p. 12) que entiende éste como "el contenido cultural que las instituciones educativas tratan de difundir en quienes las frecuentan, así como los efectos que dicho contenido provoque en sus receptores". Dicha definición identificaría al curriculum tanto con la propuesta de lo que debe enseñarse como con lo que los alumnos aprenden. Asimismo invoca la idea de proceso de desarrollo, en un continuum que recorre desde las intenciones hasta los efectos conseguidos tras ejecutar las intenciones. A partir de la definición, el mismo autor concreta aún más su concepción del curriculum e incorpora tres planos en la realidad curricular (Figura 1.1): en primer lugar los fines, objetivos o motivos -administración y profesorado-; en segundo, acciones y actividades que se desarrollan -profesorado, alumnos y contexto-; y en tercero, los resultados o efectos provocados en los sujetos receptores -alumnos-. Así, el autor va incorporando elementos característicos de su concepto de curriculum, incluyéndolos en distintos momentos del desarrollo del mismo. 


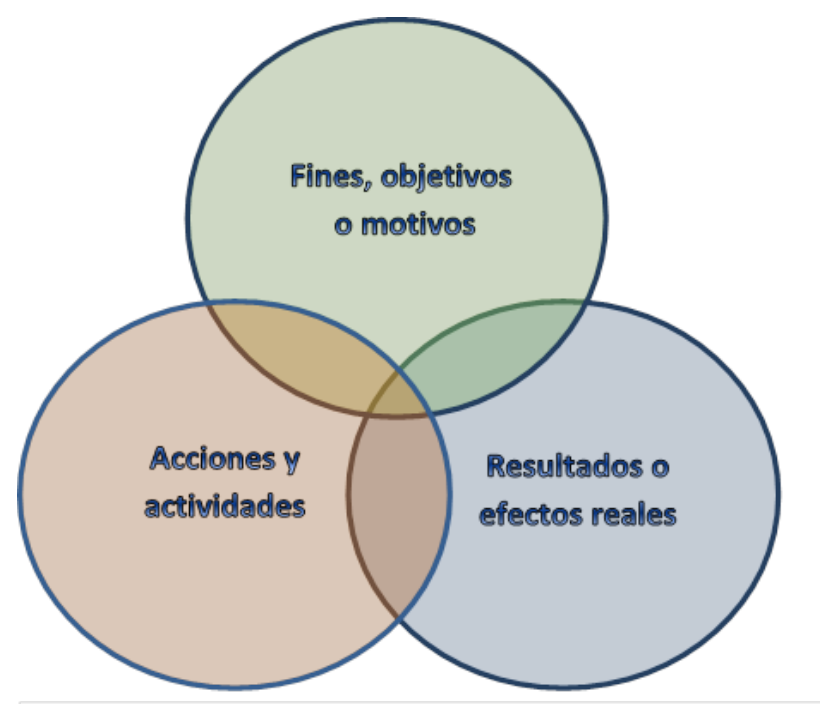

Figura 1.1 Planos de realidad del currícultum

Ya en obras anteriores, este mismo autor había ofrecido una interpretación detallada sobre elementos del curriculum y su plasmación en diferentes momentos del diseño y desarrollo curricular (Gimeno, 1988, 2010) (Figura 1.2). De esta forma, enumera y define hasta 5 posibles concreciones del curriculum producto de las decisiones en los distintos ámbitos educativos:

1) Proyecto Educativo o texto curricular, hace referencia al curriculum oficial desarrollado por las administraciones y centros.

2) Curriculum interpretado, aquel que los profesores interpretan y aquel que se refleja en los materiales curriculares (libros de texto, recursos tecnológicos, documentos,...).

3) Curriculum en la práctica, es el traslado del curriculum a la acción del aula promoviendo la interacción entre profesor, alumno, entorno y conocimiento.

4) Efectos educativos reales, de la interacción en el aula se produce un aprendizaje e interiorización por parte de los dicentes, estos efectos son medibles en toda su amplitud por el propio alumno.

5) Efectos educativos comprobables y comprobados, son aquellos efectos valorables y que son evaluados tanto por los profesores como por las administraciones. Los docentes supervisan si se adecúa a lo marcado por el curriculum interpretado y la administración mide si cumplen lo marcado en el curriculum oficial. 


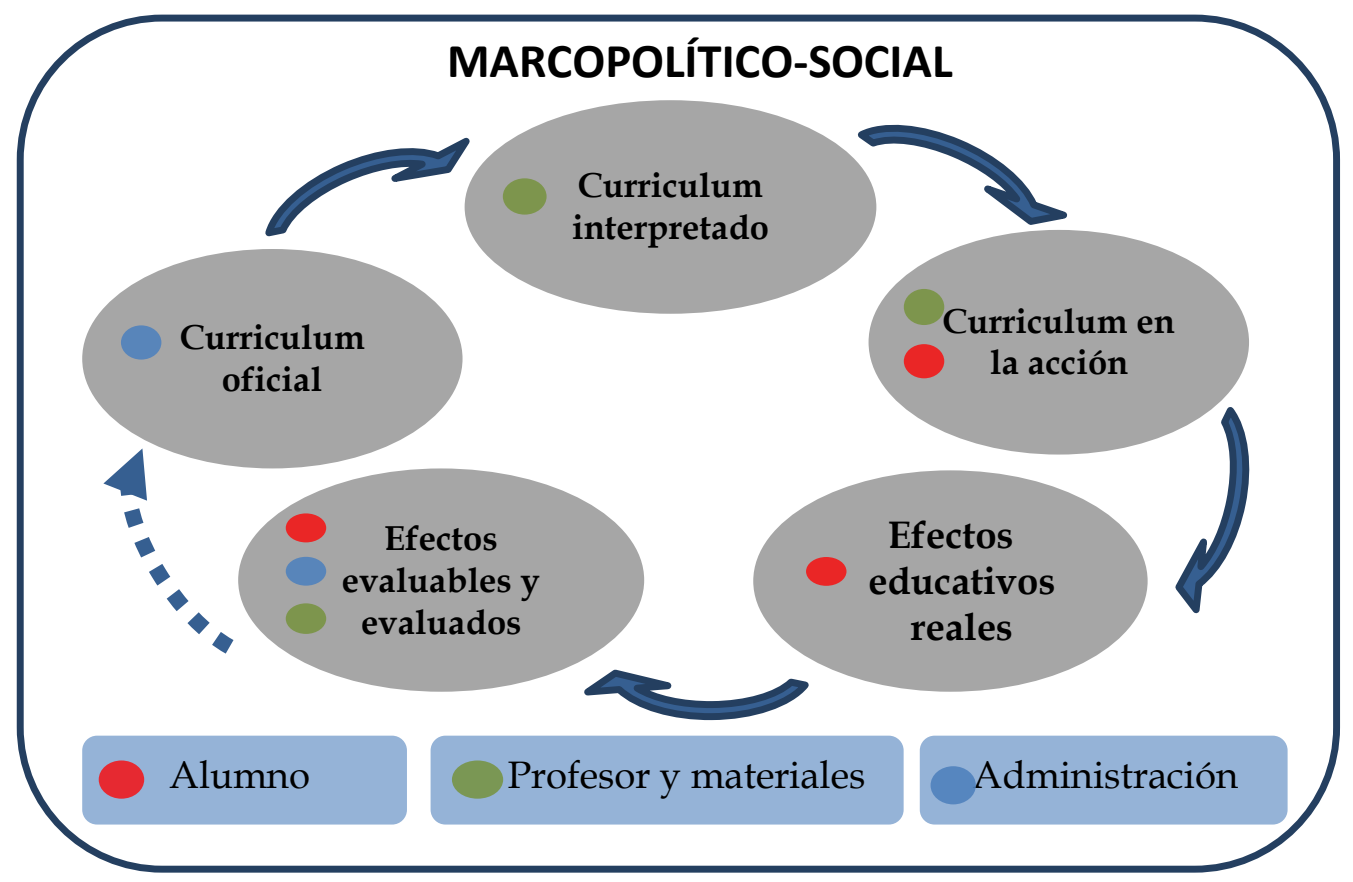

Figura 1.2 Concepción del curriculum como proceso y praxis

Por tanto, de lo anterior sintetizamos algunas premisas que permitirán entender la argumentación de aquí en adelante: Definir lo que se entiende por curriculum es una tarea complicada porque, por un lado, la naturaleza del conocimiento científico que se ocupa de esa tarea se mueve entre la reflexión epistemológica sobre el concepto de curriculum y la intención de proponer cómo intervenir a través de diversos cursos de acción sobre lo que se define como curriculum. Es decir, la teoría sobre el curriculum y el diseño y desarrollo están íntimamente ligados. Por otro lado, y como consecuencia de lo anterior, el enfoque que se adopte para resolver el concepto de curriculum, lleva aparejado una forma particular de planificar y diseñar las propuestas de actuación. $Y$, por último, las distintas concepciones sobre el curriculum otorgan diversos papeles a los elementos del mismo, entre ellos las TIC, que es, en definitiva, el núcleo de esta reflexión. Por todo ello, trataremos a partir de ahora de describir y analizar de forma sintética cuáles han sido los grandes enfoques de "reflexión ergo diseño" del curriculum, para a partir de ellos delimitar el papel de las TIC.

\subsection{Enfoques curriculares}

Podríamos señalar a John Franklin Bobbitt como el pionero en la introducción del término curriculum a través de su obra publicada en 1918, The Curriculum. Dicha obra se caracteriza por una serie de rasgos que tendrán 
una continuidad en el desarrollo posterior de la disciplina sobre el curriculum: tanto el curriculum como su desarrollo aparecen como preocupaciones interconectadas; y se pone de manifiesto cómo la ciencia política, la economía y la administración educativa en tanto que corpus disciplinares por sí mismos, no resultan adecuados para explicar la teoría y la práctica del desarrollo curricular. En otra obra posterior de Bobbitt, How to Make a Curriculum (1924), se hace más evidente la dimensión social implícita del curriculum (Null, 2008). Siguiendo a Clemente (2010), desde este primer hito hasta el momento actual podemos agrupar en torno a dos grandes enfoques las aportaciones sobre la reflexión y el diseño y desarrollo del curriculum, la perspectiva técnica y la perspectiva práctica. Dichos enfoques distan mucho de comprender el proceso de la misma forma y aunque se trata de perspectivas no opuestas, sí son desiguales tanto en la importancia que otorgan a los diferentes elementos del curriculum, como en la concepción de estos, en la forma del diseño y en el propio desarrollo.

\section{Perspectiva técnica. Los modelos tecnológicos.}

La perspectiva técnica de la planificación del curriculum otorga un peso fundamental al diseño curricular, presuponiendo que un buen diseño es garantía de una buena práctica educativa. Gira en torno a dos ejes fundamentales: una visión racional del proceso -marcada por su ordenación y formalización- y un pretendido carácter científico -que le aportarían las ciencias afines a la educación como la psicología, sociología, filosofía o la historia(Clemente, 2010). Aunque varios enfoques pueden encajar dentro de los modelos tecnológicos, el modelo de Tyler es el ejemplo más representativo de esta perspectiva. La primacía de Tyler por la racionalidad le hizo desarrollar un modelo positivista que respondiese al desarrollo sistemático de Diseño $\rightarrow$ Ejecución $\rightarrow$ Evaluación. Por lo que, su búsqueda de la eficiencia educativa se basaba en una correcta planificación curricular centrada en los objetivos, las experiencias y los mecanismos de evaluación (Hlebowitsh, 2005; Stenhouse, 1985). Tyler consideraba que el modelo aportaba a los educadores un procedimiento científico libre de valores, que podía aplicarse a todas las disciplinas y ayudar a las escuelas a lograr cualquier fin que tuvieran en mente.

Siguiendo esta línea tecnológica, nos encontramos con dos formas distintas de evolución: una de carácter simplicista de la misma, que desembocó por ejemplo en la pedagogía por objetivos con las taxonomías o en el modelo de Gagné. Y la otra de carácter más global que da cabida no sólo a la ejecución de distintos pasos formales para diseñar el curriculum, sino también a otorgar a la reflexión sobre los distintos elementos una gran importancia; situando en un plano menos rígido y más enriquecedor todo el desarrollo de planificación curricular. Un ejemplo de esta última línea lo encontramos en Hilda Taba que se ubica sólo en parte dentro de este enfoque (Clemente, 2010). Sin embargo, y 
pese a estas diferencias, ambas se rigen por el denominador común de fundamentar sus modelos en la teoría de carácter científico experimental prevaleciendo sobre lo práctico (Ramírez, 1996), sobre todo en los enfoques de carácter más simplista.

Una reconceptualización de estos modelos está teniendo lugar en los comienzos del siglo XXI, la pedagogía por competencias. Este modelo puesto en práctica desde hace tiempo en países como Chile, está resurgiendo en España y condicionando, como no puede ser de otra manera, la planificación y el diseño del curriculum, que trata de responder a nuevas ideas de eficacia, calidad y control cuando menos controvertidas (Gimeno, 2008).

\section{Perspectiva práctica. El modelo procesual}

Si Tyler consiguió hacer prevalecer durante décadas la idea de modelo tecnológico como prototipo de eficacia educativa, que hoy todavía sigue vigente aunque con variaciones tanto en el modelo de competencias que acabamos de mencionar como en determinadas corrientes psicologicistas de Estados Unidos, topó en el seno de su universidad con su mayor crítico, su compañero Schwab (Hlebowisht, 2005; Clemente 2010). Este autor cuestionó el modelo tecnicista, y apostó por la práctica como centro de conocimiento del que se nutre la planificación curricular. Schwab desafió a los especialistas en curriculum con afirmaciones como que el campo del curriculum estaba moribundo. En realidad, él reclamaba otro lenguaje para el corpus disciplinar del curriculum, que, según su punto de vista, había dado lugar a un importante desarrollo de reflexión teórica que no se había traducido en avances significativos para la práctica curricular. Para él, los problemas curriculares no son teóricos, tienen que ver con los asuntos de la práctica. Se reivindica así el desarrollo curricular como el verdadero objeto del curriculum.

Otro de los referentes dentro de la perspectiva práctica es Stenhouse (1985). Su trabajo con profesores de secundaria en las investigaciones dan un giro en el sentido que propone Schwab, pasando de una teorización desvinculada de la práctica, a una relación teórico-práctica que configura el diseño curricular desde la reflexión de la experiencia, del trabajo en el aula. Es el ya denominado como modelo procesual.

Este cambio de concepción se traslada en una planificación diferente del currículo, donde se abandona la obsesión por el control y pormenorización de los objetivos -generales y específicos- y por la selección y organización de las experiencias de aula -tal y como marcaba el modelo tecnológico-, y se da paso a un curriculum más flexible, donde los objetivos pasan a ser grandes metas o principios, los contenidos (aunque lejos de la visión academicista anterior) son junto a las actividades las piezas claves tanto del diseño como del desarrollo curricular. Como consecuencia, el profesor recupera autonomía y la posibilidad 
de aplicar lo reflexionado en la práctica. En palabras de Stenhouse (1985, p.29), "un curriculum es una tentativa para comunicar los principios y rasgos esenciales de un propósito educativo, de forma tal que permanezca abierto a discusión crítica y pueda ser trasladado efectivamente a la práctica".

Dentro de esa flexibilidad se simboliza la idea de curriculum que se adapta al contexto y a las necesidades de la sociedad en que se desarrolla. Para ello es importante que cada uno de los ámbitos de planificación curricular -administración, centro y aula- incidan en los elementos curriculares en la medida en que les afecte y sin coartar la capacidad de decisión de los otros ámbitos, buscando como fin la mejor adaptación curricular a las necesidades y características de la sociedad, del centro, del profesor y del alumno.

\subsection{Las TIC en el curriculum.}

Los dos modelos descritos en el epígrafe anterior tienen una repercusión directa, en una u otra dirección, sobre el curriculum y sus elementos. El primero, el modelo tecnológico, subraya el protagonismo de los objetivos, la evaluación y la secuenciación de actividades que persiguen los resultados previstos, contemplando el resto de elementos desde un plano casi o totalmente inexistente, o un plano altamente estructurado y secuenciado. Por el contrario, para el modelo procesual, y concibiendo como plantea Stenhouse (1985) que "sólo en las aulas escolares es posible desarrollar estrategias" (p. 54), se perfila el ámbito de aula como punto destacado de planificación y concreción curricular, donde el profesor cuenta como máximo responsable de la toma de decisiones, quien debe priorizar la organización de los contenidos, la selección y organización de actividades, la elección de los medios y recursos necesarios y una evaluación continua de los alumnos y la propia práctica.

Ambos enfoques curriculares llevan consigo distintas formas de entender los recursos TIC y, en general, los medios y materiales curriculares. Aunque en los dos casos las TIC y los medios didácticos por su naturaleza instrumental son soportes sobre los cuales se ofrecen propuestas reguladoras de contenidos y actividades para la práctica (Ramírez, 2005), sin embargo según se adopte un enfoque tecnológico o práctico se hará hincapié en unos u otros aspectos particulares de dichos soportes. De esta forma, desde el enfoque tecnológico se subrayarán las posibilidades de las TIC para ofrecer propuestas cerradas y sistemáticamente diseñadas para el trabajo sobre objetivos previamente establecidos. Las posibilidades que en este sentido ofrecen las tecnologías digitales ha favorecido la creación de productos altamente sofisticados (Spector, 2004), que llegan a identificar el diseño y desarrollo instructivo con la propia tecnología. Por el contrario, en el enfoque práctico las TIC se identifican con un recurso didáctico más que interactúa en los contextos 
reales de enseñanza con los demás componentes didácticos, tales como la organización, los contenidos, la evaluación, los objetivos, las actividades... La comprensión que se tenga de las TIC por parte de los profesionales implicados en el proceso determinará el sentido que los recursos digitales adquieran en el curriculum y se verá afectada por los estilos de trabajo que el profesor y los alumnos definan en las aulas. Asimismo, las concepciones de los profesores en torno a los medios como recursos para solucionar problemas de interacción en el aula, el conocimiento que los profesores posean de las prestaciones técnicas de los materiales disponibles y/o el conocimiento práctico que los profesores hayan adquirido en el uso y selección de los medios para situaciones de enseñanza, son en definitiva los que determinarán el papel de los mismos en los contextos reales de la práctica.

A continuación, explicaremos de forma más extensa la relación de las TIC con los enfoques curriculares señalados, así como algunas de las propuestas concretas que ilustran cada uno de ellos.

\subsubsection{TIC como recurso.}

Dentro del modelo tecnológico, el recurso TIC se concibe como un elemento curricular que pretende conseguir una enseñanza más eficaz. Por ello, la importancia de las TIC queda relegada a su utilidad para la consecución de los fines y objetivos que se buscan, debiendo quedar recogido y estructurado de forma explícita en la selección y secuenciación de actividades dentro de la propuesta curricular.

El concepto de medio desde esta perspectiva se identifica con meras formas de presentar estímulos, con meras tecnologías o soportes electromecánicos. Se considera cada medio como una unidad más o menos estable, con un grupo de atributos fijos que varían en cuanto a su eficacia en la consecución de los distintos objetivos. Se trata siempre de buscar el mejor medio de enseñanza (Ramírez 1996). La incorporación de supuestos cognitivistas a estas concepciones iniciales, añadió otros rasgos a la concepción tecnológica. De esta forma los medios se conciben como portadores de ciertos atributos que se relacionan directamente con los procesos cognitivos que el alumno pone en juego a la hora de aprender. Dichos atributos se asientan en el código simbólico mediante el cual se transmite el contenido, en los elementos de codificación del mensaje, en la naturaleza y estructura, en definitiva, de los símbolos que vehiculan la comunicación didáctica. Se subraya así el sistema de símbolos que utilizan los medios como el elemento esencial y se hace hincapié en la interacción de las representaciones simbólicas internas y su manipulación mental como base de la cognición y, por tanto, del aprendizaje (Salomon, 1981). Algunas de las preguntas características a las que trata de responder esta concepción de los medios serían: 
$\checkmark \quad$ ¿Qué grado de eficacia demuestran las TIC para lograr los objetivos del curriculum?

$\checkmark$ ¿Qué grado de eficiencia poseen las TIC para lograr los objetivos específicos?

$\checkmark \quad$ ¿En qué medida es bueno el curriculum presentado a través de las TIC?

$\checkmark$ ¿Son las TIC más eficaces que otros medios para enseñar?

$\checkmark \quad$ ¿Sirven las TIC para evaluar la consecución de los objetivos marcados?

Su visión como un recurso al servicio de los objetivos lo circunscribe a algo cerrado y con una finalidad clara y precisa, en la que lo importante no son sus posibilidades, sino su eficacia demostrada y medible en la consecución de los objetivos, ya sean desde vertientes conductistas, en el que actuaría como estímulo-respuesta; o una visión cognitivista que se centraría más en el lenguaje simbólico y su relación con los procesos cognitivos.

Además, esta idea de recurso condicionada por el enfoque sistémico de la perspectiva técnica, Diseño $\rightarrow$ Ejecución $\rightarrow$ Evaluación, desembocó en programas de ejercicio-práctica, simulación o tutoriales que poco margen de intervención dejaban para el docente (Means, 2008). Dichos programas resultan adecuados para la enseñanza de contenidos factuales y habilidades concretas más que para la ejecución de tareas abiertas o resolución de problemas complejos. Los temas aparecen sistemáticamente estructurados de tal forma que puedan trabajarse y evaluarse a través de las respuestas simples de los alumnos, en cada uno de las materias del curriculum. Si incorporan las prestaciones de la "programación ramificada" (Crowder, 1959), el software puede disponer de un algoritmo para determinar, sobre la base de las respuestas de los alumnos, qué nivel de dificultad sería más ajustado para conseguir mejores resultados individuales. Estos principios han dado lugar al desarrollo de productos comerciales que, en algunos casos han sido bien acogidos por los profesores, v. g. la serie "Pipo" de la empresa Micronet y que mezclan elementos lúdicos y educativos. Se trata, en la mayoría de los casos, de productos con un ciclo vital corto dirigidos al entrenamiento de habilidades específicas, bien acogidos por los profesores puesto que son de fácil manejo y presentan de forma atractiva tareas que de otra manera resultarían repetitivas (Becker, 1985). Con el desarrollo de las tecnologías que permiten gestionar el aprendizaje "online", también este tipo de materiales ha evolucionado hacia propuestas de plataformas de aprendizaje en la red que mantienen características similares a los materiales multimedia originales: Se basan en la presentación de escenarios simulados orientados a la resolución de problemas bien delimitados, donde el sujeto que aprende va resolviendo tareas breves de forma autónoma, obteniendo recompensas inmediatas con los aciertos logrados 
(Schank, 1997; Merchant, 2009; Nesbit y Winne, 2008; Savage et al. 2010; Abrami et al., 2008; Kafai y Giang, 2008)

Desde el punto de vista de la investigación, el enfoque tecnológico llevó a cabo en un primer momento estudios que trataban sobre la eficacia comparativa de unos medios sobre otros. Sin embargo, las revisiones sucesivas de dichos trabajos demostraron, entre otras cosas, que la pregunta sobre cuál era el medio más eficaz estaba mal formulada, puesto que, los resultados ratificaban que ningún medio era superior a otro y no existían diferencias significativas entre ellos. Asimismo, se puso de relieve que la mayoría de los medios podían ser utilizados de una manera eficaz para presentar información con objeto de conseguir numerosos objetivos instructivos diferentes (Levie y Dickie, 1972). Por último, se constató la ausencia de impacto de estas investigaciones sobre la práctica de la enseñanza (Olson, 1974). Posteriormente al incorporar los presupuestos cognitivistas, los trabajos pusieron de relieve que las características simbólicas de las experiencias instructivas mediadas, afectan diferencialmente a las destrezas activadas en el proceso de adquisición del conocimiento y al dominio de las mismas (cf. las revisiones de Salomon (1981) y Greenfield (1984)). Sin embargo, como Clark reiteradamente sugirió (1983, 1987, 1994), nunca se ha podido establecer que algún atributo, bien sea específico de un solo medio o de una clase de ellos, sea necesario para aprender alguna destreza cognitiva específica. De ahí que, el autor citado, atribuya al método instructivo el papel protagonista en la explicación del rendimiento de los estudiantes. Este debate, en cualquier caso, es un tema recurrente en relación a la investigación sobre los medios y las tecnologías y su papel en la enseñanza. Periódicamente se alzan voces que reclaman un cambio en la forma de plantear las preguntas en la investigación sobre medios hacia enfoques que traten de contestar a los desafíos de la práctica con los recursos tecnológicos. En este sentido, por ejemplo, la revisión de Zhao, Yan y Lei (2008) denuncia la debilidad del conocimiento acumulado en torno a la evaluación del efecto de las tecnologías en la enseñanza. Y cifran esa debilidad en varios aspectos, entre ellos, un enfoque de evaluación sumativo en su mayoría, falta de conocimiento sobre los efectos a largo plazo de los proyectos evaluados, dificultades en las posibilidades de generalización de los resultados obtenidos desde proyectos individuales. Asimismo, llega a ciertas conclusiones importantes como que las investigaciones sobre integración de las tecnologías cada vez van poniendo más de relieve que el efecto de las mismas depende de cómo se usen, para qué objetivos y en qué condiciones. En este mismo sentido, con diversos matices, se manifiestan otros trabajos relativamente recientes como los de Cuban (2001), Haertel y Means (2003), Olkinuora, Mikkilä-Erdmann y Nurmi (2004), Dede, Honan y Peters (2005), Area (2008), Webb (2011), Selwyn (2010), Yang (2012), Selwyn (2012). La evolución de este estado de cosas, junto con el propio desarrollo del corpus de conocimiento sobre el curriculum y los estudios sobre el pensamiento del profesor, explican en buena medida los planteamientos 
sobre las tecnologías en la enseñanza que progresivamente van incorporando presupuestos de lo que hemos definido como concepción práctica-procesual del curriculum. Y simultáneamente, se abordan estudios sobre el curriculum y la tecnología que se adscriben a presupuestos de las dos concepciones descritas.

Como venimos explicando, el modelo procesual entiende los recursos de forma mucho más flexible e integrada en los elementos del curriculum. La trascendencia que la práctica cobra en este enfoque hace que las posibilidades del recurso no se vean limitadas por la configuración del diseño previo a su uso, y concede una responsabilidad importante de los posibles efectos de las tecnologías a los agentes que intervienen en el proceso de enseñanzaaprendizaje así como a su contexto cultural y social.

Si en el anterior enfoque el recurso estaba marcado por unas directrices curriculares en base a objetivos y actividades, la perspectiva práctica/procesual entiende que la funcionalidad del recurso se ha de adaptar a necesidades que se requieran en la acción del aula y condicionada por el contenido, las actividades y la metodología. Se abre esta concepción del curriculum a la posibilidad de un uso desde una visión práctica y crítica de las TIC, atendiendo simultáneamente a los contenidos que se trabajen y a las percepciones que los docentes y el resto de los agentes educativos tengan respecto de ellas. Por tanto, en torno a las tecnologías se plantean preguntas como:

$\checkmark \quad$ ¿Cuál es la percepción que los profesores, padres, administraciones y alumnos tienen de las TIC?

$\checkmark \quad$ ¿Cuál es el grado de aceptación de las TIC dentro de las situaciones específicas de aprendizaje?

$\checkmark$ ¿Qué conceptos de relevancia, significatividad y adecuación se manejan cuando se introducen las TIC en una situación de enseñanza?

$\checkmark \quad$ ¿Cómo se perciben las TIC por los diferentes grupos interesados en relación con la satisfacción de sus necesidades?

$\checkmark \quad$ ¿De qué forma definen los roles de profesor y alumno las TIC?

$\checkmark \quad$ ¿A qué intereses sirven las TIC en la enseñanza?

$\checkmark \quad$ ¿De qué forma interactúan los contenidos, los medios y los sujetos implicados para lograr los principios generales de la educación?

$\checkmark \quad$ ¿Existe relación entre lo que demanda la sociedad y lo que las TIC aportan a la escuela?

Estas preguntas darán paso a múltiples opciones de respuesta circunscritas al contexto social, cultural y personal en donde se desarrolle la interacción de aula. Las TIC quedan por tanto como recursos que juegan un 
papel en el curriculum a merced de las necesidades concretas de cada caso y a las directrices marcadas en cada uno de los ámbitos, recayendo en el entorno del aula y en el profesor la responsabilidad del uso e integración en el curriculum.

Algunos de los productos tecnológicos que se ajustan más a los presupuestos de este enfoque han surgido desde propuestas prácticas de equipos de psicólogos constructivistas trabajando con docentes provenientes de la práctica. Un ejemplo de ello sería la propuesta del grupo de la universidad de Vanderbilt (Cognition and Technology Group at Varderbilt 1997) en torno al trabajo sobre temas de matemáticas para el curriculum de secundaria. El material elaborado, en formato DVD, se basa en una serie de principios instructivos que enfrentan a los alumnos con la tarea de resolución de problemas matemáticos complejos a través de la presentación de episodios en vídeo donde se pueden obtener todos los datos necesarios para la solución a través de la exploración directa del material. La utilización de formatos narrativos cercanos a la estructura de las novelas de misterio, el diseño de los datos "encajados" en el relato visual o las conexiones entre distintas áreas del curriculum ofrecen una propuesta de material en soporte TIC que cada profesor puede utilizar ajustándolo a las peculiaridades de su práctica. Otro ejemplo en este sentido es el software "KnowledgeForum" preparado por el equipo de Scardamalia, Bereiter y Lamon (1994). Dicho software no es más que una base de datos configurada en red, que facilita el trabajo en torno a proyectos de investigación en el aula; en un enfoque metodológico que trata de reproducir en las aulas los mecanismos de generación del conocimiento propios de las comunidades científicas. Otras propuestas de enseñanza con TIC en esta línea se pueden consultar en Ashburn y Floden (2006), Burniske y Monke (2001), Crook (1998), Pablos, Area, Valverde y Correa (2010), Wenglinsky (2005).

Con ideas basadas también en el valor que la práctica docente puede aportar para el diseño de entornos de aprendizaje on line, se han diseñado sistemas de e-learning que aplican ciertas estrategias que se han demostrado eficaces en el desempeño docente en contextos reales. Un ejemplo de ello es lo que se denomina "sistema de aviso ante decisiones incorrectas". De esta forma, en un sistema de enseñanza online el sujeto para evitar las decisiones incorrectas recibe advertencias ("si haces...entonces...), correcciones simultáneas (has hecho esto así..., ¿estás seguro de...?) y comentarios elaborados sobre distintos aspectos del problema (¡Cuidado!, esa decisión es peligrosa para...). Asimismo, se le indica la posibilidad de usar una pantalla de ayuda con información adicional. Se trata, en definitiva, de aprovechar estrategias de supervisión que se han demostrado útiles a los profesores en la práctica, para diseñar entornos de enseñanza que simulen dichas supervisiones. Otros ejemplos, también recogidos desde la práctica docente en relación a los medios didácticos son "ajustar el nivel de dificultad de los problemas, al nivel de 
capacidad del alumno", cuando esta última se incrementa también lo hace la primera; o "adaptar el tiempo de respuesta del sistema" de tal forma que cuando el sujeto responde de forma incorrecta, el tiempo de respuesta para el siguiente problema se reduce, y el sujeto recibe la explicación de la respuesta correcta antes de que haya generado otra solución incorrecta (Munro, Surmon y Pizzini 2006). En estos casos, el diseño de las tecnologías se nutre de la práctica y no al revés, como suele ocurrir en el enfoque tecnológico.

Los presupuestos de la investigación sobre tecnologías del enfoque práctico-procesual se desarrollan, en cierta manera, como reacción a cuestiones no resueltas del tecnológico. Se pone en cuestión la utilidad de los resultados del enfoque técnico, sobre todo en el sentido de su aplicabilidad inmediata, ya que, no resultan útiles para conocer lo que ocurre en las interacciones habituales entre medios y sujetos en las aulas escolares. Es por ello que se empiezan a plantear otro tipo de enfoques de investigación de carácter curricular, que tratan de estudiar las tecnologías en relación con el uso que los participantes en la situación de enseñanza hacen de ellos. Es lo que se ha denominado la perspectiva curricular en la investigación sobre medios. No sólo se cambian las preguntas que son el origen de las investigaciones sobre medios, sino también los procedimientos de recogida de datos. Por tanto, las TIC interesan dentro del contexto general de la enseñanza y del curriculum y se abordan estudios que tienen que ver con la utilización de las tecnologías en el aula, sobre todo por parte del profesor (Hadley y Sheingold, 1993; Gobbo y Girardi, 2001; Niederhauser y Stoddart, 2001; Loveless, 2003; Hennessy, Ruthven y Brindley, 2005; Ruthven, Hennessy y Deaney, 2005; Judson, 2006; Coll, Onrubia y Mauri, 2007; Drent y Meelissen, 2007; Grossman y Thompson, 2008; Hermans, Tondeur, van Braak y Valcke, 2008; Law, 2009; Diaz-Barriga, 2010; Barrantes, Casas y Luengo, 2011; Valverde, Fernández y Revuelta, 2013) y otros que abordan la figura de este último como agente de cambio e implantación de innovaciones curriculares (Plomp y Pelgrum, 1991; Kozma y Anderson, 2002; Smeets, 2005; Mueller, Wood, Willoughby, Ross y Specht,2008; Lewin, Somekh y Steadman, 2008; Inan y Lowther, 2009; Ward y Parr, 2010; Hinostroza, Labbé, Brun, y Matamala, 2011; Vanderlinde, Dexter y van Braak, 2011;). Estos trabajos adoptan un tipo de metodología de corte menos experimental y más etnográfico, analizando las situaciones reales de uso de los medios en los contextos naturales donde se producen y abordando la resolución de problemas prácticos concretos.

Por tanto, de lo dicho hasta ahora se pone de relieve cómo en las interrelaciones entre concepciones de las TIC y curriculum, van sucediéndose de forma simultánea desarrollos que se apoyan unos en los otros. En el origen de las posibilidades que se atribuían a las TIC, subyace una concepción sobre el curriculum que buscaba la racionalización sistemática del proceso de intervención educativa. Dicho proceso se identificó en algunas ocasiones con 
los propios soportes TIC y contribuyó en buena medida a hacer avanzar el conocimiento sobre todo en lo relativo al diseño de materiales. El enfoque procesual, por su parte, reivindicó el papel de la práctica y del profesor en el desarrollo del curriculum y, por ende, la relación de las TIC con el resto de los elementos del curriculum tales como objetivos, contenidos, actividades o evaluación que participan en diversa medida en los procesos de enseñanza. La investigación que se presenta se enmarca dentro del enfoque procesual puesto que trata de estudiar cómo un grupo de profesores de Educación Infantil dan sentido al uso de las TIC en su práctica profesional directa en las situaciones de aula. Y esta investigación se incluye en un proyecto más amplio donde se han indagado asuntos relacionados no sólo con la configuración de las prácticas directas de enseñanza, sino también otros relativos a las concepciones y creencias de los profesores en torno al papel de las TIC, la cultura de innovación de los centros escolares, los perfiles socioculturales de las familias de los alumnos que participan y el aprendizaje de habilidades multimedia.

Por último, es preciso referirse, aunque sea brevemente, a otra concepción en torno a los recursos digitales que los identifica con el contenido a aprender en los distintos niveles de enseñanza, reivindicando de esta forma la necesidad de la alfabetización digital de los alumnos en el sistema educativo. En el siguiente epígrafe, nos referimos brevemente a esta concepción de las TIC.

\subsubsection{Las TIC como contenido: Alfabetización Digital}

En la década de los ochenta y principios de los noventa encontramos los primeros intentos de incorporación de las TIC a la escuela, que iban encaminados a la alfabetización digital. En la mayoría de las ocasiones los recursos ejercían una función de instrucción sobre su propio uso -sistema operativo, herramientas ofimáticas, uso del hardware. A finales de los 90 comienzan las TIC a adquirir protagonismo en la cultura y la sociedad. Fenómenos como Internet o dispositivos móviles se generalizan y se presentan como nuevos canales de acceso al conocimiento, de relaciones entre las personas, gestión económica o administrativa, e incluso nuevos modos de desenvolverse en la vida cotidiana. Lejos de disminuir, el crecimiento exponencial de las TIC sobrepasa cualquier previsión. La llegada de la WEB 2.0, la repercusión de las redes sociales, la interacción más intuitiva con los recursos tecnológicos, la hegemonía de lo digital sobre lo analógico, el protagonismo del lenguaje multimedia, etc., provoca que la educación y el curriculum, se hagan eco de las necesidades y cambios socio-culturales que se producen y adaptarlos para su transmisión, junto con los demás conocimientos, a los alumnos. A esta situación, ya marcada fuertemente por las circunstancias sociales, se unieron programas nacionales como Escuela 2.0 -cancelada en 2012-, que trataban de favorecer la dotación de recursos tecnológicos. Comunidades autónomas como 
Madrid, Valencia y Murcia desestimaron la oferta y siguieron su propio sistema de dotación, un ejemplo fue el Programa de Centros Inteligentes de la Comunidad Valenciana. Esta transferencia tecnológica mayoritaria -por no decir exclusiva- de máquinas y servicios, ha sido y es cuanto menos dudosa al desestimar los fines didácticos frente a los de innovación tecnológica, quedando los primeros ilógicamente supeditados a los segundos (San Martín, 2010).

Sin embargo, no podemos obviar que esta irrupción de las TIC, supone una modificación en el modelo social, político y económico (Castells, 1996 y 2006; Kozma, 2008), y se sustenta en el uso de lenguaje multimedia y la digitalización masiva de los contenidos -por ejemplo Internet-, repercutiendo de forma directa en la cultura, y por tanto al curriculum que se enfrenta al reto de atender la formación de sujetos capaces de adquirir, entender y manejar esa información adecuadamente. Es decir, llevar a cabo la alfabetización digital de forma que los sujetos (Pérez Gómez, 2012, p. 48) puedan interaccionar con las TIC por medio de las aplicaciones sociales que vayan surgiendo.

Por ello, esta nueva alfabetización que viene planteada por las TIC, tal y como la describen Lankshear y Knobel (2008), precisa dos tipos de definiciones. En primer lugar, afecta a los conjuntos estandarizados de operaciones, que lo que pretenden es que se presenten determinadas tareas, actuaciones, demostraciones de competencias, etc. como indicadores de una adquisición estandarizada y medible de habilidades relacionadas con la alfabetización digital, lo que encajaría con el pensamiento positivista del modelo tecnológico. En segundo lugar, se encuentran las definiciones que entienden la alfabetización digital como ser capaces de comprender y utilizar la información en medios diversos, moviéndose y descifrando en cada uno de ellos su contenido, así como ser capaces de adaptarlo al medio más adecuado dependiendo de qué y cómo se quiera presentar, lo que acerca esta segunda definición al modelo procesual.

Dentro de este doble marco, las TIC se presentan como contenidos en el curriculum en un sentido técnico, puesto que se han de aprender a manejar los instrumentos y soportes a través de los cuales llega la información. Por ejemplo, en el caso del ordenador los contenidos atendería a competencias como:

$\checkmark$ Identificar sus periféricos -ratón, teclado, unidades de almacenamiento externo, CD-Rom, altavoces...-.

$\checkmark \quad$ Manejo del ratón y función de sus botones.

$\checkmark$ Manejo del teclado y función de sus teclas.

$\checkmark$ Utilización del CD-Rom. 
Además de este sentido técnico, que resulta necesario como lo es el manejo del lápiz, bolígrafo o pluma para la escritura, los contenidos relacionados con las TIC y la alfabetización digital han de responder a otro tipo de objetivos menos procedimentales y más conceptuales y actitudinales. Siguiendo con el ejemplo del ordenador serían los siguientes:

$\checkmark$ Realizar búsquedas de información de forma adecuada.

$\checkmark$ Comprender los mensajes que aporta la información en los distintos medios en los que se presenta.

$\checkmark$ Saber entender el significado social y cultural de los contenidos que se exponen.

$\checkmark$ Discriminar los diferentes lenguajes y medios en los que se presenta la información.

$\checkmark$ Comprender el funcionamiento del sistema operativo sobre el que se sustentan.

$\checkmark$ Ser críticos con la información que se recibe a través de estos medios.

Estas dos enumeraciones de objetivos, enmarcadas dentro de la alfabetización digital, son recogidas de diversas formas dentro de los curricula oficiales elaborados por distintos gobiernos. En esta línea, el estudio de Aesaert, Vanderlinde, Tondeur y van Braak (2013) analiza las diferentes conceptualizaciones de alfabetización digital y competencia digital establecidas en el curriculum oficial de tres países -Flandes, Noruega e Inglaterra. Los diferentes usos de términos que cada país recoge en sus curriculum -habilidades digitales, competencia digital, cultura digital, competencia TIC y capacidad TIC (p.143)-, refiriéndose a lo que se presupone un misma idea, dan lugar a distintas interpretaciones del concepto de alfabetización digital. Estas incertidumbres no ayudan a clarificar una definición precisa, lo que se traduce en múltiples objetivos y concreciones sobre las actitudes, conocimientos, habilidades y competencias digitales para los contextos educativos formales de cada país. De la misma manera, los resultados de la investigación realizada por Aesaert et al. (2013) son extrapolables a la situación del curriculum español, donde la alfabetización digital no tiene una identidad propia, definida y vinculada a contenidos como presenta por ejemplo la alfabetización en su concepto tradicional, sino que más bien se muestra difusa, con objetivos genéricos, específicos o transversales dependiendo del caso, pero sin una coherencia plena que delimite de forma más clara la conceptualización que desde el curriculum oficial se hace de la alfabetización digital.

Autores como Gilster (1997) y Bawden (2008), defienden el concepto de alfabetización digital en el sentido de alfabetización tradicional, con la 
diferencia de la contextualización en nuestro tiempo, la era digital. Esto hace que entender la alfabetización digital únicamente como habilidades técnicas en el uso de hardware o software carezca de sentido, debiendo ampliarse a una concepción de conjunto que reúna la integración y el uso funcional de habilidades, conocimientos, entendimiento y actitudes hacia las TIC. En consecuencia, el curriculum debe recoger, explicar y conceptualizar la alfabetización digital atendiendo a esa visión ampliada. 


\section{CAPÍTULO 2}

La etapa de Educación Infantil 



\section{La etapa de Educación Infantil}

Una vez analizado el papel de las TIC en el curriculum, resulta importante centrar la etapa educativa en la que se desarrolla la investigación. Trataremos de describir los rasgos más característicos de ésta, haciendo una breve reseña sobre sus orígenes y evolución, así como las contribuciones teóricas más destacadas para interpretar las peculiaridades de la práctica escolar en estas edades.

La Educación Infantil es una etapa educativa de carácter voluntario con identidad propia que atiende a niños y niñas desde el nacimiento hasta los seis años de edad y que precede a la escolarización obligatoria (LOE, 2006). De esta forma, se circunscribe la etapa al ámbito más propiamente escolar, sin que por ello se niegue el influjo educativo que otros contextos e instancias puedan ejercer en estas edades.

En este capítulo abordaremos dos asuntos que nos parecen esenciales para enmarcar la etapa educativa en la que se ha desarrollado nuestra investigación: por un lado, hacer un breve recorrido histórico de la evolución de las concepciones teóricas, legislativas y las perspectivas sobre lo que se entiende como Educación Infantil; y por otro, tratar de describir las características de estos alumnos, así como los aspectos metodológicos y organizativos de la etapa.

\subsection{Historia de la Educación Infantil}

\subsubsection{Los primeros referentes teóricos.}

Los antecedentes de lo que llamamos hoy Educación Infantil sientan sus cimientos en cuatro autores de referencia para las Ciencias de la Educación, y que aun cuando no establecieran un marco concreto sobre la etapa, ejercieron una importante influencia para considerar la educación desde edades tempranas como eje fundamental de la configuración del ser humano y social.

En primer lugar, Jan Amos Comenio (1592-1670), por muchos considerado padre de la pedagogía, destacaba a principios del siglo XVII la importancia de educar al hombre para la vida desde los primeros años diferenciando "cuatro distintos periodos: la infancia, puericia, adolescencia y 
juventud [...] Así, habrá una escuela materna en cada casa; una escuela pública en cada población, plaza o aldea; un gimnasio en cada ciudad y una academia en cada reino o provincia" (Comenio, 1971, p. 268).

El segundo de los autores, Jean-Jacques Rousseau (1712-1778) defendió en su obra Emilio o De la Educación (Rousseau, 1964) la importancia de la educación inicial del niño. De esta forma "la educación del hombre comienza en su nacimiento, antes de hablar, antes de oír, él se instruye ya" (p. 54). Asimismo, aunque hacía recaer en la familia la responsabilidad educativa para el correcto desarrollo del niño, en aquellos casos en que las necesidades obligan a dar la educación de los niños a preceptores y nodrizas, la elección de éstos no podía ser baladí, ha de ser pensada y meditada buscando aquellos más preparados para educar a sus vástagos (p. 47). Su concepción del niño como un ser con peculiaridades y características propias, provocó una ruptura con la concepción de niño como "adulto en miniatura". Hay que entender que la construcción de la persona pasa por varias etapas y la educación se debe adaptar a ellas:

La obra maestra de una buena educación es hacer un hombre razonable; iy se pretende educar a un niño por la razón! Esto es comenzar por el fin, es querer hacer el instrumento de la obra. Si los niños razonasen no tendrían necesidad de ser educados. (Rousseau, 1964, p. 84)

En tercer lugar, el suizo Johann Heinrich Pestalozzi (1746-1827) postuló en sus escritos la necesidad de ejercer la educación a edades tempranas: “[...] quedarán menos que medianos los beneficios que nuestro sistema puede reportar para el bienestar real de la humanidad mientras las mejoras introducidas no se extiendan también a la fase más temprana de la educación" (Pestalozzi, 1988, p.3 y 4). Sumado a esto, su concepción del niño como un ser con capacidades potenciales sobre las que hay que trabajar, dio importancia al trabajo global entendiendo el niño como "un ser dotado con todas las facultades de la naturaleza humana, si bien ninguna de ellas ha alcanzado aún su desarrollo [...] ha de atenderse con idéntica solicitud a todas las capacidades de la naturaleza humana" (p. 9), lo que da lugar una a la formación integral, más allá de la mera intelectualidad.

Por último, Friedrich Fröbel (1792-1852), el maestro alemán admirador de la metodología de Pestalozzi, con quien colaboró en el Instituto de Yverdon. 
Su obra estuvo siempre marcada por el equilibrio entre lo divino y lo terrenal. Al igual que Rousseau y Pestalozzi apuesta por el naturalismo dentro de la educación y valora a la madre como un eje fundamental en la educación de los infantes. La defensa de una educación temprana queda clara a lo largo de su obra. Sin duda una de las grandes aportaciones de Fröbel es el papel que otorga al juego como medio de transmisión de conocimiento, yendo más allá del mero entretenimiento para el niño y subrayando su valor pedagógico. Pero un juego sistematizado y apoyado en un cierto carácter científico para su utilización dentro de la Educación Infantil a partir del cual valorar la adquisición de aprendizajes físicos, intelectuales y morales (Ramos, 2010, p. 124). En base a estas ideas froebelianas surgieron en Alemania los Kindergärten o jardines de infancia, donde se aplicaban. Todo ello repercutiría de manera significativa en la estructura de la Educación Infantil tanto en América como en Europa.

Estos cuatro autores ayudaron a perfilar lo que hoy se conoce como Educación Infantil, pero fueron autores posteriores los que desarrollaron propuestas, interpretaciones, reflexiones e innovaciones que produjeron cambios de gran calado desde mediados del XIX hasta nuestros días.

\subsubsection{Referentes teóricos en el siglo XX: desde la práctica a la teoría}

En la primera parte del siglo $\mathrm{XX}$ se pueden señalar diversas aportaciones teórico-prácticas con repercusiones importantes en cómo se concibe la etapa de Educación Infantil y cómo se ha desarrollado hasta el momento actual. A continuación trataremos de describirlas en sus elementos más destacados.

Apoyado en ideas progresistas de los autores nombrados anteriormente como Pestalozzi, Fröbel o Rousseau, surgió en Europa a finales del siglo XIX un movimiento pedagógico denominado Escuela Nueva. Dicho movimiento buscaba un cambio de rumbo en el modelo tradicional de enseñanza, centrado en la concepción del niño como ser activo, actor de su propio aprendizaje y apostando por metodologías en las que el maestro ejerciera como un orientador para ayudar al niño a descubrir el conocimiento y no el único depositario del mismo. La Escuela Nueva se fundamenta en la actividad del alumnado frente a los modelos tradicionales que subrayan los contenidos como eje prioritario. Es lo que se denominó como paidocentrismo, frente al logocentrismo imperante en la educación en esa época. 
Dentro de este movimiento, una autora de referencia y sobre la que gira gran parte de lo que hoy compone la Educación Infantil es María Montessori, quien empezó en la "pedagogía reparadora" (educación especial) con resultados importantes que posteriormente aplicaría a la "pedagogía normal". Desarrolló en las "Case dei Bambini" experiencias pedagógicas que iban dirigidas a niños que aún no estaban en edad escolar. De dichas experiencias se derivaron importantes ideas que, como he señalado, siguen siendo relevantes en la actualidad: el niño como agente activo de la educación (Montessori, 2003, p.131); el niño como ser independiente, “Una acción pedagógica sobre los niños pequeños, para ser eficaz, debe ayudarlos a avanzar por el camino que conduce a su independencia."(p. 154); y, por supuesto, el aprender haciendo, muy relacionado con el aprendizaje sensorial. Precisamente el aprendizaje a través de los sentidos es su aportación más genuina. La educación sensorial es para la autora italiana, la base del desarrollo del niño. Para conseguir todo ellos, incorpora en las clases un amplio y variado material didáctico que, vinculado con unas pautas de uso, favorecían el desarrollo motriz, sensorial y cultural de los alumnos. Estos materiales y prácticas siguen siendo materiales interesantes en muchas escuelas de todo el mundo, utilizados tanto con el sentido que les dio su creadora como con perspectivas nuevas.

Otro autor de la Escuela Nueva casi contemporáneo de María Montessori es Ovide Decroly, un médico pragmatista que basaba su legado educativo en una afirmación "escuela por la vida y para la vida", ejes sobre los que giraban sus estudios y los de sus colaboradores. Su contribución más destacada es la idea de la globalización de los contenidos que pretende organizar el conocimiento escolar para estas edades con un planteamiento nuevo, rechazando la configuración por asignaturas y academicista del contenido y presentándolo al niño como un todo. Además buscaba acercar al niño a los conocimientos a través de su realidad más cercana, a partir de los llamados centros de interés, grandes temas próximos a las experiencias e intereses del alumnado de esas edades. Dicha idea, que ha sido completada y enriquecida con el tiempo, se constituye en la mejor forma de que los alumnos de estas edades entiendan y den sentido a aquello que se les quiere enseñar (Moreno, 2010, p. 241).

Celestin Freinet, otro de los autores de referencia, fundamentó su trabajo en los ideales de la Escuela Nueva. Desde la práctica, puesto que era maestro, legó a la Educación su Método Natural en el que el descubrimiento de las cosas surgía a partir de la libre expresión, la reflexión y contraste de las ideas que se van generando de las experiencias vividas. También apostó por el trabajo cooperativo entre los alumnos y por la funcionalidad de todo aquello que hace, es decir, que las tareas lleven consigo necesariamente una utilidad real. Su metodología, que no estaba dirigida a la Educación Infantil expresamente, dado que él trabajaba en una escuela no graduada, incluía 
técnicas que se han trabajado con mucha frecuencia en la Educación Infantil tales como la asamblea de clase, la biblioteca, el texto libre, etc.

Además de los aportes de algunos de los autores enmarcados dentro de la Escuela Nueva, podemos citar otras contribuciones complementarias a lo largo del siglo XX. Se producen importantes estudios desde áreas como la psicología del aprendizaje que indagan sobre los procesos de aprendizaje y dan lugar a teorías constructivistas. Unos se llevan a cabo desde enfoques más cognitivistas y evolutivos y otros desde vertientes más socioculturales. En ambos casos, la pedagogía se nutre de ello lo cual tiene repercusiones directas en la práctica de las escuelas.

Los estudios adscritos a teorías con un corte más cognitivista y evolutivo, aluden a pautas relacionadas con la evolución del niño en los diferentes estadios, vinculando de manera directa la observación y la adecuación a la madurez del alumno. En la Universidad de Ginebra, Èdouard Claparède fijaba sus principios básicos de la pedagogía en el interés y la necesidad de satisfacer las necesidades de esa edad y consideraba que el conocimiento del niño es fundamental para poder aplicar una educación adecuada. Su teoría de la educación funcional está dentro de los patrones de la Escuela Nueva ya que consideraba al niño como agente activo en el aprendizaje, pero eso sí, con rigor científico como premisa indispensable. Trabajó en el Instituto JJ Rousseau, tratando de recuperar los ideales del autor. En relación con dicho instituto se creó la Maison des Petits, un proyecto en el que trató de poner en práctica las ideas fijadas en la teoría de la educación funcional que, a través de la observación, va perfeccionando y delimitando estadios y materiales adecuados para trabajar en base a las necesidades de los niños. Tras diez años de funcionamiento de la Maison des Petits, observaron que en el primer estadio, entre 3 y 5 años de edad el niño adapta las cosas a sí mismo, a su fantasía, a sus necesidades y es donde se produce la toma de conciencia de su yo físico. Predomina en el niño la acción frente al pensamiento, y sobre todo incide en trabajos musculares, mecánicos, sensoriales, de atención y obediencia (Moreu, 2010, p.281).

Tras la muerte de Claparède tomó el relevo uno de los psicólogos más relevantes del siglo XX, Jean Piaget, quien se convirtió pronto en referente mundial por sus estudios epistemológicos y psicobiológicos que buscaban explicar los orígenes del conocimiento. Además, siendo y sintiéndose discípulo de Claparède, continuó con su obra psicopedagógica, aunque mucho más distante de lo pedagógico. Desarrolló en la Universidad de Ginebra la teoría del constructivismo genético o teoría constructivista del aprendizaje. La teoría psicogenética de Piaget constituyó una aportación científica fundamental para la psicología. Su teoría sobre los estadios de desarrollo aportó patrones esenciales en la comprensión de cómo construye el niño su conocimiento y 
configura su propio desarrollo, lo que también produjo en la pedagogía claves importantes para ayudar al niño en la construcción activa de su inteligencia y personalidad. Por lo que respecta a la comprensión de la etapa de infantil, el autor suizo nos permitió comprender cómo es el niño en esa edad. Se trata del denominado por él estadio preoperatorio ( 2 a 7 años), "se caracteriza por ser un pensamiento preconceptual, intuitivo, egocéntrico, muy influido por la percepción y donde el niño se encuentra todavía centrado en su punto de vista" (Barba, Cuenca y Gómez, 2007, p. 3)

A continuación, me referiré a otros autores posteriores a Piaget, que han legado grandes aportaciones al conocimiento sobre el aprendizaje en general y en particular al infantil. Uno de ellos es David Ausubel, con su Teoría del Aprendizaje Significativo, que resulta de gran interés para cualquier etapa educativa y también para la Educación Infantil. En ella, se valora como aprendizaje significativo, tanto el aprendizaje por descubrimiento como el que surge a través de la transmisión verbal. Postula que la información que reciben los niños ha de relacionarse con conocimientos previos mediante conexiones no arbitrarias sino sustanciales, es decir, cuando el alumno se enfrenta a nueva información éste lo conecta, de una u otra forma, con contenidos anteriores que posee y así se produce lo que Ausubel denomina aprendizaje significativo. Estos aprendizajes varían dependiendo de las edades de los sujetos, puesto que para Ausubel el desarrollo infantil está marcado por etapas del desarrollo en las que los alumnos están o no preparados, evolutivamente hablando, para enfrentarse a unos $\mathrm{u}$ otros conocimientos (Ausubel, 1983). Su obra El desarrollo infantil (1983) incluye desde los comienzos del desarrollo físico, cognitivo y lingüístico hasta aspectos de la personalidad aludiendo, entre otros, al desarrollo emocional en la infancia.

Una figura clave en la psicología, con claras influencias para desarrollar aspectos pedagógicos es el ruso Lev S. Vygotsky, representante principal de lo que se ha denominado psicología sociocultural. En sus obras muestra interesantes aportaciones en el campo del aprendizaje de la lengua y también en el desarrollo cultural del individuo. Su visión de la mediación de la sociedad, la cultura y la historia en el desarrollo cultural del individuo, desemboca en una doble aparición de las funciones, interpersonal e intrapersonal. Dicho de otra forma, lo que el niño aprende o desarrolla tiene una repercusión a nivel social y otra a nivel individual (Daniels, 2003). Dentro de esta reflexión, y sin despreciar los aspectos evolutivos de los individuos, Vygotsky considera que los procesos mentales superiores están mediados de forma sociocultural, y que el proceso de enseñanza-aprendizaje tiene su potencial en lo que se produce en la Zona de Desarrollo Próximo, que él mismo define como " la distancia entre el nivel actual de desarrollo determinado por la resolución independiente de problemas y el nivel de desarrollo potencial 
determinado por la resolución de problemas bajo la guía de un adulto o en colaboración con compañeros más capaces." (Vygotsky, 1996)

Por último, y tratándose de la etapa de Educación Infantil no podemos obviar el modelo propulsado por Loris Malaguzzi, que tuvo su desarrollo y concreción en las escuelas municipales italianas de Reggio Emilia. En la actualidad cuenta con una red importante de escuelas tanto en Italia como en otras partes del mundo. Considerada la escuela como una escuela amable, al servicio de un niño curioso que construye su aprendizaje junto a un maestro que, sin guiarse tanto por un curriculum preestablecido como por el fomento de un aprendizaje continuo, pone a disposición del alumno gran variedad de materiales para aprender juntos (Gandini, 1993; Malaguzzi, 1998). Se trata de un modelo que cultiva y guía el potencial intelectual, emocional, social y moral de cada niño (Gardner, 1998). Además, Malaguzzi considera que la vinculación de la familia y el contexto es parte fundamental del modelo, así como un maestro formado y que investiga en su propia práctica (Malaguzzi, 1998).

Hasta aquí hemos tratado de explicar algunas de las aportaciones teóricas más importantes para la Educación Infantil en la que se basan las prácticas de aula en estos niveles. Trataremos en el epígrafe siguiente de desarrollar los marcos legislativos que regulan la etapa en el momento actual, con objeto de entender el sentido de la misma dentro del sistema educativo.

\subsubsection{Evolución de la Educación Infantil en España. Marco Legislativo.}

Durante los comienzos del siglo XIX encontramos pequeños indicios sobre la regularización de la Educación Infantil. Las corrientes pestalozzianas imprimen su sello en Madrid en las escuelas de la Sociedad Cántabra y el Real Instituto Pestalozziano (Vicente, 2001, p. 327). Seguido a esto, la creación de las escuelas Virio -entre 1938 y 1950-, reguladas por la Real Orden de 24 de mayo de 1938 y supervisadas por Pablo Montesinos, supusieron una primera fase en el avance de la institucionalización de las escuelas de párvulos durante el siglo XIX. Tratando de consolidarse y como segunda fase, el compromiso del Gobierno con la etapa se reconoce a través de la Ley de Instrucción Pública de 1857 -Ley Moyano- (Colmenar, 2010). Prueba de ello es su artículo 105 donde se indica que "El Gobierno cuidará de que, por lo menos en las capitales de provincia y pueblos que lleguen a 10.000 almas, se establezcan además Escuelas de Párvulos".

Las dos fases son importantes para sentar las bases de la regularización de lo que hoy es la etapa de la Educación Infantil, aunque es en el último cuarto de siglo donde se produce el verdadero desarrollo de las escuelas de párvulos. 
En el año 1874 se avanza en la consolidación profesional de la etapa con la introducción en la Escuela Normal Central de Párvulos de un ensayo de "Jardines de Niños", bajo el amparo de la Orden de la Presidencia del Poder Ejecutivo de la República, de 31 de octubre de 1874 y con la influencia del ideario froebeliano. En esa línea, dos años más tarde surge la Cátedra de Pedagogía Especial Aplicada a Párvulos por el sistema froebeliano (Colmenar, 2010, p. 139 y 140), que unido al Curso Especial de Maestras de Párvulos creado a partir del Real Decreto de 17 de Marzo de 1882- planteaba las primeras iniciativas a la regularización profesional de las maestras de párvulos.

Como un hito casi aislado pero importante por su relevancia pedagógica, a finales de este siglo surgen por iniciativa de Andrés Majón y Manjón las escuelas del Ave María, con una pedagogía basada en el juego y con la intención de dar educación a aquellos que más lo necesitaban. Llegaron a ser más de 400 a lo largo de toda España durante la primera parte del siglo XX.

Dejando atrás el siglo XIX, con luces y sombras en lo que se refiere a la Educación Infantil, la entrada en el nuevo siglo no tuvo un comienzo fácil. Como momentos relevantes hay que avanzar hasta la Segunda República, quien inició lo que pretendió ser la extensión de la educación a todos los niños y durante comienzos de los años " 30 se crearon "salas cuna" para los menores de 2 años, "refugios infantiles" desde los 2 a los 4 años y "jardines de infancia" que abarcaban desde los 4 a los 6 años de edad. (Bejarano, 2010, p. 402). Esta expansión se vio truncada por el estallido de la Guerra Civil de 1936 y agravada, si cabe, por la Segunda Guerra Mundial.

Posteriormente, la década de los '40, con el gobierno franquista y el comienzo de una lenta "recomposición" tras los daños humanos, materiales y morales sufridos en la guerra de 1936, surge en 1945 la Ley de Educación Primaria de 17 de julio. En ella se recoge en el artículo 18 del Capítulo II, dentro de los "periodos de graduación escolar" la referencia directa al periodo de iniciación, fijando en su primer punto las escuelas maternales que comprenden hasta los 4 años de edad (García, 1996, p. 13 y 14). También se alude en sus artículos 19 y 20 a la creación de escuelas maternales y de párvulos siempre que permitan matrícula suficiente, marcando que "Los conocimientos proporcionados en estas escuelas no excederán nunca de aquellas experiencias y prácticas formativas propias de la psicología y corta edad de los párvulos. El profesorado será exclusivamente femenino", así como "Las escuelas de párvulos podrán admitir indistintamente niños y niñas cuando la matrícula no permita división por sexos." (B.O del E., 1945).

Fue por fin la Ley General de Educación del 4 de agosto de 1970 la que regulariza la Educación Preescolar como una etapa voluntaria y gratuita para los centros públicos y aquellos que se acojan a concierto, abarcando hasta la edad de 5 años. Se divide a su vez en dos etapas: la primera hasta los 3 años 
denominada Jardín de Infancia, y la segunda de 4 a 5 que recibe el nombre de Escuela de Párvulos. El objetivo fundamental es el desarrollo armónico de la personalidad del niño (art.13). Para ello, "la educación prescolar comprende juegos, actividades de lenguaje, incluida, en su caso, la lengua nativa, expresión rítmica y plástica, observación de la naturaleza, ejercicios lógicos y prenuméricos, desarrollo del sentido comunitario, principios religiosos y actitudes morales.", y entiende que los métodos "serán predominantemente activos para lograr el desarrollo de la espontaneidad, la creatividad y la responsabilidad." (art.14)

Tras la LGE del 1970 surge en 1981, y tras un periodo de implantación y las consiguientes remodelaciones necesarias para adaptarse a la situación vigente, los Programas Renovados de 1981 que incluyen nuevas orientaciones: agrupan los objetivos en bloques temáticos, se centran en las capacidades e intereses del discente, la representación gráfica, la globalización, el juego,... (García, 1996, p. 16)

Una década después de la LGE y firmada ya la constitución de 1978, aparecen la LOECE de 1980 y la LODE de 1985. Aunque ninguna de las dos leyes citadas deroga la Ley General del 70, sí incorporan importantes modificaciones, sobre todo de carácter organizativo y de gobierno, pero no afectan a la Educación Infantil. Sin embargo, sí es destacable para la etapa la orden de 26 de abril de 1985 sobre la selección de centros que participarán en el desarrollo del Programa Experimental de Educación Infantil durante el curso 1985-1986 que en su introducción dice:

La evolución de la personalidad resulta notablemente condicionada por los aprendizajes tempranos de los niños, que en función de las más recientes investigaciones sobre el desarrollo psico-evolutivo en estas edades, aconseja la necesidad de replantear el sentido de las orientaciones de la actual educación escolar.

En esa primera fase participaron un total de setenta y cuatro centros, dependientes de distintas administraciones públicas (MEC, Comunidades Autónomas y Ayuntamientos). Desde el Ministerio se publicaron diferentes documentos de trabajo para buscar un trabajo colaborativo entre los centros. Se desarrolló una segunda fase durante los curso 1986-87 y 1987-88, en la que el número de centros fue de 171 y 178 respectivamente. Llego a haber una tercera fase en el curso 1988-89. De todas estas fases surgieron hasta seis Documentos de Trabajo y un Anteproyecto de Marco curricular para Educación Infantil (Olaya, 1996). Todo este esfuerzo propició cambios en las metodologías docentes, logrando el cambio en centros y docentes de Educación Infantil. 
Finalmente, fue la LOGSE en 1990 la que acuñó, por primera vez en una Ley Orgánica Educativa el término Educación Infantil. Con ello se pretendía romper la idea de Educación Prescolar, y darle a la etapa una identidad propia y característica de la edad de los alumnos. $\mathrm{Y}$ así lo recoge en su artículo 3 que la define como una etapa que comprende hasta los seis años de edad siendo competencia de la Administración garantizar las plazas para todos aquellos que lo soliciten (art. 7). Consta de dos ciclos, el primero desde los 0 a los 3 años donde se destacan la adquisición por parte de los alumnos de habilidades motrices, iniciación en comunicación y lenguaje y pautas de convivencia y socialización; mientras que en el segundo, desde los 3 a los 6 años, se subraya el uso del lenguaje, conocer el medio, una imagen positiva de si mismo y adquirir hábitos básicos de comportamiento que le permitan una elemental autonomía personal. La organización de los contenidos será por “áreas que se correspondan con ámbitos propios de la experiencia y desarrollo infantiles, y se abordarán a través de actividades globalizadas que tengan interés y significado para el niño" y "la metodología educativa se basará en las experiencias, las actividades y el juego, en un ambiente de afecto y de confianza." (art. 9)

Por último, antes de la llegada de la LOE, surgió la LOCE (Ley Orgánica de la Calidad en la Enseñanza) que no marca puntos diferenciables con los recogidos en la LOGSE, en cuanto a los temas de contenido y propuestas aunque sí en otros punto más relacionados con ámbitos de decisión y cargos, pero pese a que llegó a aprobarse en 2003, durante el siguiente año y a través de Real Decreto se paralizó su implantación.

\subsection{La legislación actual en Educación Infantil}

\subsubsection{Ley Orgánica 2/2006 de Educación}

El marco legislativo que afecta a la investigación desarrollada en este trabajo, viene regulado por la Ley Orgánica 2/2006, de 3 de mayo, de Educación (LOE). En ella se recogen los principios generales, la identidad propia de la etapa de Educación Infantil, su carácter voluntario, así como la necesidad de una cooperación entre familia y escuela (art.12). Su estructuración se mantiene con respecto a la LOGSE en dos ciclos, el primero desde el nacimiento hasta 3 años, en el que la Administración promueve el incremento 
progresivo de plazas y un segundo ciclo, que es donde ser ha realizado la investigación, entre los 3 y los 6 años, garantizando la Administración plazas suficientes para cubrir la demanda de las familias (LOE, 2006, art. 14 y 15).

Los datos nos muestran un importante crecimiento de alumnos de Educación Infantil matriculados en los diez últimos años Como vemos en la Tabla 2.1, en el primer ciclo el número de alumnos se ha cuadruplicado con respecto al año 2000, mientras que en el segundo ciclo, aunque el aumento neto ha sido mayor, en proporción el crecimiento ha sido menor.

\begin{tabular}{ccccc}
\hline & $\mathbf{2 0 0 0 - 2 0 0 1}$ & $\mathbf{2 0 0 5 - 2 0 0 6}$ & $\mathbf{2 0 1 0 - 2 0 1 1}$ & $\mathbf{2 0 1 1 - 2 0 1 2}$ \\
Primer ciclo & 101.441 & 226.656 & 429.839 & 443.279 \\
Segundo ciclo & 1.066 .340 & 1.260 .892 & 1.441 .153 & 1.469 .101 \\
Total & 1.167 .781 & 1.487 .548 & 1.870 .992 & 1.912 .380 \\
\hline
\end{tabular}

Tabla 2.1: Matriculación de alumnos EI

(Fuente: Ministerio de Educación, 2012)

El segundo ciclo, pese a tener carácter voluntario, cuenta con un alto porcentaje de escolarización, lo que hace que la administración educativa tenga que cubrir casi al 100\% de la población comprendida entre los 3 y los 6 años.

Los objetivos marcados son muy generales y quedan recogidos en la LOE en su artículo 13. Destacan dentro de ellos el conocimiento de sí mismo y de los otros, el respeto por las diferencias, la observación de su entorno, la adquisición de autonomía progresivamente, el desarrollo de mecanismos de comunicación usando diferentes lenguajes y formas de expresión y la iniciación en el pensamiento lógico-matemático, la lectoescritura, el movimiento y el ritmo.

En cuanto a principios pedagógicos se sitúa muy cerca de la LOGSE, por ejemplo en la necesidad de atender progresivamente al desarrollo afectivo, la psicomotricidad, los hábitos de control, la comunicación, el lenguaje, la convivencia y la relación social; así como conocer el entorno en que viven, todo ello en busca de una imagen positiva y equilibrada de sí mismos con el objetivo de alcanzar la autonomía personal. Los contenidos con los que se trabaja en esta etapa se organizan igual que anteriormente por áreas curriculares que se corresponden con los ámbitos propios de la experiencia y del desarrollo infantil desde un enfoque que recoge actividades globalizadas de interés y significado para los alumnos. 
La LOE se concretará unos meses después en referencia a la Educación Infantil a través del Real Decreto 1630/2006, de 29 de diciembre, donde quedan recogidas las enseñanzas mínimas del segundo ciclo de Educación Infantil.

\subsubsection{Decreto 122/2007, de 27 de diciembre, Consejería de Educación, Castilla y León.}

Una vez establecidos por el Gobierno a través de la LOE y el Real Decreto 1630/2006 las enseñanzas mínimas del segundo ciclo de Educación Infantil, es la propia comunidad autónoma la encargada de "establecer el currículo propio del segundo ciclo de la Educación Infantil para su aplicación en los centros que impartan este ciclo, pertenecientes a su ámbito de gestión." (Consejería de Educación, 2008).

En el ámbito geográfico que afecta a esta investigación, corresponde mantener al menos el 65\% de lo fijado. El desarrollo del Decreto 122/2007 de la Consejería de Educación de Castilla y León, concreta un curriculum de Infantil organizado en torno a tres áreas:

1. De acuerdo con lo establecido en el artículo 6 del Real Decreto 1630/2006, el currículo del segundo ciclo de la Educación Infantil se organizará en las siguientes áreas:
a. Conocimiento de sí mismo y autonomía personal.
b. Conocimiento del entorno.
c. Lenguajes: Comunicación y representación.

Es en el área de Lenguajes: Comunicación y representación, donde las TIC toman un papel protagonista, puesto que se mencionan explícitamente dentro del área como unos de los contenidos mínimos con los que los niños han de trabajar en la etapa.

Dado los objetivos que se plantean en la investigación, son destacables todos aquellos aportes recogidos en la legislación que tengan que ver con dos ejes. Por un lado, aquellos relacionados con la metodología y las actividades a desarrollar dentro de la etapa y por otro aquellos aspectos que relacionan las TIC con el curriculum.

2.3. La Etapa de Educación Infantil en el contexto español. 
Cuando se hace referencia a las etapas dentro del sistema educativo, se pueden establecer diferencias entre dichas etapas atribuibles en primer lugar a los grados de madurez de los alumnos en cada momento. Pero no son esas diferencias las únicas que distinguen unas etapas de otras. De hecho, otros factores permiten caracterizar con mayor precisión las peculiaridades de cada nivel educativo. Nos referimos a cuestiones como los enfoques metodológicos propios de cada una de ellas, lo cual afecta al tratamiento que se hace de los contenidos, de la gestión de los recursos en el aula, de las técnicas de evaluación más apropiadas...Y también a otros aspectos como la cultura profesional de los docentes en cada etapa o los diversos modelos de gestión de los centros escolares. Trataremos en este epígrafe de abordar lo que es propio de la etapa de Educación Infantil sobre todo en lo relativo a la fase de desarrollo del curriculum.

La etapa de Educación Infantil, tiene como hemos dicho carácter voluntario, por tanto, la matriculación o no del alumnado en el segundo ciclo de Educación Infantil depende de la voluntad de los padres o tutores legales de los niños; si bien, presenta un alto índice de alumnos escolarizados, el 99.1\% de los alumnos de 3 años en el curso 2009-10, manteniéndose en porcentajes muy similares hasta el comienzo de la etapa obligatoria. Esto hace que la administración educativa tenga que dotarla de infraestructuras para cubrir la demanda.

Con el fin de enmarcar nuestro estudio, realizaremos un breve análisis de algunas particularidades de esta etapa de carácter psicopedagógico

\subsubsection{Características Psicológicas de la Edad}

Los alumnos están comprendidos entre 3 y 6 años, lo que lleva consigo que determinadas habilidades físicas y verbales básicas se encuentren en fase de iniciación y consolidación, así como el desarrollo de otras de carácter emocional, moral o de carácter más cognitivos. En estos primeros años de la vida los niños presentan grandes cambios en periodos de tiempo reducidos. En la siguiente tabla 2.2 se muestra la evolución a nivel cognitivo y lingüístico en diferentes estadios del desarrollo tal y como proponen García, Gutiérrez y Carriedo (2002): 


\begin{tabular}{|c|c|c|c|}
\hline Estadio & Edad & Cognición & Lenguaje \\
\hline Episódico & $0-18$ meses & $\begin{array}{ll}\text { - } & \text { Representación de } \\
& \text { acontecimientos (RA) }\end{array}$ & - Sonido, primeras palabras \\
\hline$\underline{\text { Mimético }}$ & $\begin{array}{c}18 \text { meses y } 4 \\
\text { años }\end{array}$ & $\begin{array}{l}\text { - } \quad \text { RA con palabras. } \\
\text { - Juegos, cantos, ritos } \\
\text { sociales. }\end{array}$ & $\begin{array}{ll} & \text { Diálogo. } \\
\text { - } & \text { Desarrollo gramatical, } \\
& \text { lenguaje en } \\
& \text { representación mimética }\end{array}$ \\
\hline$\underline{\text { Mítico }}$ & 4-10 años & $\begin{array}{ll}\text { - } & \text { Pensamiento narrativo. } \\
\text { - } & \text { Memoria personal. } \\
\text { - } & \text { Aprendizaje cultural. }\end{array}$ & $\begin{array}{ll}- & \text { Narraciones } \\
\text { - } & \text { Comienzo de la lectura y } \\
& \text { escritura, matemáticas }\end{array}$ \\
\hline
\end{tabular}

Tabla 2.2 Evolución a nivel cognitivo y lingüístico

Desde el punto de vista psicomotriz, entre los 2 y los 7 años, se desarrollan y consolidan movimientos fundamentales: locomotores como caminar, correr, saltar, subir, brincar...; de manipulación como lanzar, coger, dar patadas, golpear,...; y de estabilidad como inclinarse, estirarse, girarse, balancearse,... (Ross, Haith y Miller, 2001, p. 205) Y además, "la destreza motriz de un niño constituye un importante componente de sus sentimientos de competencia para enfrentar el ambiente." (Ausubel, 1983, p.208) esta cuestión "le permite pensar que es ejecutivamente independiente y capaz de atender a sus propias necesidades o bien, en caso contrario, que depende de la asistencia física que le presten los demás." (p.208).

Otro aspecto importante del alumnado de estas edades es el relacionado con el desarrollo de la personalidad. La personalidad, según Ausubel (1983), "comprende todas las predisposiciones conductuales características del individuo en un momento dado de su vida". En ella juegan un papel fundamental componentes como emociones, valores e intereses, y también determinantes como la familia, grupo de iguales, los maestros, etc. (p. 12). La escuela, además de su claro desempeño como transmisora de conocimiento y aptitudes de corte intelectual, comparte junto a la familia responsabilidades de socialización y de relación con la cultura (p. 144). Es fundamental para el niño el desarrollar estas habilidades sociales y culturales con el fin de definir "su espacio" en el mundo que le rodea. Así, el tratamiento adecuado del sistema emocional del niño, que se presenta interrelacionado con el cognitivo de múltiples formas y que está determinado a su vez por variables evolutivas, es otro pilar que se ha de trabajar y supervisar de forma individualizada. Por tanto, se ha de tener en cuenta que la transmisión de valores, ya sean culturales, sociales o universales ha de ayudar al desarrollo moral y el equilibrio en el complejo entramado idiosincrático del niño en esta etapa de la Educación Infantil. 


\subsubsection{Centros de Educación Infantil.}

Los centros educativos que imparten la etapa infantil tienen la posibilidad de organizarse de diferentes formas a nivel estructural, pudiendo ser: Escuelas Infantiles (EI), aquellos que tienen única y exclusivamente primer ciclo de infantil, el segundo ciclo de infantil o ambos. Otra modalidad de centros mucho más común son los Colegio de Educación Infantil y Primaria (CEIP), donde conviven la etapa de infantil con la de primaria -primera etapa obligatoria-. También nos encontramos con los Colegio de Enseñanza Obligatoria (CEO), los cuales abarcarían además de infantil y primaria otras de estudios secundarios. Y en el caso especial de los centros rurales encontramos los Centros Rurales Agrupados (CRA) que dependiendo de las necesidades de los pueblos incorporan diferentes niveles educativos, principalmente infantil y primaria. Las cuatro formas mencionadas, además de las que estipule la Administración para casos concretos, recogen los posibles modelos y denominaciones de los centros públicos en la etapa de Educación Infantil. En el caso de los centros privados o concertados, su denominación puede ser cualquiera menos las mencionadas para centros públicos. En este último caso la más adoptada suele ser la genérica de colegio. También encontramos centros que imparten solamente la etapa de Educación Infantil que reciben el nombre de Centro Infantil o Centro de Educación Infantil.

El número de centros y su titularidad durante el curso 2010-2011 de la Etapa de Educación Infantil, aparece recogida en la tabla 2.3 que se muestra a continuación:

\begin{tabular}{|c|c|c|c|c|c|c|c|c|c|c|}
\hline & \multicolumn{4}{|c|}{ TOTAL DE CENTROS } & \multicolumn{6}{|c|}{ DE ELLOS IMPARTEN } \\
\hline & \multirow{2}{*}{$\frac{\pi}{0}$} & \multirow{2}{*}{ 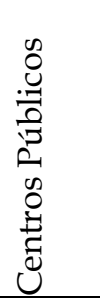 } & \multicolumn{2}{|c|}{$\begin{array}{l}\text { Centros } \\
\text { Privados }\end{array}$} & \multicolumn{3}{|c|}{$\begin{array}{l}\text { PRIMER CICLO } \\
\text { (0-3 años) }\end{array}$} & \multicolumn{3}{|c|}{$\begin{array}{l}\text { SEGUNDO CICLO } \\
\text { (3-6 años) }\end{array}$} \\
\hline & & & 胥 & 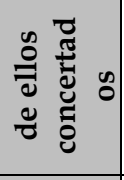 & 宽 & 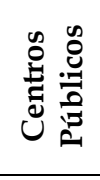 & 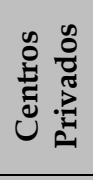 & 吾 & 递苞 & U \\
\hline España & 21.140 & 14.095 & 7.045 & 4.136 & 8.195 & 3.844 & 4.351 & 14.350 & 10.708 & 3.642 \\
\hline $\begin{array}{l}\text { Castilla y } \\
\text { León }\end{array}$ & 977 & 732 & 245 & 185 & 151 & 63 & 88 & 860 & 669 & 191 \\
\hline Salamanca & 155 & 111 & 44 & 30 & 29 & 11 & 18 & 132 & 100 & 32 \\
\hline
\end{tabular}

Tabla 2.3: Numero de centros que imparten E. Infantil durante el curso 2010-2011 (Fuente: Ministerio de Educación 2011) 


\subsubsection{Aspectos organizativos y metodológicos de la etapa}

Las características de la etapa vistas hasta ahora enmarcan la Educación Infantil como una etapa con identidad propia que presenta peculiaridades lo que repercute de forma directa en la organización y las metodologías que se desarrollan en la misma.

Espacios. Comenzando por los lugares en los que se desarrolla la práctica educativa, observamos que en los centros específicos de infantil los edificios suelen estar pensados y conformados para las edades de los alumnos, todo el centro gira en torno a unos horarios, tiempos y espacios que son flexibles y adecuados para la edad. Sin embargo, dos terceras partes de los centros que imparten la etapa de Educación Infantil tienen además otros niveles de enseñanza (primaria, secundaria, bachillerato,...) y esto hace que el centro adapte y habilite zonas específicas para las necesidades de las etapas educativas. Es decir, encontramos que en la mayoría de los centros no específicos de infantil tienen una zona delimitada para ellos, ya sea en un edificio anexo al centro, en una planta específica o en plantas en las que se encuentren separados los más pequeños de las etapas obligatorias. Asimismo, disponen normalmente de patio de recreo propio o si esto no es posible mediante el horario evitan coincidir con alumnos de otras etapas educativas.

En cuanto a las aulas suele ser habitual que sean amplias, luminosas y distribuidas en varios espacios de trabajo como los pupitres característicos de etapas posteriores, mesas comunes para trabajo individual o conjunto (estás dos normalmente cerca de la pizarra), zonas de juego, rincones temáticos, alfombra para psicomotricidad y relajación, o biblioteca. También es común encontrar dentro de las aulas de infantil un baño adaptado al que se accede directamente desde cada aula o en su defecto un baño contiguo.

Tiempos. Al igual que se ha visto con respecto a los espacios, los tiempos en la etapa de infantil se rigen con pautas distintas del resto de la educación obligatoria. Así, es normal encontrar descansos más frecuentes, cambios de actividad y temática cada poco tiempo, tareas cortas y concisas o recreos más largos. Tal es la flexibilidad de estos cursos, que es habitual encontrar centros que usen en los primeros días del inicio del curso periodos de adaptación para el alumnado. Esto lo realizan, de distintas maneras según el centro, por ejemplo, yendo días no consecutivos durante las primeras semanas, 
o en jornadas lectivas más reducidas, o combinaciones de las mismas, aumentando poco a poco el tiempo en la escuela para que los niños se adapten de forma más natural a la misma.

Metodologías. Vistos los aspectos anteriores y sus peculiaridades e importancia dentro de la etapa, las metodologías no pueden ser menos y se tornan como aspecto fundamental en infantil. Las características del alumnado tanto de desarrollo psicológico como motor, los recursos, los espacios, el enfoque curricular, los objetivos que se persiguen o las características personales y profesionales de los docentes influyen de manera sustancial en las metodologías utilizadas en las aulas. En este sentido, podríamos destacar algunos ejes fundamentales o principios básicos en los que se asentarían las metodologías de la etapa: el carácter globalizado del conocimiento, el fomento de la creatividad, el valor de la experimentación y el descubrimiento como formas de desarrollar el papel activo del niño en el aprendizaje; la socialización y el trabajo en equipo, para fortalecer aspectos interrelacionales y adaptativos al contexto social que les rodea; la personalización, individualización y normalización de cada niño con el fin de desarrollar identidades propias y personales en el sujeto; y por último el valor de juego como fuente de placer y de conocimiento. Estos principios se vienen plasmando en metodologías singulares de la etapa, que frecuentemente son más complementarias que alternativas.

Una metodología característica de las aulas de infantil es la del Trabajo por rincones, que favorece la participación activa del niño y da lugar a la combinación de tareas y el trabajo globalizado de los contenidos. Se caracteriza por disponer de una serie de rincones de juego organizados por el docente "que tienen que ser polivalentes, es decir, ofrecer diferentes posibilidades y alternativas" (Ibáñez, 2007). Cada rincón dispone de un espacio diferenciado en el aula así como un nombre concreto que está vinculado con las actividades que en él se realizan, por ejemplo, rincón de las construcciones, rincón de las letras, rincón de lógica-matemática o de los números, rincón para pensar, rincón de lectura o biblioteca, rincón de plástica, rincón de juego simbólico, rincón del ordenador, etc. No hay una configuración estándar, sino que es el propio docente quien decide cuántos y cuáles son los rincones. En este tipo de metodología, la organización del aula se puede encontrar con dos líneas distintas de trabajo: los rincones, entendidos como complemento de la actividad del curso; o los rincones, entendidos como un contenido específico (Gervilla, 
2006, p.38). La primera, supone que el rincón es utilizado por el alumno en pos de una labor acabada o en su tiempo libre. Lo que sitúa por un lado al rincón como algo secundario en dependencia de una condición previa para su utilización -por ejemplo, acabar la tarea-, y por otro como algo a lo que tienen acceso los mejor adaptados al funcionamiento de la clase -los que antes acaban. La segunda, otorga al rincón un valor equitativo al de otras actividades que se puedan realizar fuera de ellos, y los turnos de uso están fundamentados en la planificación y organización que el maestro crea oportuna para garantizar el acceso a todos los alumnos. (Gervilla, 2006).

Además de esta metodología de trabajo por rincones, que suele ser generalizada en las aulas de infantil, existen otras que, sin necesidad de ser excluyentes sino más bien complementarias, aparecen en el aula en configuraciones diversas, variando sustancialmente en función de los perfiles docentes. Así pues, encontramos metodologías basadas en el trabajo individual, en las que el alumno desarrolla su tarea bajo el control del docente, donde las explicaciones y la supervisión desempeñan una importante misión que ha de valorar y adaptarse a las necesidades de cada niño ante la tarea. Metodologías de trabajo en grupo o cooperativa, el profesor asigna las tareas por grupos definidos previamente y todos realizan la misma tarea bajo el control del profesor, que se convierte en una figura importante en la coordinación de los grupos y la planificación y supervisión de las actividades. Metodología de trabajo por proyectos, donde el docente plantea los contenidos en base a proyectos y los trabaja de forma grupal con los alumnos, quienes siguen las pautas y pasos planificados por el docente con el fin de obtener los resultado previstos de una forma experimental y deductiva. Metodología vivencial, basada en la idea de Freinet, donde la espontaneidad del alumno y la función del profesor como animador y educador permitirá relacionar los centros de interés de los niños buscando que aprendan a través de experimentos, vivencias, etc. adecuadas a las características de cada alumno. Metodología creativa, que trata de fomentar aquellos aspectos relacionados con la inventiva, la imaginación y la creación particular de cada niño, de cada sujeto. Sin ser directiva y sin buscar ese pensamiento lógico, pese a considerarse también importante, fomenta en los niños la compresión y aceptación de diferentes posibilidades de solución o usos frente a variadas situaciones o recursos. De nuevo, la espontaneidad y la idiosincrasia de cada niño dan lugar a un amplio abanico de posibilidades para hacer frente a los procesos de 
aprendizaje. Metodología de normalización, en la que el docente afronta el reto de conseguir normalizar o interiorizar en el alumno acciones, ideas, protocolos, pautas, comportamientos, etc. En definitiva, adquirir aquellas rutinas que le faciliten al niño el desarrollo integral y lo ayuden a desenvolverse de manera adecuada en el contexto que les rodea, comprendiendo y asimilando las normas social y culturalmente acordadas.

Todas estas metodologías citadas, pueden coexistir en diferentes combinaciones metodológicas dependiendo de múltiples variables que afectan en el proceso de enseñanza-aprendizaje, por ejemplo, el alumnado, el docente, el contexto, el aula, el curriculum, etc. A partir de ahí son los docentes lo que deciden y configuran las metodologías de enseñanza en el aula.

\subsubsection{Recursos.}

El papel que juegan los recursos en la etapa de Educación Infantil dadas las características del alumnado es fundamental. La dificultad para el pensamiento abstracto en los niños de estas edades, el desarrollo de la creatividad y la imaginación, la necesidad de materializar los pensamientos, de utilizar y experimentar con materiales y objetos concretos precisa de una dotación del material tangible diverso y abundante para el trabajo diario. Sin embargo, al tratarse de una etapa no obligatoria las Administraciones inciden más en dotación de recursos para otros niveles como puede ser la Escuela 2.0, quedando las partidas presupuestarias de la etapa en manos de las gestiones de los centros, lo que en ocasiones y más en las circunstancias de crisis como las actuales, puede ver mermada dicha dotación.

Al margen de mayores o menores dotaciones dependiendo de los centros, la Administración u otros agentes, los recursos que se encuentran en las aulas suelen ser similares y están distribuidos y pensados para el trabajo en los rincones, lo que no impide que en algunos se usen indistintamente por su versatilidad para más de un rincón. De esta forma, encontraremos dependiendo del rincón unos u otros materiales con los que trabajar. Por ejemplo, el rincón de las letras, podrá contar con recursos como el abecedario en piezas, puzzles para formar sílabas o palabras, imágenes que asocien fonemas y grafías, fichas para trabajar la escritura, etc.; el Rincón lógico-matemático contará con regletas, fichas, ábacos, figuras geométricas, números, figuras con tamaños, etc.; el rincón del ordenador tendrá un ordenador, pantalla, altavoces o auriculares, 
teclado, ratón, distinto software que pueda trabajar los contenidos que se desea, conexión a internet, etc.; en el rincón de plástica habrá plastilina, pinturas, rotuladores, acuarelas, tizas, gomets (gommette), etc. Así cada uno de los rincones contará con material para desarrollar las distintas tareas de clase y además otro material más polivalente que se adapte a varios rincones y que no pertenezca a ninguno específico. Ello hace importante que exista una apropiada y variada dotación de recursos para este ciclo en concreto.

\subsubsection{Las TIC como recurso del aula}

Dado el objeto de estudio de nuestra investigación y su relación directa con las TIC, es importante situar los recursos tecnológicos dentro de las características de la etapa. Aunque en el capítulo anterior, lo hayamos abordado desde el curriculum y en el siguiente capítulo lo hagamos en relación con el profesorado parece importante delimitarlo dentro del contexto de la Educación Infantil y sus características. Y sobre todo porque en los dos capítulos mencionados la idea protagonista identifica a las TIC con recursos materiales que permiten desarrollar distintos aspectos del curriculum. Por tanto, son propuestas reguladoras en torno a contenidos y actividades curriculares.

Las TIC: integración en el aula. Centrados en la importancia que adquiere la presencia de las TIC en la Educación Infantil, se pueden mencionar tres aspectos que justifican la presencia de las TIC en la etapa (Bolstad, 2004):

- Forman parte activa tanto de los contextos donde se desenvuelve el niño como de las personas que lo rodean.

- Ofrecen nuevas oportunidades que favorecen el fortalecimiento de aspectos formativos que aborda la etapa de Educación Infantil.

- Las administraciones muestran un gran interés en lo referente a la integración de las TIC en el ámbito educativo (leyes, políticas, proyectos, etc.)

En el primero de los puntos que marca Bolstad, encontramos una clara referencia a la importancia de que la escuela se adapte a las necesidades de los niños para desenvolverse en la sociedad que les rodea, que entiendan su funcionamiento y aprendan sus lenguajes. El siguiente punto muestra las TIC como una herramienta complementaria, que puede aportar elementos de refuerzo en la comprensión de otros conceptos, actitudes o procedimientos que se deben adquirir en la etapa evolutiva de los niños. El tercero y último punto, 
trasluce un interés por satisfacer por parte de las Administraciones la incorporación de avances que se producen en la sociedad e incluirlos como parte del curriculum. Como se ve reflejado claramente en la LOE (2006) en su artículo 14 donde dice que "fomentarán una primera aproximación a la lectura y a la escritura, así como experiencias de iniciación temprana en habilidades numéricas básicas, en las tecnologías de la información y la comunicación y en la expresión visual y musical", lo que en buena medida viene a refrendar la idea de Bolstad.

La idea de "nativo digital" (Prensky, 2001), que se podría aplicar al alumnado actual de Educación Infantil, con su inmersión en sistemas multimedia y audiovisuales desde el nacimiento, requiere de un aprendizaje, reflexión y guía para un uso eficaz. Así lo recoge el RD 1630/2006 por el que se establecen las enseñanzas mínimas para el segundo ciclo de Educación Infantil. Indicando dentro de Lenguajes: comunicación y representación un bloque para su trabajo y desarrollo: Bloque 2: lenguaje audiovisual y tecnologías de la información y la comunicación. En él se alude a varios puntos de interés sobre el lenguaje audiovisual y las TIC, como son su uso, en el carácter manipulativo; su acercamiento a producciones como películas, dibujos o videojuegos desde una visión tanto crítica como estética de los contenidos; su separación entre realidad y representación audiovisual; y por último la correcta utilización, en el sentido de tiempo de uso moderado.

Esta mención curricular, se refleja y concreta en la posibilidad de una integración de recursos TIC en el aula, que puede variar desde soportes básicos como el radiocasete hasta otros más sofisticados como la pizarra digital. En cualquiera de los casos se pueden señalar dos niveles de análisis: uno respecto de la dotación de recursos, que depende desde los centros hasta las Administraciones, del que ya se han dado anteriormente algunas ideas al respecto; y otro respecto del uso didáctico de estos recursos y su lenguaje, principalmente ligado a las capacidades y concepciones del docente, del que se tratará en profundidad en el siguiente capítulo.

Estudios científicos. Revisando estudios que relacionan TIC y Educación Infantil, aparecen diferentes aportaciones que indagan sobre diversas líneas de investigación. Por ejemplo, algunos analizan el efecto positivo o negativo a nivel social del uso de las TIC en los niños (Attewell, Suazo-García \& Battle, 2003) presentando posturas en ambos polos, por un 
lado, aquellos que defienden su uso aludiendo a mejoras en capacidades (Papert, 1996) y por otro, autores que defienden que el uso de estos recursos perjudica el desarrollo del niño a niveles emocionales y físicos, ya que lo priva de la realización de otras actividades que equilibran su desarrollo integral (Healy, 1998) o sustituyen procesos de aprendizaje necesarios para el niño, ocupando el lugar que corresponde al uso de materiales tangibles y experiencias con el entorno que favorecen su crecimiento (Alliance for Childhood, 2000).

Si adoptamos un enfoque más curricular, los estudios se centran en la existencia de mejoras en los resultados académicos de los alumnos provocados por la integración y uso de las TIC en el proceso de enseñanza-aprendizaje. Algunos de ellos presentan resultados significativos sobre la mejora de los niños a través de estos recursos (Parette, Stoner, \& Watts, 2009; Waxman, Lin \& Michko 2003; Padron, Waxman, Lee, Lin, \& Michko, 2010). Sin embargo, otros estudios son cautos y avisan de la necesidad de seguir estudiando y analizando el impacto de las TIC en los resultados académicos (Fuchs \& Woessmann, 2004; Attewell, Suazo-García \& Battle, 2003).

Estos estudios que aparecen en la literatura científica no se circunscriben específicamente a la etapa de la Educación Infantil, sino que normalmente abarcan una edad más amplia. Esta constante en la investigación radica en el interés mayoritario por el campo de la enseñanza de la lectura y de la lógico-matemática, lo que explica que los estudios cubran edades superiores a los 6 años. En una revisión de 36 artículos científicos sobre estudios de tecnología y alfabetización que realizó Cathy Burnett (2010), se muestra la ausencia de datos sobre niños menores de 3 años y tan solo 11 estudios aludían a edades inferiores a 5 años. De ahí la dificultad para extrapolar datos referentes únicamente a los rangos de edad del segundo ciclo de Educación Infantil.

No obstante, en la incertidumbre que todo esto genera, con puntos de vista contradictorios, el avance y creación de nuevo software sigue adelante (Abrani et al., 2008) e incluso presenta a los educadores herramientas para evaluar el software y facilitar la elección del más adecuado para los alumnos de Educación Infantil (Wood et al., 2012). 
Dicho esto, queda clara que la vinculación de las TIC en la educación Infantil contempla una doble vertiente. Por un lado, su función dentro del curriculum como un contenido que se debe trabajar y con el que los niños deben familiarizarse -alfabetización digital. Y por otro, las TIC como un recurso o herramienta dentro del aula que queda a disposición del profesor para su utilización didáctica.

Profesorado de la Etapa. Aunque en el próximo capítulo se abordará en profundidad el papel del profesorado en relación con el conocimiento profesional docente y el uso de las TIC, conviene situar de forma general cuáles son las características peculiares que presentan los profesores de esta etapa, quienes para el desempeño profesional en la actualidad deben necesariamente tener una titulación especializada o una certificación de la Administración de su cualificación profesional para dar clase en dicha etapa. Aunque esta profesionalización hoy tiene un claro enfoque educativo, encuentra en el pasado un perfil feminizado y asistencial que todavía hoy supone un hándicap con el que los maestros de Educación Infantil han de enfrentarse (Sánchez, 2001). Las mujeres, que en otros tiempos ocupaban la totalidad de las plazas, siguen en la actualidad suponiendo una mayoría muy significativa frente a los varones (tabla 2.4). Un informe de la Red de Atención a la Infancia de la Comisión Europea destaca que "sería positivo para los niños que hubiera más personas de sexo masculino dedicadas a su cuidado" (1990), y cada vez nos encontramos con una mayor aceptación social de que los hombres ocupen puestos en la primera etapa educativa (Martín y Thió de Pol, 2011).

\begin{tabular}{ccc} 
& $\begin{array}{c}\mathbf{2 0 1 0 - 2 0 1 1} \\
\text { Total de profesores }\end{array}$ & $\begin{array}{c}\text { 2010-2011 } \\
\text { Número de mujeres }\end{array}$ \\
Castilla y León & 17.039 & $13.797(80,9 \%)$ \\
Salamanca & 2.368 & $1.866(78,8 \%)$ \\
España & 351.782 & $288.654(82 \%)$ \\
\hline
\end{tabular}

Tabla 2.4: Número de mujeres en las etapas de E. Infantil y E. Primaria (Fuente: Ministerio de Educación, Cultura y Deporte)

Además de la mencionada feminización, encontramos que el profesorado se enfrenta a dificultades a la hora de conceptualizar y reconocer su ejercicio profesional. La corta edad de los sujetos y la necesidad todavía de una gran supervisión y cuidados hacen que los maestros de Educación Infantil 
sean vistos y valorados socialmente más con perfiles de cuidadores más que de educadores. Este es un hándicap que repercute directamente, ya no sólo en la sociedad, sino en la visión propia que el maestro hace de sí mismo y de su profesión.

Un estudio realizado por Debra Harwood et. al (2013) analiza las concepciones de 25 profesores de Educación Infantil tienen sobre su propio desarrollo profesional. El perfil en el que mayoritariamente se encajaban a sí mismos presentaba una imagen compleja y la asunción de múltiples facetas que encajan dentro del papel que han de desempeñar en la clase. En consecuencia, describían roles caracterizados por acciones como cuidando, facilitando, produciendo, dando, ofreciendo, guiando en los entornos y las oportunidades de aprendizaje, situándose también en una orientación teórica ecológica en el desarrollo del niño (p. 9).

Sin embargo, establecer un rol determinado y genérico es una labor complicada, puesto que los maestros adaptan distintos roles en función de múltiples variables que condicionan cada caso particular. Así, tal y como muestran Baek, Jung y Kim (2008) está práctica compleja se ve inmersa -por las características de la etapa- en un dinamismo para el que los profesionales deben de estar preparados para responder de la forma más adecuada adoptando el rol que desde su conocimiento profesional convenga a cada situación. Por tanto, que el docente sea un observador, un facilitador, un guía, un intérprete, un líder, un miembro más del grupo, etc. depende no sólo del profesor, sino de el entorno que le rodea y los sujetos que participan en él.

Cuáles son sus funciones, qué requisitos debe cumplir, cuál debe ser su formación inicial, qué sabemos del conocimiento profesional en esta etapa,... Éstas y otras muchas son preguntas que los investigadores tratan de responder (Sanchidrián, 2010; Antón, 2007; Sánchez, 2001) de una u otra forma. Lo que sí parece claro y la mayoría de los autores coinciden, es que el profesorado de esta etapa es complejo y ha de ser un profesorado dinámico y versátil que sepa compaginar los cuidados que requieren los niños de esas edades con los procesos de enseñanza para la formación integral atendiendo a los principios básicos de la etapa.

De cualquier manera, en el capítulo a continuación se desarrollarán con más precisión todos los elementos relacionados con el ejercicio profesional de 
los docentes que permitirán interpretar en profundidad las claves del trabajo de los profesores de Educación Infantil de este estudio. 


\section{CAPÍTULO}

\section{El papel del}

profesorado ante las TIC 



\section{El papel del profesorado ante las TIC}

\subsection{Aspectos previos}

Uno de los elementos claves para explicar la incorporación de las TIC en los procesos de enseñanza lo constituye el profesor. En cualquier proceso de innovación, y la incorporación de las TIC se puede identificar con uno de ellos, el profesor desempeña un papel fundamental, sobre todo en la etapa que Fullan (1991) identifica, después de la de iniciación, como la segunda fase de los procesos de innovación, la fase de implementación y continuación. La cual se caracteriza porque los cambios afectan de forma fundamental a los objetivos, las estructuras y roles de la organización, lo cual conduciría tanto a empezar a usar nuevos enfoques en la enseñanza (nuevas estrategias o actividades), como a cambiar las creencias (concepciones y teorías pedagógicas en los profesores). Esta segunda fase habitualmente no se verifica en todo el sistema educativo, en todo caso suele afectar a elementos aislados, y no repercute en toda la organización: la innovación se diluye o se ajusta a lo que ya hay, sin afectar prácticamente a ningún proceso educativo esencial. Las razones para explicar las dificultades de esos últimos cambios profundos son muy diversas. En lo que respecta a los profesores y su "supuesta" resistencia ante las nuevas tecnologías, el propio Fullan explica que no se produce porque rechacen la necesidad del cambio en relación a estos recursos, sino porque se resisten a los cambios que se les imponen cuando no se les dan las suficientes oportunidades a largo plazo para dotar a las tecnologías de sentido en su trabajo docente. Plantea, por tanto, la dificultad, frecuentemente observada, de impulsar las innovaciones de "arriba-abajo", desde la administración educativa.

De la misma manera que Fullan, Dawes (1999) no calificaría de "resistentes al cambio" a los profesores. La autora considera que desde el marco de su conocimiento profesional, los profesores toman decisiones racionales y fundamentadas sobre programas y materiales que se les pide que usen. Por tanto, estas decisiones están orientadas a confirmar sus creencias sobre la efectividad educativa de las innovaciones y de hecho en los centros escolares se están produciendo constantemente innovaciones reales y cambios organizativos. Más que hablar de profesores "resistentes" podríamos considerar que aceptan el cambio cuando éste se puede llevar a cabo. 
En cualquier caso lo que sí parece estar demostrado es que para explicar el efecto de las innovaciones basadas en TIC es necesario relacionar dicha innovación con ciertas características del profesor como la edad, la experiencia profesional, la formación del profesor en relación a las TIC, las actitudes de los profesores hacia la enseñanza con estos soportes y las habilidades y conocimiento con respecto a las TIC.

Para el trabajo que nos ocupa en este caso, nos interesan sobre todo los enfoques que se están desarrollando más recientemente que tratan de elaborar un marco de interpretación riguroso para explicar los elementos y causas que influyen en cómo los profesores configuran sus prácticas docentes con las TIC. Estos planteamientos han abundado en la idea del conocimiento profesional del docente. Dada la relevancia de dicho enfoque para el trabajo, trataremos de describirlo con más detalle en el siguiente epígrafe.

\subsection{El conocimiento profesional del docente y las TIC}

Para entender el papel del docente en la incorporación de las TIC en este estudio, resultan muy valiosas las aportaciones de Loveless (2003), porque explica la adopción de estos recursos por los profesores recurriendo a la idea denominada "conocimiento profesional del docente" (Shulman, 1986, 1987).

Shulman diferenció claramente los conocimientos implicados en la labor del profesor. De manera sintética, los clasificó en:

$\checkmark$ Conocimiento pedagógico general que incluiría un conocimiento de las teorías de aprendizaje, de las teorías de enseñanza, una comprensión de la filosofía educativa, un conocimiento general sobre los alumnos y un conocimiento sobre los principios y técnicas para el manejo de la clase. Es decir, conocimientos y creencias de los profesores sobre la enseñanza, el aprendizaje y los aprendices que trasciende a una disciplina o materia concreta.

$\checkmark$ Conocimiento sobre la disciplina que incluiría los contenidos de cada área curricular, es decir los principales conceptos de cada disciplina y las relaciones entre ellos. Constituiría tanto el conocimiento sustantivo como formal de la materia objeto de enseñanza (Grossman, 1989; Grossman, Wilson y Shulman, 1989). 
Teniendo en cuenta los dos anteriores, Shulman hace referencia a otro cuerpo de contenidos que denominó:

$\checkmark$ Conocimiento pedagógico de la disciplina, considerado como el más importante y que implicaría la comprensión por parte del profesor de lo que significa enseñar una determinada materia a los alumnos. Sus componentes serían el conocimiento de los recursos bibliográficos sobre el tema, el conocimiento de la comprensión de la materia por parte de los alumnos, la comprensión de los conceptos principales de la disciplina y las relaciones entre ellos y los conocimientos curriculares sobre materiales, fuentes y recursos disponibles para la enseñanza de una disciplina concreta, así como los prerrequisitos necesarios para el estudio de una materia concreta dentro del curriculum. En definitiva, se trataría de tomar conciencia sobre la forma de conceptualizar esa materia para ser enseñada.

Un resumen del planteamiento de Shulman que trata de recoger los detalles más destacados de su enfoque, se puede contrastar en la figura 3.1. En todo caso, a partir de las ideas de Shulman, otros autores han reelaborado algunos aspectos como en la propuesta de Grimmett y MacKinnon (1992); Angulo (1999) sobre el conocimiento de oficio como una síntesis del conocimiento docente de Shulman.

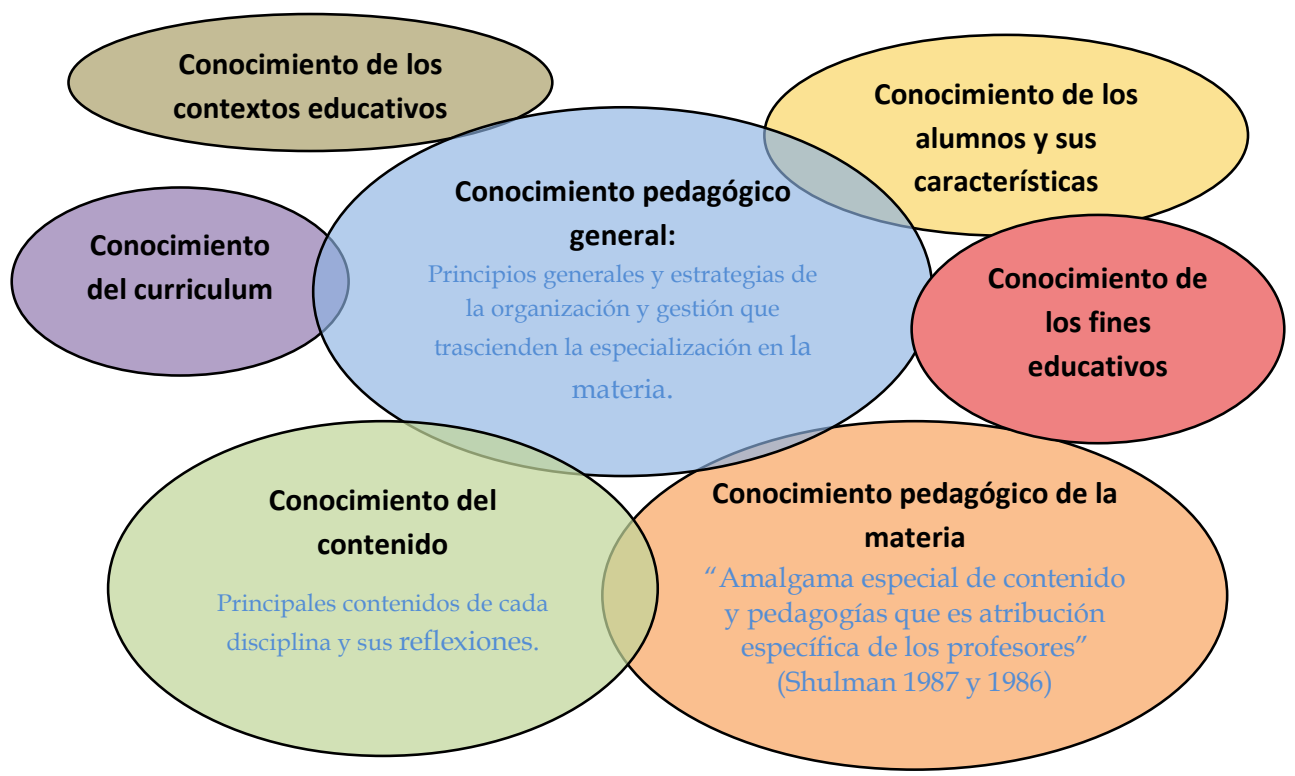

Figura 3.1: Composición del conocimiento profesional docente 
Utilizando el enfoque de Shulman, Loveless (2003), entiende que el conocimiento pedagógico de la disciplina es clave para poder comprender el papel de las TIC como recursos para presentar el contenido de forma apropiada a los alumnos. Este conocimiento lo adquieren los profesores en situaciones que son relevantes y directas. Aunque esto suele suceder en las prácticas reales de clase, donde interactúan con los alumnos, el conocimiento profesional también se adquiere en experiencias regladas de formación, asociaciones profesionales, en redes informales de asesoramiento, etc.

En cualquier caso, lo que interesa para este trabajo, de forma particular, es discernir qué aspectos de las TIC entrarían a formar parte de ese conocimiento pedagógico de la materia, Puesto que ello sería fundamental para explicar cual es el uso que hacen los docentes de estos recursos. Como Zhao, Frank y Ellefson (2006) proponen, son varios los elementos que configuran ese conocimiento, a saber:

$\checkmark$ Conocimiento de la función inherente a la tecnología. ¿Para qué sirve? Por ejemplo, un programa de correo electrónico permite resolver problemas de comunicación. En nuestra investigación analizamos un recurso tecnológico, el Kids Smart, que ofrece no sólo sitios donde almacenar contenidos con un formato prediseñado, sino también aplicaciones que permiten desarrollar procesos de comunicación y colaboración por su conexión a la red, un entorno amigable para alumnos de edades tempranas...

$\checkmark$ Conocimiento de cómo funciona y de las condiciones que permiten usar esa tecnología. Por ejemplo, si decidimos que los alumnos trabajen a través del correo electrónico debemos asegurarnos que existe acceso a la red, cómo están conectados los ordenadores, de qué programas de correo electrónico se dispone, instalar programas antivirus...

$\checkmark$ Conocimiento de las funciones de las tecnologías como soluciones a problemas de la disciplina. Por ejemplo, la función de insertar comentarios en un documento word puede ser muy útil para evaluar de manera formativa documentos producidos por los 
alumnos. Este tipo de conocimiento tiene un carácter local y muy contextualizado y pertenece a cada profesor en particular.

$\checkmark$ Conocimiento de cómo acceder al asesoramiento técnico y social: dónde se debe acudir para solucionar problemas técnicos o de asesoramiento ético.

Pero, además, siguiendo a estos mismos autores, las posibilidades de que los profesores decidan utilizar o no las TIC en su práctica, también depende de: (a) que confíen en que usar la tecnología les reportará ciertos beneficios y (b) que valoren que la tecnología es compatible con las prácticas existentes. Algunos de los elementos que los profesores juzgan como beneficiosos son, además del rendimiento de los alumnos, otros de índole socio profesional como el status social en el centro, las condiciones económicas y las relaciones con los colegas (Becker, 2001). Entre los inconvenientes cabría citar, pérdida de control sobre los alumnos, cambios demasiado radicales en las prácticas de aula.

Estas ideas han dado pie a desarrollos más elaborados del conocimiento profesional del docente en relación con las TIC como el concepto de "Technological Pedagogical Content Knowledge" (TPCK) (Koehler y Mishra, 2008) que sería el conocimiento producto de la intersección entre el conocimiento de la disciplina, el conocimiento pedagógico de la materia y el conocimiento tecnológico. Tal concepto contribuiría a que el docente otorgue un sentido curricular al uso de las tecnologías en sus prácticas de clase.

En cualquier caso, el que el docente disponga de todos estos tipos de conocimiento que se acaban de describir, no garantiza que incorpore a sus prácticas directas el uso de estas herramientas. Otros autores, como McCroryWallace (2004), recurren a la idea de Schwab sobre el "potencial curricular" de los recursos y medios didácticos para explicar la incorporación de las TIC (en su caso Internet) a las prácticas de enseñanza. De esta forma para que un profesor use una tecnología en su aula, se exige un conocimiento de cómo hacerlo con sus alumnos concretos para conseguir los objetivos curriculares que se propone. En muchos casos ello demanda que el profesor transforme en potencial curricular las posibilidades de la tecnología, de la misma manera que lo hace con otros materiales, aunque posiblemente con menos esfuerzo en el caso de materiales didácticos tradicionales. En el trabajo que nos ocupa, éste será uno de los grandes objetivos del estudio, analizar 
cómo los profesores trasforman las posibilidades de la tecnología en realidad curricular, dándoles sentido en su práctica docente.

Sin embargo, otro conjunto de componentes juegan un papel muy importante cuando se explican las razones de los docentes para la incorporación de las TIC en las prácticas de aula. En párrafos anteriores, nos referimos a estos otros elementos aludiendo a la percepción que los profesores tienen sobre los beneficios que les pueden o no reportar las TIC. Estas percepciones, más relacionadas con el ámbito de las creencias y las actitudes, son también un factor importante al explicar si los docentes incorporan o no las TIC. Trataremos de ampliar este tema en a continuación en el siguiente epígrafe.

\subsection{Percepción docente de las TIC}

Comprender el grado de integración de las TIC en el aula está condicionado, además por el conocimiento de la disciplina (Shulman, 1987), por el conocimiento individual del docente (Angulo, 1999). En éste último se asientan las creencias, prejuicios y actitudes. En el caso concreto del uso de las TIC, los estudios demuestran que existen elementos que pueden hacer decantar la balanza hacia la aceptación o el rechazo. Mumtaz (2000) en una revisión de la literatura al respecto, indica tres factores interrelacionados entre sí que afectan a la integración docente de las TIC: las instituciones, los recursos y el propio maestro.

Las instituciones -barreras de primer orden (Ertmer, 1999)- escapan del control del docente, sin embargo, influyen de manera directa en las creencias y actitudes del profesorado, de forma positiva cuando las instituciones apoyan la labor de integración, dan facilidades, reconocen el trabajo, otorgan formación y soporte, etc; y negativa cuando presionan al docente, no ofrecen redes de apoyo, se mantienen estáticas y se refugian en su figura tradicional... En cuanto a los recursos -también como barreras de primer orden-, su escasez es un impedimento para la adopción de las TIC. La falta de software y hardware condiciona en gran medida las actitudes y creencias docentes así como sus prácticas de aula (Rosen y Weil, 1995; Hadley y Sheingold, 1993), por el contrario, una dotación de recursos, instalaciones, conexiones y software adecuado facilita la correcta integración y mejora la percepción docente (McDougall y Squires, 1997). 
Por último, el propio maestro -barrera de segundo orden-, presenta importantes elementos y variables que pueden incidir en las creencias y actitudes. La percepción positiva de su propia competencia digital, actitudes favorables hacia las tecnologías, su domino de los recursos, la motivación o desmotivación docente, la reflexión o no sobre la práctica o un enfoque innovador o tradicional son, entre otros, factores que determinan dichas actitudes y creencias sobre el uso de las TIC en el aula (Valverde, Fernández y Revuelta, 2013; Moseley y Higgins, 1999; Paraskeva Bouta y Papagianni 2008).

Dentro de las creencias y actitudes hacia el uso de las TIC, cabe destacar el reciente estudio de Ertmer et al (2012), donde los resultados demuestran que de los 12 sujetos estudiados 11 mostraban perfiles coherentes entre sus creencias y el desarrollo de su práctica con TIC. Esta casuística se opone a resultados de investigaciones anteriores (Ertmer et al, 2001; Fang, 1996), donde la práctica se veía más influida por factores relacionados con el alumnado, el libro de texto o la cultura escolar que por las creencias y actitudes. La explicación de esta discordancia puede deberse a que se trata de profesores que han sido premiados por su trabajo con las TIC en el aula. Pese a este condicionante, Ertmer et al (2012) concluyen que existe la necesidad de abordar las barreras de segundo orden -conocimientos y habilidades, actitudes y creencias- siendo más importantes que las de primer orden, para tratar así de romper la resistencia de los docentes ante las TIC. De igual forma lo manifiestan los profesores de su estudio cuando se les pregunta sobre los factores que afectan a la integración de las TIC, indicando que las creencias y actitudes son facilitadores de uso de TIC en su caso, y paradójicamente obstaculizadores para sus compañeros. En referencia a estos últimos definían con palabras como "miedo", "asustado", "intimidado", "reticente",... las actitudes de los compañeros.

Otros estudios no defienden un perfil tan extremo, por ejemplo el de Loveless (2003) refleja que la mayoría de los profesores le atribuyen a las TIC tanto rasgos positivos como negativos, bien sea en el aula, bien en su vida personal. Además, muestra cómo los profesores expresan su preocupación por las demandas que recaen sobre ellos en relación con los cambios continuos de la tecnología y su uso con los alumnos. Esta percepción de "velocidad de cambio" en las TIC es común entre los docentes, provocando situaciones de ansiedad, 
sensación de perdida de control ante fallos de los equipos, desinformación en el uso para cada una de las edades,... (Specht, Wood \& Willoughby, 2002).

Por tanto, el docente se encuentra ante la introducción de un nuevo elemento que ha de encajar en su práctica diaria, lo que presenta una serie de dificultades sobre las que deben de reflexionar y adaptarse. Su falta de conocimiento técnico y teórico de la disciplina no ayuda a integrar los recursos (Suárez et al., 2013); si a ello se suma que los centros y la administración introducen de los materiales educativos -software y hardware- sin tener en cuenta la percepción ni formación del docente, sino más bien, las modas y necesidades de mercado, nos encontramos con un papel del profesor como un mero transmisor de contenidos TIC en el aula (Area, 2010).

Pese a este panorama, muchos docentes muestran actitudes favorables a la integración y uso de las TIC (Trigueros, Sánchez y Vera, 2010; Ramírez, Cañedo y Clemente, 2012; Ertmer et al. 2012). Algunos estudios como el de Valverde, Fernández y Revuelta (2013), ponen de relieve que los profesores innovadores, encuentran en los recursos TIC una herramienta que ayuda o contribuye a facilitar su labor docente, lo que genera en ellos un "bienestar subjetivo" repercutiendo en su práctica, actitud y contexto de manera positiva y fomentando una perspectiva favorable a la integración de las TIC en el aula.

Esta ambigüedad que queda patente en los párrafos anterior sobre las perspectivas del profesorado ante las TIC, puede deberse a muchos factores: desde aquellos que son de carácter contextual, legislativo, organizativo o de accesibilidad, pasando por las propias estructuras y lenguajes de los recursos TIC, hasta aquellos que aluden a la idiosincrasia de cada docente tanto a nivel profesional como personal. En el tabla 3.1 y tabla 3.2, se resumen algunas de las reticencias de los profesores en relación a las TIC, así como las medidas que se podrían tomar para trabajar sobre ellas (Grabowski, 2004): 
RESISTENCIAS

Existen muy diferentes opciones tecnológicas y cada una de ellas supone un desafío para usar en la clase.

Los profesores carecen de las habilidades para encontrar recursos y materiales TIC y prepararlos para utilizarlos en sus clases.

Los profesores temen que si deciden usar las TIC, les ocupará mucho tiempo la planificación y desarrollo de su trabajo.

Los profesores temen que los ordenadores se estropeen o vayan mal durante el desarrollo de las clases.

Los profesores estiman que necesitan invertir una gran cantidad de tiempo en aprender nuevas técnicas para la incorporación de las TIC al aula.

Gran parte de los contenidos escolares se rigen por los estándares del curriculum oficial.

Los profesores temen el cambio de enseñanza centrada en el profesor como autoridad a entornos en el que el alumno es generador activo de aprendizaje más que receptor pasivo de información.

Los profesores saben utilizar diversas estrategias de enseñanzaaprendizaje que funcionan habitualmente en sus clases $y$ no confían en que éstas sean efectivas o funcionen con las TIC

Los profesores se sienten presionados para utilizar de forma masiva las TIC en su práctica docente.
¿CÓMO TRABAJAR?

Ayudar a los profesores a determinar cómo usar cada recurso en su propio centro y con la configuración particular de su clase, de tal manera que el recurso se adapte a su práctica y su utilización no sea un gran evento que se produce de manera aislada

Presentar a los profesores diferentes tipos de recursos y materiales adecuados para la clase.

Para aquellos profesores realmente interesados ofertar formación para desarrollar, producir e integrar recursos TIC

Formar a los profesores para entender el tipo de recursos TIC que son accesibles para la enseñanza y para usar estrategias que les permitan localizar rápidamente recursos TIC

Los administradores deberían contemplar presupuestos para el apoyo técnico a los profesores, más que hacer recaer en éstos dicha responsabilidad.

Deberían mostrarse los recursos TIC como cualquier otro recurso didáctico y decidir sobre ellos, igual que se hace con los otros.

La Administración debería ver que aprender con TIC supone desarrollar habilidades de orden superior, por lo que es muy importante que los profesores accedan a formación que permita utilizar las TIC potencialmente para la enseñanza.

Desarrollar materiales y recursos TIC que se ajusten a los curricula oficiales y así facilitar su incorporación a las prácticas escolares.

Las estrategias de clase para usar las TIC deberían tener en cuenta esta nueva percepción del entorno y del proceso de aprendizaje, así como los modos tradicionales de enseñanza.

Las estrategias para utilizar las TIC en la práctica docente deberían aplicar las estrategias más efectivas y habituales que normalmente utilizan los profesores y no limitarse exclusivamente a un enfoque determinado.

Usar las TIC en clase no siempre significa una utilización extensiva. Sólo aquello con lo que realmente cada profesor se siente cómodo y está relacionado con su proceso de enseñanza.

Tabla 3.1: ¿Cómo trabajar las resistencias del profesorado ante las TIC? 


\subsection{El docente y sus capacidades ante las TIC}

De lo que se viene exponiendo hasta ahora, se pueden ir perfilando algunas ideas que en relación con el profesor y las TIC, podrían marcar lo que deberían ser los futuros desarrollos en este tema. Investigadores, expertos en el tema y organismos internacionales han desarrollado propuestas sobre cómo facilitar a través de la intervención directa con los profesores la integración de las Tic. En este sentido, muchos gobiernos incluyen políticas de formación permanente del profesorado sobre las TIC para solventar carencias (UNESCO, 2011), lo cual "a priori" debería repercutir de forma positiva en la integración de las TIC. Ahora bien, tal y como muestran Suárez et al. (2013) la excesiva y prolongada focalización en competencias técnicas de las TIC en los procesos de formación permanente, ha ido en detrimento de las habilidades pedagógicas frente a las tecnológicas en la práctica de aula con estos recursos (p. 51). En consecuencia, la formación técnica puede tener un efecto en el uso del recurso, pero no necesariamente en su aplicación correcta desde el punto de vista pedagógico. Sin embargo, resulta aventurado concluir sobre el efecto de la formación en la integración de las tecnologías. Tal como Haertel y Means (2003) advierten, es necesario desarrollar estrategias de investigación diversas y complementarias para evaluar el grado de implementación y el impacto de las tecnologías en la enseñanza. Ningún enfoque ni metodología individual resulta apropiado para esta tarea. En este mismo sentido, y en la revisión de Lawless y Pellegrino (2007) acerca de las investigaciones sobre desarrollo profesional del docente y TIC, ya se advertía de la necesidad de que las cuestiones de investigación sobre el tema estuvieran teóricamente bien fundamentadas sobre todo en lo que afecta a cuestiones como el muestreo, los instrumentos de investigación y las técnicas de análisis.

De todos modos y como se menciona al comienzo del capítulo, el profesor es uno de los ejes centrales que explican la incorporación en el sistema educativo formal de las TIC (Mueller, Wood y Willoughby, 2008). De ahí que el delimitar las competencias TIC de los docentes se haya convertido en un foco de interés de los investigadores e instituciones en ese campo. Muchos estudios concluyen que pese a la introducción de tecnología en los centros, todavía no se ha llegado a explotar todo el potencial que las TIC pueden aportar al proceso de enseñanza-aprendizaje (Informe 2012 sobre el estado del sistema educativo; Ertmer y Ottenbreif-Leftwich, 2010; Specht, Wood y Willoughby, 2002). Por ello 
se alude, entre otras causas, a la falta de formación del profesorado en relación con las tecnologías como uno de los hándicap a la hora de afrontar su uso en el aula.

Desde la UNESCO se planteó en el año 2008 un proyecto ICT-CST (Estándares de Competencias Docentes TIC), donde se recogen una serie de habilidades que el profesor debe alcanzar para entrar dentro de lo que estiman un perfil TIC adecuado, se acompaña de una guía de implementación y se enmarca desde tres posibles enfoques, cada uno más complejo que el anterior:

- Alfabetización tecnológica +

Profundización de conocimiento ++

- Creación de Conocimiento +++

Los docentes deben de presentar una serie de habilidades que les facilite el uso de las TIC en cada enfoque. Dichas habilidades viene definidas en función de seis componentes del sistema educativo (UNESCO, 2011, p. 6):

$>$ Políticas

$>$ Curriculum y evaluación

$>$ Pedagógico

$>$ Tecnologías de la Información y la Comunicación

$>$ Organización y Administración

$>$ Desarrollo profesional docente

Otra propuesta que alude a las competencias TIC de los docentes, es la que sugieren Suárez et al (2013), y que aparece resumida en la figura 3.2 a continuación: 


\section{COMPETENCIAS TECNOLÓGICAS}

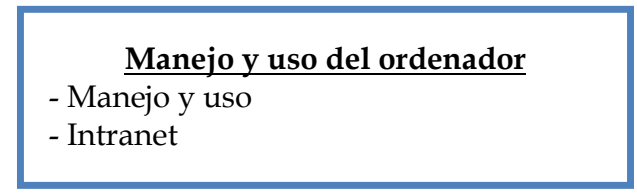

Tecnologías de la Inf. y la comunic.

- Internet: Búsqueda de información

- Internet: Medio de comunicación

- Diseños de páginas Web: Editor avanzado.

\section{Multimedia y presentaciones}

- Software educativo

- Progr. de presentaciones multimedia

- Bases de datos

\section{Aplicaciones informáticas básicas}

- Procesador de texto

- Hoja de cálculo

- Bases de datos

\section{COMPETENCIAS PEDAGÓGICAS}

Problemas éticos y legales

- Problemas éticos y legales derivados de los recursos tecnológicos

\section{Innovación y comunicación}

- TIC como medio de formación en TIC -Participación en la colaboración y comunicación con la comunidad educ.

Diseño de ambientes con TIC

- Diseñar situaciones de aprendizaje.

- Crear un entorno integrado en TIC

- TIC como instrumento de evaluac.

\section{Planificación de la enseñanza}

- Selección de materiales

- Evaluación de recursos tecnológicos

- Diseño de materiales mediante TIC

Figura 3.2 Dimensiones de las competencias TIC Fuente: Suárez Rodríguez, J.M. et al (2013), p. 45

Todas estas propuestas, en demasiadas ocasiones, obedecen a una fuerte necesidad de actuar, de intervenir en el proceso educativo, pero no se apoyan en una base de conocimiento sustancial derivado de la investigación sobre lo que funciona y porqué con respecto a la tecnología, la enseñanza y el aprendizaje. Como ya mencionábamos anteriormente, en la ya clásica revisión de Mumtaz (2000) sobre los elementos que afectan a la utilización por parte de los profesores de las TIC, se concluye que tres son los factores que explican de forma interrelacionada el uso: la institución, los recursos y el profesor. Con respecto al profesor, son precisamente las creencias del mismo sobre cómo se debe enseñar el contenido de la materia y las habilidades relacionadas con la gestión de las actividades de clase, así como las destrezas en el manejo de las TIC las que tienen mayor peso en la utilización por parte del docente de las 
tecnologías. Pero los otros dos factores detectados, la institución y los recursos, también explican los mecanismos de uso. En este sentido trabajos como el de San Martin (2010), ponen de relieve los inadecuados modelos de transferencia tecnológica que se utilizan para incorporar los recursos en los centros, importados en su mayoría de ámbitos productivos que nada comparten con los contextos de enseñanza. Otros estudios como el de Ramírez, Cañedo, Clemente, Jiménez y Martín (2011) concluyen sobre las incoherencias entre decisiones estructurales, regulaciones administrativas y prácticas curriculares con respecto a las TIC, que dificultan la incorporación de los recursos digitales por parte de los profesores.

A modo de resumen, resulta esclarecedora la respuesta que ofrece Zhao (2003) a la pregunta de qué deberían saber los profesores sobre tecnología. En primer lugar, desmenuza dicha pregunta en otras cuatro: Cuál es la naturaleza del uso de la tecnología, qué tecnologías deberían conocer los profesores, cuánto deberían conocer los profesores sobre esas tecnologías y, por último, cómo los programas de formación del docente podrían enseñar el conocimiento tecnológico. Asimismo, ofrece algunas respuestas tentativas a dichas preguntas: (a) la utilización de la tecnología es básicamente un proceso mediante el cual el usuario transforma un artefacto en una herramienta, un objeto en una solución a un problema específico; (b) la tecnología debería considerarse como un componente integral del conocimiento del profesor. El conocimiento pedagógico y las creencias del profesor deberían incorporar el conocimiento sobre cómo puede usarse la tecnología para resolver sus propios problemas. Por tanto una fuente adecuada para identificar lo que los profesores deberían saber, es conocer lo que ya hacen y saben; (c) los profesores pueden tener diferentes niveles de comprensión de la tecnología, los niveles que precisan para desarrollar sus prácticas de enseñanza; y (d) los programas de formación del profesorado en tecnologías deberían adoptar dos enfoques diferentes: cursos específicos sobre tecnologías concretas o cursos sobre integración de las tecnologías en los currículos en vigor. Cada enfoque tiene sus ventajas y sus inconvenientes.

En definitiva, aunque la literatura científica poco a poco va abriendo caminos sobre los que avanzar y reflexionar en torno a la capacidades TIC que los docentes deben tener, queda un gran trabajo tanto en su formación - inicial 
o permanente - como en la delimitación de qué recursos TIC son los más adecuados a las intenciones del sistema educativo.

\subsection{Profesor, TIC y Educación Infantil}

Lo visto hasta ahora permite establecer cuál es el estado de la cuestión en torno al profesor y al conocimiento profesional docente en relación con las TIC. En la mayoría de los estudios e investigaciones a las que se ha hecho referencia el foco de atención se sitúa en las etapas de la educación obligatoria y postobligatoria, pero los puntos de confluencia entre estudios indican que la generalización a todo el conjunto de profesores, incluyendo los de Educación Infantil, son más que posibles.

En relación a la etapa de Educación Infantil se plantea una doble particularidad: por un lado los estudios específicos sobre la etapa y en particular sobre el uso de las tecnologías resultan escasos en su conjunto. Por otro lado, la etapa por su propia naturaleza plantea peculiaridades singulares que afectan a profesores y a alumnos y a la relación de éstos con las TIC.

A la escasez de estudios sobre la etapa de Educación Infantil y las TIC, hay que sumar el hecho de que una gran mayoría de los existentes (Attewell, Suzao-García, \& Battle, 2003; Goldberg, Russell, \& Cook, 2003; Abrami, Savage, Wade, Hipps, \& Lopez, 2008; Labbo, Love, \& Ryan, 2007) se centre en los procesos relacionados con la lectoescritura en sus niveles iniciales y el conocimiento lógico-matemático, muchos de los cuales recogen datos de la etapa de infantil pero incorporando lo que en el sistema educativo español sería el primer ciclo de la etapa primaria.

En cualquier caso, los profesores de Educación Infantil se enfrentan a la tarea de la incorporación de los recursos digitales en sus aulas, gestionando unas condiciones de enseñanza especialmente particulares. Dichas condiciones se podrían resumir en los rasgos a continuación:

$\checkmark$ Los alumnos, por su momento evolutivo, tienen niveles de habilidades físicas y verbales menos desarrollados, son menos capaces de trabajar solos.

$\checkmark$ El entorno de aprendizaje se caracteriza por una menor frecuencia de situaciones formales de aprendizaje, actividades que son más 
breves en el tiempo, una mayor diversificación de tareas, más actividades manuales, menos trabajo de pupitre y más supervisión.

$\checkmark$ Aunque prácticamente la mayoría de los niños entre 3 y 6 años están escolarizados, se trata de una etapa no obligatoria. Ello puede repercutir negativamente en la provisión de recursos desde la administración educativa para las aulas de esta etapa.

En lo que respecta a los alumnos de esta etapa, el uso del ordenador en edades tempranas plantea retos físicos debido a sus habilidades motóricas aún inmaduras. El manejo del ratón, la localización de elementos en las pantallas, la interpretación de mensajes escritos son desafíos físicos, motores y cognitivos de especial relevancia en los alumnos de infantil. Sin embargo, hay trabajos que ilustran las ventajas específicas para los alumnos de estas etapas de los materiales digitales (Gimbert \& Cristol 2004; Lee \& Choi, 2008; Lin, 2012): acceso a diseños motivadores por su apariencia; presentaciones dinámicas, coloridas e interactivas; posibilidad de desarrollar procesos de enseñanza individuales y aprendizaje independiente y capacidad de los recursos TIC para mostrar los efectos inmediatos de las acciones en entornos simulados.

Todos los elementos descritos, configuran una situación que afecta especialmente a los profesores que enseñan en este periodo escolar y que afecta, también, al papel que se espera que desempeñen las TIC en la etapa, independientemente de su experiencia profesional (Gialamas \& Nikolopoulou, 2010).

Los estudios sobre TIC y profesores de la etapa de Educación Infantil, trazan un panorama con altibajos (Mueller, Wood \& Willoughby, 2008). Los docentes de esta etapa perciben que sus carencias formativas junto con los escasos recursos disponibles, pueden tener repercusiones importantes si tienen que seleccionar programas y soportes adecuados para los alumnos con los que trabajan directamente. Así, los profesores de la etapa de Educación Infantil, dado el carácter no obligatorio de este periodo, suelen disponer de menos apoyos externos y menos recursos materiales para abordar la introducción de los recursos digitales en sus aulas (Siraj-Blatchford \& Siraj-Blatchford, 2006). Gran parte del trabajo de selección, adquisición e introducción de los recursos recae sobre ellos, así como el mantenimiento técnico de los equipos. Generalmente los profesores de esta etapa consideran que los recursos TIC 
aportan posibilidades adicionales de desarrollo de actividades para los niños, a través de medios muy atractivos, compatibles con enfoques pedagógicos centrados en el alumno. Sin embargo, no consideran que las TIC sean el elemento central de la enseñanza (Lin, 2012).

Otros estudios han abordado también aspectos diversos relacionados con los docentes de la etapa de Educación Infantil. Autores como Haugland (cit. en Specht, Wood y Willoughby, 2002), defienden la importancia del perfil docente en la introducción de ordenadores con un impacto positivo en el aula. Para él, tres de los cuatro factores claves para una correcta integración de las TIC se refieren al profesor: estar abiertos a la tecnología y ser receptivos a la integración del ordenador en clase; ser conscientes del potencial de los ordenadores y su papel positivo en el aula; y formarse para la integración del ordenador en clase. La carencia de uno de estos rasgos dificulta la incorporación eficaz del ordenador en clase, aunque no sólo depende de esto, sino, como el propio autor subraya, de las programaciones de la etapa.

Otro estudio que se presenta relevante para la etapa de Educación Infantil recoge la idea de "maestro integral" (Chen y Chang, 2006). Con esa denominación los autores aluden a un planteamiento de formación de carácter multimodal para el profesorado (tabla 3.2), sustentado por un enfoque multidimensional en el que las actitudes, habilidades y prácticas se afrontan desde diversas posibilidades que se centran en la materia de forma integrada y con fines globalizados para avanzar desde el grado de principiante al de experto.

Como resultado, Chen y Chang (2006), con una muestra de 175 maestros de infantil con perfiles docentes similares, y de los cuales 134 no se habían sometido a la formación con el planteamiento de "maestro integral", frente a 31 que sí, obtuvieron resultados significativos a favor de los profesores formados dentro del enfoque "maestro integral" en todas la variables analizadas actitudes, conocimientos y habilidades, métodos instructivos y materiales instructivos-. La materia sobre la que se hizo la investigación la denominaron tecnología, y se centraba en la introducción del ordenador en las prácticas de aula. Pero este estudio de enfoque multimodal de formación aunque sí demuestra que se produce una mejora en cuanto a las actitudes, no profundiza en los resultados de las prácticas directas de aula de forma precisa. 


\begin{tabular}{cl}
\hline Multidimensional & $\begin{array}{l}\text { Programas se enfocan en las actitudes, habilidades y } \\
\text { prácticas de los maestros; ofrecen múltiples maneras de } \\
\text { aprender y desarrollar; y acomodan necesidades y } \\
\text { motivaciones diversas de parte de los maestros. }\end{array}$ \\
\hline Específico a materias & $\begin{array}{l}\text { Objetivos se diseñan según los requerimientos de contenido } \\
\text { y de desempeño de materias específicas de desarrollo } \\
\text { profesional. }\end{array}$ \\
\hline Integrado & $\begin{array}{l}\text { Estrategias instructivas facilitan relaciones entrelazadas y } \\
\text { dinámicas entre actitudes, habilidades y prácticas. El } \\
\text { maestro utiliza todas sus habilidades al participar en la } \\
\text { instrucción, más bien que limitar el proceso de aprendizaje } \\
\text { a metas aisladas y estrechamente definidas. }\end{array}$ \\
\hline Enfocado en el & $\begin{array}{l}\text { Programas apoyan el crecimiento del maestro desde el } \\
\text { nivel de principiante hacia el de experto, fomentado así el } \\
\text { crecimiento continuo. }\end{array}$ \\
\hline desarrollo &
\end{tabular}

Tabla 3.2 Características del “maestro integral”. Fuente: Chen y Chang (2006)

En el trabajo de Cuban (2001), se describe cómo se usa el ordenador en varias aulas de Educación Infantil donde se desarrolla el estudio. En diez de los once centros analizados, el uso más frecuente del ordenador se producía durante el tiempo de "elección libre", es decir de 30 a 60 minutos diarios que los alumnos disponían para hacer lo que desearan en los espacios de pintura, juego de bloques y legos, lectura y otros. El acceso al ordenador se realizaba según la norma "del primero que llega, coge sitio", negociando los propios niños los turnos. Sólo en algún caso los profesores lo organizaban con hojas de registro. Excepto para dos de los once profesores observados, el ordenador no era una actividad de aprendizaje más importante que el juego con bloques y legos, sentarse a escuchar historias a través de auriculares o trabajar en el rincón de artes plásticas. En definitiva, los profesores de Educación Infantil del estudio de Cuban, habían adaptado una innovación a las formas de enseñar propias de Educación Infantil desde hace décadas.

Por último, y muy relacionado con nuestra investigación, es reseñable el trabajo de Ajlouni y Aljarrah (2011), en el que miden el impacto del uso del Kidsmart de IBM en Jordania. Tras una comparativa entre dos grupos -uno de control y otro experimental - compuestos de 52 profesores cada uno, los 
resultados ofrecen diferencias significativas a favor de los profesores instruidos y formados en la utilización del recurso con respecto a las habilidades relacionadas con las TIC de sus alumnos.

Estas indagaciones parece que ratifican lo que en apartados anteriores se ha dejado entrever. Primero, los docentes son parte fundamental para explicar el efecto de la incorporación de las TIC en los procesos de enseñanzaaprendizaje. Segundo, la formación para el desarrollo profesional docente en el uso de recursos TIC debe afrontarse desde doble vertiente, pedagógica y tecnológica. Y tercero, los factores actitudinales y creencias de los profesores tienen una gran influencia en las prácticas de aula y la integración de los recursos. 


\section{CAPÍTULO 4}

Prácticas de aula y sistema de análisis 



\section{Prácticas de aula y sistemas de análisis.}

Lo que se ha explicado hasta ahora, nos confirma que la enseñanza formal aparece como un fenómeno complejo (Stenhouse, 1985; Gimeno, 1988 y 2010). En él diversos agentes, culturas, contextos, políticas, metodologías, contenidos, recursos y medios configuran un proceso de construcción curricular que abarca desde el curriculum oficial hasta el curriculum en la acción. No obstante, este puente que el curriculum tiende entre la teoría y la práctica no tiene un carácter lineal, sino que desemboca en situaciones contextualizadas y adaptadas al aula, en las que la interacción entre profesor y alumno cobra significado y se erige como el último eslabón de concreción curricular, "donde todo proyecto, toda idea, toda intención, se hace realidad de una forma u otra" (Gimeno, 1988, p. 240).

Los diferentes enfoques adoptados a la hora del diseño, planificación y desarrollo curricular, tal y como recogemos en el capitulo 1, determinan de forma decisiva la función que se otorga a cada uno de los elementos intervinientes en la praxis. Así, desde el enfoque más técnico, la práctica de aula adquiere su sentido como un proceso reproductivo de las actividades previamente diseñadas a partir de la racionalidad y los marcos teóricocientíficos establecidos. Por ello, la interacción que se produzca en el aula debe contemplarse como una ejecución curricular cuyo fin es la búsqueda de la eficiencia en el binomio diseño y evaluación, o lo que es lo mismo entre objetivos y resultados. Debido a este concepto sistematizado y racionalista de la educación, el profesor se perfila como mero ejecutor de una planificación establecida y el alumno como receptor donde se verifica o no la consecución de unos objetivos y contenidos predefinidos. Es por tanto, como ya hemos venido señalando, un camino enfocado a la racionalización del proceso y limita el dinamismo de los procesos de enseñanza-aprendizaje en su contexto más inmediato.

Sin embargo, desde un enfoque procesual, la práctica de aula toma una relevancia significativa sobre todo en dos niveles. Por un lado, el aula pasa a ser considerado uno de los ámbitos de planificación curricular, donde la figura del docente adquiere mayor responsabilidad y autonomía tanto en la toma de 
decisiones como en los procesos de diseño, planificación y evaluación de las actividades (Clemente, 2010). Y por otro, la consideración de la praxis como un ámbito de reflexión y creación de conocimiento teórico, que tanto profesores como investigadores deben abordar para producir conocimiento respecto de los procesos de planificación y diseño curricular, entendidos desde una concepción dinámica y flexible del curriculum. Así, tal y como indica Gimeno (2012), lo que ocurre dentro de las instituciones educativas y principalmente en el aula es lo que concreta las transformaciones culturales de los estudiantes que se pretenden con el curriculum.

Atendiendo a las características de los dos enfoques, los modelos positivistas, que hacen de la práctica un elemento supeditado al diseño curricular y dependiente de resultados, se antojan pobres frente a los modelos de enfoque práctico, lo cuales contemplan la práctica en el aula como un ámbito fundamental en la toma de decisiones y el diseño y planificación curricular, asignando al binomio profesor-alumno un papel protagonista en el proceso de enseñanza-aprendizaje. En el marco de esta segunda opción, nuestra investigación contempla la importancia que adquieren las prácticas de aula, con el profesor como eje central, para tratar de analizar y comprender qué sucede en relación con los procesos de innovación en el ámbito del aula, y más concretamente aquellos relacionados con las TIC.

Por ello, y sin tratar de ser redundantes, entender la práctica de aula como algo estático, controlado y generalizable, no deja de ser, cuanto menos, una fábula teórica alejada de la realidad. En contra de esta idea y de acuerdo con el planteamiento desde el que realizamos la investigación, resulta más acertado comprender la praxis bajo el marco de una estructura flexible y variada, que posibilite atender a las necesidades y peculiaridades que presentan los diferentes agentes y entornos donde tiene lugar el proceso educativo. Esta concepción supone, por un lado, caracterizarla por un alto grado de complejidad (Gimeno, 1988); y por otro, asignar al docente la responsabilidad final del proceso de enseñanza-aprendizaje dentro del aula. Este peso que recae sobre el profesorado, hace que los investigadores nos interesemos de forma particular por encontrar patrones y explicaciones, que ayuden a esclarecer preguntas como ¿cuáles son las estrategias del profesor para controlar procesos tan complejos?, ¿cómo adquiere el profesor esas estrategias?, ¿qué elementos curriculares tienen más peso en las prácticas de aula?, ¿cómo afronta el profesor 
el reto de la praxis?, ¿qué papel juega el alumno en todo este proceso?, ¿cómo influyen los otros agentes educativos que no forman parte directa de la práctica de aula?, ¿cómo se estructuran las sesiones dentro del aula?, ¿cómo se incorporan las innovaciones al aula?, ¿cómo se enfrentan los profesores a esos fenómenos de innovación?...

\subsection{La planificación: antes de la práctica.}

Cuando pensamos en la práctica de aula no es posible asociarla a fenómenos de enseñanza espontáneos (Gimeno, 1988), sino que lo relacionamos con acciones reguladas a través de patrones metodológicos que tienen una planificación previa y van enfocados a la consecución de un fin determinado, ya sea a corto, medio o largo plazo. Estas acciones que el profesor desarrolla en interacción con el alumnado, representan el núcleo más importante del proceso de enseñanza-aprendizaje en el aula, y requieren para adquirir sentido completo contemplar en su composición aspectos contextuales (Popkewitz, 1986) y materiales (Smith y Connolly, 1980). Por tanto, si nos preguntamos sobre cuál es la estructura que presentan las prácticas de aula, no hay una respuesta unívoca, aunque sí se pueden detectar ciertos aspectos que en un grado o en otro ayudan a perfilar puntos comunes.

En este sentido y desde la visión del profesor, la estructura de la praxis requiere que se consideren aspectos como la pluridimensionalidad, simultaneidad, inmediatez, impredictibilidad, historicidad, negociabilidad, implicabilidad y variabilidad de los ambientes donde se desarrolla la acción directa (Gimeno, 1988). Es decir, las situaciones de las prácticas reales se caracterizan por estos rasgos que se acaban de enumerar (y que están reflejados en la Figura 4.1). Ante tales rasgos y dado que la enseñanza y la práctica, tal y como hemos indicado al inicio del capítulo, son fenómenos complejos, lo que sucede en la clase requiere por parte del docente desarrollar mecanismos de control (o gestión) que le permitan ajustar de la forma más adecuada lo planificado con el desarrollo en el aula del proceso de enseñanza-aprendizaje. Dichos mecanismos no se centran única y exclusivamente en un conocimiento teórico, sino que se presentan en varios niveles de conocimiento que se entremezclan para desembocar en cada momento determinado en una pauta de comportamiento concreta por parte del profesor. Como indica Shulman (1986), el conocimiento en el desarrollo profesional docente muestra tres formas distintas: un conocimiento proposicional, un conocimiento de caso y un 
conocimiento estratégico; este último se erige como fundamental para el docente en la práctica, puesto que le permite decidir cómo actuar en una circunstancia determinada y en un momento determinado tomando como base sus conocimientos teóricos, prácticos y vivenciales. Es lo que Angulo (1990) denomina, tal y como indicamos en el capítulo 3, el conocimiento de oficio.

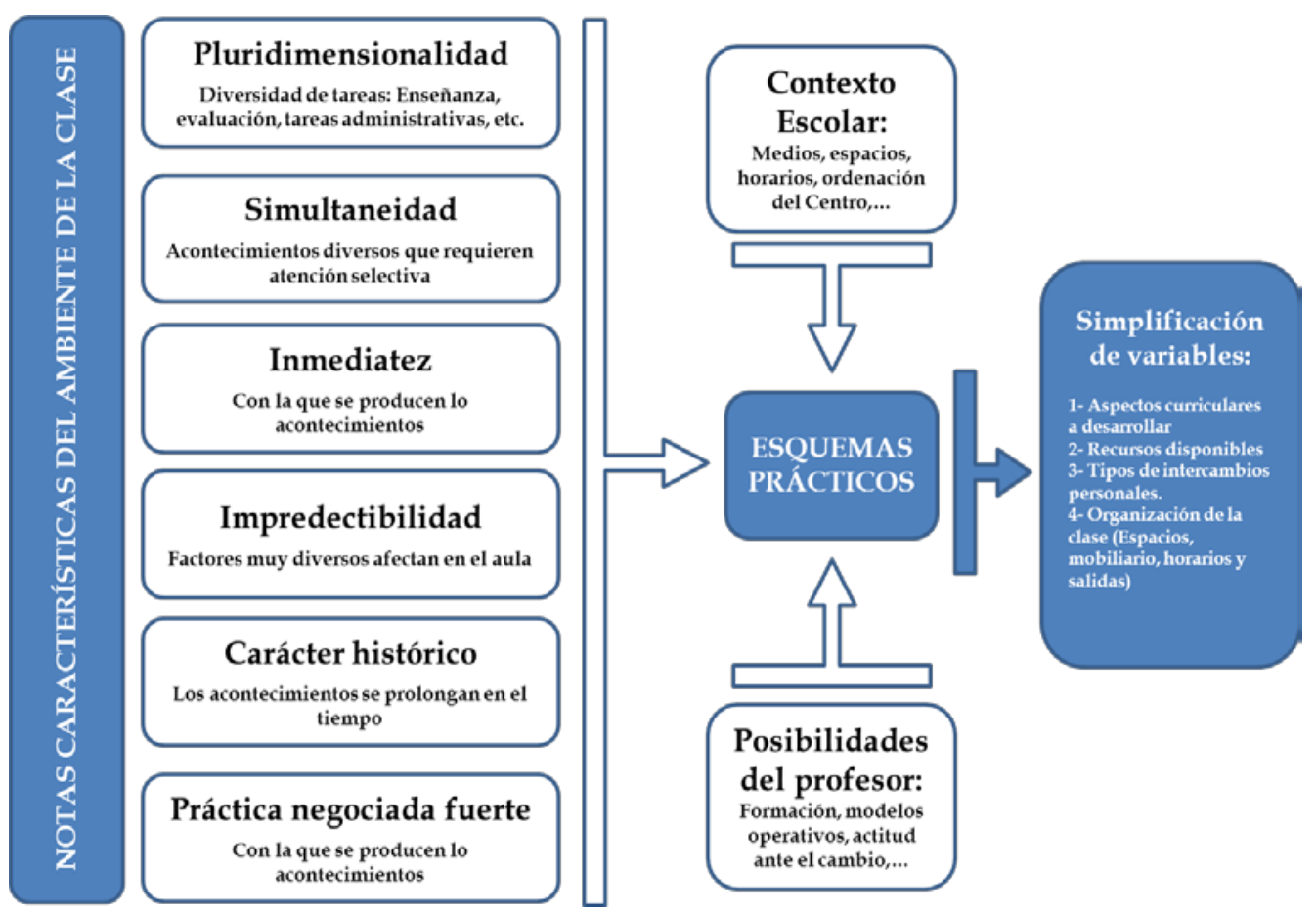

Figura 4.1 Elaboración propia a partir de J. Gimeno (1988)

El conocimiento de oficio o el estratégico por su configuración y evolución hace que existan forzosamente diferencias significativas entre docentes expertos y noveles. Numerosos autores (Yinger, 1987; Angulo, 1990; Borko, Roberts y Shavelson, 2008; Leinhardt y Greeno, 1986; Kardos y Jonhson, 2007; Gimeno, 1988; Hogan, Rabinowitz y Craven, 2003) han planteado en sus investigaciones aspectos relacionados con este tema, otorgando a la experiencia un papel importante para la comprensión y desarrollo de los comportamientos de los docentes en el aula. Esta cuestión parece ratificar la idea en torno a las formas de conocimiento docente que plantea Shulman (1986), y con ello la construcción a partir de ellas del perfil profesional de cada docente. Desde ese punto de partida, el profesor toma decisiones para llevar a cabo acciones que le 
permitan desenvolverse de la forma más adecuada durante el transcurso de la clase. Tal y como indica Gimeno (1988), el profesor no puede lanzarse a la improvisación vacío de ideas, sino que con antelación debe "prefigurar el marco en el que se llevará a cabo la actividad escolar, de acuerdo con las tareas que vayan a realizarse" (p.247). Así, encontramos por un lado, que la planificación no puede reflejarse como algo estático dentro del aula, sino más bien como una guía de referencia para el profesor que facilita la estructuración de lo que sucederá en el transcurso de la clase. Y por otro lado, que son las actividades las que estructuran la práctica de aula.

En otras palabras, en la práctica de aula el profesor juega con un guión previo -propuesto, adaptado o creado-, pensado ex profeso para unos contenidos, un tiempo, un alumnado y un contexto específico, que se estructura en diferentes actividades, que a su vez están compuestas de una o varias tareas y tratan de conseguir a través de ellos los objetivos marcados, y sobre este guión, seguirá de la forma más fiel posible siempre que las circunstancias y variables que influyen en el transcurso de la clase lo permitan. A partir de ahí, el docente debe anticiparse y modificar aquello que considere oportuno para evitar posibles situaciones de desajuste.

\subsection{Estructura y desarrollo: las actividades y los esquemas de acción.}

En el apartado anterior, dibujábamos unos primeros rasgos de la estructura más genérica de las prácticas de aula. Analizarlo más en profundidad, supone tener en cuenta una serie de cuestiones previas, que acordes con la línea de nuestra investigación, se convierten en ejes fundamentales para tratar de comprender la arquitectura y el desarrollo de dichas prácticas. De esta manera y en primer lugar, la necesidad de una unidad de análisis que permita estudiar lo que sucede en la interacción entre profesor y alumnos en el aula, nos encamina a identificar a las actividades de clase como estructuras del curriculum en la acción que posibilitan captar y examinar la complejidad de la praxis. En segundo lugar, recurriremos al concepto de esquemas prácticos de acción de los profesores (Shavelson, 1986) como guiones de actuación que permiten controlar la práctica y desarrollar patrones estables sobre los que se configuran diversos modelos pedagógicos en los contextos reales, convirtiéndose en referentes de la práctica. Y en tercer y último lugar, la combinación de los dos anteriores contribuye a explicar los mecanismos sobre 
los que se desenvuelve el proceso de enseñanza con objeto de conseguir los objetivos fijados para el desarrollo curricular.

Teniendo en cuenta esto, cuando comienza una clase los sujetos que participan (profesor y alumnos), el entorno (centro y aula) y los recursos (pizarras, cuadernos, ordenadores, programas, libros de texto...) se orquestan bajo la dirección del profesor en base a unas pautas dirigidas y pensadas para un espacio y un tiempo determinado. Ese ambiente presenta una alta complejidad, no sólo ya por las características idiosincrásicas del alumnado, sino por otros aspectos como pueden ser las regulaciones administrativas (curriculum oficial, ley de educación, PEC, horarios...), contextuales (tamaño del aula, dotación de recursos, ratio, situación geográfica,...), sociales (nivel socio-familiar, nivel económico, participación de los padres...) o culturales (costumbres, valores, ideologías, creencias...) que dificultan de forma sustancial un control pleno sobre la acción educativa que permita una reproducción fiel de lo planificado. Por ello, esta situación hace que el profesorado requiera de estrategias que permitan facilitar y agilizar la toma de decisiones sobre las situaciones reales de enseñanza (Borko, Roberts, y Shavelson, 2008).

De acuerdo con lo dicho, tanto la estructura como el desarrollo de la clase giran en torno a las actividades con las que se van ocupando el tiempo de clase. Para Doyle y Carter (1984) las tareas académicas o actividades representan para el alumno diferentes conjuntos de operaciones para procesar la información así como diferentes niveles de comprensión del contenido. Así, dichas tareas para su formulación deben tener en cuenta los requisitos que se exigen a los alumnos al realizarse, los recursos de los que se dispone para desarrollarla y los pasos que han de seguir para ejecutarla correctamente. A esto, unimos las circunstancias ya mencionadas en párrafos anteriores como la duración, el espacio donde se realizan, el número de estudiantes, la forma de uso de los recursos, el tipo de alumnado y las expectativas de comportamiento del profesor y los alumnos durante la tarea o actividad. Con este conjunto se desarrolla un ambiente de trabajo para que, a través de las acciones que se ponen en marcha, los estudiantes puedan adquirir los conocimientos correspondientes a los objetivos fijados para la sesión.

En una línea similar, Gimeno (1988) analiza las tareas o actividades usando los dos términos de manera indistinta- desde la vertiente pedagógica, en la que se aúna tanto la acción característica en el momento de su realización, como su naturaleza peculiar que la convierte en la unidad de análisis ideal 
para la reflexión e investigación. Aunque realiza distinciones entre tareas formales y educativas, según su contenido más o menos académico; en sentido estricto, las considera como la estructura central sobre la que se asienta la práctica pedagógica. Según esto las tareas o actividades configuran el microambiente de una sesión o el general de la clase; mediatizan la asimilación que hace cada alumno en particular del curriculum; expresan el estilo de los profesores; vinculan los planteamientos didácticos y curriculares con los organizativos; poseen un significado tanto a nivel social como personal que se estructura como elemento socializador de los sujetos; y define el microambiente y el ambiente general de la clase.

Siguiendo con la idea de que las actividades se establecen como mecanismos que ayudan al docente al desarrollo de las prácticas de aula, es importante compaginarlas con otros elementos que facilitan tanto a profesores como alumnos el desenvolvimiento en estas circunstancias concretas. Hemos hablado de los esquemas prácticos de acción, los cuales pertenecen a los docentes y son ellos los que los aplican en función de sus conocimientos teóricos, experiencia docente y creencias y valores. La idea de "esquemas de acción" que en su día aportaran Leinhardt y Greeno (1986) y Leinhardt (1990) al tratar de explicar los mecanismos que ponen en funcionamiento los profesores cuando se manejan en ambientes complejos, dinámicos, no siempre claramente definidos en lo referente a sus objetivos se identifica con patrones de comportamiento profesional que afectan a diversos tipos de actividades académicas, entre ellas las actuaciones en clase (Gimeno, 1988). Estas actuaciones llegan a conformarse como rutinas profesionales que permiten al profesor desarrollar su acción en torno a conductas estructuradas de alumnos y profesores por medio de actividades orientadas al logro de una finalidad. De acuerdo con Gimeno (1988), los esquemas de acción no sólo tendrían relevancia en la práctica docente directa, sino también en otras actuaciones profesionales. Una tesis similar subyace a la idea de Putnam y Borko (2000, p.13) sobre que el conocimiento de los profesores está ligado al contexto, asociado a rasgos característicos de las clases y las actividades que en ellas se desarrollan y organizado en torno a tareas que los profesores llevan a cabo en los ambientes de aula, y que emplean de forma recurrente para situaciones similares. La idea de que los esquemas de acción son empleados por los profesores para las tareas de planificación y de enseñanza directa en el aula, conecta con la definición de estructuras de actividad/tipos de actividad tal como la describe, por ejemplo, Windschitl (2004. p.25): 
"El término "estructura de la actividad" está tomado de los teóricos socioculturales y se refiere a un conjunto de interacciones y actividades de clase que llevan asociados prácticas discursivas, materiales fácilmente reconocibles, patrones de conducta, y roles característicos de los participantes. "Tomar apuntes", "desarrollar un debate" y "hacer un experimento" podrían considerarse estructuras de actividad. Aunque el término "actividades" se refiere a fenómenos específicos que ocurren en las aulas, las estructuras que subyacen a éstas son más generales y aplicables en contextos múltiples".

Por tanto, el comportamiento del profesor en el aula se va forjando con el tiempo, con pequeñas modificaciones que paulatinamente van incorporando y probando en el aula. Así, dada la homogeneidad del sistema, la formación del profesorado, de los medios con los que cuenta y las condiciones, nos encontramos con que no existe un amplio repertorio de esquemas prácticos (Gimeno 1988, p. 259), lo que hace que en torno a ellos ajusten las tareas y las reproduzcan de forma más o menos sistemática para crear un ambiente o microambiente en el aula o la sesión. Esta sistematización de las tareas hace que los alumnos y el profesor interactúen dentro de un marco como es el aula con unas reglas definidas que ayuden a ambos a facilitar la consecución de los objetivos.

Leinhardt, Weidman y Hammond (1987) examinaron cómo profesores expertos introducen e incorporan las rutinas de clase en su día a día. Estos comportamientos rutinarios facilitan tanto al profesor como al alumno sistematizar algunos comportamientos que buscan la comprensión de determinados contenidos. Es decir, lo que las rutinas permiten es interiorizar diferentes contenidos a través de estructuras de actividades similares o idénticas que hace que la instrucción sea fluida, predecible y centre el tema de trabajo. Dichas rutinas, a su vez están compuestas de una serie de normas de funcionamiento que tanto profesor como alumno comprenden, manejan y aplican de forma rápida debido al uso reiterado de la misma a lo largo de varias sesiones de clase (por ejemplo: levantar la mano para preguntar, responder todos juntos cuando el profesor hace una tarea en ese sentido, poner los trabajos finalizados encima de la mesa del profesor, mirar en el diccionario cuando se duda de una palabra, etc.). Este tipo de conductas facilitan que el profesor pueda atender a otros elementos para ajustar la práctica de aula a la planificación previa que tenía de la misma. 
Las modificaciones que se realizan a medida que se lleva a cabo la práctica se apoya en la toma de decisiones, esta toma de decisiones es un vínculo entre el pensamiento y la práctica (Borko, Roberts, y Shavelson, 2008), lo que hace que se ajuste con las medidas que cada profesor considere necesarias para reconducir la clase. El cómo lo haga depende de muchos factores, y uno de los fundamentales son sus esquemas prácticos y su conocimiento profesional docente.

\subsection{El profesor. Situación privilegiada ante el estudio de la práctica de aula.}

Hemos tratado con anterioridad de mostrar la importancia del profesor en los procesos de innovación y más concretamente la integración de las TIC relacionándolo con el conocimiento profesional docente, la percepción que tiene sobre las TIC y las capacidades con las que cuenta para su manejo y control. Siguiendo esta línea del profesor como figura central, parece también importante profundizar en el papel que desempeña en las prácticas de aula. Puesto que, al estar situado dentro de la clase, desempeñando su rol de forma activa, hace que lo ubiquemos, a priori, en un lugar privilegiado del que destacamos fundamentalmente tres funciones: 1) como intérprete del curriculum oficial, 2) como agente activo en el proceso de enseñanzaaprendizaje y 3) como evaluador de lo que sucede en el aula.

$\mathrm{Si}$ atendemos a la primera de ellas, intérprete del curriculum, y lo relacionamos con la práctica de aula, aparece la figura del docente como aquél que transforma el contenido del curriculum oficial en contenido inteligible para el alumno. Así, el conocimiento de unos contenidos concretos basados en indicaciones y "consensos" administrativos, sociales y culturales, son interpretados e interiorizados, lo que hace que pasen a formar parte del conocimiento profesional docente, más concretamente vinculándose con el conocimiento del contenido y conocimiento del curriculum (Shulman, 1976).

De esta forma, una vez interpretado e interiorizado el currículo, el profesor en su rol de agente activo debe explicitar dicho conocimiento en la práctica de aula, siendo él quien puede transformar las concepciones, los procedimientos o las actitudes en representaciones y acciones pedagógicas (Shulman, 1986) accesibles y facilitadoras para el aprendizaje significativo del alumno con quien se produce la interacción en clase. Esta desenvoltura en la praxis se relaciona de forma directa con un conocimiento pedagógico general 
(metodología), con un conocimiento didáctico de la materia (actividades y recursos), vinculado a su vez al conocimiento de los contextos educativos (el centro y el aula) y al conocimiento de sus alumnos y las características (alumnado).

Por último, la función del docente como evaluador puede analizarse desde una doble vertiente. En primer lugar y relacionado, como venimos haciendo hasta ahora, con el conocimiento profesional, influyen el conocimiento de los fines educativos y de nuevo el conocimiento del curriculum y el conocimiento de las características de los alumnos. En consecuencia, el profesor es quien evalúa la adquisición, o no, de los objetivos marcados para los alumnos y que deben obtener por medio de las interacciones que se llevan a cabo en la práctica de aula, ya sea con el docente o con los recursos. $\mathrm{Y}$ en segundo lugar, la función evaluadora del profesor abarca también la propia reflexión sobre su práctica, pasando así a adoptar planteamientos cercanos al enfoque de investigación-acción, que pueden ayudar a esclarecer y propiciar cambios en sus metodologías de aula y generar nuevo conocimiento.

En este sentido, a los investigadores nos interesa saber cuál es la relación entre el conocimiento profesional docente y la práctica de aula, para así poder comprender los fenómenos que ocurren en ella y determinar patrones comunes y generalizables que ayuden a su compresión, siempre y cuando se contemplen desde líneas de investigación como las que propusieron Schwab (1985) o Stenhouse (1985), planteando la práctica como centro de conocimiento. Por ello, qué mejor forma de nutrirnos de este conocimiento sobre el que investigar y reflexionar que a través del estudio de la situación privilegiada que ocupa el docente en la práctica de aula, analizando su ejercicio práctico y sus concepciones sobre el mismo, y contemplando de esta manera la planificación, el diseño, el desarrollo y la evaluación del curriculum como puntos de referencia y objeto de estudio. En definitiva, desearíamos congelar instantes de tiempo de la práctica de enseñanza, para desmenuzar los procesos implicados. Pero es evidente que el proceso de toma de decisiones de los profesores, sus comportamientos, las posibilidades de los recursos que se gestionan, los tipos de actividades que se desarrollan se mueven en un cambio continuo y todo ello repercute directamente sobre el profesor retroalimentando en tiempo real su conocimiento profesional $\mathrm{y}$, por ende, la naturaleza de su razonamiento pedagógico. 
Aunque hasta ahora hay que reconocer que es complicado encontrar estudios que relacionen de forma directa el conocimiento profesional docente $\mathrm{y}$ la práctica en el aula en todo su conjunto (Borko, Roberts, y Shavelson, 2008, p.64). Una de esas excepciones la encontramos en el estudio de Schoenfeld (1998), en el que se trata de aunar todas las piezas que componen la práctica de aula y mostrar en un estudio longitudinal cómo se vincula el conocimiento profesional docente y la acción, es decir, la práctica de aula. Schoenfeld muestra un análisis, tal y como él indica, limitado aunque ambicioso. Su idea es poder analizar esta relación y desempeño docente desde una visión global, atendiendo a la identidad propia de cada sujeto de estudio, para así tratar de encontrar no sólo qué hacen ellos en el aula, sino que dentro del contexto particular comprender qué es lo que permite hacer lo que hacen dentro del aula.

Si restringimos el corpus de estudios a aquéllos que han tratado de analizar la relación entre la práctica en contextos de enseñanza directa y el uso de las TIC, aún se reduce más el cómputo total (Webb y Cox, 2004). Algunos de los resultados obtenidos en esos estudios apuntan a tendencias valiosas para la comprensión de la relación entre prácticas y TIC. Por ejemplo, en estudios longitudinales como el de Pedretti et al. (1998) o Linn y Hsi (2000) se subraya la importancia de las interacciones en clase, en particular, las asociadas con el aprendizaje colaborativo o el control del aprendizaje para contribuir a un uso efectivo de las TIC. En cualquier caso ambos aspectos son complejos: se producen ganancias al aumentar la colaboración de los alumnos y su autonomía, pero el papel del profesor al gestionar el aprendizaje y promover la colaboración, es crucial. Por otra parte, otros estudios sobre prácticas y TIC (Crook, 1998; Clements, 2000) subrayan la necesidad de que el docente planifique cuidadosamente las actividades que a través de las TIC permitirán a sus alumnos aprender en colaboración y controlar su propio aprendizaje. En definitiva la investigación sobre prácticas efectivas con TIC dibuja un panorama complejo en el que es difícil definir las características de los buenos profesores (Brown et al, 2001), aunque sólo los mejores docentes (Hay McBer, 2000) consiguen que sus alumnos gestionen de forma autónoma sus aprendizajes.

Hasta aquí, y con lo aportado a la praxis en relación con el docente, lo que parece claro dentro de las prácticas de aula es que, tal y como indica Gimeno (1988), las actividades y el profesor son punto de referencia sobre los que las investigaciones han de indagar en busca de resultados e interpretaciones que puedan ayudar a entender y estructurar de forma global 
qué sucede realmente en un aula determinada y si es posible encontrar tendencias o patrones de actuación comunes generalizables más allá de cada clase. Para ello, sin duda, se constituyen como herramienta fundamental los sistemas de análisis que permiten recoger, codificar, analizar e interpretar lo obtenido en los registros de lo que sucede en los contextos de la práctica. Pero ¿qué sistemas son los más adecuados para comprender mejor qué pasa en las aulas? ¿cuáles nos permiten resolver las preguntas que planteamos? ¿qué unidades de análisis son las adecuadas en el desarrollo de una clase?...

\subsection{Sistemas de análisis. Planificación, observación, análisis e interpretación.}

Las investigaciones plantean siempre problemas a la hora de buscar la coherencia entre los datos obtenidos y los objetivos y/o hipótesis que se formulan. De esta manera, podemos encontrar divergencias entre unas y otras ciencias marcadas, entre otras cosas, por las características de los objetos de estudio que seleccionamos. Así, cuando operamos por ejemplo dentro de las denominadas ciencias puras, los objetos de estudio aparecen con una cierta estabilidad que permite analizarlo de una forma aparentemente objetiva, cuantificable y generalizable. Sin embargo, dentro de las denominadas ciencias sociales el panorama es muy diferente, puesto que el objeto de estudio por lo general se presenta dinámico y sensible a los cambios que las variables que lo rodean (contextuales, culturales, sociales, temporales, evolutivas,...) pueden ejercer sobre él, sometiendo las prácticas de los investigadores a una dificultad añadida a la hora de controlar la totalidad de variables que se relacionan con el objeto de estudio.

Las ciencias de la educación, que son el ámbito en el que se centra la investigación, comparten las características generales de las ciencias sociales, ya que se encuentran circunscritas dentro de ellas. Por lo que los objetos de estudio suelen enmarcarse en un contexto donde es difícil aislar y controlar en su totalidad para su estudio todos los elementos que participan.

\subsubsection{El método.}

Como ocurría con los enfoques de diseño curricular, dentro de los sistemas de análisis surgen también discrepancias. Los investigadores se apoyan sobre los distintos modelos o métodos en función de que sus concepciones teóricas se acerquen a modelos más positivistas, o por el contrario a perspectivas más fenomenológicas. Es decir, por un lado se encuentran los de 
corte cuantitativo, que para determinados investigadores bajo el prisma de modelos racionalistas son los únicos que aportan carácter científico a las indagaciones y buscan como fin encontrar una relación directa entre hechos y causas. Mientras que por otro, están aquellos que aportan un enfoque cualitativo, donde predomina la compresión de lo que sucede desde una visión fenomenológica, preguntándose qué pasa en un determinado contexto en un momento particular (Taylor, S.J. y Bogdan, R.C., 2009). Dentro de este segundo grupo, donde se sitúa esta investigación, cada vez más autores defienden la legitimidad de los análisis cualitativos como métodos científicos y rigurosos (Flick, 2007; Stake, 2006).

En la actualidad la investigación cualitativa se ha enriquecido con cada vez mayores nociones teóricas y científicas que la apoyan y va logrando progresivamente la repercusión y el prestigio que mantienen los modelos cuantitativos -sobre todo a niveles institucionales-. Prueba del prestigio de lo cuantitativo la tenemos en los informes PISA $(2000,2003,2006,2009)$ que desde su creación por la OCDE se desarrollan con un aparato analítico que marca estándares y realiza evaluaciones con calificaciones porcentuales o numéricas, estableciendo medias y evaluando competencias de los alumnos, generando datos comparativos a nivel internacional, lo que da lugar a ránkings de comunidades y países. Estos informes situados claramente en un plano cuantitativo, buscan medir, evaluar y cotejar resultados, y encajan dentro de diseños cuantitativos de medición. $Y$ demasiado a menudo, su intención de generalizar estándares educativos y su perfil centrado en los contenidos y la evaluación de los mismos hace que las administraciones -locales, autonómicas, estatales o internacionales- los utilicen en muchos casos para tomar decisiones políticas (Santín, 2006; Calero y Escardibul, 2007).

Bastante lejos de esa perspectiva y retomando el asunto que nos ocupa en este capítulo, las prácticas de aula requieren por su complejidad una interpretación más allá de lo puramente cuantitativo. Lo cual no quiere decir que se sacrifique el rigor, pero sí que se adopte un enfoque más ecológico (Cole, Hood, Raymodn, y McDermott, 2002), y que los datos se interpreten sin perder de vista el contexto. Así, la medida cuantificada del aprendizaje del alumno no es más que un elemento dentro de todo el entramado de interacciones y procesos que suceden en el aula, siendo sólo el producto que se exterioriza o explicita pero no el producto real (Gimeno, 1988), que presenta una visión mucho más compleja y personal. Por lo tanto, estamos en sintonía con Flick (2007) cuando indica que afrontar los análisis de las ciencias sociales 
desde la inducción tiene más sentido que desde enfoques deductivos, y sobre todo en ámbitos como el que nos ocupa tan dinámicos y complejos, donde la exactitud extrapolada de otras ciencias no hace sino dificultar la comprensión de lo que realmente sucede dentro de los contextos de enseñanza formales.

Con lo visto hasta ahora parece por tanto necesario adoptar métodos cualitativos para poder explicar lo que sucede dentro de las aulas, ya que al encontrarnos ante diseños no experimentales, ni siquiera cuasi-experimentales, el delimitar variables experimentales que afecten a las prácticas de aula como objeto de estudio se presenta como un trabajo ímprobo, si no imposible. En esta línea cualitativa surgen muchos posibles enfoques sobre los que trabajar en las investigaciones. Tal y como recoge Tójar (2006) algunos de las tradiciones o métodos más representativos de la investigación cualitativa serían: etnografía, etnometodología, fenomenología, interaccionismo simbólico, estudios de caso, investigación-acción y teoría fundamentada. Cada uno de ellos supone un posible enfoque, que deberá seleccionarse en función del diseño de la investigación por el que se apueste. En consecuencia, hay que contemplar aspectos relacionados con circunstancias contextuales, naturaleza del objeto de estudio, posibilidades de la investigación, instrumentos, técnicas disponibles, etc., buscando el más apropiado que facilite explicar o interpretar los datos para tratar de responder a las preguntas y a los objetivos marcados para el estudio.

Dentro de las prácticas de aula, la elección del método de investigación es un asunto de gran trascendencia, sobre todo porque hay que valorar y tener en cuenta cuáles son las posibilidades reales entre lo que tenemos o podemos tener y lo que queremos tratar de comprender o explicar. Dentro de los metodologías ofrecidas por la perspectiva cualitativa hay que destacar dos que nos pueden acercar a la realidad del aula concibiéndola, tal y como venimos diciendo, como algo complejo y contextualizado. Estos dos métodos son la investigación-acción y el estudio de caso, los dos con sus ventajas e inconvenientes para los estudios.

\section{Investigación-acción}

El método de investigación-acción supone de entrada "un diseño de investigación orientado al cambio y dirigido a la mejora de las condiciones actuales" (Tójar, 2006, p.108). Así, en educación pueden aparecer diferentes nombres que se encuadren dentro de este método tales como investigación en el aula, investigación colaborativa o investigación participativa (Latorre, 2004), 
investigación feminista, etnografía neo-marxista, evaluación democrática, metodología participante o investigación evaluativa (Tójar, 2006, p.113), llevando de forma implícita un matiz de cambio que se rige por un ciclo de planificación $\rightarrow$ acción $\rightarrow$ observación $\rightarrow$ reflexión, aunque luego presenten peculiaridades concretas en cada uno de ellos (p. 110). Pese a estas matizaciones, un denominador común en este método es la figura del investigador como el motor de reflexión y cambio de la práctica en busca de la mejora del proceso, en el caso que nos atañe, la práctica educativa.

Por tanto, para que se den las condiciones de investigación en el aula es indispensable hacer partícipe al docente de la investigación y que él, de forma sistemática y rigurosa, analice y a la vez actúe sobre su práctica. Estas circunstancias de inicio son complicadas por dos motivos: (1) la necesidad de una formación investigadora en el docente, que no siempre tiene y además requiere conocimientos teóricos y prácticos específicos; (2) la carga de trabajo extra que supone ya no sólo planificar y actuar de forma sistemática, sino también sistematizar en el proceso de enseñanza la observación y la reflexión, cerrando el ciclo e influyendo y modificando las planificaciones y actuaciones posteriores.

La importancia de esta investigación está ligada a los modelos de diseño curricular procesuales, así dentro de la investigación en el aula se pueden citar estudios como los desarrollados por Stenhouse (1985) o Elliot (1988) que defienden la importancia de la práctica como fuente de conocimiento. Aunque como hemos mencionado con anterioridad, pese a que la investigación-acción es un método que puede realizar grandes aportes para la compresión de lo que sucede en las prácticas de aula, su aplicación no se presenta fácil y requiere esfuerzos conjuntos de todos los agentes implicados en la práctica educativa y en la investigación.

\section{Estudio de caso}

La realización de un estudio de caso en el ámbito de la investigación, y más en el de las ciencias sociales, supone un método muy indicado para tratar de comprender qué sucede en un contexto determinado como puede ser el aula (Stake, 1998). Aquí, a diferencia del método anterior los agentes que desarrollan la práctica de aula son objeto de estudio pero no agente de cambio durante el proceso de investigación, es decir, el docente forma parte de la investigación en calidad de sujeto estudiado y las observaciones, análisis y reflexiones son 
realizadas por el investigador, que trata de comprender desde su diseño de investigación qué sucede en la interacción de los agentes, los recursos y/o el contexto que componen el estudio de caso.

Las definiciones sobre qué es un estudio de caso varían en la forma, aunque sustancialmente significan lo mismo. Juan Carlos Tójar (2006) entiende el estudio de caso como "una investigación descriptiva, exhaustiva y en profundidad de un caso, tratando de descubrir e identificar los problemas y las causas que pueden subyacer en el origen de los mismos" (p. 112). Por su parte, la autora Helen Simons (2011) define un estudio de caso como "un estudio de lo singular, de lo particular" (p.19). En esta línea, Robert Stake (1998) lo define como "el estudio de la particularidad y de la complejidad de un caso singular, para llegar a comprender su actividad en circunstancias importantes" (p. 11). Estas tres definiciones, tienen en común la singularidad del objeto de estudio, lo que resulta lógico por la idiosincrasia de los agentes educativos -profesores y alumnos- y las características contextualizadas del entorno -aula-. Sin embargo, una de las definiciones más acertadas, a nuestro entender, de estudio de caso la proporciona Ying (1984, p. 23, citado en, Tójar, 2006) que lo entiende como una indagación empírica que "investiga un fenómeno contemporáneo dentro de su contexto real de existencia, cuando los límites y el contexto no son claramente evidentes y en los cuales existen múltiples fuentes de evidencia que pueden usarse".

En esta línea, nuestra investigación se inclina por el estudio de caso como método más ajustado para la consecución de los objetivos de investigación marcados. No se busca con este tipo de estudios hacer generalizaciones, sino más bien tratar de ver qué sucede en cada caso concreto y con ello qué se puede aportar a los modelos generales a partir de la compresión de modelos singulares. En sí mismo un caso puede contener generalizaciones dentro de él, pero no tienen porqué ser extrapolables a otros casos. En otras palabras, dentro del caso podemos encontrar repeticiones en actividades, reglas, respuestas, comportamientos, intervenciones, etc. y esto alcanza a comprenderse en sí mismo como una generalización menor durante el estudio del caso (Stake, 1998), lo que ayudará a la compresión de qué es o qué pasa en lo que estamos investigando.

Sin embargo, un estudio de caso va más allá de la mera observación de, en nuestro caso, las prácticas de aula. Puesto que por su complejidad recogemos información tan variada y abundante respecto de agentes, medios y 
recursos que componen la práctica educativa podría parecer un cúmulo de datos ininteligible. De ahí que sea preciso delimitar el tema sobre el que se quiere investigar como parte fundamental del diseño de investigación. La delimitación precisa del tema, permite, a su vez, concretar los aspectos susceptibles de ser registrados en la recogida de datos porque puedan aportar claridad a las preguntas formuladas.

Por tanto, ¿qué sentido tiene hacer un estudio de caso, ya sea de caso único o múltiple, si no se cuenta con un sistema de análisis pensado y adaptado a las preguntas que nos formulamos respecto del objeto de estudio? Un sistema de análisis capaz de estructurar la información recogida atendiendo a los presupuestos de los constructos teóricos que explican en nuestro caso el funcionamiento de los procesos de enseñanza en las prácticas reales con TIC.

\subsubsection{La construcción de la herramienta de análisis de las prácticas.}

Parece claro que el propósito de este trabajo se encamina a comprender cómo se gestionan los recursos TIC en los contextos de la práctica directa en las aulas. Eso significa que para el estudio es preciso recoger datos sobre dichas experiencias reales y sistematizarlos de manera que se pueda explicar qué papel juegan los elementos que intervienen en el desenvolvimiento de las acciones de la práctica (bien sean elementos ligados al curriculum, al conocimiento profesional del docente, a las TIC o a las peculiaridades de las etapa educativa, que hemos descrito hasta ahora como los ejes sobre los que se desenvuelven las actuaciones en la enseñanza directa). Pero las prácticas de aula de las que nos queremos ocupar requieren de, entre otras cosas, un análisis del discurso y de las interacciones entre profesores y alumnos durante el transcurso de la clase, dado que es uno de los asuntos más visibles de lo que ocurre en las aulas. Pero asimismo, es importante utilizar un sistema que, dentro de un marco cualitativo, pueda obtener la mayor cantidad de información posible de los registros de cada caso estudiado e interpretar en profundidad los datos que vayan apareciendo y que permitan analizar la riqueza de las situaciones de enseñanza registradas. Es interesante, antes de profundizar en el sistema de análisis enmarcar en el sentido que lo hacen Mercer, Littleton y Wegerif (2004) tanto los análisis del discurso cuantitativos como los cualitativos para valorar los pros y contras a la hora de trabajar con los datos analizados desde la compresión de texto o el análisis del discurso (tabla 4.1). 


\section{ANÁLISIS CUANTITATIVO}

- Es un análisis efectivo a la hora de manejar grandes grupos de datos.

- Es posible hacer comparaciones numéricas que se pueden someter a análisis estadísticos

- Los investigadores trabajan con categorías predefinidas, lo que hace que se pierda información que pueda ser valiosa para los análisis.

- Las categorías predeterminadas limitarían la sensibilidad sobre lo que ocurre en ese momento actual.

- El análisis no puede manejar que formas de significado son construidas entre los sujetos, con el tiempo, a través de la interacción.

\section{ANÁLISIS CUALITATIVO}

- Una conversación transcrita se mantiene durante el análisis, en vez de ser reducida a categorías en las primeras etapas.

- Las categorías surgen de los propios datos de la investigación.

- En los resultados las interacciones y conversaciones para ilustrar los análisis

- Los datos transcritos permiten solucionar malentendidos o aparentes puntos de vista.

- El tema de análisis permite la introducción de nuevos aspectos que emergen de los datos.
- Cuando hay una gran cantidad de datos el manejo de ellos es complicado mediante estos métodos.

- Es muy difícil plantear generalizaciones en la investigación.

- Los investigadores se encuentran con críticas por apoyar sus argumentos en casos concretos si tratan de generalizar.

Tabla 4.1: Ventajas e inconvenientes del análisis cuantitativo y cualitativo. Elaboración propia a partir de (Mercer, Littleton y Wegerif, 2004)

En concreto y con respecto a las prácticas de aula, el discurso entre profesores y alumnos se convierte en un medio para comprender qué pasa en el aula. Su análisis supone, dependiendo del enfoque que se le quiera dar, una fuente de conocimiento para tratar de interpretar qué sucede durante el proceso de enseñanza, en función de las intenciones de los investigadores. Esta 
utilización del lenguaje situado entre profesor y alumno nos ofrece estructuras que, por su composición, se pueden tomar como unidades de estudio - básicas o no- (Mercer, Littleton y Wegerif, 2004). Siendo éstas susceptibles de ser analizadas y estudiadas.

Por tanto las múltiples perspectivas con las que se puede interpretar un mismo discurso depende desde el inicio una relación del diseño de investigación por el que se opte. De esta forma, dependiendo de qué preguntas o hipótesis nos planteemos en el diseño repercutirá de un modo u otro en las dimensiones del análisis: “¿qué es lo relevante y merece la pena analizar?" (Sánchez, Rosales y García, 2010). En otras palabras, la dependencia de la estructura del sistema de análisis que adoptamos está circunscrita a qué es lo que esperamos extraer de los datos. Por ello, no es lo mismo analizar el discurso de las prácticas de aula en busca de respuestas a cosas tan diversas como el aprendizaje del alumno, la organización del aula, la dotación de recursos o, como en el caso de nuestro estudio, el desarrollo de la práctica docente en los procesos de incorporación de las TIC.

Para poder extraer conclusiones de las prácticas de aula en base a las dimensiones de análisis, es condición necesaria segmentar primero los datos en unidades de análisis que permitan un manejo de los mismos (Sánchez, Rosales y García, 2010), de esta forma se trata de dar coherencia en relación con el diseño de investigación a lo que sucede en el proceso de interacción de la clase. Así, los autores citados distribuyen de diferentes formas estas unidades de análisis para adecuarlas a las pretensiones de sus estudios.

En un estudio sobre la enseñanza de la lengua en el aula, los autores Sánchez, Rosales y García (2010) muestran un sistema de análisis de estructuración jerárquico para el análisis de las prácticas de aula y del discurso de profesor-alumno, descomponiendo el discurso en diferentes unidades que abarcan desde estructuras más generales a otras más concretas que matizan las anteriores, tales como lecciones, ATA (Actividades Típicas de Aula), episodios y ciclos (tabla 4.2). Esto que en principio parece complejo se refleja en la práctica de forma similar a como lo hacen los círculos concéntricos en matemáticas, los análisis sintácticos en lenguaje, o la descomposición de moléculas en elementos en física. 


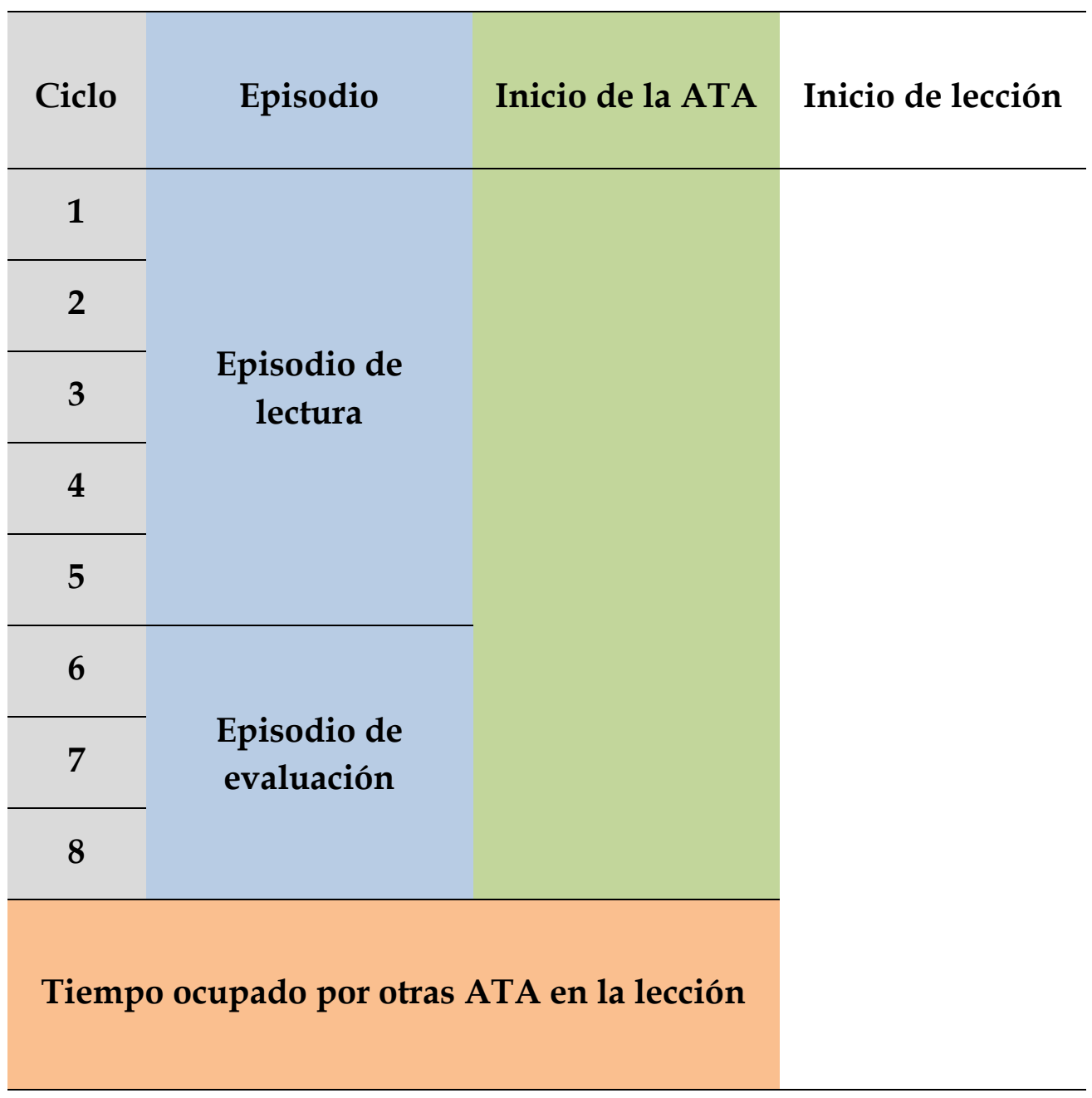

Tabla 4.2: Conjunto de la actividad de lectura colectiva.

Adaptación de (Sánchez, Rosales y García, 2010)

Burns y Anderson (1987) dentro del modelo ecológico, ven el comportamiento del docente como un eje fundamental. Dicho comportamiento se compone de dos fenómenos. Por un lado, el aspecto humano que presenta cada profesor; y por otro, el del medio físico en el que se desarrolla. Dentro de este marco, lo que nos interesa resaltar es el sistema de análisis que presenta de las prácticas de aula. Al igual que plantean los autores anteriores, Burns y Anderson (1987) toman la lección como unidad de análisis, que se divide a su vez en lo que denominan segmentos, los cuales son comprendidos como partes constituyentes de una lección. Presentan, al igual que lo hacen las ATA, una 
configuración propia y sus propios patrones de comportamiento que determinan el comportamiento tanto de profesores como de alumnos. La composición de esos segmentos que estructuran la lección está basada en: (1) propuestas de actividad -procedimiento, trasmisión, revisión, práctica, desarrollo...-; (2) el formato que dichas actividades tengan -pregunta respuesta, exposición oral, visionado de película, programa de ordenador, lectura, demostración...-; y (3) el tema y los contenidos que se decidan tratar matemáticas, artes, ciencias, lengua...- así como la dificultad que presentan fácil, difícil o moderado-. El análisis de estas unidades de segmentación se puede relacionar de forma directa, según los autores, con los roles de los estudiantes y profesores, su relación con las tareas, los comportamientos que tienen en la clase y todo ello explicaría el modo en que se producen las interacciones.

Al estudiar los puntos en común y las discrepancias en estos sistemas de análisis, independientemente de que tengan o no relación en su fin de investigación, surge el tema de las actividades, sobre el que venimos insistiendo reiteradamente, como unidad de análisis fundamental para comprender qué sucede en las aulas tanto en un caso como en el otro, ya sea bajo el nombre de ATA o segmento de lección. Si a esto unimos la relevancia que autores como Doyle y Carter (1984) o Gimeno (1988) otorgan a las actividades dentro del curriculum en la acción, estás se consolidan como una de las unidades de análisis que ayudarán a interpretar y comprender lo que sucede dentro de las aulas. Así, se entiende que a través de las actividades podemos tomar conciencia de cómo se desenvuelve el profesor en el transcurso de la clase.

De acuerdo con esta afirmación sobre la importancia de las actividades como referentes para los análisis de la investigación de la práctica, hemos de tener en cuenta que nuestro estudio aborda una etapa de enseñanza con unas características muy particulares. Estas características, como hemos explicado en capítulos anteriores, tienen una repercusión en la manera que tiene el docente de gestionar su intervención en el aula. Si bien las ATA se pueden entender para todos los niveles educativos como actividades fácilmente identificables, que tienen un carácter global y un objetivo del que todos somos conscientes, no ocurre lo mismo con el estudio del papel que juega el profesor en el desarrollo de la misma. Las características del alumnado, el contexto, los recursos, los contenidos, los objetivos, etc. implican matices importantes que vinculan tipos de actividades característicos con etapas de enseñanza diferenciadas. 
Las investigaciones mencionadas (Sánchez, Rosales y García, 2010; Burns y Anderson, 1987) dan a la interacción del profesor y alumnos, a través del análisis del discurso, un papel relevante para la compresión de los fines que les ocupan. Sin embargo, nuestra investigación, que pretende ver cómo se desenvuelven y gestionan los profesores las prácticas de aula en las que se utilizan recursos TIC, no aborda de forma idéntica esas interacciones profesoralumno, sino que apoya su categorización y análisis tanto en el discurso del profesor como en las acciones que desarrolla sobre los elementos del curriculum, analizando simultáneamente la transcripción del discurso y el registro visual de lo que se desenvuelve en el aula. Esta decisión viene justificada por varios motivos relacionados con las peculiaridades de la etapa de Educación Infantil tales como: (1) Aunque en todas las etapas educativas, el discurso del alumno no es equivalente al del profesor, en el caso de la etapa de infantil esta diferencia es aún más acusada por el nivel madurativo y de desarrollo de los alumnos. (2) Como consecuencia de la anterior premisa, en las aulas de Educación Infantil el discurso del profesor adquiere un papel especialmente relevante como indicador de las decisiones sobre gestión, organización y toma de decisiones en torno al desarrollo del curriculum en el aula. (3) Sin embargo, la transcripción de las interacciones orales que se producen en las aulas de Educación Infantil no es suficiente para entender el sentido y el significado instructivo de lo que acontece en la acción. Es, por tanto, preciso simultanear el análisis del discurso con el registro visual para entender en su totalidad los procesos de comunicación en aulas donde los alumnos aún están en etapas evolutivas y madurativas tempranas.

Por tanto el sistema de análisis que se ha construido para esta investigación, que se explicará con mayor detalle en el apartado de instrumentos de análisis, se asienta en primer lugar en la identificación de las ATA que configuran los patrones de actividad genéricos sobre los que se desenvuelven las prácticas. Estos patrones de actividad serían uno de los primeros indicadores de lo que hemos denominado "esquemas prácticos de acción", según la terminología de Leinhardt y Greeno (1986) y Leinhardt (1990). Pero además nos interesa comprender cuál es el papel que desempeña el profesor dentro de dichas ATAs, en otras palabras, cómo se configuran internamente los patrones de la actividad de la acción. Para ello, distinguimos dos elementos, lo que denominamos por un lado "acciones instructivas" y por otro "elementos del curriculum". Entendemos por acciones instructivas aquellas que el profesor lleva a cabo con el fin de conseguir los fines del proceso 
de enseñanza tales como identificar, explicar, planificar, recapitular y supervisar (Sánchez, Rosales y Cañedo, 1999). Y entendemos por elementos del curriculum aquellos sobre los que el profesor ejecuta sus acciones, a saber, objetivos, contenidos, tareas y recursos (Gimeno, 2010). En relación a los recursos y dado el protagonismo que tienen para los objetivos de esta investigación, distinguimos entre recursos TIC (sobre soportes digitales) y recursos No TIC (sobre soportes analógicos). La estructura del sistema de análisis permite indagar sobre aquellos elementos que desde el marco teórico estimamos hemos expuesto porque explican los factores que intervienen cuando se gestionan los recursos TIC en el aula. Desde aquellos estrechamente relacionados con el conocimiento del docente, hasta otros más cercanos al fenómeno del desarrollo del curriculum.

Por último, puesto que esta investigación se enfoca desde una metodología de estudio de casos, es importante tener en cuenta los datos del contexto donde se ubica cada caso. En este sentido, la investigación tendrá en cuenta las características de los centros, del aula y los alumnos, así como de los docentes que forman parte de cada caso. 


\section{CAPÍTULO 5}

Objetivos 



\section{Objetivos}

Tal y como se ha indicado en el marco teórico, en las aulas los profesores y los alumnos interactúan con objeto de desarrollar el curriculum, desenvolviéndose en un ambiente donde se gestionan simultáneamente múltiples elementos: medios, lenguajes, recursos, espacios y tiempos organizados de diferentes modos.

Por tanto, el propósito de esta investigación radica en comprender, a través del análisis de los procesos de enseñanza directos en las aulas, cómo los docentes de Educación Infantil desarrollan su práctica profesional ante la introducción de los recursos TIC en el aula, más concretamente de "El Rincón del Ratón".

Estos procesos de integración de las TIC que pueden ser vistos desde visiones positivas (Bolstad, 2004) o negativas (Healy, 1998), son en última instancia gestionados por el docente en el aula. Autores como Fullan (1991) refuerzan esta idea, cuando afirma que es el docente el eje central de las diversas fases de los modelos de innovación. Además, sus decisiones son racionales y se basan en los recursos que usan en sus clases (Dawes, 1999). En este sentido, nos interesa en la investigación estudiar cuáles son los patrones de actividad sobre los que los profesores vertebran sus clases - entendidas como estructuras de planificación y gestión de elementos organizativos y curriculares-. De esta forma y apoyándonos en los presupuestos del modelo de conocimiento profesional del docente (Shulman, 1986, 1987), podemos suponer que encontraremos diferentes patrones de actividad o ATAs en función de los distintos profesores que analizaremos. En la misma línea, y puesto que es uno de los ejes prioritarios de este trabajo, consideramos que si tales diferencias entre los profesores se confirman, ello será un indicador de modelos diversos de gestión e integración del recurso TIC en las prácticas de aula. De ahí que otro de los objetivos de este trabajo se dirija a detectar cuáles son los patrones o estructuras de actividad que permiten dar sentido al recurso TIC dentro del desarrollo del curriculum en las aulas de Educación Infantil del estudio.

Asimismo, estos patrones de actividad o esquemas de acción (Leinhardt y Greeno, 1986; Leinhardt, 1990) que se desarrollan durante las clases, esperamos que se configuren de formas particulares en lo que respecta al papel que el docente desempeñará en cada uno de ellos. Éste será también otro de los 
objetivos que nos planteamos en esta investigación, analizar cuál es el papel que el docente desempeña en cada una de las estructuras de actividad detectadas cuando incorporan un recurso TIC en sus aulas. Para poder estudiar esta cuestión, analizaremos lo que el profesor hace categorizándolo en cinco acciones de enseñanza que se explicarán en el capítulo 6 del sistema de categorías utilizado. Pero, además del rol del docente, nos interesa conocer sobre qué elementos del curriculum ejecuta el profesor sus acciones en la enseñanza directa de clase. Se establece de esta forma otro de los objetivos de la investigación: analizar e interpretar qué elementos del curriculum gestiona el profesor y de qué forma en cada uno de los patrones, estructuras o tipos de actividad que se van desenvolviendo en el transcurso de las clases.

En relación con el ya mencionado conocimiento profesional de los docentes (Shulman, 1986, 1987), suponemos que pueden aparecer, dependiendo de los docentes, distintas maneras de gestionar las clases en relación con los tipos o estructuras de actividad, el papel del profesor y los elementos del curriculum. En esta misma línea y puesto que es uno de los ejes prioritarios de este trabajo, consideramos que también podemos encontrar diferencias en cuanto a la integración y uso de los recursos TIC asociadas a los profesores estudiados.

Por último, debido a las características de la etapa que se detallan en el capítulo 2 suponemos que pueden aparecer diferencias en los aspectos enumerados anteriormente (tipos o patrones de actividad, papel del profesor y elementos del curriculum) ligadas a los distintos cursos de los que consta el segundo ciclo de Educación Infantil. Y estas diferencias cabe suponer que afecten no sólo a los patrones de actividad en los que se incorpore el uso de las TIC, sino en su conjunto a todos los tipos de actividad detectados.

Tras esta explicación y justificación de los objetivos y partiendo del objetivo general fijado: cómo los docentes de Educación Infantil desarrollan su práctica profesional ante la introducción de los recursos TIC en el aula, recogemos en la siguiente lista los objetivos específicos de la investigación:

1. Analizar cuáles son las actividades típicas de aula o patrones de actividad sobre las que los profesores vertebran sus prácticas.

2. Identificar cuáles son las estructuras de actividades sobre las que el recurso TIC toma sentido en el desarrollo de la clase. 
3. Interpretar y analizar cuál es el papel del docente en los patrones o tipos de actividades tanto en relación con las TIC como sin ella.

4. Interpretar y analizar qué elementos del curriculum son gestionados y de qué forma en cada uno de los tipos, estructuras o patrones de actividades encontrados en las clases.

5. Estudiar si existen diferencias en cada uno de los aspectos analizados (tipos de actividad, papel del profesor y elementos del curriculum) en función de los distintos cursos del segundo ciclo de Educación Infantil.

Estos objetivos marcados, tanto el general como aquellos de carácter más específico que proponemos para este trabajo, tratan de aportar, en la medida de lo posible y con las peculiaridades que los casos presentan, datos e interpretaciones que faciliten la comprensión de los procesos de integración de los recursos TIC en el aula de Educación Infantil desde el análisis de las prácticas de aula. 


\section{CAPÍTULO}

\section{Metodología}





\section{Metodología}

\subsection{Diseño de la investigación}

La investigación que se expone en este trabajo es parte de un proyecto más amplio del estudio de la integración de las TIC en diversas aulas de Educación Infantil. En este sentido y para tratar de entender el alcance de la investigación en su contexto, parece conveniente hacer un recorrido sobre los procedimientos y las acciones que se han puesto en marcha en el Proyecto I+D EDU2009-11295 donde adquiere sentido el presente estudio.

Esta investigación se llevó a cabo, por tanto, dentro de un proyecto más amplio que surge como iniciativa del Centro Internacional en Tecnologías Avanzadas (CITA-http://www.citafgsr.org/cita/) de la Fundación Germán Sánchez Ruipérez con el apoyo de la empresa IBM en la comarca rural de Peñaranda de Bracamonte (Salamanca). El objetivo del proyecto era introducir el pupitre tecnológico “El Rincón del Ratón” en las clases de infantil de los centros implicados, junto con el apoyo tecnológico de un asesor que acudía a las aulas de manera quincenal y el apoyo de la investigación desarrollada por el equipo de investigación del proyecto I+D EDU2009-11295.

El proyecto de investigación, que ha estado desarrollándose a lo largo de tres años, se centra en el estudio de las prácticas reales con el recurso TIC, además de realizar una evaluación de los efectos que dichas prácticas tienen sobre el proceso de aprendizaje de los alumnos. A lo largo del proyecto se están recogiendo datos relativos a los profesores (sus actuaciones directas con el recurso digital en las aulas, sus actitudes y concepciones sobre el papel de las TIC en la enseñanza), a los centros (la cultura de innovación, la dotación de recursos) y a los alumnos (perfil familiar en relación con las TIC y aprendizaje de habilidades multimedia).

Como acabamos de señalar, el tiempo fijado para el trabajo de campo de la investigación ha sido de tres años. Durante este periodo se utilizaron diversas técnicas de recogidas de datos con objeto de obtener información de las prácticas, los centros, las familias y el proceso de aprendizaje.

Se pudo acceder a un total de 8 centros que participaban en el proyecto de "El Rincón del Ratón". Además contamos con un total de 26 profesores a lo 


\section{Metodología}

largo de los tres años de la investigación, aunque el total de aulas a las que teníamos acceso por año era de 17. De estos 26 docentes 11 de ellos permitieron las grabaciones de sus prácticas, de ahí que en este trabajo se recojan datos de ese número de profesores.

En cuanto a los 8 centros, colaboraron de forma activa a través de la cumplimentación de un cuestionario (Anexo I), lo que ayudaba a comprobar aspectos organizativos del centro y de dotación con respecto a las TIC, y además facilitaron la recogida de información sobre el número de alumnos, profesores y algunos documentos del centro. Que en este trabajo se hayan recogido datos de 6 de ellos solamente se debe a que nos referimos únicamente a los centros de los profesores que permitieron la grabación de sus sesiones de clase.

Para delimitar mejor el entorno en el que se desarrollaba la investigación, solicitamos a los padres de los alumnos de Educación Infantil de los centros que cumplimentaran un cuestionario (Anexo II). De esta manera obteníamos datos sobre la dotación de recursos TIC en las familias así como el uso que hacían de los mismos.

En relación a cada docente individual se obtuvieron datos en diferentes momentos:

(1) A través de una entrevista inicial (Anexo III) al comienzo de la investigación se obtuvo información respecto a su perfil profesional y sus concepciones, creencias, formación, manejo y valoración acerca de las TIC y su uso educativo.

(2) Mediante grabaciones en vídeo y audio de sesiones de clase de entre 45 y 60 minutos cuando desarrollaban sus prácticas y utilizaban el recurso TIC en el aula, se recogió información sobre el desenvolvimiento de las clases. Dichas grabaciones se programaron de forma escalonada: tres durante el primer año (una por cada trimestre del curso escolar), dos en el segundo año y una en el tercero. Las razones de esta distribución se basaban en primer lugar en que se observó que no eran necesarias más grabaciones puesto que los docentes mostraban estilos de prácticas constantes, de tal forma que el aumento del número de grabaciones no llevaba aparejado un incremento de la cantidad de información recogida (Smolkowski y Gunn, 2012). Y por otra parte, tampoco resultaba necesario "cansar" a los docentes con "incursiones" constantes en sus 
aulas que no incrementaban la cantidad de información relevante para los objetivos de la investigación.

(3) Por medio de entrevistas grabadas inmediatamente antes y después de las sesiones de clase se recopilaban datos respecto a cómo llevarían a cabo el desarrollo de la sesión que habían planificado, qué papel atribuían a las TIC en el desarrollo de la misma, así como valoraciones "a posteriori" sobre el transcurso de la sesión.

Para valorar el cambio de los docentes a lo largo de los tres años transcurridos, en el último año de grabaciones -curso 2011/2012- les entregábamos a los profesores una encuesta final en la que deberían volver a contestar las preguntas de la entrevista inicial (Anexo I).

Por último, con objeto de evaluar el efecto de las prácticas sobre el proceso de aprendizaje de los alumnos, a partir del segundo año del proyecto se elaboraron fichas de evaluación destinadas a valorar las habilidades digitales del alumnado, que fueron completadas por los profesores y el asesor tecnológico en cuatro ocasiones a lo largo de dos años. Esta fase del proceso, sigue aún abierta con objeto de refinar y contrastar los datos obtenidos, así como los instrumentos elaborados.

\subsection{Centros y participantes}

El corpus de nuestro trabajo lo constituyen 6 centros a los que pertenecen los 11 profesores sobre los que se ha realizado nuestro estudio. Como hemos venido mencionando a lo largo de los capítulos anteriores nos encontramos con la necesidad de enmarcar una investigación de casos múltiple en el contexto particular de cada aula. Por ello, entendemos que es necesario ofrecer información del contexto escolar en el que se desenvuelven los profesores teniendo en cuenta aspectos relacionados tanto con el aula y el centro, como con el entorno cultural, económico y familiar que rodea al alumnado.

Como veremos a lo largo de este capítulo contamos con diferentes profesores que trabajan en alguno de los 6 centros, entre los que podemos encontrar similitudes y diferencias en aspectos que pueden afectar tanto a la integración de los recursos TIC como al desarrollo didáctico de las clases. Es decir, la estructura, organización, dotación de recursos, número de alumnos, aulas, etc. pueden ser factores que condicionen las prácticas de aula. 
Por ello, a través de dos cuestionarios, uno de ellos pasado al equipo directivo y otro a los padres de los alumnos de EI, así como revisiones de los PEC, documentos, estadísticas e informes a los que hemos podido tener acceso tratamos, en la medida de lo posible, de obtener información sobre esos rasgos característicos de los diferentes centros y de los profesores. En este capítulo planteamos una distinción:

1. Comenzaremos realizando una descripción de cada centro de forma particular, elaborada a partir de los datos a los que hemos tenido acceso en la investigación. Además, para complementar estos datos de los centros, también indicaremos algunos rasgos comunes que faciliten su visión de conjunto.

2. Presentaremos los datos relativos al profesorado que ha participado en la investigación, para así poder también caracterizar cada uno de los casos de una forma mucho más precisa.

\subsubsection{Centros}

\section{Centro 1}

Contexto socio-económico y socio-cultural.

El centro 1 se sitúa en un contexto rural con una población inferior a 2000 habitantes, distando de la capital de la provincia $50 \mathrm{~km}$. Su economía está basada predominantemente en la ganadería y la agricultura, existiendo también, aunque en menor medida, actividades relacionada con el sector servicios, pequeñas industrias de manufacturación y empresas de construcción.

Desde el punto de vista socio-cultural, la cercanía con el CITA y los acuerdos y proyectos que desarrollan con esta institución hace que realicen visitas periódicas de carácter formativo para los alumnos. Las familias de los alumnos del centro tienen, al menos en la etapa de Educación Infantil a la que hemos tenido acceso, un nivel de estudios básicos o de formación profesional en el caso de los padres, y formación profesional y estudios universitarios en el caso de las madres (Figura 6.1). 


\section{Tipología}

Se trata de un centro público dependiente de la Junta de Castilla y León. Su estructura obedece a los denominados CEO (Centro de Educación Obligatoria), que corresponde a aquellos que cuentan con los ciclos completos de Educación Primaria y Educación Secundaria, a lo que en este caso se une también el segundo ciclo de Educación Infantil, aunque este no sea de carácter obligatorio. Además de sus características propias este centro reúne también la condición de ser la cabecera de un CRA de un total de cinco localidades de la comarca de las cuales tres cuentan con centro propio.

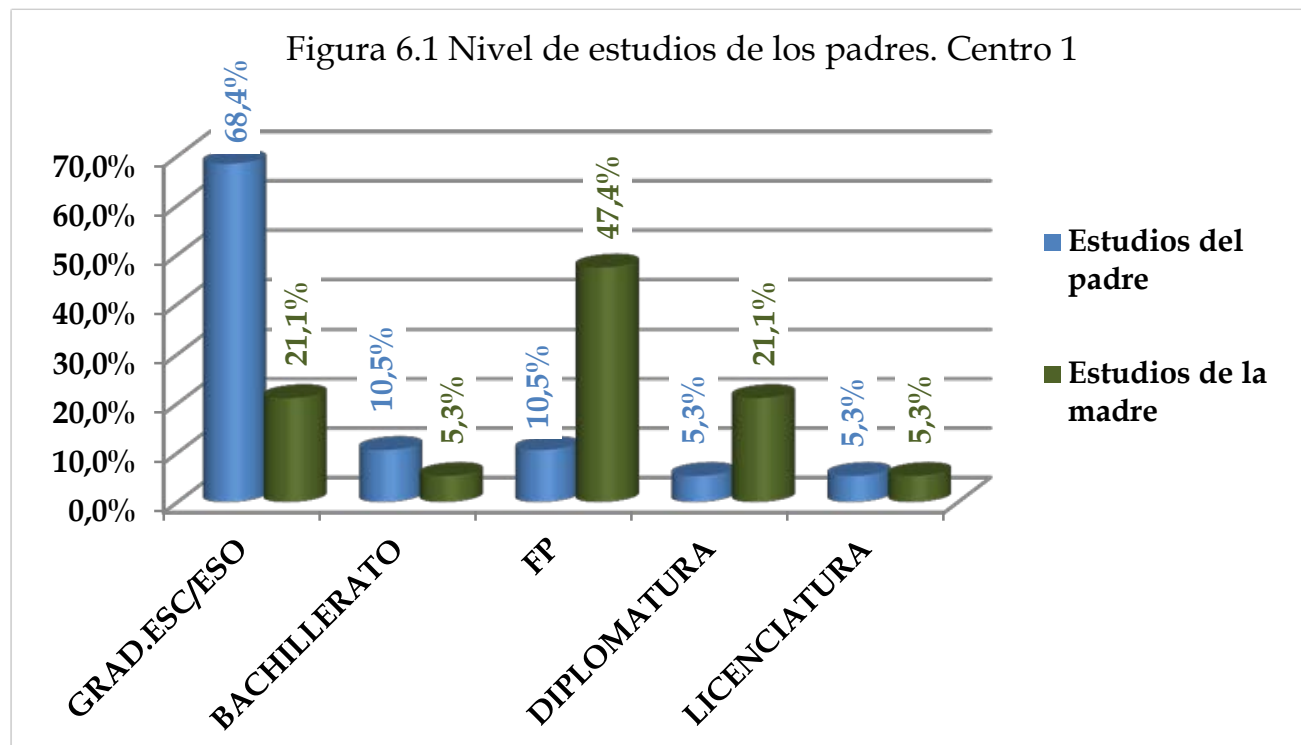

Estructura organizativa y alumnado

Se imparten clases desde el primer curso del $2^{\circ}$ ciclo de EI ( 3 años), hasta cuarto curso de la ESO (16-18 años). Los cursos se distribuyen entre tres localidades, de las que una es la cabecera (la de mayor población) y las otras son dependientes de ésta. En las tres se oferta tanto el segundo ciclo de EI como los tres ciclos de los que consta la Educación Primaria. En cuanto a la ESO solo está presente en la cabecera (Tabla 6.1). 


\begin{tabular}{|c|c|c|c|c|c|c|c|c|c|c|c|c|c|}
\hline & \multicolumn{3}{|c|}{$\begin{array}{l}\text { Educación } \\
\text { Infantil }\end{array}$} & \multicolumn{6}{|c|}{$\begin{array}{l}\text { Educación } \\
\text { Primaria }\end{array}$} & \multicolumn{4}{|c|}{$\begin{array}{l}\text { Educación } \\
\text { Secundaria }\end{array}$} \\
\hline & $\begin{array}{c}3 \\
\text { años }\end{array}$ & $\begin{array}{c}4 \\
\text { años }\end{array}$ & $\begin{array}{c}5 \\
\text { años }\end{array}$ & $1^{\circ}$ & $2^{\circ}$ & $3^{\circ}$ & $4^{o}$ & $5^{\circ}$ & $6^{\circ}$ & $1^{o}$ & $2^{\circ}$ & $3^{\circ}$ & $4^{\circ}$ \\
\hline Centro 1.1* & $\checkmark$ & $\checkmark$ & $\checkmark$ & $\checkmark$ & $\checkmark$ & $\checkmark$ & $\checkmark$ & $\checkmark$ & $\checkmark$ & $\checkmark$ & $\checkmark$ & $\checkmark$ & $\checkmark$ \\
\hline \multirow[t]{2}{*}{ Centro 1.2} & $\checkmark$ & $\checkmark$ & $\checkmark$ & $\checkmark$ & $\checkmark$ & $\checkmark$ & $\checkmark$ & $\checkmark$ & $\checkmark$ & $x$ & $x$ & $x$ & $x$ \\
\hline & \multicolumn{3}{|c|}{ Aula Unitaria } & & & & & & & & & & \\
\hline \multirow[t]{2}{*}{ Centro 1.3} & $\checkmark$ & $\checkmark$ & $\checkmark$ & $\checkmark$ & $\checkmark$ & $\checkmark$ & $\checkmark$ & $\checkmark$ & $\checkmark$ & $x$ & $x$ & $x$ & $x$ \\
\hline & \multicolumn{3}{|c|}{ Aula Unitaria } & & & & & & & & & & \\
\hline
\end{tabular}

Tabla 6.1 niveles educativos en el centro 1 por localidades

*El centro 1.1 corresponde a la cabecera del centro.

Los edificios se organizan de diferente forma dependiendo de la localidad, teniendo los centros 1.1 y 1.3 un único edificio para EI y EP. Mientras que en el centro 1.2 se encuentra separadas las aulas en diferentes edificios.
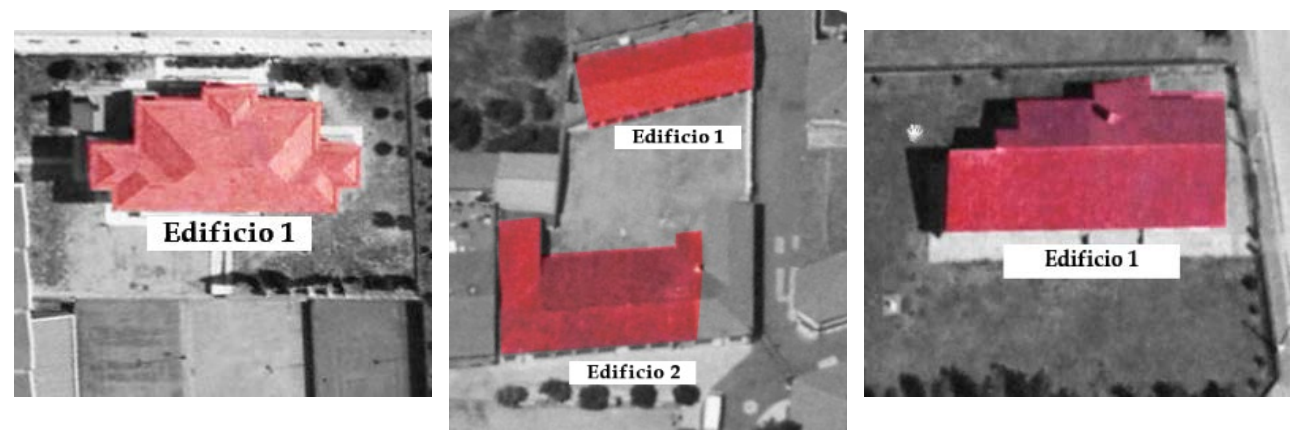

Las agrupaciones no son siempre estables, ni existe una línea para cada curso, sino que en función del número de alumnos se pueden agrupar, en aulas unitarias que abarquen todo un ciclo - centro 1.1 y centro 1.2 en cuanto a la Educación Infantil-, algunos cursos - centro 1.1- o incluso en una misma clase diferentes etapas educativas como EI y EP - centro 1.3.

La distribución del alumnado durante los tres cursos académicos que ha durado la investigación ha sido variable, como puede comprobarse en la Tabla 6.2: 


\begin{tabular}{|c|c|c|c|c|}
\hline $\begin{array}{l}\text { 2.1.1 Curso } \\
\text { académico }\end{array}$ & 2009-2010 & 2010-2011 & 2011-2012 & 2012-2013 \\
\hline $\begin{array}{c}\text { Centro } 1.1 \\
\mathrm{~N}^{\mathrm{o}} \text { alumnos E.I. }\end{array}$ & $\begin{array}{c}25 \\
2 \text { aulas }\end{array}$ & $\begin{array}{c}22 \\
2 \text { aulas }\end{array}$ & $\begin{array}{c}15 \\
\text { Aula } \\
\text { unitaria }\end{array}$ & $\begin{array}{c}8 \\
\text { Aula } \\
\text { unitaria }\end{array}$ \\
\hline $\begin{array}{c}\text { Centro } 1.2 \\
\mathrm{~N}^{\mathrm{o}} \text { alumnos E.I. }\end{array}$ & $\begin{array}{c}10 \\
\text { Aula } \\
\text { unitaria }\end{array}$ & $\begin{array}{c}6 \\
\text { Aula } \\
\text { unitaria }\end{array}$ & $\begin{array}{c}10 \\
\text { Aula } \\
\text { unitaria }\end{array}$ & $\begin{array}{c}10 \\
\text { Aula } \\
\text { unitaria }\end{array}$ \\
\hline $\begin{array}{c}\text { Centro } 1.3 \\
\mathrm{~N}^{\mathrm{o}} \text { alumnos E.I. }\end{array}$ & $\begin{array}{c}3 \\
\text { Aula } \\
\text { unitaria }\end{array}$ & $\begin{array}{c}5 \\
\text { Aula } \\
\text { unitaria }\end{array}$ & $\begin{array}{c}4 \\
\text { Aula } \\
\text { unitaria }\end{array}$ & $\begin{array}{c}3 \\
\text { Aula } \\
\text { unitaria }\end{array}$ \\
\hline $\begin{array}{l}\mathrm{N}^{0} \text { de alumnos total en } \\
\text { centros y etapas }\end{array}$ & 155 & 156 & 157 & 154 \\
\hline
\end{tabular}

Tabla 6.2. Número de alumnos en el centro 1 y en la etapa de Educación Infantil.

Aulas y dotación de recursos TIC.

El centro cuenta con diferentes tipos de aulas -ordinarias, biblioteca, informática, salas de profesores, gimnasio, etc.- en los que los dispositivos tecnológicos pueden tener una mayor o menor presencia. Los datos obtenidos del equipo directivo a través de un cuestionario aplicado a todos los centros de la investigación, arrojan una dotación de 23 ordenadores repartidos tanto por aulas ordinarias como en espacios específicos. En las aulas de Educación Infantil, aparte del Rincón del Ratón introducido con el proyecto del CITA, se dispone de un ordenador situado en el aula de 5 años del centro 1.1. El centro 1.2 cuenta con el aula de informática justo al lado del aula de infantil. También tiene acceso a 2 PDI, aunque ninguna de ellas se encuentra en la etapa de infantil.

El centro dispone de conexión de banda ancha que llega a diferentes aulas, entre ellas al aula de infantil en la que se encuentra el ordenador del centro $1.1 \mathrm{y}$ en el aula unitaria del centro 1.2. Esta última se habilitó al introducir el Rincón del Ratón.

A lo largo de la investigación, los diversos planes de la Administración y el CITA han hecho que el centro 1.1 incorpore ordenadores portátiles dentro del marco de programa Red XXI -escuela 2.0- para los alumnos del tercer ciclo de Educación Primaria, y con tabletas digitales dentro del programa Dedos - 
CITA- para el último curso de Educación Infantil. Además ha apostado por una plataforma de aprendizaje que conecta al centro y a profesores con los padres y los alumnos, donde existen clases virtuales con recursos, actividades e información importante tanto para padres como para alumnos.

Actitud hacia las TIC

La actitud que muestra el centro 1 desde el equipo directivo hacia las TIC es bastante favorable e integradora, tal y como muestra la participación en diversos proyectos innovadores como pueden ser las tabletas digitales y las aulas virtuales, que se encuentra relacionados directamente con las TIC.

Profesorado y TIC

La plantilla de profesores suma un total de 29 docentes de los cuales 21 tienen su plaza definitiva en el centro, 6 son interinos y 2 de ellos están en expectativa del destino definitivo. En Educación Infantil, de los 4 profesores de la etapa, todos cuentan con plaza definitiva en el centro, lo que hace que haya bastante estabilidad.

El centro dispone de 1 profesor que ejerce de coordinador TIC, con liberación de horas para desempeñar dicha función. El equipo directivo no se pronuncia respecto del uso de los recursos TIC de los docentes en el centro, pero su participación en los diferentes proyectos relacionados con las TIC permite suponer que al menos una parte sí incorpora estos recursos en sus clases. Los profesores que han participado en la investigación, también muestran una actitud favorable ante las TIC, aunque estos datos se especificarán de forma más particular en la descripción que hacemos de cada uno de los participantes.

Familia y TIC

Los datos con los que contamos de los padres de los alumnos que participan en la investigación muestran que las familias disponen de diferentes recursos TIC en sus casas. Además del inventario de recursos en el ámbito doméstico, también obtuvimos datos sobre el uso que se le da a los recursos en general, así como cuáles son los más usados por los hijos, el tiempo que le dedican y en compañía de quién realizan los niños el uso de los recursos TIC del hogar. Estos datos se muestran a continuación en la Figura 6.2: 
Figura 6.2 Disponibilidad y uso de recursos en el hogar

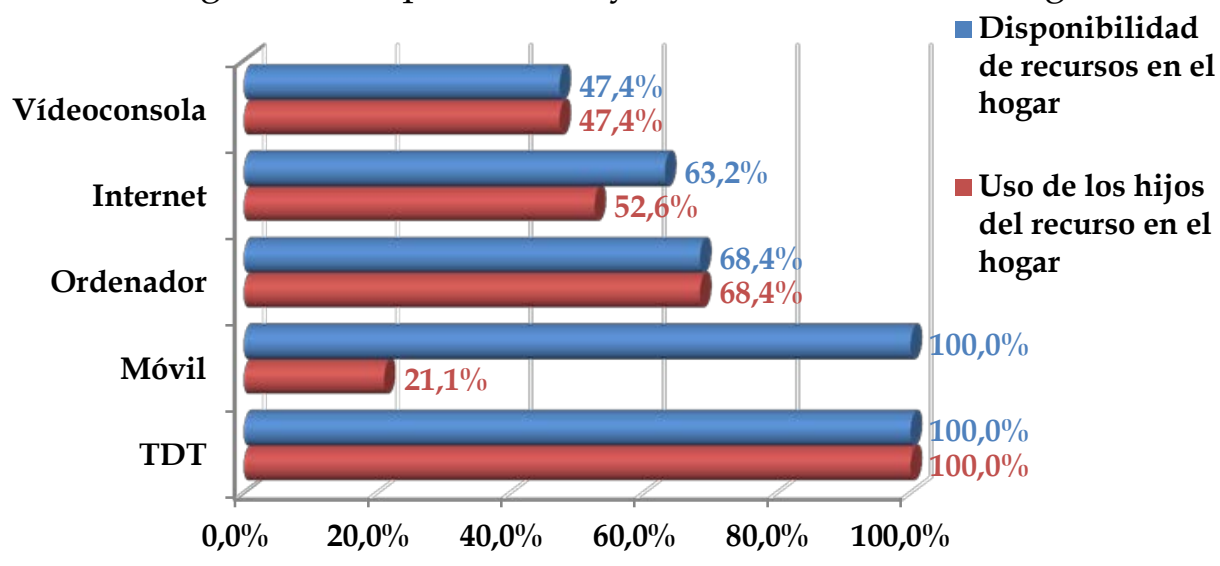

Otros aspectos importantes que hemos recogido del cuestionario pasado a los padres, nos muestra por un lado el uso que se le da a los recursos en el ámbito familiar (Figura 6.3) y por otro, en compañía de quién usan los recursos los hijos y si los padres tienen fijado un límite de horas de utilización para los menores (Figura 6.4 y Figura 6.5).

Figura 6.3 Uso de los recursos TIC por los padres

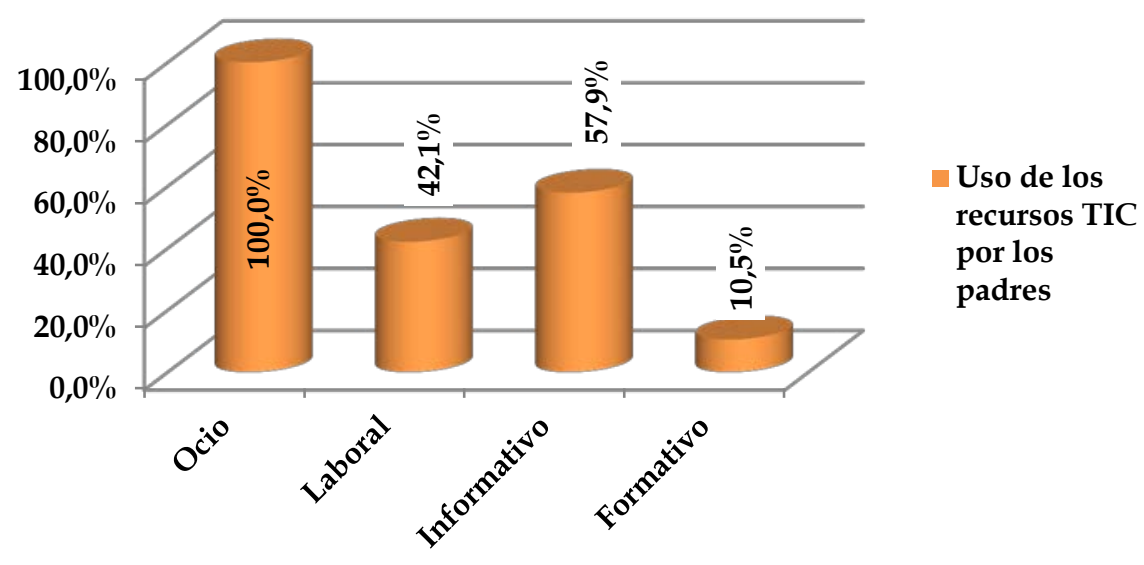


Figura 6.4 Quién acompaña al niño cuando usa el recurso TIC

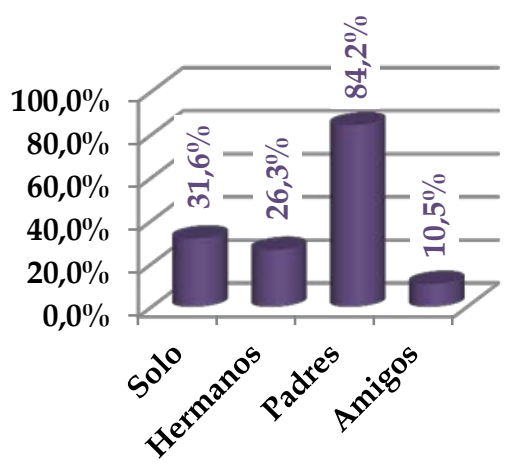

Figura 6.5 Límite en el uso de los recursos

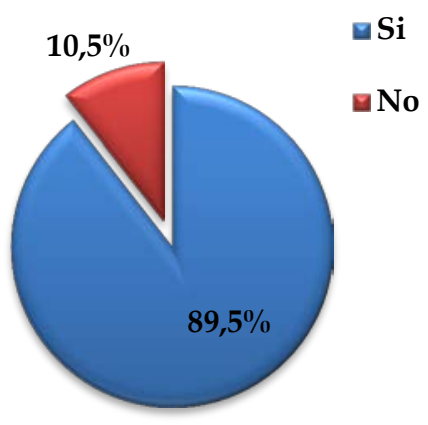

Por último, en relación con el grado de acuerdo que los padres muestran ante la utilización de las TIC en el ámbito escolar los resultados indican que hay una buena aceptación de que se dedique tiempo escolar para dicho manejo (Figura 6.6).

Figura 6.6 aceptación del uso de las TIC en el tiempo escolar

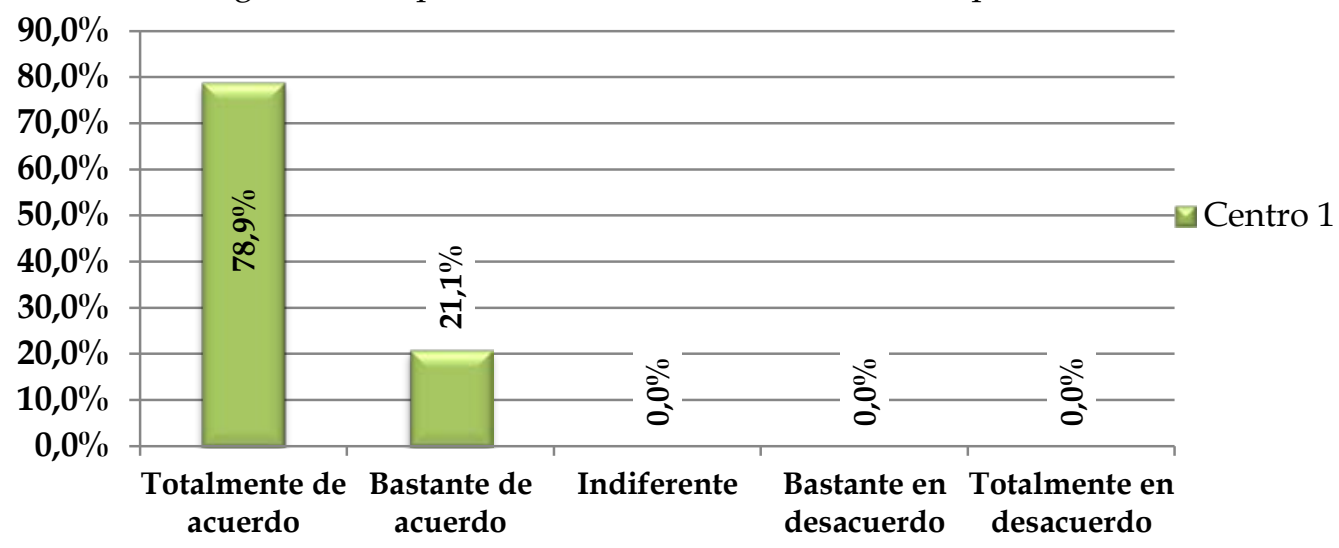




\section{Centro 2}

Contexto socio-económico y socio-cultural.

El centro 2 se encuentra situado en un municipio de más de 5000 habitantes, su distancia con la capital de la provincia es de $42 \mathrm{~km}$. Al igual que en el caso anterior, la economía se basa en la agricultura y la ganadería, aunque al tratarse de una localidad mayor que es cabecera de comarca, también la industria y el sector servicios tienen un peso relativamente considerable en las actividades laborales. Pese a ello, el ámbito en el que se enmarca sigue siendo rural. Al tener mayores ingresos municipales que otros centros situados en otras localidades, se ofrecen más actividades culturales, a lo que hay que sumar que cuenta con dos sedes de la Fundación Germán Sánchez Ruipérez, una dedicada al fomento de la lectura y actividades culturales y otra relacionada con las tecnologías como es el CITA.

$\mathrm{Si}$ atendemos al nivel socio-cultural de los padres de los niños de infantil, la información recabada en el cuestionario pasado a las familias muestra que son las madres las que alcanzan mayor porcentaje en los niveles de estudios superiores, mientras que más de la mitad de los padres han obtenido el graduado escolar, tal y como queda reflejado en la siguiente Figura 6.7:

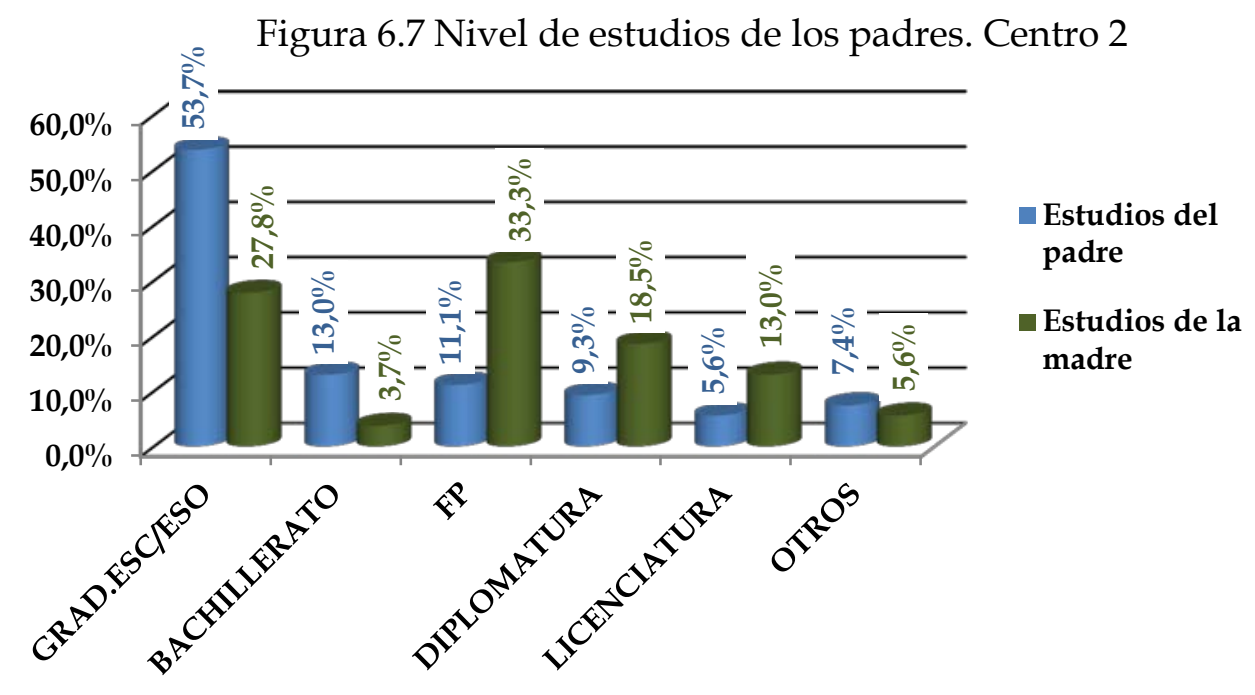


Tipología

El centro 2 es el único concertado entre los 6 centros del proyecto, a lo que hay que sumar la mención de bilingüe. La gestión del centro corresponde a una orden religiosa y el concierto abarca todos los niveles educativos que se imparten, desde primero del segundo ciclo de Educación Infantil, hasta $4^{\circ}$ de la ESO.

\section{Estructura organizativa y alumnado}

Como acabamos de mencionar, cuenta con diferentes cursos que comprenden desde el primer curso del $2^{\circ}$ ciclo de EI ( 3 años), hasta cuarto curso de la ESO (16-18 años) teniendo en cada uno de sus cursos una o dos líneas, siempre dependiendo del número de alumnos que haya en cada uno de los cursos (Tabla 6.3).

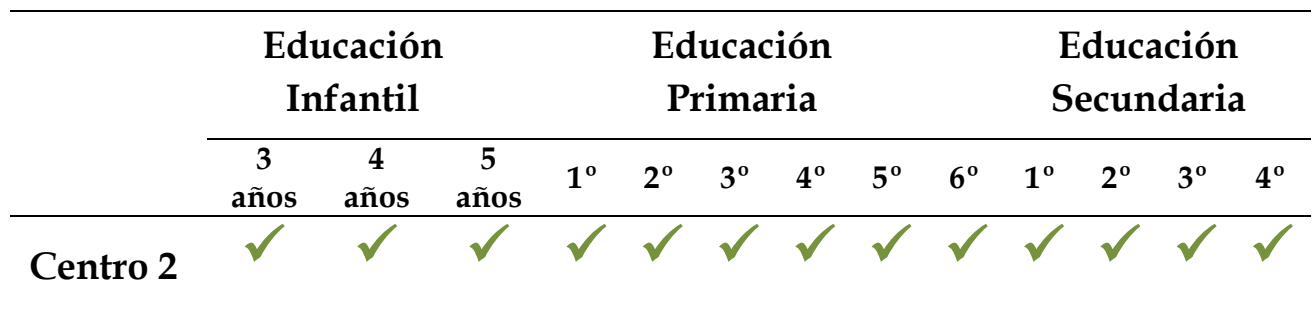

Tabla 6.3 niveles educativos en el centro 2

A diferencia de lo que ocurría en el centro 1, no encontramos en este centro agrupaciones de cursos en aulas unitarias. En el caso de Educación Infantil cuenta con los tres cursos y en todos ellos el número de alumnos es superior a 20 por aula.

Las aulas ordinarias están ubicadas en un único edificio en el que los diferentes cursos se distribuyen por proximidad de edad y ciclos.

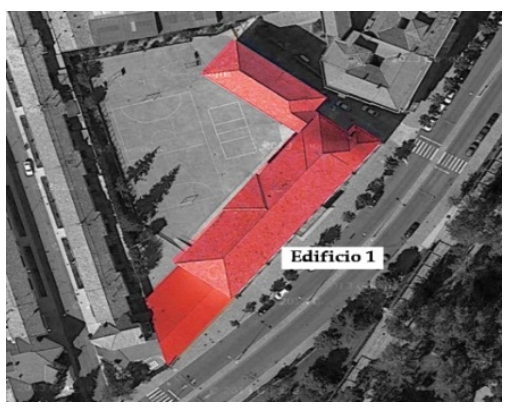


El número de alumnos en el centro es el mayor de todos los centros de la investigación y su distribución en las aulas de infantil a lo largo del periodo que ha durado la investigación se muestra en la siguiente Tabla 6.4:

\begin{tabular}{lcccc}
\hline \multicolumn{1}{c}{ Curso académico } & 2009-2010 & 2010-2011 & 2011-2012 & 2012-2013 \\
\hline $\mathrm{N}^{\circ}$ alumnos E.I. 3 años & 26 & 24 & 20 & \\
\hline $\mathrm{N}^{\circ}$ alumnos E.I. 4 años & 26 & 26 & 25 & \\
\hline $\mathrm{N}^{\circ}$ alumnos E.I. 5 años & 20 & 26 & 27 & \\
\hline $\begin{array}{l}\mathrm{N}^{\circ} \text { de alumnos en todos los } \\
\text { centros y etapas }\end{array}$ & 317 & 309 & 306 & \\
\hline
\end{tabular}

Tabla $6.4 \mathrm{~N}^{\mathrm{o}}$ de alumnos en el centro 2 y en la etapa de Educación Infantil.

Aulas y dotación de recursos TIC.

Se trata de un centro de tamaño grande y con un número considerable de aulas específicas. La ubicación de los recursos tecnológicos se concentra sobre todo en las aulas de informática, donde cuentan con 26 ordenadores. Asimismo cuentan con 2 ordenadores en aulas de primaria, 7 en las aulas de ESO, 2 en la sala de profesores y los 3 ordenadores del proyecto en las aulas de infantil. A diferencia de lo que ocurría en el centro 1, sí cuentan con una PDI en uno de los cursos de infantil y tienen previsto colocar otra en los otros dos restantes, a lo que hay que sumar otras $2 \mathrm{PDI}$ en primaria, 7 PDI en ESO y 1 en el aula de informática.

A esta dotación se añade una red de conexión a Internet disponible en todas las aulas ordinarias y en aulas específicas del centro. Aunque tal y como indica el equipo directivo, este uso de internet se limita más a sesiones puntuales que a una utilización continuada.

El mantenimiento de los recursos TIC se aborda con la contratación de una empresa externa, quien se encarga de reparar lo posibles problemas en los equipos del centro.

Actitud hacia las TIC

La actitud del centro 2 parece a priori buena en cuanto a la dotación en las aulas, puesto que el equipamiento de que disponen supone una inversión económica bastante alta en los recursos TIC. Cuentan también con una 
biblioteca digital en la que se encuentran recursos interactivos separados por etapas educativas. Pese a ello los proyectos de innovación a los que se refiere el equipo directivo están enfocados a otras temáticas no relacionadas de forma directa con las TIC.

Profesorado y TIC

El centro cuenta con una plantilla de 28 profesores, como personal indefinido. Los 3 profesores de infantil con los que cuenta el centro también forman parte de ese profesorado con plaza con contrato indefinido. Esto hace que la estabilidad y continuidad en los proyectos que se emprendan pueda ofrecer ciertas garantías, al menos respecto de la composición de los equipos docentes.

El centro no asigna a ningún docente las tareas de coordinador TIC. Cada profesor aplica e introduce en su aula los recursos, y en caso de surgir problemas se recurre a la empresa externa con la que se ha contratado el servicio de mantenimiento.

Familia y TIC

En cuanto a las familias, nos encontramos en los hogares con recursos tecnológicos que los niños utilizan fuera del horario escolar. Los datos relativos a los aparatos tecnológicos de uso doméstico en los hogares de los alumnos de infantil, tal y como aparece en la Figura 6.7, señalan que más del $80 \%$ cuenta con ordenador en casa y más del $60 \%$ con Internet (Fig. 5.8).

Figura 6.8 Disponibilidad y uso de los recursos en el

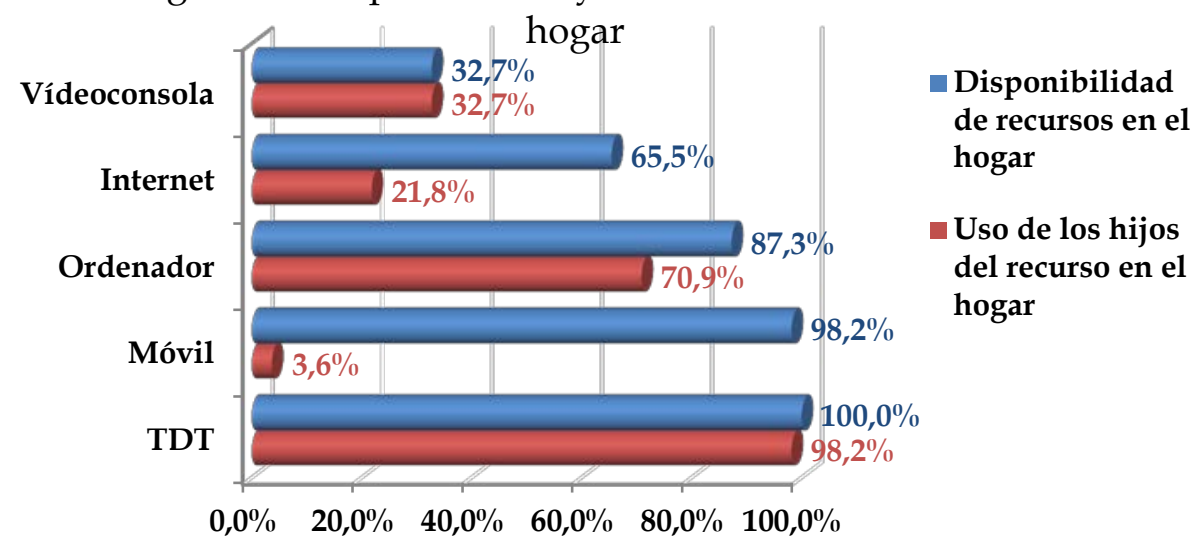


Al igual que ocurría anteriormente, los padres de los niños de infantil hacen un uso de los recursos mayoritariamente destinado al ocio, seguido del informativo. El ámbito laboral también tiene un porcentaje superior al 50\% y en último lugar encontramos el uso de los recursos con fines formativos (Figura 6.9).

Figura 6.9 Forma de uso de los recursos TIC por los padres

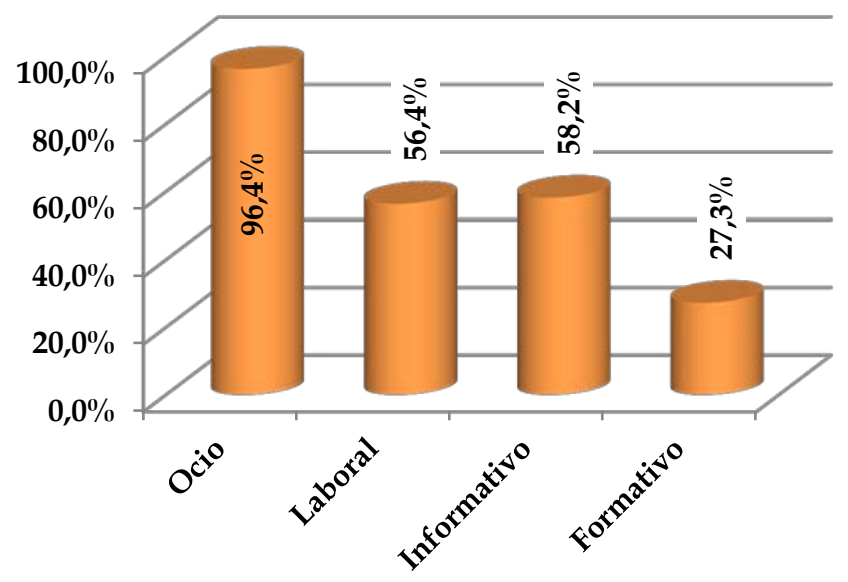

Uso de los recursos TIC por los padres

Por otro lado, en relación con el uso que los niños hacen de estos recursos, vemos que lo hacen en compañía de los padres-más de un $80 \%$-, mientras que en porcentajes inferiores al $20 \%$ junto con amigos, hermanos o en solitario (Figura 6.10 y Figura 6.11).

Figura 6.10 Quién acompaña al niño cuando usa el recurso TIC

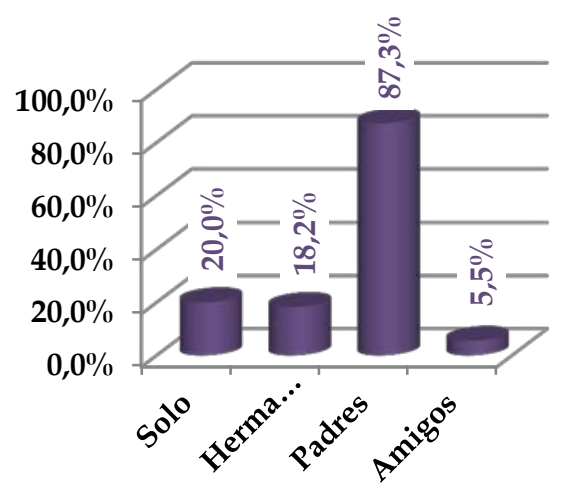

Figura 6.11 Límite en el uso de los recursos

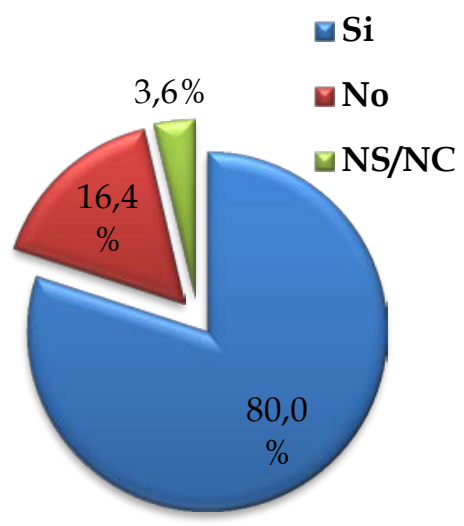


El grado de aceptación de los padres ante el uso en el aula indica que a un pequeño porcentaje le es indiferente y el resto adopta una actitud favorable ante esa circunstancia (Figura6.12).

Figura 6.12 aceptación del uso de las TIC en el tiempo escolar

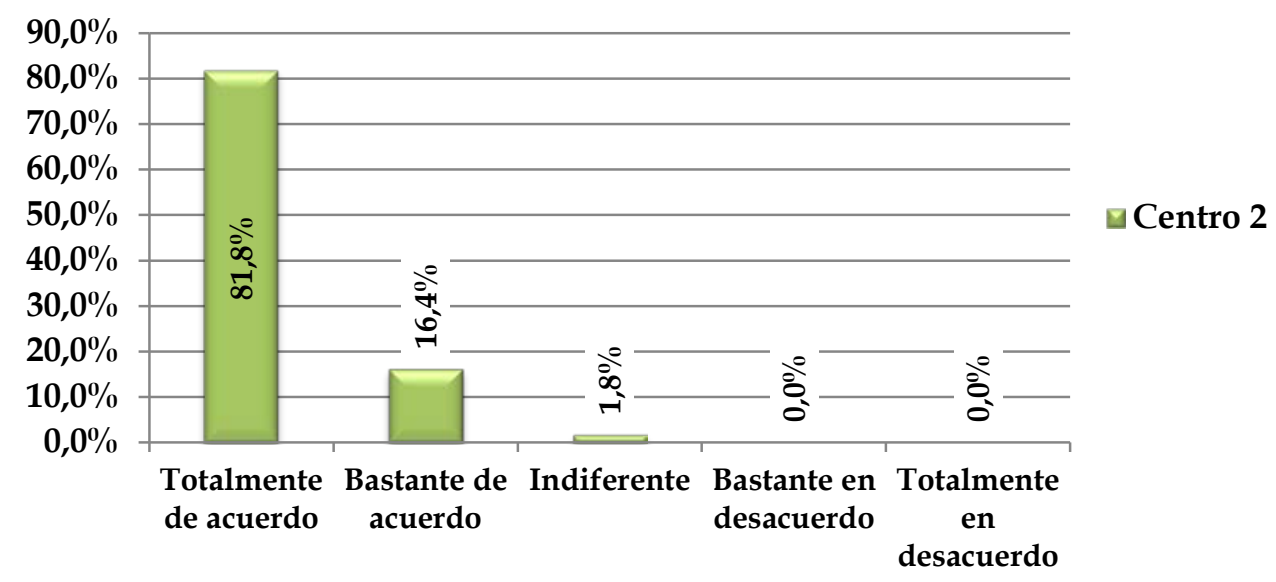




\section{Centro 3}

Contexto socio-económico y socio-cultural.

El centro 3 se encuentra situado en la misma población que el centro 2 . De esta forma y al tratarse de una localidad no excesivamente grande, tampoco existen diferencias socio-económicas y socio culturales por la zona del casco urbano en la que se encuentra, de forma que el contexto que rodea al centro es similar al del anterior, disponiendo asimismo del acceso a las actividades culturales que les ofrece la Fundación y el CITA.

Sin embargo, los datos recogidos de los padres de los alumnos sí pueden ser relevantes a la hora de contextualizar de forma más específica cada centro y marcar diferencias a nivel socio-familiar de los alumnos. En los datos del cuestionario pasado a los padres, al igual que en los casos anteriores, las madres poseen mayor nivel de estudios que los padres. Más de un $60 \%$ de los padres no alcanza niveles superiores al graduado, y ninguno de ellos posee una licenciatura. Las madres, aunque en su mayoría han obtenido el graduado escolar, aparecen más en los otros niveles, teniendo un 33\% estudios de formación profesional y un $18 \%$ una diplomatura. Estos datos se pueden ver en su conjunto en la Figura 6.13:

Figura 6.13 Nivel de estudios de los padres

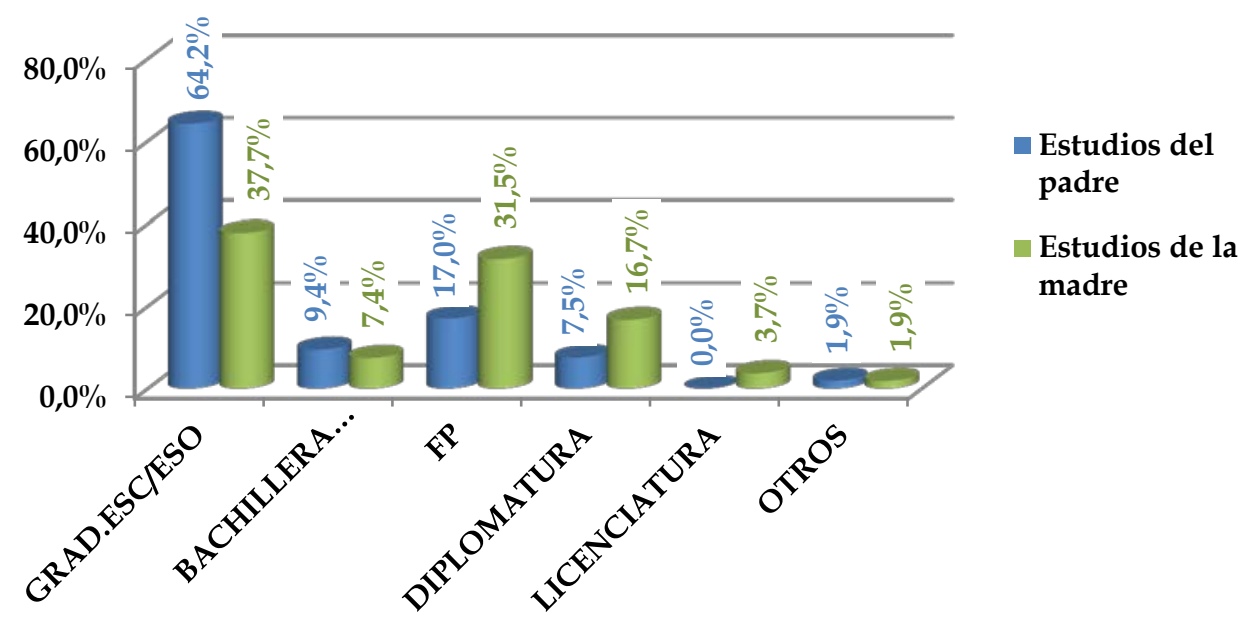


Tipología

El centro es de carácter público, y cuenta con las etapas de Educación Infantil y Educación Primaria, por lo que se trata de un CEIP (Centro de Educación Infantil y Primaria).

\section{Estructura organizativa y alumnado}

A diferencia de los dos centros anteriores, este centro no cuenta con ningún curso de Educación Secundaria, y abarca desde el primer curso del $2^{\circ}$ ciclo de EI (3 años), hasta sexto curso de Educación Primaria (12 años) teniendo una línea por curso. Así, en la etapa que aborda nuestra investigación hay tres líneas correspondientes a 3, 4 y 5 años (Tabla 6.5).

\begin{tabular}{|c|c|c|c|c|c|c|c|c|c|c|c|c|c|}
\hline & \multicolumn{3}{|c|}{$\begin{array}{l}\text { Educación } \\
\text { Infantil }\end{array}$} & \multicolumn{6}{|c|}{$\begin{array}{c}\text { Educación } \\
\text { Primaria }\end{array}$} & \multicolumn{4}{|c|}{$\begin{array}{l}\text { Educación } \\
\text { Secundaria }\end{array}$} \\
\hline & $\begin{array}{c}3 \\
\text { años }\end{array}$ & $\begin{array}{c}4 \\
\text { años }\end{array}$ & $\begin{array}{c}5 \\
\text { años }\end{array}$ & $1^{o}$ & $2^{\circ}$ & $3^{\circ}$ & $4^{o}$ & $5^{\circ}$ & $6^{0}$ & $1^{o}$ & $2^{\circ}$ & $3^{\circ}$ & $4^{o}$ \\
\hline Centro 3 & $\checkmark$ & $\sqrt{ }$ & $\sqrt{ }$ & $\sqrt{ }$ & $\checkmark$ & $\sqrt{ }$ & $\checkmark$ & $l$ & $\sqrt{ }$ & $x$ & $x$ & $x$ & $x$ \\
\hline
\end{tabular}

Tabla 6.5 Niveles educativos en el centro 3

Pese a tener las tres líneas en la etapa de infantil, la disparidad en el número de alumnos está condicionada en gran medida por el crecimiento demográfico de años concretos, es decir, los nacimientos que haya en la localidad o en su defecto las familias que se asienten nuevas en la localidad con hijos en las edades que comprende la etapa educativa. Así podemos encontrar desde cursos con 22 alumnos hasta otros con 10, aunque por norma general los grupos suelen estar en torno a los 20 alumnos.

\begin{tabular}{|c|c|c|c|c|}
\hline Curso académico & $\begin{array}{l}2009- \\
2010\end{array}$ & $\begin{array}{c}2010- \\
2011\end{array}$ & $\begin{array}{c}2011- \\
2012\end{array}$ & $\begin{array}{r}2012 \\
2013\end{array}$ \\
\hline $\mathrm{N}^{\mathrm{o}}$ alumnos E.I. 3 años & 17 & 22 & 11 & 10 \\
\hline $\mathrm{N}^{\circ}$ alumnos E.I. 4 años & 17 & 18 & 22 & 11 \\
\hline $\mathrm{N}^{\mathrm{o}}$ alumnos E.I. 5 años & 20 & 18 & 20 & 24 \\
\hline $\begin{array}{l}\mathrm{N}^{0} \text { de alumnos en todos los } \\
\text { centros y etapas }\end{array}$ & 178 & 175 & 178 & 176 \\
\hline
\end{tabular}


Estas aulas de infantil se encuentran repartidas en 2 edificios, 1 exclusivamente destinado a esta etapa de EI -edificio 2- en la que se encuentran los dos primeros cursos. Y en el otro edificio -edificio 1- se encuentran los cursos de primaria y el último curso de EI.

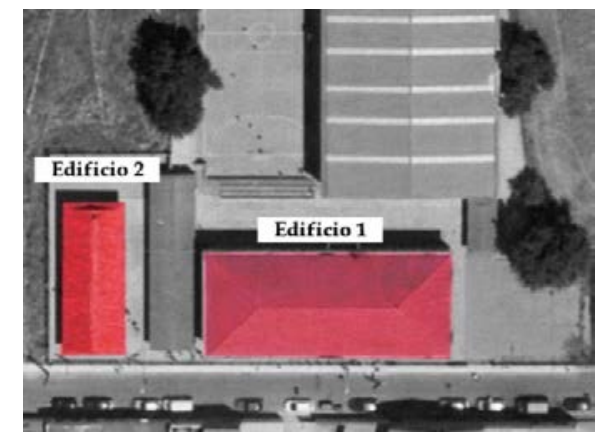

Aulas y dotación de recursos TIC.

Igual que en los otros centros existen diversos tipos de espacios, como aulas de informática, biblioteca, gimnasio, etc. La dotación en general es notablemente buena, cuentan con diferentes programas de innovación que giran en torno a las TIC, lo que supone que haya una adecuada dotación de recursos en ese sentido. En el cuestionario rellenado por el equipo directivo, indica que cuentan con 24 ordenadores distribuidos 3 en las aulas de EI, 6 en las aulas de primaria, 10 en las de informática, 1 en el aula de tecnología y 4 en otros espacios del centro. También es significativa la dotación de PDI en el centro, pues disponen de 7 unidades de las que 1 se encuentra en la etapa de Educación Infantil. Además está provisto de conexión a Internet en las aulas ordinarias y en otros lugares del centro donde se precisa la conexión. Los problemas que puedan surgir en los recursos TIC están derivados a la contratación de una empresa externa, siendo ésta la que se encarga de reparar los equipos del centro.

\section{Actitud hacia las TIC}

El equipo directivo muestra un claro apoyo a la integración de las TIC en las aulas y en el centro. Su participación en proyectos está enfocada de manera muy directa a dicha integración tecnológica, por ejemplo: Proyecto de aulas 2.0, Plan de informática, El Rincón del Ratón y Plan Red XXI. Estos proyectos que están tan directamente relacionados con las tecnologías, hacen 
que el centro presente una actitud en general positiva hacia las TIC y de hecho han solicitado ser evaluados por la Junta para el certificado de Centro TIC.

Profesorado y TIC

El centro dispone de una plantilla de 16 profesores, de los que tan sólo dos son interinos y el resto definitivos. Se trata, por tanto, de un equipo docente bastante estable. En relación con las TIC, un profesor del centro está liberado de horas y se ocupa de gestionar los recursos tecnológicos del centro, además de ello también contratan una empresa externa que les aporta el servicio técnico en los casos en los que es necesario.

De los 3 profesores de infantil, el primer año de investigación 1 de ellos era interino, y los otros 2 eran definitivos. En el segundo año, se incorporó un tercer docente que entró con plaza definitiva en el centro. Asimismo existe una cuarta profesora que comparte la tutoría de uno de los cursos de infantil, puesto que la directora es profesora de infantil y tiene reducción horaria que cubre esta cuarta persona.

Familia y TIC

Los recursos TIC de los que disponen la familias en el caso del centro 3 indica que en todas las familias hay TDT y prácticamente en todas teléfono móvil. El equipamiento a nivel informático aparece en al menos el $80 \%$ de los hogares, un $48 \%$ cuenta además con Internet y las videoconsolas, ya sean fijas o portátiles, están en el $53 \%$ de los hogares. El uso por los hijos de estos recursos varía dependiendo del tipo de recurso, siendo casi del 100\% en cuanto a la TDT y variando dependiendo del recurso (Figura 6.14).

Figura 6.14 Disponibilidad en el hogar y uso de los hijos de los recursos TIC

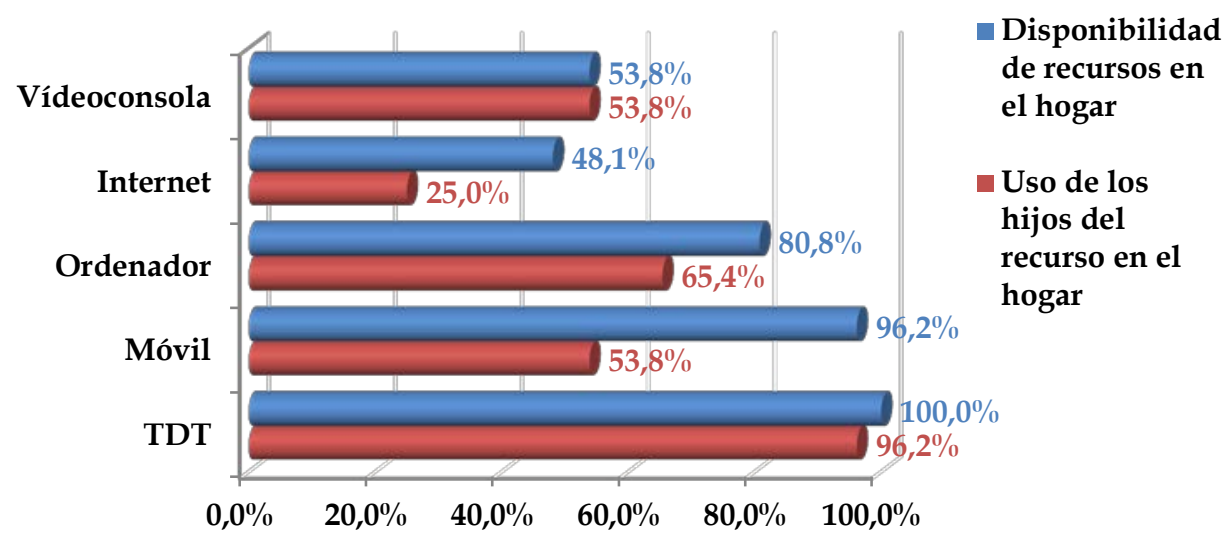


Si atendemos a qué usos le dan los padres a los recursos (Figura 6.15), observamos que la tendencia, que es generalizada en los centros que hemos visto hasta ahora, es hacia el ocio con un $92 \%$ de los hogares que usan los recursos para este ámbito, seguido del informativo y el laboral, 42\% y 32\% respectivamente y en último lugar aparece el ámbito formativo con un 19\% de los hogares que los emplean para ello.

Figura 6.15 Forma de uso de los recursos TIC por los padres

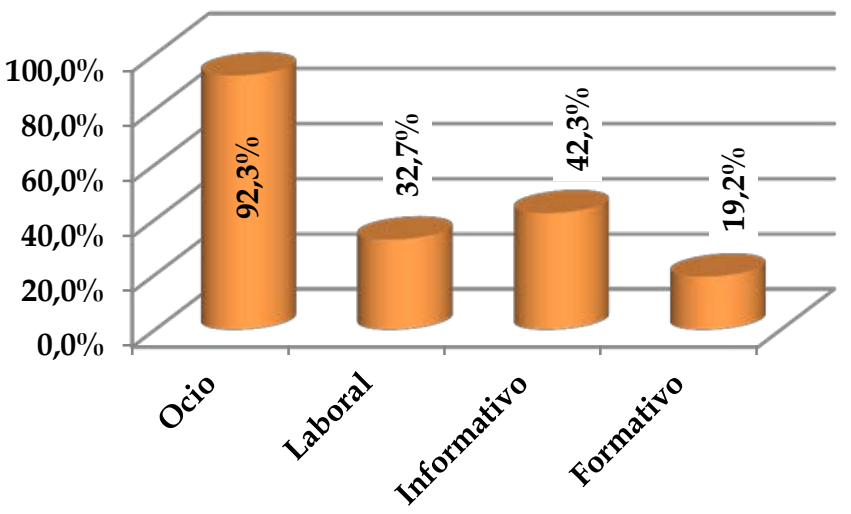

$$
\begin{aligned}
& \text { Uso de los } \\
& \text { recursos TIC } \\
& \text { por los padres }
\end{aligned}
$$

Por otro lado, el alumno mayoritariamente usa el recurso en compañía de los padres, en pocas ocasiones solo o con hermanos y todavía menos en compañía de amigos (Figura 6.16), además un porcentaje cercano a las tres cuartas partes de los padres tiene establecido algún límite en el uso de los recursos (Figura 6.17).

Figura 6.16 Quién acompaña al niño cuando usa el recurso TIC

Figura 6.17 Límite en el uso de los recursos
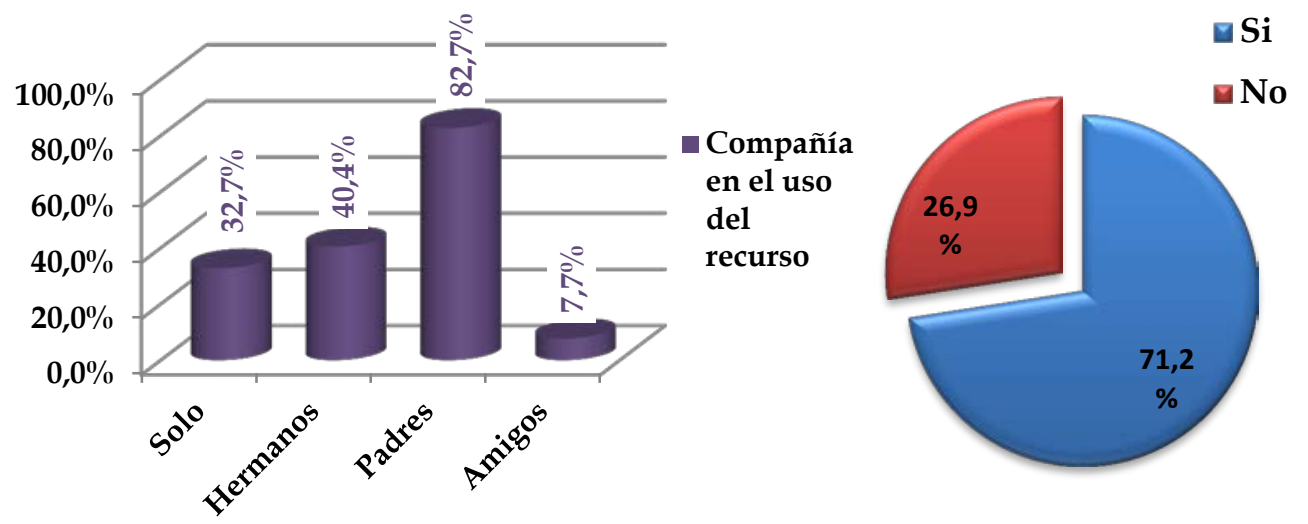
En relación con la aceptación, todos los padres muestran, en mayor o menor grado, una aceptación del uso de las TIC dentro del contexto escolar en que se encuentran sus hijos (Figura 6.18)

Figura 6.18 Aceptación del uso de las TIC en el tiempo escolar

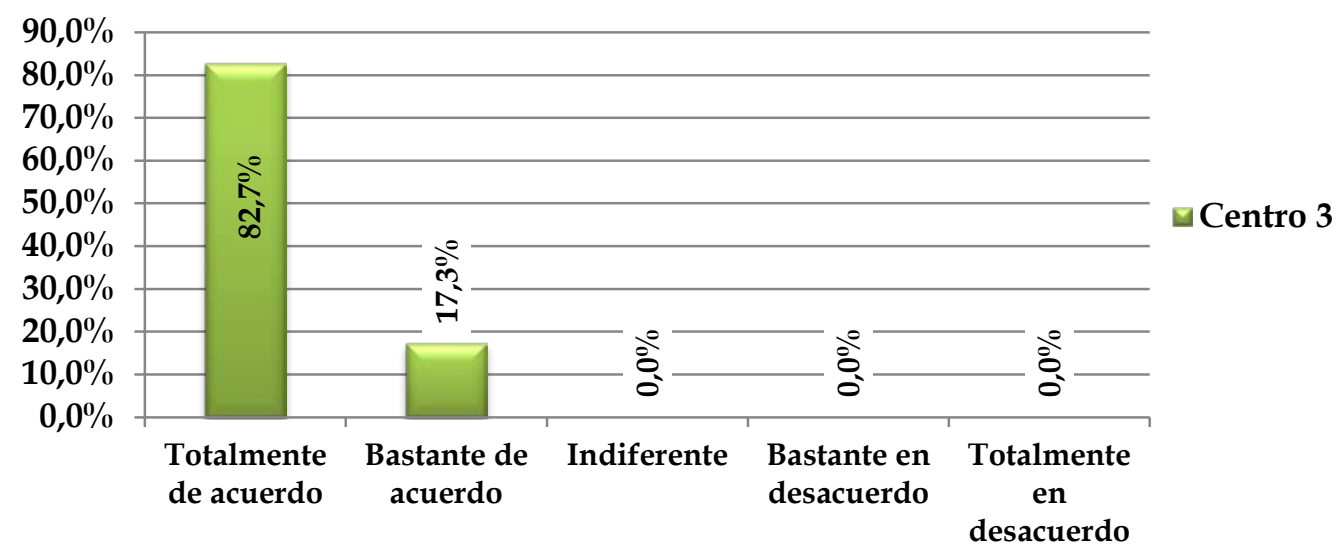




\section{Centro 4}

Contexto socio-económico y socio-cultural.

El centro 4 se trata del tercero y último de los centros que están situados en la misma localidad de más de 5000 habitantes que hemos descrito para el centro 2 y 3, por lo tanto, el contexto socio-económico es similar al de los 2 centros anteriores. Pudiendo asistir igualmente a las actividades culturales que les ofrecen la Fundación y el CITA.

Los estudios cursados por los padres de los alumnos de infantil en el centro 4, siguen las mismas tendencias de los centros escolares en esta localidad con un mayor nivel de estudios de las madres frente a los padres. Casi un $30 \%$ de las madres han cursado estudios universitarios y alrededor de un $70 \%$ estudios posteriores al graduado escolar. Sin embargo, alrededor de un $60 \%$ de los varones no alcanzan niveles superiores al graduado. Esta diferencia queda patente en la Figura 6.19:

Figura 6.19 Nivel de estudios de los padres

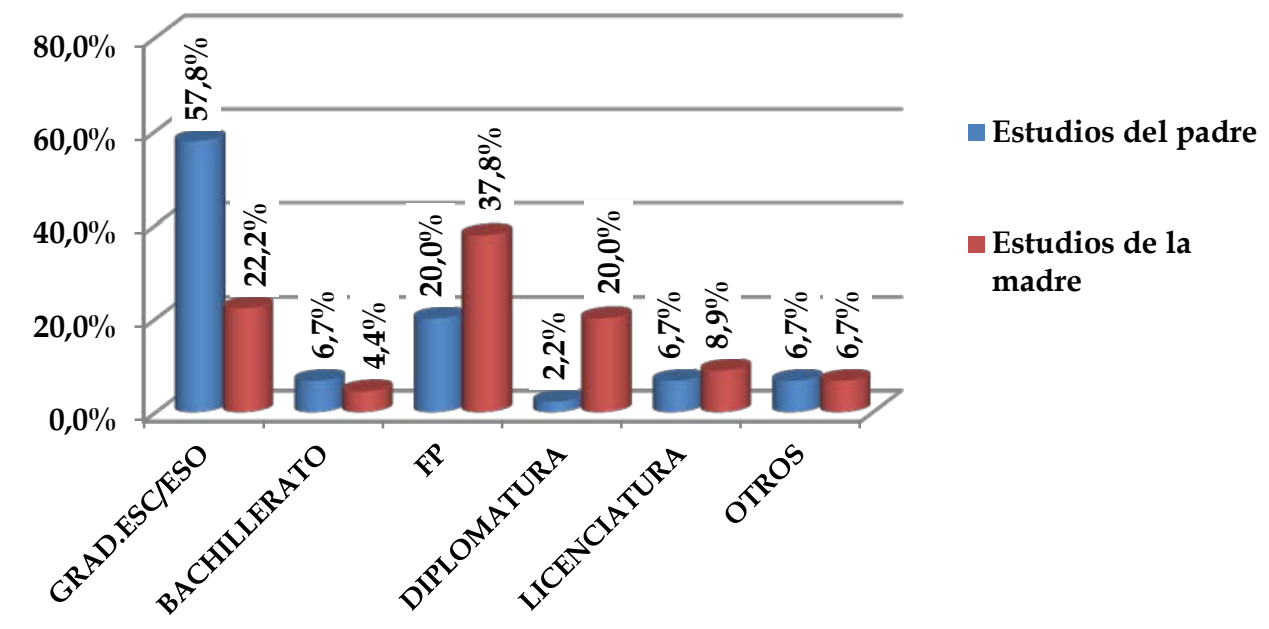

Tipología

El centro es de carácter público, contando con las etapas obligatorias de Educación Infantil y Educación Primaria, por lo que tiene la denominación de Centro de Educación Infantil y Primaria (CEIP). 
Estructura organizativa y alumnado

Como hemos mencionado en la tipología, los cursos que abarca van desde comienzo del segundo de Educación Infantil hasta final de la Educación Primaria (Tabla 6.7). Por lo que acoge a alumnos entre los 3 y los 12 años.

\begin{tabular}{|c|c|c|c|c|c|c|c|c|c|c|c|c|c|}
\hline & \multicolumn{3}{|c|}{$\begin{array}{c}\text { Educación } \\
\text { Infantil }\end{array}$} & \multicolumn{6}{|c|}{$\begin{array}{l}\text { Educación } \\
\text { Primaria }\end{array}$} & \multicolumn{4}{|c|}{$\begin{array}{l}\text { Educación } \\
\text { Secundaria }\end{array}$} \\
\hline & $\begin{array}{c}3 \\
\text { años }\end{array}$ & $\begin{array}{c}4 \\
\text { años }\end{array}$ & $\begin{array}{c}5 \\
\text { años }\end{array}$ & $1^{o}$ & $2^{o}$ & $3^{0}$ & $4^{o}$ & $5^{\circ}$ & $6^{\circ}$ & $1^{\circ}$ & $2^{\circ}$ & $3^{\circ}$ & $4^{o}$ \\
\hline Centro 3 & $\checkmark$ & 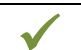 & 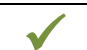 & $\checkmark$ & & 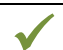 & & $\sqrt{ }$ & 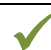 & $x$ & $x$ & $x$ & $x$ \\
\hline
\end{tabular}

Tabla 6.7 Niveles educativos en el centro 4

La etapa de Educación Infantil está organizada con una línea para cada curso y cuenta con un número más o menos fijo de alumnos que oscila ligeramente dependiendo del año escolar (Tabla 6.8).

Curso académico

2009-2010 2010-2011 2011-2012 2012-2013

\begin{tabular}{lllll}
\hline $\mathrm{N}^{\mathrm{o}}$ alumnos E.I. 3 años & 18 & 24 & 16 & 20 \\
\hline $\mathrm{N}^{\mathrm{o}}$ alumnos E.I. 4 años & 17 & 20 & 21 & 18 \\
\hline $\mathrm{N}^{\mathrm{o}}$ alumnos E.I. 5 años & 17 & 16 & 20 & 22 \\
\hline $\begin{array}{l}\mathrm{N}^{\circ} \text { de alumnos en todos lo } \\
\text { centros y etapas }\end{array}$ & 170 & 175 & 173 & 183 \\
\hline
\end{tabular}

Tabla $6.8 \mathrm{~N}^{\mathrm{o}}$ de alumnos en el centro 4 y en la etapa de Educación Infantil.

El centro dispone de un edificio independiente para la etapa de infantil y el primer curso de primaria, con gimnasio y patios cubiertos y al aire libre edificio 2-. El edificio principal del centro alberga las aulas de EP restantes así como también otras aulas específicas -edificio 1-.

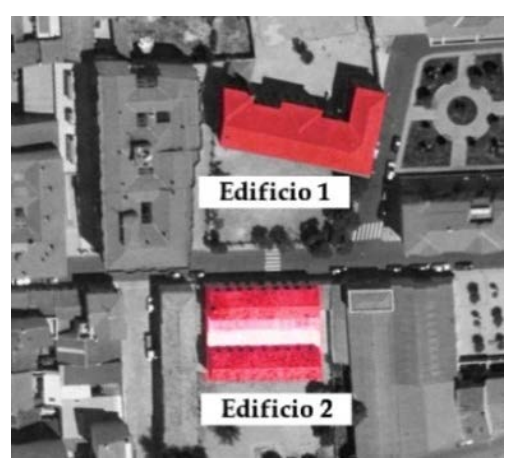


Aulas y dotación de recursos TIC.

Existen diferentes aulas repartidas entre los dos edificios, como ocurre en todos los centros vistos hasta ahora. La dotación de recursos TIC es de un total de 37 ordenadores, distribuidos entre aula de informática (23), ordinarias (8), sala de profesores (1) y otros espacios del centro (5); también hay 7 pizarras digitales, ninguna de ellas en el aula de infantil. El centro tiene un profesor especialista liberado de horas lectivas para el desempeño de coordinador TIC. A diferencia de los centros vistos hasta ahora, no cuentan con una empresa externa contratada para solucionar los problemas que puedan surgir con los recursos digitales.

Actitud hacia las TIC

Aunque no están en ningún proyecto de innovación relacionado con las TIC, sí ofrecen liberación de horas para aquellos que quieran desempeñar formación relacionada con el uso de recursos tecnológicos.

Profesorado y TIC

La plantilla está constituida por un total de 18 profesores, de los que 2 son interinos, 2 están en expectativa de destino y el resto tienen plaza definitiva. La etapa de nuestra investigación cuenta con 4 profesores, 3 de ellos definitivos y 1 interino $y$, al igual que ocurría en el centro 3,1 de los miembros se encarga de la dirección del centro, de tal manera que el profesor interino realiza la sustitución en las horas ocupadas en las labores de dirección.

Familia y TIC

Los recursos TIC de los que disponen las familias en el caso del centro 4 mantienen la línea de los anteriores en cuanto a la disponibilidad de TDT, y cuentan con un alto índice de ordenadores entre las familias: $93 \%$ de ellas disponen de este recurso, siendo además muy utilizado por los pequeños en el hogar. Al contrario que en el centro 3 las videoconsolas se sitúan por debajo del $50 \%$ e Internet se encuentra en menor porcentaje tanto en disponibilidad de las familias como en uso de los niños (Figura 6.20). 
Figura 6.20 Disponibilidad en el hogar y uso de los hijos de los recursos TIC

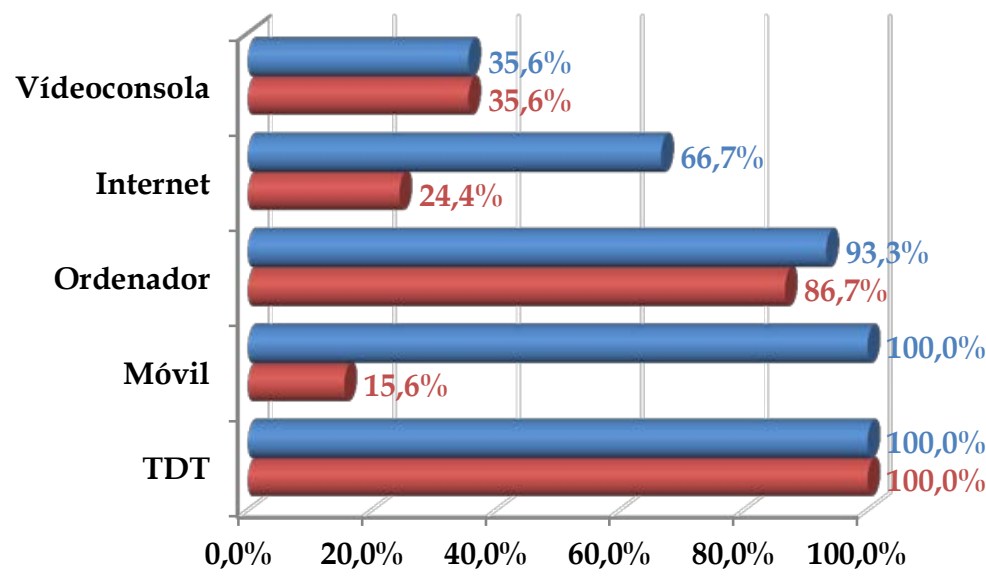

- Disponibilidad de recursos en el hogar

- Uso de los hijos del recurso en el hogar

El uso de los recursos TIC es mayoritariamente dentro del ámbito de ocio y seguido del informativo, laboral y formativo respectivamente (Figura $6.21)$.

Figura 6.21 Uso de los recursos TIC por los padres

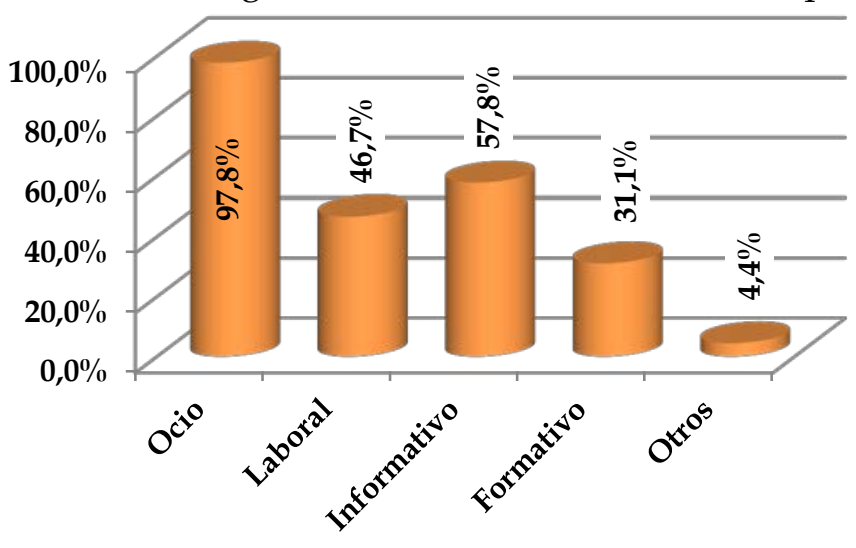

Uso de los recursos TIC por los padres

Los alumnos usan las tecnologías en casa mayoritariamente acompañados de sus progenitores, alejándose más el porcentaje de uso con hermanos, amigos o de forma individual, que en todos los casos se encuentra por debajo del 30\%. Estas diferencias quedan representadas en la Figura 6.22 a continuación: 
Figura 6.22 Quién acompaña al niño cuando usa el recurso

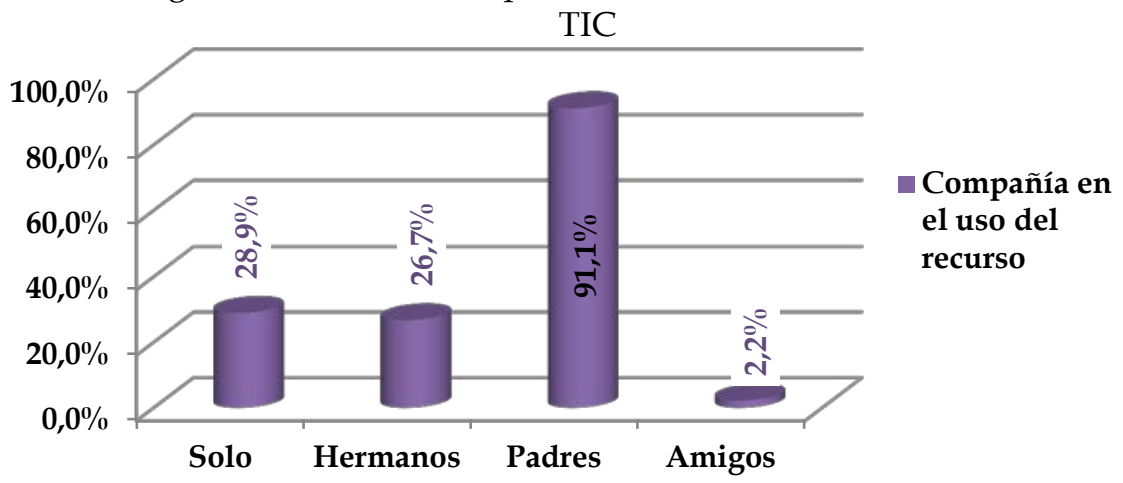

En cuanto a la limitación de uso, un porcentaje superior a una cuarta parte de los padres no limita el tiempo de uso de los recursos TIC, mientras que los restantes sí marcan algún límite de uso en cuanto a las horas que los niños pueden emplear (Figura 6.23)

Figura 6.23 Límite en el uso de los recursos

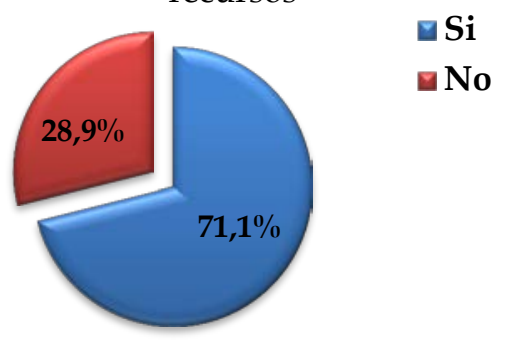

Finalmente, los padres de los alumnos de infantil presenta una aceptación mayoritaria del recurso tal y como podemos ver en la Figura 6.4.

Figura 5.24 Aceptación del uso de las TIC en el tiempo escolar

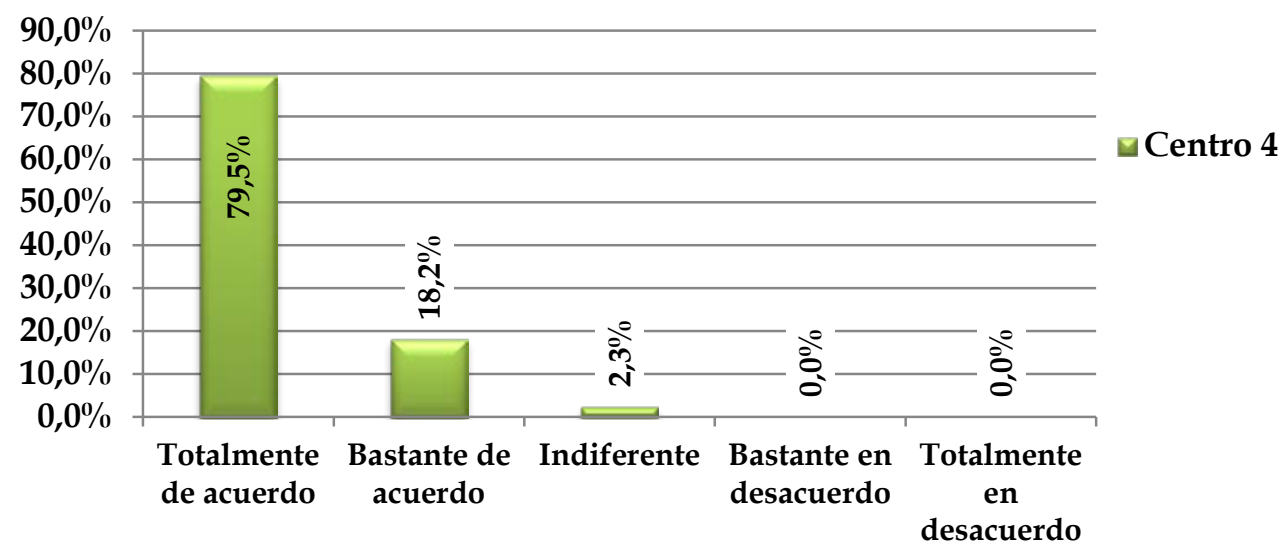




\section{Centro 5}

Contexto socio-económico y socio-cultural.

El centro 5 está situado en una localidad de menos de 2000 habitantes, a unos $30 \mathrm{~km}$ de la capital de la provincia. La actividad económica del pueblo es mayoritariamente agrícola y ganadera y en menor medida la construcción. Predomina el trabajador por cuenta ajena en el propio pueblo o en otras zonas cercanas de la provincia.

La lejanía con la localidad en la que se encuentra el CITA hace que las visitas no sean frecuentes. En cuanto a las familias y el nivel de estudios que predomina, tanto de padres como de madres, es el de graduado escolar, aunque otros niveles tienen también porcentajes apreciables (Figura 6.25)

Figura 6.25 Nivel de estudios de los padres

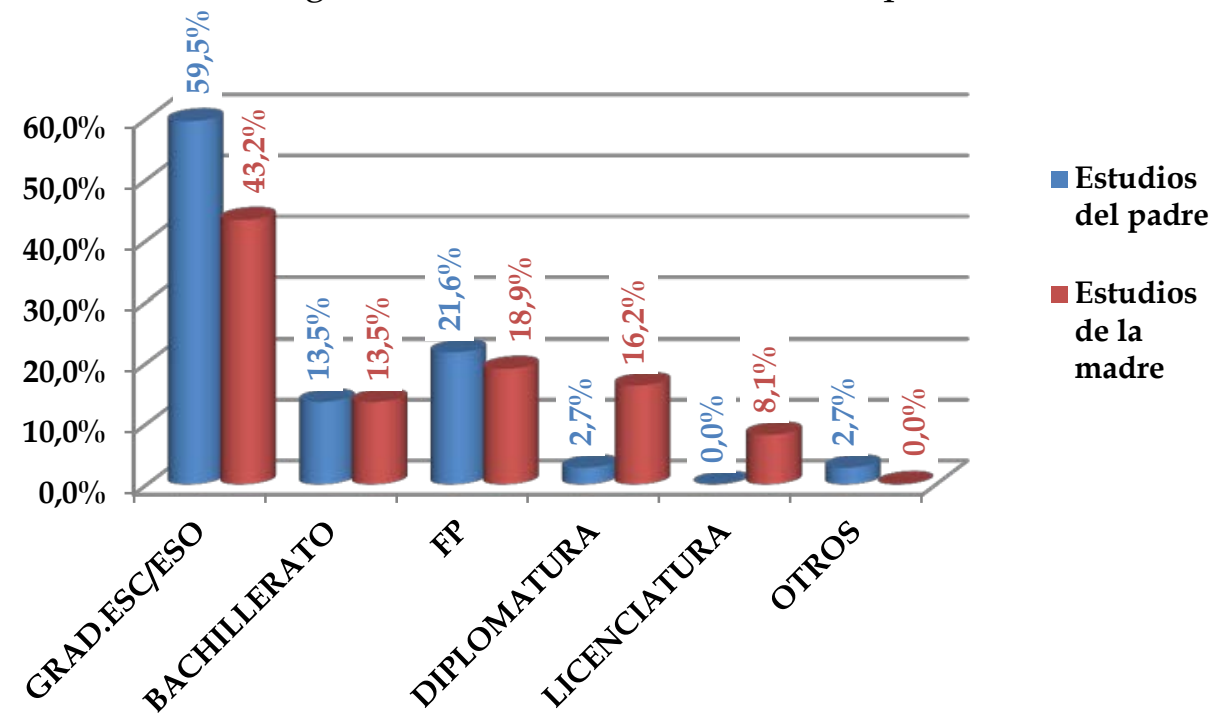

El centro es de carácter público, contando con las etapas de Educación Infantil y Educación Primaria, esta segunda de carácter obligatorio.

\section{Estructura organizativa y alumnado}

El centro acoge a alumnos de la etapa de Educación Infantil y Primaria, por tanto, de edades comprendidas entre lo 3 y los 12 años (Tabla 6.9). 


\begin{tabular}{|c|c|c|c|c|c|c|c|c|c|c|c|c|c|}
\hline & \multicolumn{3}{|c|}{$\begin{array}{c}\text { Educación } \\
\text { Infantil }\end{array}$} & \multicolumn{6}{|c|}{$\begin{array}{c}\text { Educación } \\
\text { Primaria }\end{array}$} & \multicolumn{4}{|c|}{$\begin{array}{l}\text { Educación } \\
\text { Secundaria }\end{array}$} \\
\hline & $\begin{array}{c}3 \\
\text { años }\end{array}$ & $\begin{array}{c}4 \\
\text { años }\end{array}$ & $\begin{array}{c}5 \\
\text { años }\end{array}$ & $1^{o}$ & $2^{\circ}$ & $3^{\circ}$ & $4^{o}$ & $5^{0}$ & $6^{0}$ & $1^{0}$ & $2^{o}$ & $3^{0}$ & $4^{o}$ \\
\hline Centro 5 & $\checkmark$ & $\sqrt{ }$ & $\checkmark$ & $\checkmark$ & $\sqrt{ }$ & $\checkmark$ & $\checkmark$ & $\checkmark$ & $\checkmark$ & $x$ & $x$ & $x$ & $x$ \\
\hline
\end{tabular}

Tabla 6.9 Niveles educativos en el centro 5

Por el número de alumnos que presenta en la etapa de Educación Infantil mantiene hasta el momento un curso por año. Pero al igual que ocurre con otros centros, la dependencia del crecimiento demográfico o la inmigración a la zona hace que esta circunstancia se pueda ver sujeta a modificaciones (Tabla 6.10).

\section{Curso académico}

2009-2010 2010-2011 2011-2012 2012-2013

\begin{tabular}{lcccc}
\hline $\mathrm{N}^{\mathrm{o}}$ alumnos E.I. 3 años & 9 & 7 & 13 & 16 \\
\hline $\mathrm{N}^{\mathrm{o}}$ alumnos E.I. 4 años & 17 & 9 & 7 & 13 \\
\hline $\mathrm{N}^{\mathrm{o}}$ alumnos E.I. 5 años & 16 & 17 & 10 & 7 \\
\hline $\begin{array}{l}\mathrm{N}^{\circ} \text { de alumnos en todos lo } \\
\text { centros y etapas }\end{array}$ & 109 & 107 & 112 & 112 \\
\hline
\end{tabular}

Tabla $6.10 \mathrm{~N}^{\mathrm{o}}$ de alumnos en el centro 5 y en la etapa de Educación Infantil.

Las aulas se reparten entre dos edificios. En el Edificio 1 se ubican las aulas específicas junto con todas las aulas ordinarias de primaria y 1 de infantil en uno de ellos. En el Edificio 2 cuenta con 2 aulas destinadas exclusivamente al alumnado de infantil en las que se encuentran los 2 primeros cursos del ciclo. También cuentan con patios diferenciados para la etapa de primaria y la de

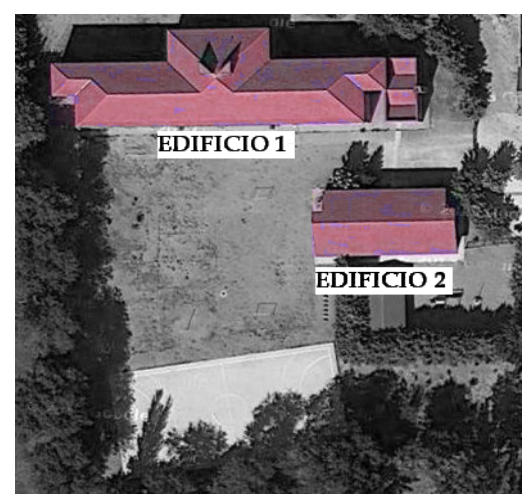


infantil.

Aulas y dotación de recursos TIC.

El centro está dotado de diversas aulas específicas y aulas ordinarias. Dentro de las ordinarias 6 corresponden a primaria y 3 a infantil. La dotación de recursos TIC en estas aulas es de 5 ordenadores en Infantil, de los cuales 3 son del proyecto del Rincón del Ratón, y en las aulas de primaria 3 ordenadores más. A esto hay que sumar 17 ordenadores en el aula de informática y 1 en otros espacios, por lo que hay un total de 26 ordenadores en el centro. En cuanto a las PDI, encontramos 3 pizarras, 2 de ellas en primaria y otra en otro espacio del centro. A lo largo del periodo de la investigación se añadió -que tengamos constancia- 1 PDI más en una de las aulas de infantil.

\section{Actitud hacia las TIC}

No contamos con datos que puedan permitir valorar una actitud del centro hacia las TIC concreta. No aparece ninguna referencia directa a proyecto de innovación relacionado con las TIC. El único dato que se obtuvo es que cuentan con liberación de horas para uno de los docentes para que se encargue de la supervisión de los recursos tecnológicos.

\section{Profesorado y TIC}

La plantilla de profesorado consta de 12 profesores, 11 de ellos con plaza fija y 1 de ellos está en expectativa de destino. En el caso concreto de la etapa de Educación Infantil, la totalidad de los profesores tienen plaza definitiva en el centro.

Según los datos del equipo directivo, los docentes sí usan las TIC tanto para sesiones puntuales como para hacer que el alumnado trabaje frecuentemente con dichos recursos.

\section{Familia y TIC}

Las familias disponen de un equipamiento en la línea de la tendencia general de los centros que hemos visto hasta ahora. Todos tienen TDT y móvil y un porcentaje cercano al $80 \%$ cuenta con ordenador en el hogar. La 
combinación entre disponibilidad de recurso en el hogar y el uso de los niños varía dependiendo del tipo de recurso (Figura 6.26)

Figura 6.26 Disponibilidad en el hogar y uso de los hijos de los recursos TIC

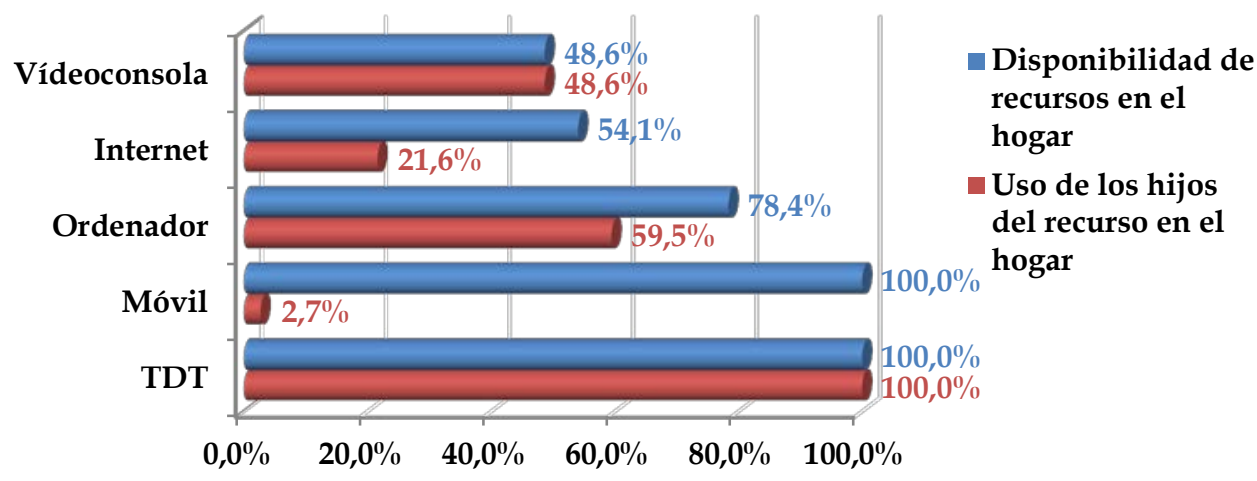

Cuando preguntamos a los padres por el uso que hacen ellos de los recursos TIC aluden mayoritariamente al ocio, seguido del informativo, laboral y formativo respectivamente (Figura 6.27).

Figura 6.27 Uso de los recursos TIC por los padres

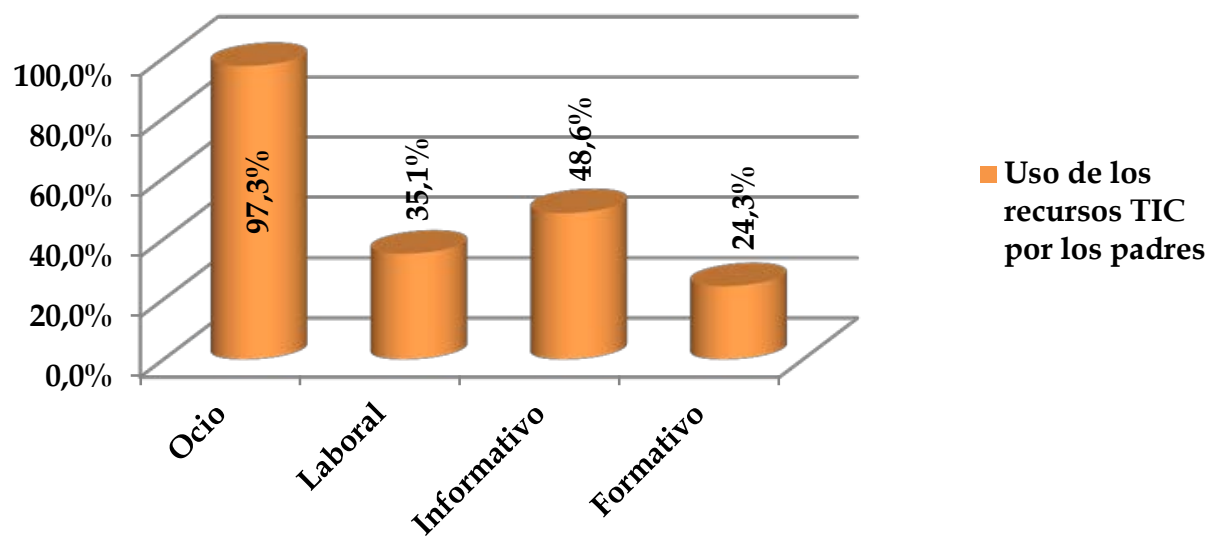

En relación con el uso que hacen los hijos, cuando responden los padres ante la pregunta de con quién usa el niño los recursos en casa, un porcentaje superior al $80 \%$ responde que con los padres, siendo muy superior al uso 
individual y con hermanos que está aproximadamente en el 20\% (Figura 6.28). $\mathrm{Si}$ además intentamos saber si ponen límites a ese uso, en torno al $70 \%$ responden de forma afirmativa y cerca del 30\% no lo hacen (Figura 6.29).

Figura 6.28 Quién acompaña al niño cuando usa el recurso TIC

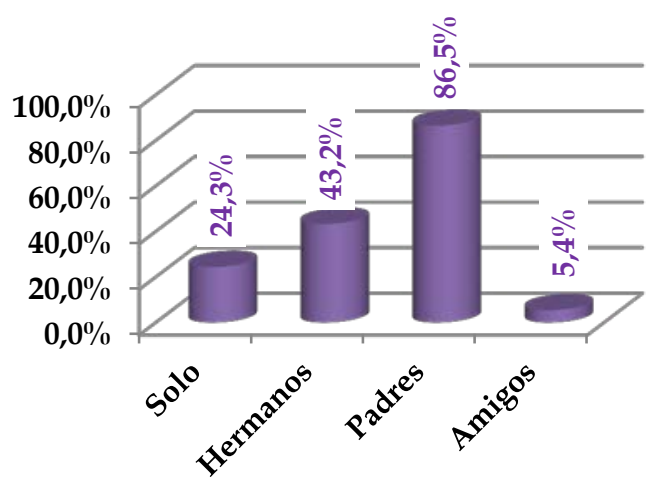

Figura 6.29 Límite en el uso de los recursos

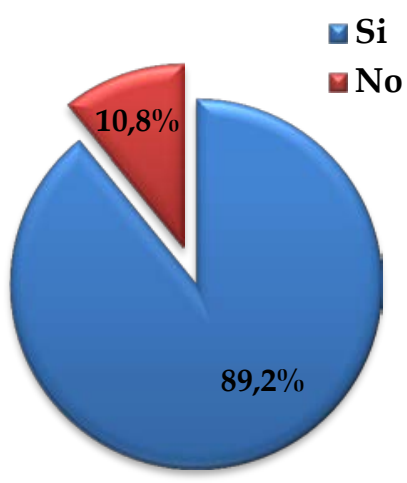

Si atendemos a la aceptación que muestran los padres de los niños ante el uso de recursos TIC dentro del horario escolar, vemos que se muestran en su totalidad con una actitud favorable ante ello (Figura 6.30).

Figura 6.30 Aceptación del uso de las TIC en el tiempo escolar

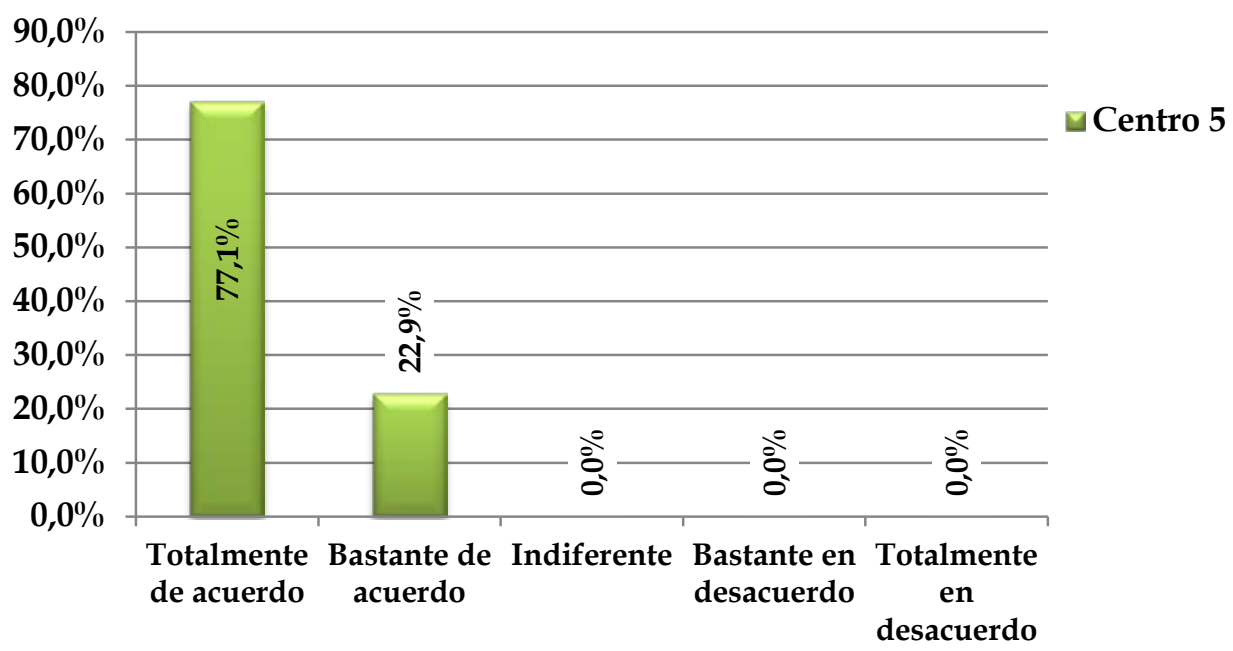




\section{Centro 6}

Contexto socio-económico y socio-cultural.

El centro 6, al igual que ocurría con el centro 1, abarca diferentes localidades, concretamente 4 . La cabecera dista de la capital de provincia $56 \mathrm{~km}$. y se sitúa en una localidad que supera en poco los 1000 habitantes. El resto son localidades de menos de 500 habitantes. La actividad económica en la zona es predominantemente la agricultura y la ganadería, que como hemos podido ver es la predominante en todos los centros de la investigación.

Desde un punto de vista socio-cultural, el pueblo donde se encuentra la cabecera cuenta con biblioteca, para el resto de actividades culturales es la diputación quien se encarga de esas gestiones. El CITA y la Fundación están alejados de estas localidades lo que dificulta el acceso al igual que ocurre con el centro 5. Si analizamos el nivel de estudios de los padres del alumnado de infantil observamos que el nivel de formación se reparte entre graduado escolar y formación profesional, con los mismos porcentajes en padres y madres (Figura 6.31).

Figura 6.31 Nivel de estudios de los padres

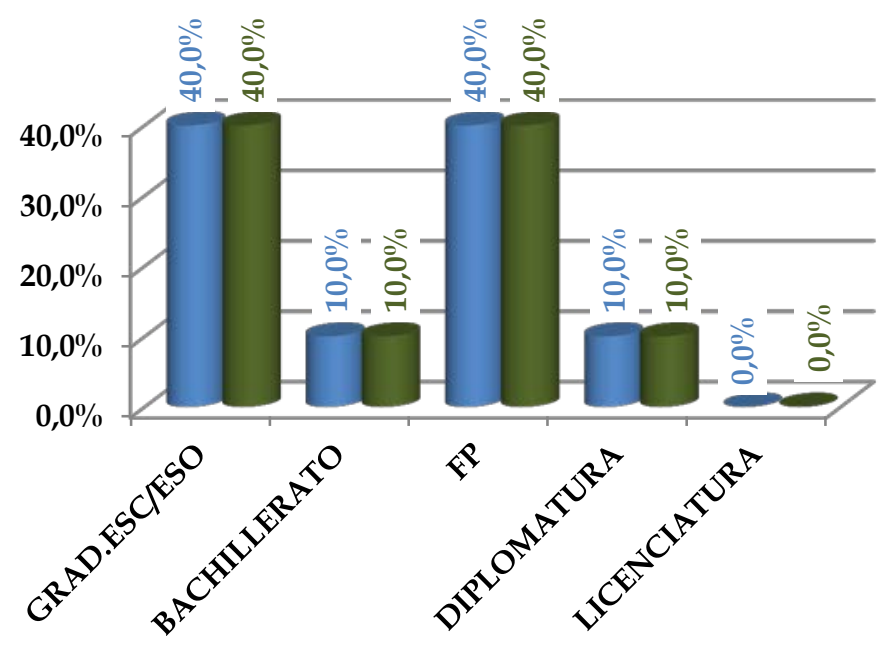
Estudios del padre
Estudios de la madre

Tipología

Se trata de un Centro Rural Agrupado (CRA) de carácter público y cuya financiación depende de la Junta de Castilla y León. Esto hace que exista una cabecera y tres centros dependientes de ella. 


\section{Estructura organizativa y alumnado}

El centro abarca desde $2^{\circ}$ ciclo de EI ( 3 años), hasta $6^{\circ}$ curso de primaria (12 años) en todos los centros de las localidades, y es en la cabecera donde cuenta además con el primer ciclo de ESO aunque en el curso 2012/2013 se dejó de impartir en el centro ese ciclo de la etapa de secundaria.

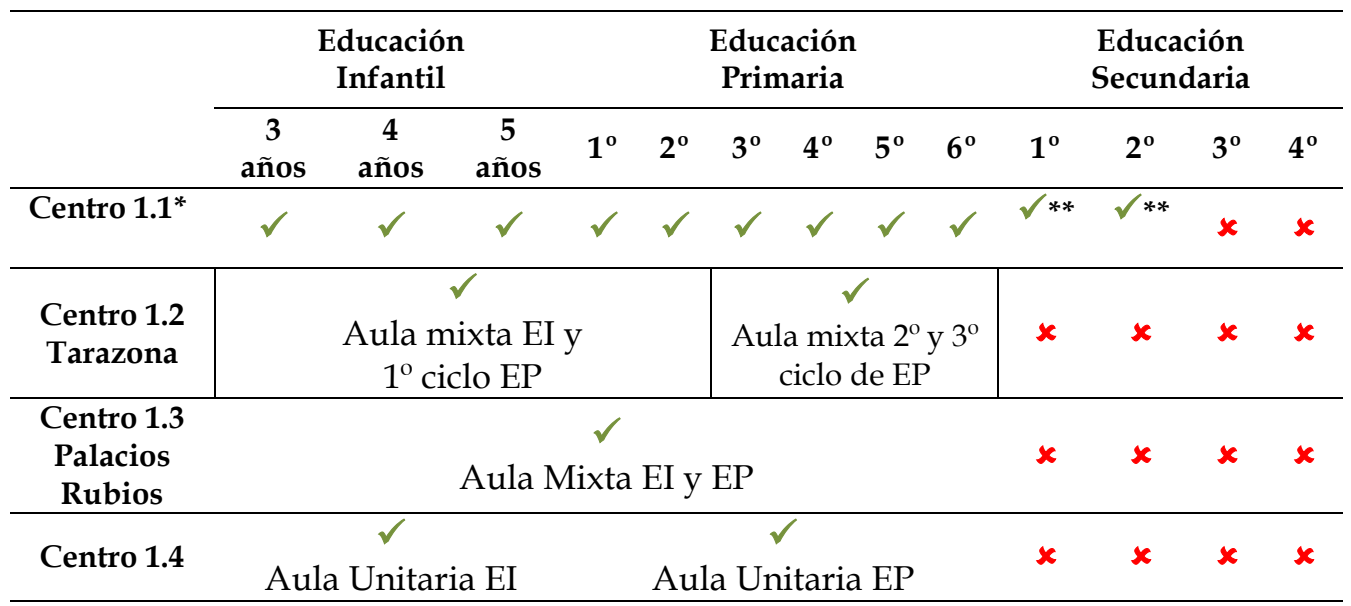

Tabla 6.11 niveles educativos en el centro 1 por localidades

*El centro 1.1 corresponde a la cabecera del centro.

${ }^{* *}$ Cursos que desaparecen del centro 1.1 en el curso 2012-2013

Los edificios se organizan de diferente forma dependiendo de la localidad, teniendo el centro de la cabecera dos edificios, uno de ellos, el edificio 2, destinado a Educación Infantil en el año en el que empezó la investigación (2009) y pasando en el año 2011 a ser gimnasio, quedando en el edificio 1 concentradas todas las aulas que recogerían desde 3 años en Infantil hasta los 14 de $2^{\circ}$ de ESO.

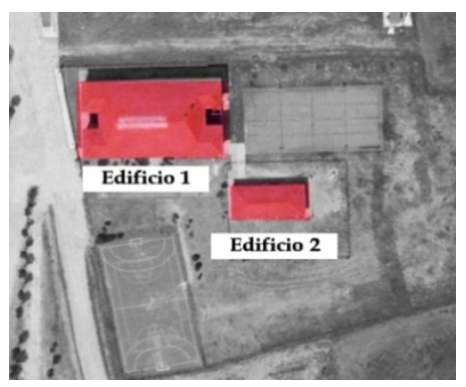

Las agrupaciones de los cursos varían en cada localidad con diferentes combinaciones que en función de los centros y el número de alumnos suponen 
cambios en la distribución de las aulas. Los datos de los alumnos en el centro aparecen recogidos en la Tabla 6.12:

\begin{tabular}{ccccc}
\hline Curso académico & 2009-2010 & 2010-2011 & 2011-2012 & 2012-2013 \\
\hline $\begin{array}{c}\text { Centro 1.1 } \\
\mathbf{N}^{\mathbf{0}} \text { alumnos E.I. }\end{array}$ & 11 & 17 & 22 & 33 \\
\hline $\begin{array}{c}\text { Centro 1.2 } \\
\mathbf{N}^{\mathbf{0}} \text { alumnos E.I. }\end{array}$ & 1 & 1 & 1 & 1 \\
\hline $\begin{array}{c}\text { Centro 1.3 } \\
\mathbf{N}^{\mathbf{0}} \text { alumnos E.I. }\end{array}$ & 5 & 4 & 2 & 2 \\
\hline $\begin{array}{c}\text { Centro 1.4 } \\
\mathbf{N}^{0} \text { alumnos E.I. }\end{array}$ & 4 & 3 & 3 & 2 \\
\hline $\begin{array}{c}\mathbf{N}^{0} \text { de alumnos total en } \\
\text { centros y etapas * }\end{array}$ & - & - & - & 79 \\
\hline
\end{tabular}

Tabla $6.12 \mathrm{~N}^{\circ}$ de alumnos en el centro 1 y en la etapa de Educación Infantil.

*No se han podido obtener los datos totales del 2009-2010 al 2011-2012

Aulas y dotación de recursos TIC.

En el caso de la cabecera, Educación Primaria y el primer ciclo de ESO disponen de un aula para cada ciclo, es decir, 3 aulas para primaria y 1 para secundaria en las que se agrupan 2 cursos. Para Educación Infantil hay 2 aulas para los 3 cursos. En el resto de centros hay diferentes distribuciones de aulas configurándose tal y como aparece en la Tabla 6.11 y siempre dependiendo de los nuevos alumnos que entren en el centro.

Con respecto a la cabecera del CRA, cuenta con aulas ordinarias, de informática, biblioteca, gimnasio,... La dotación de recursos es bastante limitada. Tienen sólo ordenadores en las aulas ordinarias de infantil, 1 que se suma a los dos que aporta el proyecto. A esta dotación hay que añadir los equipos del aula de informática que además cuenta con la única PDI del centro. En otros espacios que no son de acceso a los alumnos también se dispone de equipos informáticos.

Pese a que el número de recursos no es muy amplio, es posible la conexión a Internet en todos aquellos espacios donde hay un equipo informático, tanto en las aulas ordinarias como en las específicas.

Actitud hacia las TIC

Aunque algunos de los profesores pueden usarlas en sus clases, el centro no se caracteriza por trabajar en proyectos de innovación en cuanto al 
uso de las TIC, ni tampoco por aportar una formación específica para el profesorado. Sin embargo, sí cuentan con liberación de horas para quien se encarga del mantenimiento de los equipos en el centro y en este caso no tienen contratada ninguna empresa que solvente los problemas que puedan surgir en los recursos tecnológicos.

Profesorado y TIC

La plantilla de 12 profesores se compone de 9 profesionales con plaza definitiva. También tiene 2 que se encuentran en interinidad, otro en expectativa de destino y por último 1 en prácticas. Este profesorado está compuesto por diferentes especialistas de los que algunos imparten docencia en varios de los cuatro centros que integran el CRA.

Familia y TIC

Analizando los datos de los cuestionarios de las familias, se pone de relieve que la dotación tecnológica es bastante buena, contando con TDT y teléfono móvil y ordenador en casi la totalidad de los hogares. Más reducida aunque por encima del $50 \%$ es la conexión a Internet en casa. El porcentaje más bajo es para las videoconsolas que se sitúa en un $30 \%$. En cuanto al uso en relación con la dotación con la que cuentan en su hogar se refleja de forma clara en la Figura 6.32:

Figura 6.32 Disponibilidad y uso de recursos en el hogar

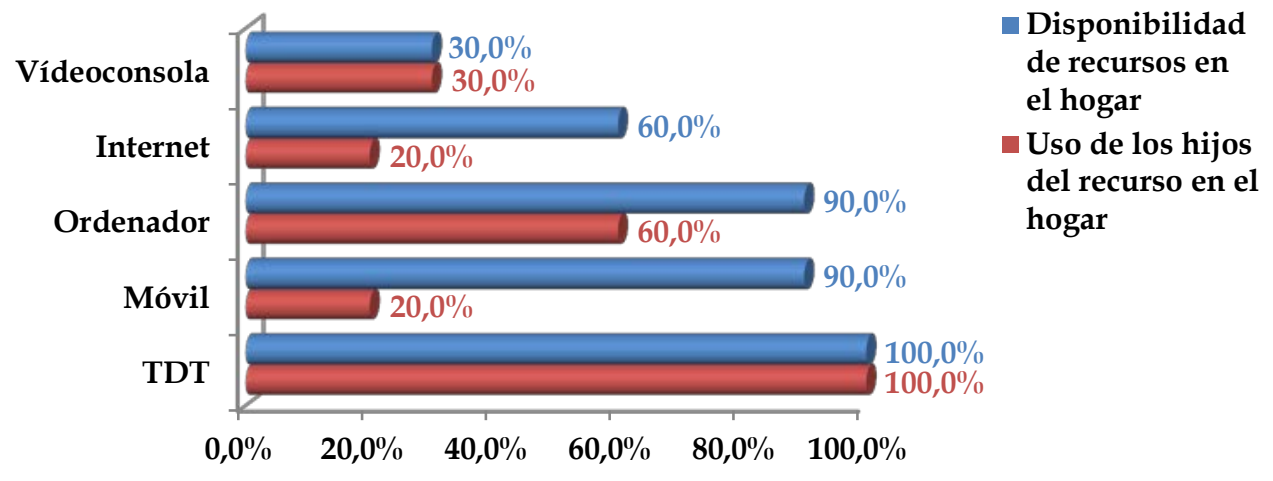

Observando los datos que nos ofrecen en relación con los ámbitos de uso de los recursos tecnológicos del hogar predomina, al igual que en todos los centros anteriores, el uso para el ocio. Sin embargo, en este caso concreto el ámbito informativo se iguala al del ocio. Menos importante es el uso laboral y 
por último, tal y como también es tendencia general entre los centros, el uso formativo (Figura 6.33).

Figura 6.33 Uso de los recursos TIC por los padres

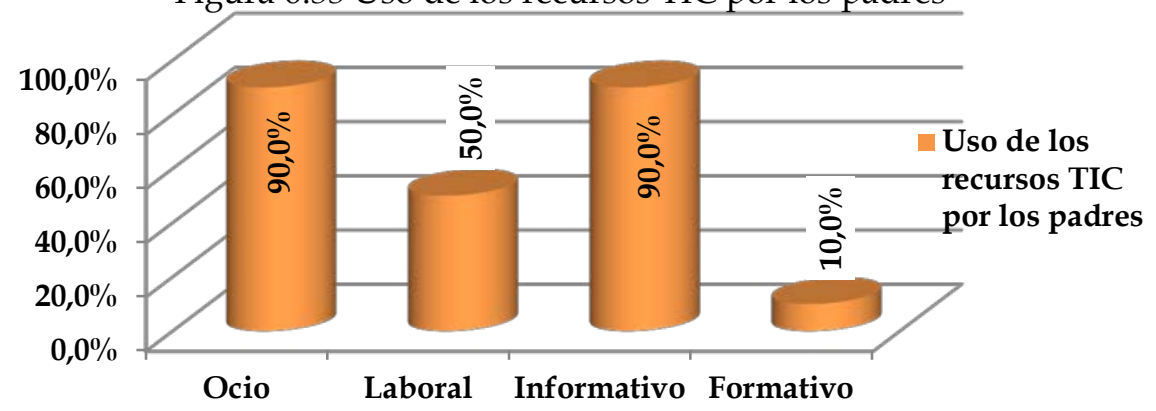

La totalidad del alumnado usa los recursos TIC con los padres, aunque también se acompaña de los amigos, hermanos o en solitario (Figura 6.34). Además de usarlo con supervisión de los padres, también estos en la mayoría de los casos establecen límites en el uso de los recursos dentro del ámbito familiar (Figura 6.35).

Figura 6.34 Quién acompaña al niño cuando usa el recurso TIC

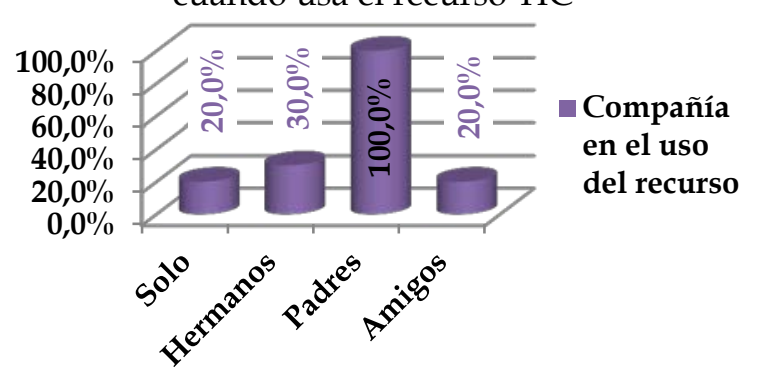

Figura 6.36 Límite en el

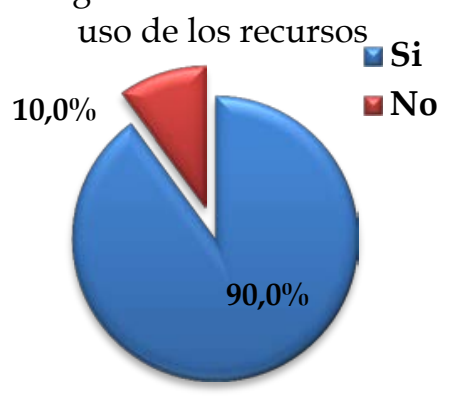

Finalmente, la aceptación del uso del recurso durante el tiempo escolar es muy positiva, ya que todos los padres o están de acuerdo o totalmente de acuerdo en dicho uso en tiempo escolar (Figura 6.36).

Figura 6.36 Aceptación del uso de las TIC en el tiempo escolar

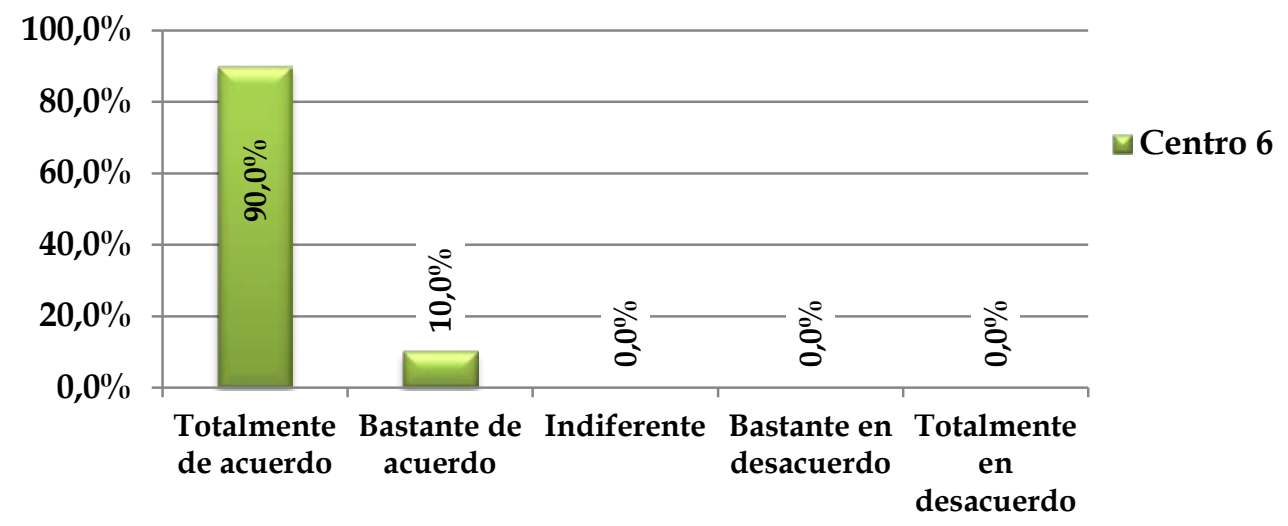




\subsubsection{Datos comparativos: Centros.}

Para facilitar una visión conjunta de los centros, trataremos de destacar aquellos aspectos que puedan ser sintetizados y comparados para el conjunto de los centros. Así, los seis centros descritos hasta ahora se encuentran dentro del ámbito rural, aunque hayamos podido encontrar diferencias en cuanto a la tipología y al número de habitantes de las localidades (Figura 6.37).

Figura 6.37 Número de habitantes en las localidades

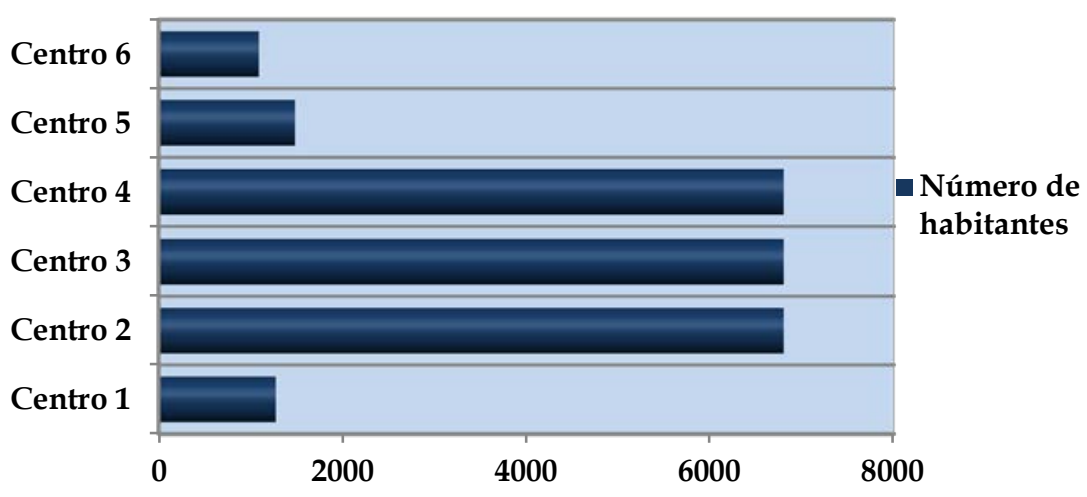

La totalidad de los centros cuentan con las etapas comprendidas entre segundo ciclo de infantil y primaria y la mitad de ellos tienen además cursos de la etapa de ESO (Figura 6.38).

Figura 6.38 Curso máximo impartido en los centros

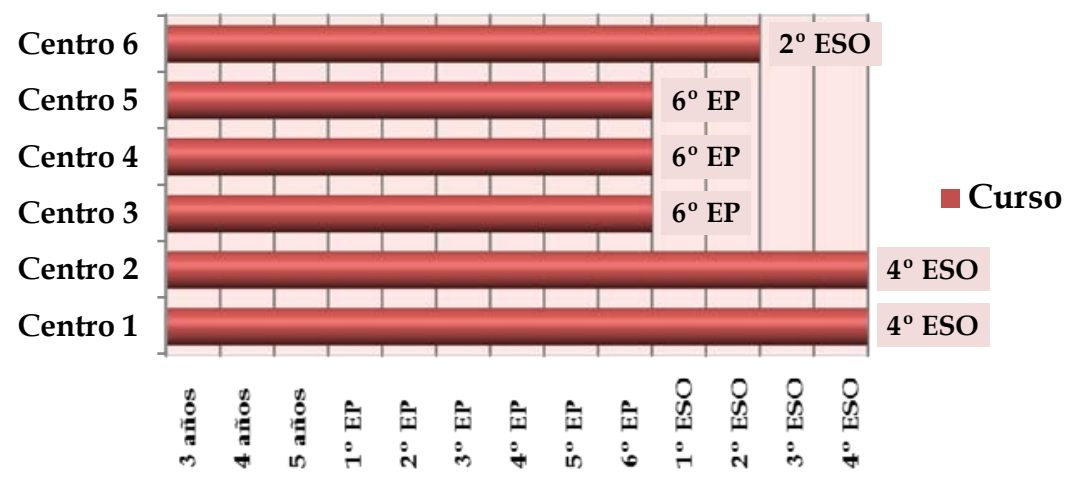

Todos ellos tienen contacto con el CITA en cuanto al proyecto del Rincón del Ratón, aunque la distancia geográfica hace que la relación en otros aspectos no sea equivalente, es decir, aquellos centros que están en la misma localidad o muy próximos al centro - centro 1, 2, 3, y 4- disponen de mayor 
acceso a otros proyectos o programas sobre recursos TIC de los que oferta el CITA.

En conjunto las dotaciones de recursos de los centros difieren tanto en número como en organización, pero en el caso de las aulas de EI está homogeneizadas por la intervención del proyecto del CITA "El Rincón del Ratón", puesto que allí donde se implanta se dota al aula de un pupitre tecnológico adaptado y del software correspondiente en cada uno de ellos. Además, durante los tres años que duró la investigación, los centros contaron con un asesor tecnológico que ponía el CITA al servicio de las aulas que participaban en el "Rincón del Ratón".

Si analizamos dentro de los centros los datos ofrecidos por las familias del alumnado de infantil, predomina un nivel de estudios de graduado escolar tanto para hombres como para mujeres, pero estas últimas cuentan en conjunto con un nivel más alto de estudios (Figura 6.39).

Figura 6.39 Nivel de estudios de los padres de los alumnos de EI en el conjunto de los centros

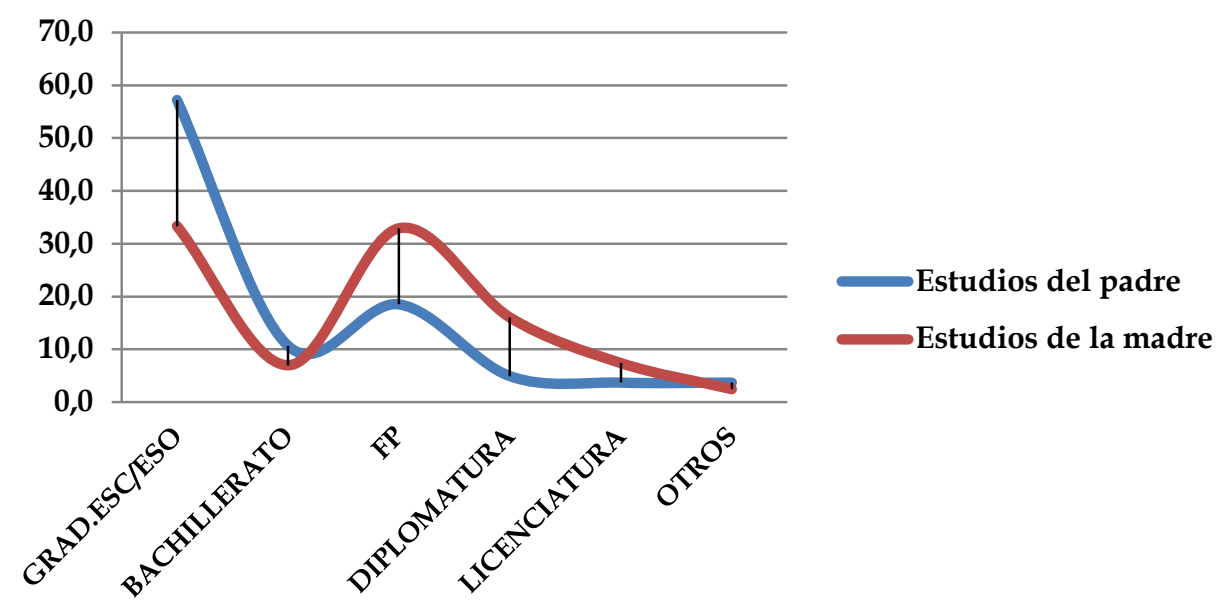

El entorno familiar dispone de tecnologías similares a la que aparece en las escuelas, es decir, los ordenadores $(82,6 \%)$ con conexión a Internet en algunos casos (57\%). Pero además, entran en juego otros aparatos tecnológicos como pueden ser la TDT (100\%), los móviles (98,3\%) o las videoconsolas (38\%), lo cuales también son usados por los niños en sus casas. Cuando preguntamos a los padres por el uso que hacen de los recursos TIC en los hogares nos indican que de forma mayoritaria está enfocado al ocio $(94,2 \%)$, aunque otros ámbitos 
como el informativo (53,3\%), el laboral $(42,1 \%)$ o el formativo $(22,7 \%)$ también tienen cabida en el seno familiar.

Por ultimo, el entorno familiar de los centros es muy semejante en cuanto a la aceptación del uso de las TIC en el horario escolar, no encontramos ningún caso en el que se esté bastante en desacuerdo o totalmente en desacuerdo y la mayoría están de acuerdo ya sea bastante o totalmente (Figura 6.40).

Figura 6.40 A ceptación del uso de TIC en el horario escolar

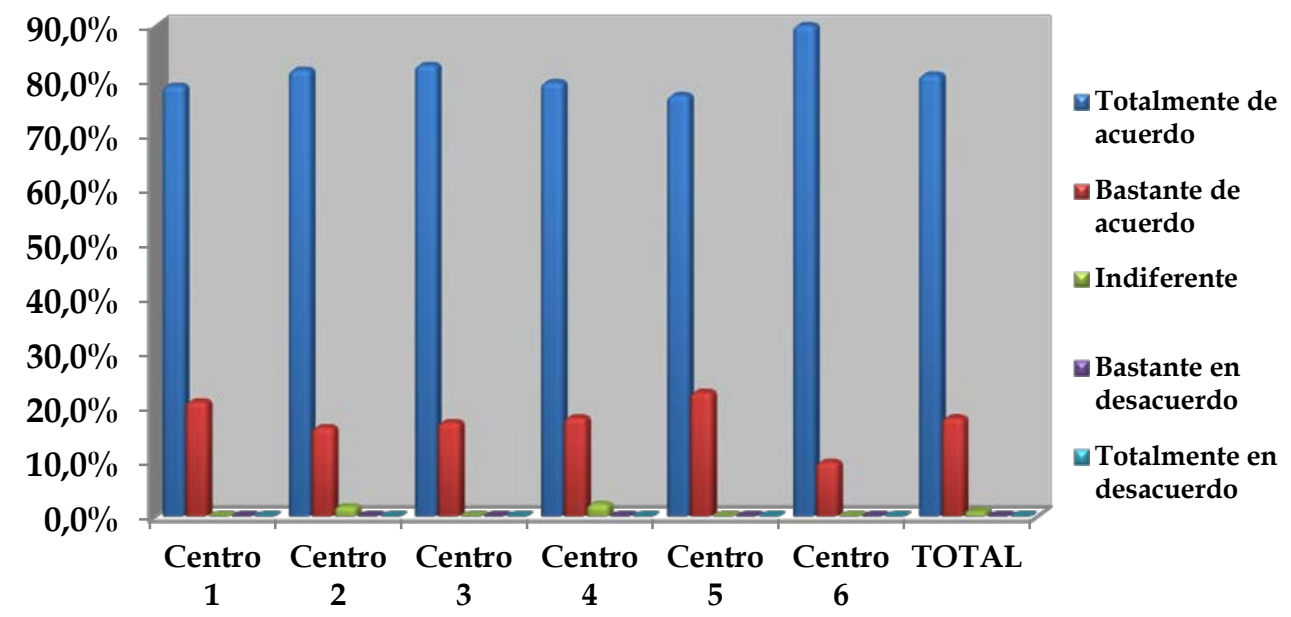

Estos datos nos muestran que en su conjunto, hay rasgos comunes entre los centros de la investigación y el contexto socio-familiar de los alumnos que participan. Si bien somos conscientes que internamente existen elementos particulares diferenciadores en cada uno de los casos.

\subsubsection{Participantes}

Si hasta ahora hemos comentado las características de los centros y de las familias de los alumnos de EI, en este apartado nos centraremos en el profesorado tratando de describir los rasgos característicos de cada uno de ellos, ya que son las prácticas de estos profesores los pilares sobre los que se centra cada uno de los casos del estudio de la integración de las TIC en el aula. 
Contamos con un total de 11 docentes de los que hemos recogido grabaciones de sus prácticas de aula. Todos ellos participaban, como ya hemos mencionado con anterioridad, en el proyecto de "El Rincón de Ratón" promovido por el CITA y perteneciente al programa KidSmart de IBM. Para determinar algunos aspectos de su perfil como docente, mostramos a continuación una serie de datos en relación con su carrera profesional como maestros y su formación y participación en iniciativas vinculadas con las TIC.

Los datos que aportamos se recogieron en una entrevista inicial que fue contestada por cada profesor en el momento en que se incorpora al proyecto de "El Rincón del Ratón", por lo que podemos encontrar diferencias en uno a dos años en los momentos que cada profesor rellena la entrevista inicial. A ésta hay que sumar en algunos casos otra entrevista final en la que hemos tratado de recoger la evolución que han tenido durante los tres años que ha durado la investigación, lógicamente esto ha afectado a aquellos docentes que han participado durante todo el periodo de investigación.

\section{Profesora 1}

La profesora 1 cuenta con una experiencia docente de 5 años, tan sólo tenía un año de antigüedad en el centro 1 en el momento en que empezó la investigación, aunque al tratarse de su centro definitivo de destino hemos tenido la opción de grabarla durante dos años (Tabla 6.13).

\begin{tabular}{cccc}
\hline & $2009-2010$ & $2010-2011$ & $2011-2012$ \\
\hline $1^{\circ}$ EI & - & - & - \\
\hline $2^{\circ}$ EI & - & - & - \\
\hline $3^{\circ}$ EI & - & $\checkmark$ & - \\
\hline Aula unitaria & $\checkmark$ & - & - \\
\hline
\end{tabular}

Tabla 6.13 Cursos impartidos en cada año durante la investigación

El centro 1 se enmarca, como ya hemos mencionado, dentro de los denominados CRA, lo que hace que la movilidad del profesorado entre los centros de las diferentes localidades es bastante común. En el caso de la profesora 1 ha permanecido durante el primer año de la investigación en un aula unitaria de la etapa de EI del centro 1.2 y el segundo año en el centro 1.1 - 
la cabecera- donde impartía en una clase graduada con alumnos de 5 años que compaginaba con cargos de gestión.

No había participado en el proyecto de "El Rincón del Ratón", y era la primera vez que trabaja con el pupitre y los programas que KidSmart y el CITA facilitan con el recurso. Sin embargo, muestra una actitud favorable a la participación en el proyecto, ya que cuando se le pregunta por la motivación que le ha llevado a participar en él dice: "Cuando me lo presentaron me pareció un proyecto muy atractivo para los niños". Y ve las TIC como "un apoyo muy bueno a la hora de mejorar el proceso de enseñanza aprendizaje..." para su clase.

En relación con las TIC y la formación recibida para la puesta en marcha del proyecto, valora de forma positiva su formación previa con estas tecnologías: "Creo que mi formación en TIC es bastante buena o por lo menos aceptable para el uso que doy dentro del aula". Dentro del proyecto no ha recibido ninguna formación concreta por parte de los técnicos de CITA y en cuanto a la información que le dieron la ve "escasa, ya que me presentaron el proyecto, (¿en qué consistía), pusieron el ordenador pero ni siquiera lo encendieron". La formación actual relacionada con las TIC la hace de forma voluntaria y comentaba que "este curso estoy realizando una formación en pizarras digitales".

Vista las motivaciones y la formación, cuando se le pregunta sobre el uso del recurso en relación con el curriculum de la etapa, marca objetivos de conocimiento del recurso, habilidades básicas de manejo del recurso, realización de múltiples tareas y para fomentar la autoestima a través del trabajo autónomo en el ordenador. Los contenidos relacionados con el recurso "no he seguido ningún criterio para la selección de los programas, ya vienen instalados en el ordenador" aunque sí tiene "un criterio a la hora de trabajar con los niños de las tres edades esos programas". Y lo utiliza para "reforzar ciertos aprendizajes" dentro de lo que denomina "juego por rincones".

El trabajo con este tipo de recursos TIC lo ve muy motivador y flexible ya que permite trabajar "de manera individual... por parejas... colectivamente". Y en su caso la introducción del recurso en el aula no le supone "mucho esfuerzo, todo lo contrario, satisfacción de ver que los niños están aprendiendo y les está gustando". Tampoco afecta a su forma habitual de evaluar en el aula. 


\section{Profesora 2}

La profesora 2 cuenta con una experiencia docente de 25 años, de los que 18 de ellos ha sido en el centro 2, que al tratarse de un colegio concertado no cuenta con un sistema de concurso de traslados que facilite la movilidad de una forma tan regulada y frecuente como en el ámbito público. Cuenta con plaza definitiva en el centro e imparte a diferentes cursos a lo largo de la investigación (Tabla 6.14).

\begin{tabular}{cccc}
\hline & $2009-2010$ & $2010-2011$ & $2011-2012$ \\
\hline $1^{\circ}$ EI & - & - & $\checkmark$ \\
\hline $2^{\circ}$ EI & $\checkmark$ & - & - \\
\hline $3^{\circ}$ EI & - & $\checkmark$ & - \\
\hline Aula unitaria & - & - & - \\
\hline
\end{tabular}

Tabla 6.14 Cursos impartidos en cada año durante la investigación

Cuando comenzó la investigación era el primer año en el que contaba con el recurso en el aula, por lo que no había tenido experiencia previa con él. Pero cuando le preguntamos por los motivos que la animaron a participar en el proyecto menciona: "tengo una buena motivación hacia las TIC" lo que la sitúan en una actitud favorable ante la integración del recurso dentro del aula.

La formación previa que tiene en TIC la considera adecuada, "puedo trabajar y crear actividades con los programas que el CITA nos ha dado y hacer mis programaciones". Además valora de forma muy positiva tanto la información, "muy buena por parte de los profesionales del CITA", como la formación, "siempre facilitan las búsquedas que orientan el trabajo con las TIC y que ayudan". Cuenta con el apoyo del equipo directivo y de los compañeros para la introducción de "El Rincón del Ratón” en el aula.

En relación con el ámbito curricular su objetivo principal es "que los alumnos vean y utilicen las TIC como una herramienta más para sus tareas". Considera que desde estos recursos TIC sí se pueden trabajar los contenidos de las tres áreas curriculares a través de los programas. Trabaja de forma similar con el recurso a como lo hace con otras actividades como trabajo en gran grupo y por parejas "esta técnica no es nueva y en la asamblea también la usamos". 
Para el uso del recurso dentro de la organización concreta del aula comenta que "el profesor necesitaría ayuda por parte de otra persona para llegar a atender a más alumnos" y lo valora como algo que mejora contenidos, secuenciación y otros aspectos en función de los programas que se utilicen. El esfuerzo de introducirla es gratificante "no es un trabajo, porque me gusta, pero sí deben prepararse para establecer lo que quiere tratar y cómo cada día". En cuanto a la evaluación no modifica pero "sí amplia, pues ellos aprenden más rápido y hay que ofrecer más contenidos y más actividades".

\section{Profesor 3}

El profesor 3 cuenta con 10 años de experiencia docente y se acaba de incorporar al centro 3, se encuentra en expectativa de destino por lo que su paso por el centro fue durante el curso 2009-2010, obteniendo sólo datos de ese año para la investigación. El curso en el que estaba era $1^{\circ}$ de EI, con alumnos de 3 años (Tabla 6.15).

\begin{tabular}{cccc}
\hline & $2009-2010$ & $2010-2011$ & 2011-2012 \\
\hline $1^{\circ}$ EI & $\checkmark$ & - & - \\
\hline $2^{\circ}$ EI & - & - & - \\
\hline $3^{\circ}$ EI & - & - & - \\
\hline Aula unitaria & - & - & - \\
\hline
\end{tabular}

Tabla 6.15 Cursos impartidos en cada año durante la investigación

Al igual que las dos profesoras anteriores tampoco ha tenido experiencia previa en "El Rincón del Ratón", y cuando le preguntamos sobre la motivación que le ha hecho participar en el proyecto lo relaciona con "cooperar con las iniciativas del centro".

La formación previa que ha recibido la valora de una forma "muy positiva", y ha sido adquirida a través de "cursos de formación permanente del profesorado y mi trabajo personal". Sin embargo, la formación y la información recibida para la introducción de ese recurso en el aula han sido "nulas". Pese a ello, sí encuentra apoyos tanto por el equipo directivo como por los compañeros para su introducción en el aula "principalmente por parte del equipo directivo que facilitó el proceso". 
Desde el punto de vista curricular el profesor 3 pretende conseguir la integración en el aula, que los alumnos se familiaricen y usen el ordenador para trabajar conceptos. Los programas que trae los valora de forma cauta en cuanto a los contenidos ya que dice que "no conoce todos los programas del proyecto. El uso que le dan mis alumnos se limita al uso del ratón" aunque también matiza que "por ahora cumple las expectativas". Para las actividades del aula cuenta con el recurso como un herramienta que complementa las actividades de las unidades didácticas.

Entiende el recurso como algo motivante para los alumnos y que se nota mejoría en los resultados. Pero su integración supone "la creación de un nuevo rincón en el aula y la estructuración de tiempos", aunque no supone un esfuerzo mayor, porque comenta, "en mi experiencia docente es un elemento que siempre he utilizado". Además tampoco le supone en el momento en que realizamos la entrevista cambios en la forma de evaluar, pues los alumnos "se encuentran en la fase de manejo del ratón".

\section{Profesora 4}

La profesora 4 cuenta con 30 años de experiencia de los que los últimos 16 años han sido en el centro 3. Contamos con grabaciones durante los tres años y pasa por los tres cursos de la etapa (Tabla 6.16)

\begin{tabular}{cccc}
\hline & $2009-2010$ & $2010-2011$ & $2011-2012$ \\
\hline $1^{\circ}$ EI & - & - & $\checkmark$ \\
\hline $2^{\circ}$ EI & $\checkmark$ & - & - \\
\hline $3^{\circ}$ EI & - & $\checkmark$ & - \\
\hline Aula unitaria & - & - & - \\
\hline
\end{tabular}

Tabla 6.16 Cursos impartidos en cada año durante la investigación

$\mathrm{Al}$ contrario que los tres anteriores sí había tenido contacto con "El Rincón del Ratón" el año anterior. Por lo que cuando le preguntamos por las motivaciones que le llevan a participar en el proyecto nos dice: "que los niños y yo podamos hacer un seguimiento de la experiencia que iniciamos el curso pasado." Además ve las TIC como algo que refuerza el aprendizaje en los contenidos de lectoescritura y matemáticas. 
Considera que su formación previa en TIC es suficiente, pero también indica que a veces tiene carencias en las cuestiones de carácter más técnico de los recursos. La información recibida para la introducción del proyecto ha sido "a través de la dirección del colegio y del CITA". Y la formación relacionada con el recurso que se le ha proporcionado ha sido principalmente en aspectos técnicos de los programas y en contenidos del recurso sobre lectoescritura, lógico-matemática y música. Para los problemas técnicos con el recurso que reconoce que pueden presentarle dificultades, comenta que ha recibido apoyo del CITA. Mientras que para la introducción le han apoyado tanto compañeros como el equipo directivo.

Desde el punto de vista curricular, plantea objetivos como adquirir habilidad con el ratón, reforzar contenidos de las tres áreas y disfrutar de los programas a través de su utilización. En cuanto a los contenidos cuando le preguntamos sobre si se pueden trabajar todos los contenidos de las tres áreas curriculares expone que "sí, la mayoría" y sigue criterios "de menor a mayor complejidad" y "teniendo en cuenta los contenidos de las áreas" para la selección de los programas que va a usar, aunque aclara que el tener el recurso no cambia la forma de plantear las actividades, sino que más bien lo ve como una introducción a la actividad.

Considera que con el recurso los alumnos "se sienten protagonistas y disfrutan bastante, sobre todo en las de tipo lúdico y musical" y no le supone ni más esfuerzo su introducción, ni tampoco cambios organizativos en el aula. En referencia a la evaluación, si le preguntamos si le supone cambios nos contesta que "no, ya que nuestra evaluación es continua, individualizada [...] y globalizada. Además nuestros informes y boletines tienen determinados ítems para evaluar las TIC que coinciden plenamente con los objetivo propuestos".

\section{Profesora 5}

La profesora 5 cuenta con 20 años de experiencia docente y cuatro de antigüedad en el centro 3 . Han sido posibles grabaciones durante los 3 años de la investigación (Tabla 6.17). Además, compagina sus clases con cargos de gestión al igual que ocurría con la profesora 1. 


\begin{tabular}{cccc}
\hline & $2009-2010$ & $2010-2011$ & $2011-2012$ \\
\hline $1^{\circ}$ EI & - & - & - \\
\hline $2^{\circ}$ EI & - & $\checkmark$ & - \\
\hline $3^{\circ}$ EI & $\checkmark$ & - & $\checkmark$ \\
\hline Aula unitaria & - & - & - \\
\hline
\end{tabular}

Tabla 6.17 Cursos impartidos en cada año durante la investigación

Cuenta con experiencia en "El Rincón del Ratón”, y la motivación que la impulsó a participar en el proyecto son "la propuesta del CITA hace dos cursos" y "las posibilidades educativas de las TIC". Además ve el papel de las TIC como algo que favorece el proceso de enseñanza aprendizaje del alumnado, aumento del interés y la motivación de maestros y alumnos desde recursos atractivos e interactivos.

En cuanto a la formación previa en TIC ha realizado muchos cursos en diferentes modalidades por lo que considera que ha "adquirido un nivel medio". Y piensa que "es necesario un reciclaje constante sobre este tema debido a la continua evolución y progresión de las $\mathrm{TIC}^{\prime \prime}$. La información y la formación las valora muy positivamente desde el CITA, tanto a nivel de asesoramiento como formativo. Señala que el CITA aporta apoyo en caso de problemas técnicos siempre y cuando el centro no sea capaz de resolverlos previamente. Indica también que desde el colegio "una de la líneas prioritarias de acción es la generalización de las TIC en el aula”.

En el aspecto curricular, plantea como objetivo general "integrar las TIC en el proceso de enseñanza-aprendizaje de los alumnos/as", e indica que los contenidos los trabajan de forma global y sigue criterios de secuenciación de los programas propuestos y los ha relacionado por temas y contenidos que recoge en la unidad didáctica. Asimismo, indica que las TIC no implican el plantear las actividades de forma distinta, sino que al estar integradas "sería al contrario, tendría que plantear de forma diferente las actividades si no contara con estos recursos."

Ve estos recursos como muy motivadores para los niños e indica que mediante registros los alumnos pasan por todos los rincones, entre los que incluye la "pizarra digital" y "el rincón del ratón". En su caso sí supusieron cambios en la organización del aula, puesto que en un principio supuso "cambiar la infraestructura del aula", "distribuir los espacios según los recursos 
existentes" y "organizar los tiempos en función de la distribución de la clase". Y el esfuerzo añadido atendiendo a tres puntos: la necesidad de formación, la disponibilidad de recursos y la puesta en práctica y la evaluación continua. Con relación a este último indica que supone introducir en las programaciones todos los elementos, con los que se incluyen los relacionados con los recursos TIC.

\section{Profesora 6}

La profesora 6 lleva impartiendo clase desde hace 22 años, de los que los últimos 6 años han sido en el centro 4 . Se cuenta con grabaciones durante el primer curso (Tabla 6.18)

\begin{tabular}{cccc}
\hline & $2009-2010$ & $2010-2011$ & $2011-2012$ \\
\hline $1^{\circ} \mathrm{EI}$ & - & - & - \\
\hline $2^{\circ} \mathrm{EI}$ & - & - & - \\
\hline $3^{\circ} \mathrm{EI}$ & $\checkmark$ & - & - \\
\hline Aula unitaria & - & - & - \\
\hline
\end{tabular}

Tabla 6.18 Cursos impartidos en cada año durante la investigación

No ha tenido experiencia previa con "El Rincón del Ratón" y las motivaciones que le animaron a estar en el proyecto eran la importancia que en la actualidad tenían las nuevas tecnologías y que era un medio y recurso para favorecer y facilitar el proceso de aprendizaje de la lectoescritura. Y ve el recurso como algo que "les atrae mucho la imagen, centrando su atención. Posibilitando, en suma, mejorar su proceso de aprendizaje".

En relación con su formación previa la valora como media, indicando que "he recibido cursos en CFIES, CITA,...". También indica que la información recibida sobre el recurso en el momento de su introducción "ha sido adecuada". Y destaca sobre todo la ayuda de la orientadora tanto en la información como en la formación, "la ayuda de la orientadora tecnológica del CITA ha sido y es muy importante en el mantenimiento del recurso en el aula". Los problemas técnicos se solucionan desde el centro primeramente y el CITA "ha ayudado puntualmente cuando lo hemos necesitado". El equipo directivo, del que forma 
parte la profesora 6, apoya todas las iniciativas relacionadas con las TIC al igual que los compañeros del colegio.

El principal objetivo curricular que se marca es "que los niños aprendan a leer y escribir" para ello entiende el recurso "como medio facilitador del proceso". También indica que trabajar con el recurso supone plantear las actividades de una forma distinta, "más individualizada".

Aprecia en el recurso un potencial por su interactividad que desemboca en una buena motivación del alumnado para trabajar con él " por lo que tiene de interactivo". Pero esto desemboca en la necesidad de que para "utilizar este recurso se hace necesario una atención más individualizada" lo que supone cambios en la organización. También indica que sí le cuesta mucho esfuerzo introducir el recurso, sobre todo por "falta de tiempo para afianzarme en los conocimientos nuevos informáticos". En cuanto a la evaluación, la introducción del recurso supone "un elemento más para la evaluación global".

\section{Profesor 7}

El profesor 7 cuenta con 23 años de experiencia docente. Tiene plaza definitiva en el centro 5 y cuenta con 9 años de antigüedad en el mismo. Ya había tenido experiencia previa con "El Rincón del Ratón", y hemos podido realizar las grabaciones durante los tres años de la investigación (Tabla 6.19)

\begin{tabular}{cccc}
\hline & $2009-2010$ & $2010-2011$ & $2011-2012$ \\
\hline $1^{\circ}$ EI & - & $\checkmark$ & - \\
\hline $2^{\text {o }}$ EI & - & - & $\checkmark$ \\
\hline $3^{\text {o }}$ EI & $\checkmark$ & - & - \\
\hline Aula unitaria & - & - & - \\
\hline
\end{tabular}

Tabla 6.19 Cursos impartidos en cada año durante la investigación

La motivación de participar es para colaborar con el desarrollo del proyecto de investigación entre el CITA y la Universidad de Salamanca. Y ve las TIC como algo importante en el trabajo de la clase sobre todo por nivel de motivación que genera en el alumnado "a partir del cual es mucho más fácil trabajar conceptos, desarrollar capacidades,...". 
Lo relativo a la formación previa, cuenta con "multitud de cursos relacionados con las TIC, desde generalistas en su uso hasta específicos de algún programa o entorno operativo (Jclic, Linux,...)" a través de CFIES y online. Aunque también aclara que "lo que realmente llevo a cabo es a base de ir experimentando en el aula en relación con los alumnos." Sin embargo, la información dada en la introducción del recurso de "El rincón del Ratón" en el aula ha sido poca y la formación nula. Los problemas técnicos que surgen en el equipo siempre y cuando no genere coste económico los resuelve el propio profesor. En cuanto a los apoyos para la introducción del recurso comenta que "como es una actividad que va a afectar sólo a infantil el resto del centro no manifiesta un interés concreto."

A nivel curricular, se plantea como objetivos con las TIC en su aula la"motivación, adquisición de determinados conceptos, creatividad, autonomía y solidaridad e introducción en el mundo de las TIC". Respecto a la organización de las actividades, es un recurso que ya está introducido en el aula, por lo que no cuenta con un planteamiento distinto. Sólo implica esa modificación cuando va "el técnico del CITA a trabajar con los niños que va jugando con ellos de 2 en 2 ".

Al igual que los profesores anteriores, la motivación la ve como un importante efecto del recurso, "todos quieren ir a ese rincón en primer lugar (hay cuatro rincones en el aula, tienen que pasar por los cuatro todos los días)" y espera que el aprendizaje "sea significativo, no solo repetitivo". Como ya comentaba antes el ordenador está introducido como un rincón más por lo que no le supone ni mucho esfuerzo, ni cambios en la organización. Sí supone cambios en la evaluación pero son menores comentando respecto a esto que "sólo me obliga a tener algún ítem más".

\section{Profesora 8}

La profesora 8 tiene ocho años de experiencia docente, desde hace dos años es parte de la plantilla del centro 6 y cuenta con plaza definitiva en el centro. Su incorporación al proyecto se llevo a cabo durante el curso 2010-2011 (Tabla 6.20), puesto que en cursos anteriores había estado en otros centros del CRA y no en la cabecera. 


\begin{tabular}{cccc}
\hline & $2009-2010$ & $2010-2011$ & $2011-2012$ \\
\hline $1^{\circ}$ EI & - & $\checkmark$ & $\checkmark$ \\
\hline $2^{\circ}$ EI & - & - & - \\
\hline $3^{\circ}$ EI & - & - & - \\
\hline Aula unitaria & - & - & - \\
\hline
\end{tabular}

Tabla 6.20 Cursos impartidos en cada año durante la investigación

Las motivaciones de participar en "El Rincón de Ratón" son muy diversas, desde "la motivación que genera a los alumnos el tener un ordenador en clase" y "aprovechamiento y oportunidad del uso del recurso del pupitre digital [...] en un CRA no llega a todas las localidades, sólo tenemos la suerte de que se priorice en la cabecera". Además se muestra abierta a estas experiencias con TIC, "estoy dispuesta a participar en todo lo que sea posible" que las ve como una herramienta más, y también en cuanto a facilitar el desarrollo de la investigación indicando que "el poder colaborar con la USAL y el CITA, siempre y cuando les podamos ayudar los profesores en la investigación en este tema".

Su formación previa cuenta con cursos especializados como pueden ser Word, Access, Excel, PowerPoint,... aunque indica que "este tipo de contenidos no los puedes aplicar en el aula". Y muestra su interés porque se convoquen cursos de PDI, y otros relacionados con las TIC en Educación Infantil. Considera que su "formación es todavía muy escasa y me gustaría aprender más". La información ha sido únicamente en el claustro por la directora y en cuanto a la formación comenta que "tampoco creo que tuviera que revivir formación por parte del asesor (CITA), porque como es un recurso que siempre he tenido en el aula no suponía para mí ninguna novedad". Los problemas técnicos son solucionados por ella o por el asesor del CITA.

Si miramos la relación con el ámbito curricular, la profesora 8 se marca objetivos en relación con recurso TIC tales como "familiarizarse y conocer el ordenador en sí", "usar el ordenador para diferentes tareas", "mejorar la habilidad óculo-manual", "trabajar los contenidos de las unidades didácticas" y "proporcionar el manejo del ordenador a niños/as que no lo tienen en su casa". Además, considera que sí se pueden trabajar tanto contenidos conceptuales, como procedimentales y actitudinales. Esto favorece el generar "aprendizaje cooperativo" y "aprendizaje significativo". Aunque menciona que no siempre es el medio más indicado ya que por ejemplo "los valores (amistad, respeto 
tolerancia, compartir, solidaridad,...) es mejor trabajarlos de otra manera, a través de cuentos...".

La integración no supone cambios en la planificación de las actividades, y la organización espacial de su clase está estructurada teniendo en cuenta el rincón del ordenador, que lo utiliza en los tiempos dedicados a la actividad por rincones. En cuanto a la pregunta de si le supone mucho esfuerzo indica que "no. Utilizan este rincón de manera autónoma, sólo tengo que preocuparme de encenderlo, y al principio de curso abrirles el $\mathrm{CD}$, pero ahora ya saben abrirlo". Asimismo, tampoco le supone cambios en su forma habitual de evaluar.

\section{Profesora 9}

La profesora 9 cuenta con 12 años de experiencia y el curso 2010-2011 es su primer año de permanencia en el centro 3. La plaza con la que cuenta es definitiva y ha venido de un traslado de otra comunidad autónoma. Hemos podido realizar grabaciones durante dos cursos académicos (Tabla 6.21) y en los años previos no había tenido contacto con el proyecto.

\begin{tabular}{cccc}
\hline & $2009-2010$ & $2010-2011$ & $2011-2012$ \\
\hline $1^{\circ} \mathrm{EI}$ & - & $\checkmark$ & - \\
\hline $2^{\circ} \mathrm{EI}$ & - & - & $\checkmark$ \\
\hline $3^{\circ} \mathrm{EI}$ & - & - & - \\
\hline Aula unitaria & - & - & - \\
\hline
\end{tabular}

Tabla 6.21 Cursos impartidos en cada año durante la investigación

La principal motivación para participar en el proyecto es "el interés y la motivación que las TIC son para los alumnos", valorándolas como herramientas que "optimizan el proceso ya que refuerzan contenidos y en otras ocasiones los ilustran".

En relación con la formación previa, considera que es media alta, ya que comenta que "he recibido formación en TIC desde el inicio de mi carrera y a 
nivel personal he procurado investigar". Atendiendo a la información y la formación recibida para la introducción del pupitre tecnológico en el aula la considera adecuada en ambos casos, aunque no ve apoyos por parte del centro ni de los compañeros. A nivel técnico, indica al CITA como entidad que aporta las soluciones a los problemas que pueda tener.

Desde el punto de vista curricular, en torno al rincón se plantea objetivos como "reforzar contenidos de las tres áreas, motivar hacia nuevos contenidos, ilustrar contenidos de forma más gráfica e interactiva, evaluar la consecución de objetivos y contenidos y aproximar las TIC a niños/as". Elige los programas del ordenador en función de que respondan o no a los centros de interés y considera que "sí, es posible trabajar las tres áreas". Pero la introducción en clase no le supone trabajar las actividades de forma distinta, por lo que lo considera integrado en la dinámica de clase.

La motivación que genera en el alumnado la considera alta, aunque respecto al rendimiento argumenta que "no considero que haya mejorado el rendimiento general aunque sí el de algunos niños que por su peculiaridades individuales han respondido mejor a este estímulo". Además, no le supone esfuerzo su introducción. Tampoco cambios en su forma de evaluar, ni en la organización concreta del aula, encajando dicho recurso TIC "dentro del tiempo y del espacio de rincones libres".

\section{Profesora 10}

La profesora 10 cuenta con 14 años de experiencia docente y el curso 2011-2012 es el primero que se encuentra en el centro 1.2. No cuenta con plaza definitiva, por lo que su paso por el centro es temporal. Disponemos de una grabación durante el último año de la investigación (Tabla 6.22)

\begin{tabular}{cccc}
\hline & $2009-2010$ & $2010-2011$ & $2011-2012$ \\
\hline $1^{\circ}$ EI & - & - & - \\
\hline $2^{\text {o }}$ EI & - & - & - \\
\hline $3^{\circ}$ EI & - & - & - \\
\hline Aula unitaria & - & - & $\checkmark$ \\
\hline
\end{tabular}

Tabla 6.22 Cursos impartidos en cada año durante la investigación 
La principal motivación de participar en el proyecto era para poder mantener el ordenador en el aula, aunque indica que "también le resultó interesante la idea de tener un apoyo por parte del CITA". Además considera que el recurso es "altamente motivador que contribuye a reforzar y ampliar múltiples aspectos del currículo".

La formación previa la califica de "autodidácta", aunque también comenta que ha recibido formación "en el CFIE y el CITA sobre el manejo de programas o aplicaciones específicas". La información ha sido escasa puesto que los alumnos ya habían trabajado con el recurso y la formación recibida para la integración en el aula ha sido nula en su caso. Cuenta desde el centro con apoyos para solución de problemas técnicos, puesto que "un profesor del centro se ocupa de todos los ordenadores".

Sobre el uso del recurso en relación con el currículo, busca objetivos relacionados con el manejo y uso del ordenador, refuerzo y apoyo de contenido de las áreas, y matiza "siempre como refuerzo, no como objetivo a conseguir exclusivamente a través del uso del ordenador". En cuanto a los contenidos cree que se pueden trabajar todos con el rincón lo que implica plantear las actividades de una forma más lúdica ya que entiende que para los alumnos "trabajar con el ordenador supone un juego".

Considera que el recurso hace que tengan mejores resultados en lectoescritura, y ve que aporta "un aprendizaje muy práctico donde aplican rápidamente el contenido aprendido y que inmediatamente les da información sobre su evaluación". La integración del recurso le supone un cambio, que es "dedicarle un tiempo semanal en el horario", lo que no genera ningún esfuerzo ya que estaba habituada a su uso. En relación con la evaluación indica que "afecta sólo en que tengo más aspectos que evaluar y más información a la hora de evaluar los contenidos trabajados".

\section{Profesora 11}

La profesora 11 es su primer año de experiencia docente y por lo tanto también lo es en el centro 3. Contamos con una grabación durante el último año de la investigación (Tabla 6.23) 


\begin{tabular}{cccc}
\hline & $2009-2010$ & $2010-2011$ & $2011-2012$ \\
\hline $1^{\circ}$ EI & - & - & - \\
\hline $2^{\circ}$ EI & - & - & - \\
\hline $3^{\circ}$ EI & - & - & $\checkmark$ \\
\hline Aula unitaria & - & - & \\
\hline
\end{tabular}

Tabla 6.23 Cursos impartidos en cada año durante la investigación

Las principales motivaciones que le animan a participar es la influencia que tiene en los niños en cuanto a la motivación que despierta y considera que las TIC "mejoran el proceso de enseñanza aprendizaje tanto para alumnos como para el maestro".

Los cursos que ha realizado relacionados con las TIC previamente han sido a través de CFIE, CITA, ... y en el momento de presentarle el recurso indica que ha "recibido buena información" aunque no menciona nada ni del apoyo técnico, ni de la formación en el recurso. Sin embargo sí considera que los compañeros y el equipo directivo le apoyan en la introducción de las TIC en el aula.

Dentro del ámbito curricular, su objetivo con el trabajo en "El Rincón del Ratón" es "favorecer la motivación en diferentes contenidos a través del uso de las TIC". Y a su vez considera que se pueden trabajar los contenidos de las tres áreas de Infantil mediante los programas que tiene el recurso y no le supone plantear las actividades de forma diferente en el aula.

Entiende el ordenador como algo "que favorece la motivación y ayuda a aprender a través de juegos" que es además "diferente al clásico aprendizaje por fichas. Esta manera de trabajar no le supone cambios en la organización del aula que ya "está organizada para trabajo por rincones"; ni tampoco le supone ningún esfuerzo el introducir el recurso. En cuanto a la evaluación, no supone cambios en su forma de evaluar aunque sí dice que ha "incluido nuevos criterios de evaluación con los cuales valorar el avance de mis alumnos en el uso de las TIC".

\subsubsection{Datos comparativos: Profesores.}

Los docentes descritos hasta ahora tienen distintos perfiles que se han detallado de forma individual. Al igual que hemos hecho con los centros el mostrarlos de forma comparativa puede ayudar a adquirir una visión más 
clarificadora de las diferencias que podamos encontrar entre cada uno de los casos que forman parte de la investigación.

De esta manera, encontramos distintos perfiles en función de la experiencia docente de los distintos profesores (Figura 6.41) que se sitúan desde 30 años la profesora con más experiencia y con 1 año la que menos.

Figura 6.41 Años de experiencia docente

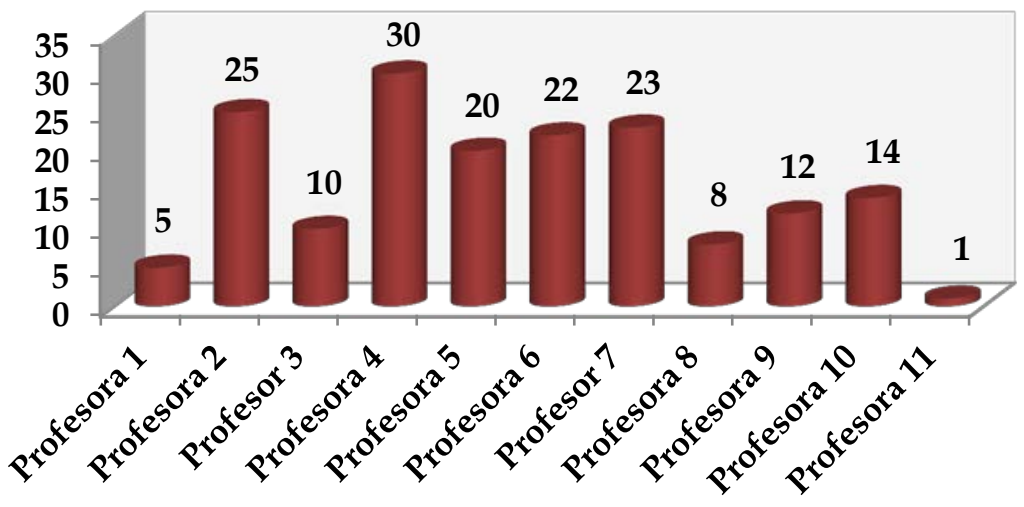

También encontramos variaciones en los años en los que se han podido realizar grabaciones a cada uno de los docentes (Tabla 6.24), debido por un lado a las características de las plazas -definitiva, interino o en expectativa de destino- $\mathrm{o}$ a los concursos de traslados.

\begin{tabular}{llll}
\hline & \multicolumn{1}{c}{ 2009-2010 } & \multicolumn{1}{c}{ 2010-2011 } & \multicolumn{1}{c}{ 2011-2012 } \\
\hline Profesora 1 & $\checkmark$ Aula Unitaria & $\checkmark 5$ años & $\times$ Sin grabación \\
\hline Profesora 2 & $\checkmark 4$ años $\left(2^{\circ} \mathrm{EI}\right)$ & $\checkmark 5$ años $\left(3^{\circ} \mathrm{EI}\right)$ & $\checkmark 3$ años $\left(1^{\circ} \mathrm{EI}\right)$ \\
\hline Profesor 3 & $\checkmark 3$ años $\left(1^{\circ} \mathrm{EI}\right)$ & $\times$ Sin grabación & $\times$ Sin grabación \\
\hline Profesora 4 & $\checkmark 4$ años $\left(2^{\circ} \mathrm{EI}\right)$ & $\checkmark 5$ años $\left(3^{\circ} \mathrm{EI}\right)$ & $\checkmark 3$ años $\left(1^{\circ} \mathrm{EI}\right)$ \\
\hline Profesora 5 & $\checkmark 5$ años $\left(3^{\circ} \mathrm{EI}\right)$ & $\checkmark 4$ años $\left(2^{\circ} \mathrm{EI}\right)$ & $\checkmark 5$ años $\left(3^{\circ} \mathrm{EI}\right)$ \\
\hline Profesora 6 & $\checkmark 5$ años $\left(3^{\circ} \mathrm{EI}\right)$ & $\times \operatorname{Sin}$ grabación & $\times$ Sin grabación \\
\hline Profesor 7 & $\checkmark 5$ años $\left(3^{\circ} \mathrm{EI}\right)$ & $\checkmark 3$ años $\left(1^{\circ} \mathrm{EI}\right)$ & $\checkmark 4$ años $\left(2^{\circ} \mathrm{EI}\right)$ \\
\hline Profesora 8 & $\times$ Sin grabación & $\checkmark 3$ años $\left(1^{\circ} \mathrm{EI}\right)$ & $\checkmark 3$ años $\left(1^{\circ} \mathrm{EI}\right)$ \\
\hline Profesora 9 & $\times$ Sin grabación & $\checkmark 3$ años $\left(1^{\circ} \mathrm{EI}\right)$ & $\checkmark 4$ años $\left(2^{\circ} \mathrm{EI}\right)$ \\
\hline Profesora 10 & $\times$ Sin grabación & $\times$ Sin grabación & $\checkmark$ Aula Unitaria \\
\hline Profesora 11 & $\times$ Sin grabación & $\times$ Sin grabación & $\checkmark 3$ años $\left(1^{\circ} \mathrm{EI}\right)$ \\
\hline
\end{tabular}

Tabla 6.24 Cursos en los que se realizan las grabaciones a cada profesor 
Si valoramos el uso de "El Rincón del Ratón" con anterioridad al comienzo de la investigación, vemos que hay dos profesores que ya habían participado en el proyecto del CITA, el resto que era la primera vez que contaban con este recurso adaptado por IBM en su aula. Aunque algunos sí reconocen haber tenido ordenadores de sobre mesa en sus clases y haber trabajado con ellos, aunque no con las características adaptativas para la etapa que ofrece "El Rincón del Ratón".

En cuanto a número de grabaciones realizadas han sido asimétricas entre el profesorado, en las que contamos en algunos casos con 1 sola grabación y en otros con 6, tal y como se muestra en la Tabla 6.25:

\begin{tabular}{lcccc}
\hline & $2009-2010$ & $2010-2011$ & 2011-2012 & Total \\
\hline Profesora 1 & 3 & 2 & $x$ & 5 \\
\hline Profesora 2 & 1 & 2 & 1 & 4 \\
\hline Profesor 3 & 3 & $x$ & $x$ & 3 \\
\hline Profesora 4 & 3 & 2 & 1 & 6 \\
\hline Profesora 5 & 3 & 2 & 1 & 6 \\
\hline Profesora 6 & 3 & $x$ & $x$ & 3 \\
\hline Profesor 7 & 3 & 2 & 1 & 6 \\
\hline Profesora 8 & $x$ & 2 & 1 & 3 \\
\hline Profesora 9 & $x$ & 2 & 1 & 3 \\
\hline Profesora 10 & $\times$ & $x$ & 1 & 1 \\
\hline Profesora 11 & $x$ & $x$ & 1 & 1 \\
\hline Total & 19 & 14 & 8 & 41 \\
\hline
\end{tabular}

Tabla 6.25 Número de grabaciones realizadas a los profesores por curso 
Esta diferencia que se muestra en la tabla anterior ha estado determinada por cuatro cuestiones:

- La movilidad del profesorado a otros centros durante el periodo de la investigación.

- La ocupación de cargos de gestión que reducían la carga horaria del profesor.

- Motivos personales que suponían que en el momento de la grabación no estuvieran desempeñando su trabajo en el aula (bajas, matrimonios, etc.)

- $\quad$ El año de entrada en el proyecto ya que en el 2009/2010 se realizaron 3 grabaciones/año, en el 2010/2011 dos grabaciones/año y en el 2011/2012 una grabación/año.

Al igual que pasaba con la comparativa de los centros, estos datos pretenden dar una visión de conjunto que facilite analizar las similitudes y diferencias entre los docentes y a la vez ayudar a contextualizar y comprender mejor las características en las que se desarrolla la investigación.

\subsection{Sistema de análisis. Procedimiento de análisis de las clases.}

Como venimos describiendo hasta ahora, en el proyecto en el que se inscribe este trabajo se han obtenido datos de diversa naturaleza en relación con las concepciones de los docentes, la formación recibida, su evolución frente a las TIC, evaluaciones de los alumnos, prácticas docentes, aspectos sociofamiliares y socio-económicos del entorno y del centro, etc. La necesidad de delimitar con precisión en este trabajo lo que constituye el eje sobre el que centrar el objeto de investigación, ha dado lugar a que sean las prácticas de aula de los profesores el elemento clave sobre el que se ha indagado. De esta manera y para este propósito, disponemos de 39 horas y 34 minutos de grabación directa que se reparten en 41 sesiones diferentes de clase, las cuales están distribuidas a lo largo de los distintos niveles de la etapa y durante los cursos académicos 2009/2010, 2010/2011 y 2011/2012 (Tabla 6.26).

\begin{tabular}{cccccc}
\hline $\begin{array}{c}\text { AÑO DE } \\
\text { GRABACIÓN }\end{array}$ & $\mathbf{1}^{\mathbf{0}}$ EI & $\mathbf{2}^{\mathbf{0}}$ EI & $\mathbf{3}^{\mathbf{0}}$ EI & $\begin{array}{c}\text { Aula } \\
\text { Unitaria }\end{array}$ & TOTAL \\
\hline $2009-2010$ & 3 & 4 & 9 & 3 & 19 \\
\hline $2010-2011$ & 6 & 2 & 6 & 0 & 14 \\
\hline $2011-2012$ & 3 & 2 & 2 & 1 & 8 \\
\hline TOTAL & 12 & 8 & 17 & 4 & 41 \\
\hline
\end{tabular}

Tabla 6.26 Número de grabaciones por curso académico en cada año 
Estas sesiones que oscilan entre 45 y 60 minutos, son la materia de la que se nutre la investigación y fueron transcritas en su totalidad para facilitar el análisis del discurso del docente durante el desarrollo de la clase. En cualquier caso, aunque nos apoyemos en el análisis del discurso a través del texto transcrito, al categorizar dicho discurso se utilizó de forma simultánea el visionado del vídeo de la sesión correspondiente al texto, con objeto de buscar una mayor precisión en el análisis. No podemos perder de vista la etapa educativa en la que se sitúa la investigación y la importancia de los componentes no verbales en la comunicación entre alumnos y profesores de este nivel.

Como ya indicábamos en el capítulo 4 el análisis del discurso que llevan a cabo Sánchez, García y Rosales (2010) -aunque contemplan un fin diferente en la investigación- nos sirvió como punto de partida para construir nuestro propio sistema de análisis. En este sentido aprovechamos la idea de ATA (Actividad típica de aula) para delimitar cuáles son los patrones de actividad genéricos en los que los docentes apoyan su práctica y cómo los gestionan temporalmente a lo largo de la sesión.

A continuación explicaremos de forma detallada el sistema de análisis, que se resume en la figura 6.42 siguiente:

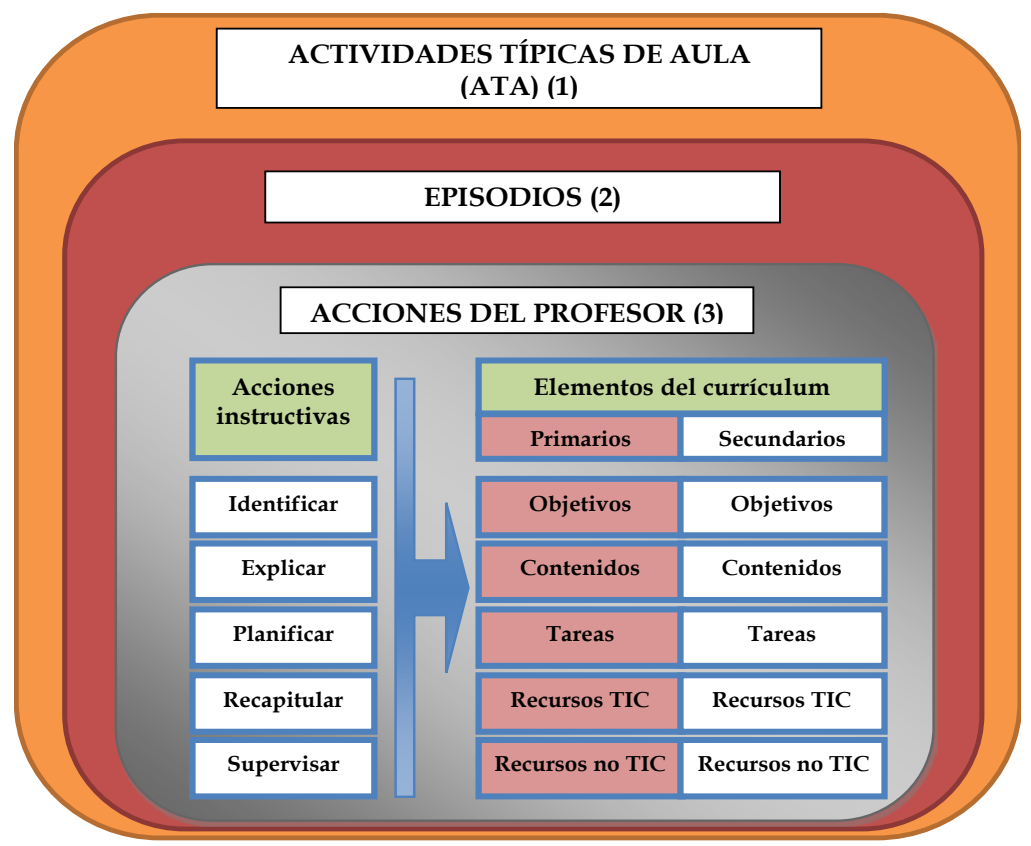

Figura 6.42 Estructura del sistema de análisis 


\section{Metodología}

La aplicación del sistema de análisis permite desmenuzar lo que ocurre en las clases, estableciendo categorías de estudio de la práctica que nos informan sobre los tipos de actividad que enmarcan las actuaciones de los profesores, el papel de los distintos elementos del curriculum en la configuración de las prácticas y los roles que con más frecuencia desempeñan los docentes.

El sistema de análisis descompone las sesiones grabadas en diversas categorías, la primera de las cuales se refiere a lo que denominamos Actividades Típicas de Aula (en adelante ATA).

\section{Actividades Típicas de Aula (ATA)}

Las Actividades Típicas de Aula se organizan en torno a una serie de acciones fácilmente reconocibles cuyo patrón organizativo es recurrente para situaciones similares. "Preparar la salida al recreo", "Realizar tareas con recurso TIC", "Corregir trabajos en clase" "Reconocer el tiempo meteorológico, día de la semana y mes del año" son patrones típicos de actividad en las aulas de infantil estudiadas. De esta forma, cada sesión de clase se estructura en torno a ATAs sucesivas que trazan el boceto genérico sobre el que alumnos y profesores organizan el trabajo en las aulas.

Una vez trazada la secuencia de ATAs de cada sesión de clase, procedemos a estudiar el papel de los profesores en el desempeño de las actividades del aula (acciones instructivas) y el papel de los distintos elementos del curriculum en la configuración de las prácticas de cada sesión. Explicaremos cada uno de estas categorías en detalle.

\section{Acciones Instructivas}

En el segundo nivel del análisis de las prácticas de aula, nos interesa desentrañar con más precisión qué está ocurriendo en el aula, y más concretamente, cómo gestiona el profesor los elementos de la clase. Para ello, se analizan lo que hemos denominado acciones instructivas del profesor, que permiten comprender qué hace el profesor en el aula y qué rol desempeña en su interacción con los alumnos. El sistema de análisis contempla cinco acciones instructivas que se describen a continuación:

- Identificar: enunciados que se dedican a hacer referencia de manera indicativa o señalizadora a los elementos a los que se refieren. Por 
ejemplo: "Así que sentadita y calladita", "Vale y mirar ya empieza el cuento".

- Planificar: enunciados que sirven para organizar los elementos en relación con las metas y los medios que se persiguen. Por ejemplo: "A ver, que vamos a trabajar luego todos con el ordenador, ir acabando, pegar todo", "Y vosotros, los demás ir dejando el trabajo encima de la mesa e iros colocando para ver el cuento de los reinos y las reinas los camellos y las cárceles"

- Explicar: enunciados que desarrollan o aclaran en mayor o menor medida los elementos a los que se refieren. Por ejemplo: "Pero por qué no pintas primero toda esa parte de amarillo y luego ya pintas morado mejor... Vale, es que si no se te va a mezclar mucho", "Eres el responsable, pero mandar callar sólo puede mandar callar la señorita"

- Recapitular: enunciados que recuerdan, repiten y/o actualizan los elementos a los que se refieren. Por ejemplo: "Mira Lucía, ya te lo he dicho tres veces esta mañana que dejes de dar voces para hablar", "Hemos dicho que hacemos todas en grande"

- Supervisar-evaluar: enunciados que buscan controlar la consecución y/o desarrollo de los elementos a los que se refiere. Por ejemplo: “ ¿Ya has terminado todas? A ver si las tienes bien: hormiga, granja, gusano, tijera, guante, flauta, foca y huevo. ${ }_{\text {jFenomenal }}$ Pues te has ganado una pegatina", "A ver Iván, ¿de qué color le vamos a pintar el coche a papá?"

Ahora bien, este segundo nivel de análisis se completa relacionando las acciones instructivas del profesor con los elementos del curriculum sobre las cuales se ejecutan. Y ello es así, porque como señalábamos en el marco teórico el profesor organiza y gestiona en su práctica directa elementos curriculares y organizativos con objeto de desarrollar el curriculum. A continuación se describen dichos elementos.

\section{Elementos del curriculum}

Como acabamos de señalar, dentro del segundo nivel de análisis, además de que el profesor actúe de una determinada forma, es importante para la investigación conocer hacia qué elementos del curriculum se dirigen dichas acciones de tal forma que se pueda estudiar cómo se construye el desarrollo del 
curriculum en la práctica. En el listado siguiente se definen y ejemplifican estos elementos del sistema de análisis:

- Objetivos: hace referencia a la finalidad del proceso de enseñanzaaprendizaje, al para qué de dicho proceso. Ejemplo: "Porque va a poder poner las llaves del tractor aquí" (a propósito de una manualidad que los niños estaban haciendo para el día del padre) (identifica-objetivo)

- Contenidos: se refiere a los conocimientos que han de adquirirse en el proceso de enseñanza-aprendizaje. Ejemplo: "A ver, Javier te ayuda, ¿cuál es la primera letra de esa palabra?" (supervisa-contenido), "a ver si encontramos... mírala... ah no, ésta es la C, la G no la encontramos, no hay G" (identifica-contenidos)

- Tareas: se identifican con las acciones concretas que profesores y alumnos han de realizar para desarrollar el curriculum. Ejemplo: "Pues termínalo, deja la frase ahí para hacerla luego y primero terminas eso, que si no, no nos da tiempo" (planifica-tarea), “Cómo va esto? ¿Cuál estás haciendo Jorge? Ah, que has empezado por ese lado de allí" (supervisa-tarea)

- Recursos TIC: se relacionan con los soportes digitales sobre los que se realizan las tareas y se presentan los contenidos. Ejemplo: "mira esta es la que borraba (la tecla), esta y ahora con esta flecha nos vamos para delante y ahora separamos o no" (explica-recurso TIC), "(a los alumnos del ordenador) Vamos a cambiar de juego. Vamos a jugar al del ratón." (planifica-Recurso TIC)

- Recursos no TIC: se refieren a soportes analógicos sobre los que se realizan las tareas y se presentan los contenidos. Ejemplo: "Bueno pues sabéis que hemos dicho que los libros que nos enseñan cosas en la parte de arriba. Y los cuentos y las historias en la parte de abajo, y estos dijimos que los que eso ahí tumbados ahí... Este también es de cuentos, y este también es de cuentos, así que todos éstos tienen que ser ahí" (explica-recurso noTIC), "Miguel, venga busca esa hoja de los jarrones, venga. Vamos a ver, vamos a ver qué ha pasado con las flores..." (identifica-Recurso No TIC).

Con respecto a los elementos del currículo sobre los que actúa el profesor distinguimos dos planos: primario y secundario, para reflejar las múltiples ocasiones en que el profesor actúa sobre un elemento del currículo en primer plano y se apoya en segundo plano en otro elemento diferente; por ejemplo: "(sobre la pantalla del ordenador) Es un burrito de cuento, se limpia el 
hocico y se pone elegante" (explica contenido (primario) apoyándose en recurso TIC (secundario); " (indicando en la pantalla) A ver, el burro, el perro, el gato y el gallo, ¿Dónde, dónde iban estos, estos cuatro animales? " (supervisacontenido (primario) señalando explícitamente en las imágenes del recurso TIC (secundario). La distinción de estos dos niveles en los elementos del curriculum surgió en la configuración del sistema de análisis al observar cómo los profesores actuaban directamente en la práctica. Con mucha frecuencia, los profesores trabajaban con los alumnos aspectos de las tareas o de los contenidos del curriculum, recurriendo para ello a los materiales sobre los que se realizaban las tareas o se presentaban los contenidos. Explicaban, supervisaban, planificaban tareas y contenidos sobre la base del medio de presentación. Este segundo nivel de los elementos del curriculum no aparece explícitamente en todas las acciones del profesor; sin embargo, nos resultaba especialmente relevante captar estos mecanismos de la actuación de los profesores, puesto que pretendíamos estudiar el papel de las TIC en las prácticas de aula. En un sentido similar, aunque en relación al uso que los profesores hacen de los libros de texto, Sosniak y Stodolsky (1993, p. 271) subrayan la funcionalidad que los docentes otorgan a los materiales como herramientas profesionales para su práctica.

Este procedimiento de análisis se ejecuta sobre la transcripción de las grabaciones de las sesiones de clase de forma simultánea al visionado de la grabación. El sistema permite encajar en niveles de concreción sucesivos lo que se desarrolla en la práctica del aula. En la figura 6.42 más arriba se ha mostrado una síntesis del procedimiento; en ella se reflejan los tres momentos de la aplicación del sistema de análisis:

- División de la clase en ATA, es decir en actividades globales que vertebran la clase.

- Segmentación de las ATA identificando las acciones instructivas que lleva a cabo el profesor. Por acuerdo interjueces se estableció como criterio de segmentación de las acciones el que se produjera un cambio en la acción del profesor: o bien sobre el contenido de la acción (desde planificar a explicar...), o bien sobre el elemento primario del curriculum sobre el que se actúa (desde contenidos a tareas...) o bien sobre el interlocutor al que se dirige el profesor (del grupo a un alumno, de un alumno a otro alumno...). 
- Identificación de los elementos del curriculum primarios y secundarios sobre los que se ejecutan las acciones instructivas.

La secuencia desarrollada para la aplicación del sistema de análisis sobre el conjunto de las clases transcritas se realizó como sigue:

- Categorización de una clase simultáneamente por tres miembros del equipo de investigación formados en el sistema con el objetivo de llegar a acuerdos sobre los contenidos de la categorización.

- Trabajo por parejas de los seis miembros del equipo de investigación en la categorización de otra de las clases objeto de estudio.

- Trabajo individual de los seis miembros del equipo de investigación para categorizar el resto de las clases grabadas.

- Revisión del grado de concordancia en la categorización de las clases analizadas y, en su caso, adopción de acuerdos sobre las discrepancias que pudieran surgir, hasta conseguir una categorización unívoca. Esta fase se inició con un grado de acuerdo que superaba el $84.2 \%$ para las categorizaciones individuales y un $100 \%$ en la revisión de la categorización final conjunta.

- Introducción de los datos obtenidos en el programa SPSS 19 generando una matriz de datos que permite aplicar sobre ellos análisis estadísticos.

La aplicación del sistema de análisis sobre las clases permite obtener el recuento de frecuencias en cada una de las categorías. Dicho recuento constituye la muestra sobre la que se han obtenido los datos que se ofrecen en el apartado de resultados y que aparecen en las tablas 6.27 y 6.28 a continuación. 


\begin{tabular}{ccc} 
ATA & $\begin{array}{c}\mathbf{N}^{0} \text { de ATA } \\
\text { (f) }\end{array}$ & $\begin{array}{c}\mathbf{N}^{0} \text { de Acciones } \\
\text { Instructivas (f) }\end{array}$ \\
\hline Planificación / organización de tareas & 37 & 490 \\
\hline Organización para salida al recreo & 15 & 489 \\
\hline Visionado de película con recurso TIC & 2 & 156 \\
\hline Pasar lista & 4 & 39 \\
\hline Fecha y tiempo meteorológico & 5 & 108 \\
\hline Explicación de tarea & 8 & 263 \\
\hline Recitado de poesía & 2 & 97 \\
\hline Realización de tarea por rincones & 10 & 3123 \\
\hline Realización de tarea con y sin TIC relacionada & 15 & 2595 \\
\hline Realización de tarea con y sin TIC independiente & 16 & 3127 \\
\hline Realización de tarea con TIC & 11 & 1898 \\
\hline Realización de tarea sin TIC & 10 & 416 \\
\hline Corrección de trabajos en clase & 7 & 609 \\
\hline Organización vuelta del recreo & 2 & 33 \\
\hline Juego libre & 4 & 325 \\
\hline Comer el bocadillo & 3 & 177 \\
\hline Lectura de imágenes con recurso no TIC & 1 & 72 \\
\hline Lectura de imágenes con recurso TIC & 1 & 29 \\
\hline Elección de lectura para casa & 1 & 24 \\
\hline TOTAL & 154 & 14070 \\
\hline
\end{tabular}

Tabla 6.27 Frecuencia y acciones instructivas por ATA total sesiones.

\begin{tabular}{ccccc}
$\begin{array}{c}\text { Acciones } \\
\text { instructivas }\end{array}$ & $(\mathrm{f})$ & $\begin{array}{c}\text { Elementos del } \\
\text { curriculum }\end{array}$ & $\begin{array}{c}\text { Primarios } \\
\text { (f) }\end{array}$ & $\begin{array}{c}\text { Secundarios } \\
\text { (f) }\end{array}$ \\
\hline IDENTIFICAR & 4658 & OBJETIVOS & 4 & 1 \\
\hline EXPLICAR & 1215 & CONTENIDOS & 3482 & 421 \\
\hline PLANIFICAR & 1923 & TAREAS & 9138 & 1099 \\
\hline RECAPITULAR & 60 & RECURSOS TIC & 786 & 3852 \\
\hline SUPERVISAR & 6214 & RECURSOS NO TIC & 659 & 3796 \\
\hline TOTAL & 14070 & TOTAL & 14070 & 9169 \\
\hline
\end{tabular}

Tabla 6.28 Frecuencia de acciones instructivas y elementos del curriculum. 
Resulta muy importante entender en la tabla 6.27 los dos tipos de datos consignados. El primero de los datos se refiere al número de ATAs detectadas en las sesiones analizadas y el segundo de los datos al número de acciones instructivas del profesor que se ejecutan en dichas ATAs. El número de ATAs, ofrece información sobre los patrones de actividad que estructuran las clases. Mientras que el número de acciones instructivas ejecutadas en las ATAs, informa sobre el peso relativo de las ATAs en el transcurso temporal de las sesiones. 


\section{CAPÍTULO 7}

Resultados 



\section{Resultados}

\section{Introducción}

La presentación de los resultados se organizará atendiendo a distintos criterios que permitan responder a los objetivos de la investigación. De esta manera, los resultados se organizarán como sigue:

- Descripción de los resultados obtenidos en relación a cada uno de los patrones o estructuras de actividad (ATA) detectadas en las grabaciones, atendiendo a los distintos elementos del sistema de categorías.

- Descripción de los resultados obtenidos en relación a cada uno de los profesores que participan en el estudio, atendiendo a los distintos elementos del sistema de categorías.

- Resultados comparativos en función de tres elementos: patrones o estructuras de actividad (ATA), profesores y curso de la etapa de Educación Infantil, con objeto de estudiar si existen diferencias vinculadas a dichos aspectos.

7.1. Datos descriptivos por ATAs: Cómo se configura cada patrón de actividad en el transcurso de las clases.

En las 41 grabaciones de los 11 profesores analizadas hemos detectado un total de 19 Actividades Típicas de Aula diferentes. El número de veces que aparecen dichas ATAs a lo largo de las sesiones así como el peso que cada una de ellas tienen en el total, queda reflejado en la tabla 7.1.

Cada una de las ATAs que aparecen en la tabla anterior tiene peculiaridades en su configuración debido a razones diversas que van desde el propósito que persigue la actividad, su carácter más o menos académico o, incluso, la etapa en la que se desarrolla. Por ello, a continuación abordaremos la descripción pormenorizada de estas 19 ATAs detectadas en la investigación. 


\begin{tabular}{|c|c|c|}
\hline ATA & $\begin{array}{l}\mathrm{N}^{0} \text { de ATA } \\
\text { (f) }\end{array}$ & $\begin{array}{l}\mathrm{N}^{0} \text { de Acciones } \\
\text { Instructivas (f) }\end{array}$ \\
\hline Planificación / organización de tareas & 37 & 490 \\
\hline Organización para salida al recreo & 15 & 489 \\
\hline Visionado de película con recurso TIC & 2 & 156 \\
\hline Pasar lista & 4 & 39 \\
\hline Fecha y tiempo meteorológico & 5 & 108 \\
\hline Explicación de tarea & 8 & 263 \\
\hline Recitado de poesía & 2 & 97 \\
\hline Realización de tarea por rincones & 10 & 3123 \\
\hline Realización de tarea con y sin TIC relacionada & 15 & 2595 \\
\hline Realización de tarea con y sin TIC independiente & 16 & 3127 \\
\hline Realización de tarea con TIC & 11 & 1898 \\
\hline Realización de tarea sin TIC & 10 & 416 \\
\hline Corrección de trabajos en clase & 7 & 609 \\
\hline Organización vuelta del recreo & 2 & 33 \\
\hline Juego libre & 4 & 325 \\
\hline Comer el bocadillo & 3 & 177 \\
\hline Lectura de imágenes con recurso no TIC & 1 & 72 \\
\hline Lectura de imágenes con recurso TIC & 1 & 29 \\
\hline Elección de lectura para casa & 1 & 24 \\
\hline TOTAL & 154 & 14070 \\
\hline
\end{tabular}

Tabla 7.1 Frecuencia de ATAs y acciones instructivas por ATA en el total de las sesiones.

\subsubsection{Planificación/organización de tareas}

El docente utiliza la planificación/organización de tareas para preparar al alumnado estructurando las tareas concretas que se van a desarrollar en la clase de forma más inmediata. Por tanto, mediante esta ATA se dan pormenores a los alumnos respecto de los tiempos y la forma de trabajo que se van a llevar a cabo a continuación en la clase. Se trata de la ATA que más veces aparece a lo largo de las grabaciones recogidas, con una frecuencia de 37, aunque su peso en el trascurso temporal sea relativo (490 acciones instructivas), lo que supone una media de 13,2 acciones por cada ATA de planificación/organización de tareas. Esto quiere decir que los profesores planifican 
y organizan las tareas de forma habitual, aunque ello ocupe un tiempo relativamente corto de las sesiones de clase.

En cuanto a su composición interna, en lo referente a las acciones instructivas, podemos indicar que predominan la supervisión: A ver cómo utilizamos el ordenador (Supervisa-Tarea-Recurso TIC, Caso 8); la identificación: No, no estos no, cariño, los de abajo, los de abajo, espera..., (Identifica-Recurso no TIC, Caso 4); y la planificación: Ponerlos esos en la parte de arriba porque en la otra, está aquí en la parte de arriba porque en la otra no cabe. Y luego, a ver si los forramos (Planifica-Tarea-Recurso no TIC, Caso 7), quedando relegados a un segundo plano la explicación: Mirad, en la pizarra, chicos, vais a poder pintar también, los números, uno para José María y otro para Nerea, ¿de acuerdo? Con los rotuladores de la pizarra. (Explica-Tarea-Recurso no TIC, Caso 1); y la recapitulación: Venga. Adrián, lo habias hecho antes, ¿no? Una vez. (Recapitula-Tarea-Recurso no TIC, Caso 5) (Figura 7.1).

Figura 7.1 Planificación/Organización de tareas. Acciones instructivas

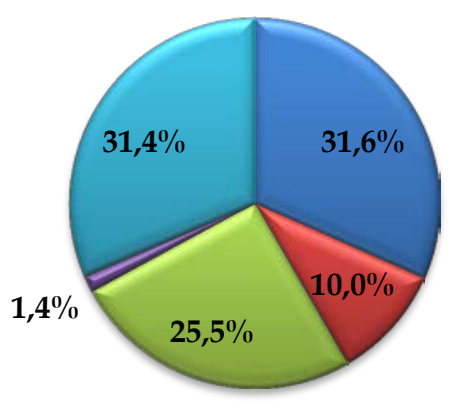

\author{
$\because$ IDENTIFICAR \\ IEXPLICAR \\ $\triangle$ PLANIFICAR \\ $\square$ RECAPITULAR \\ $\square$ SUPERVISAR
}

Si además atendemos a los elementos del curriculum primarios y secundarios sobre los que van dirigidos las acciones del profesor dentro de esta ATA, observamos que destacan de forma significativa dentro de los primarios las tareas que ocupan casi las tres cuartas partes del total, y dentro de los elementos secundarios el recurso TIC y el recurso no TIC que juntos suman más del $80 \%$ (Figura 7.2). 
Figura 7.2 Planificación/Organización de tareas.

E.Currículum Primarios y Secundarios

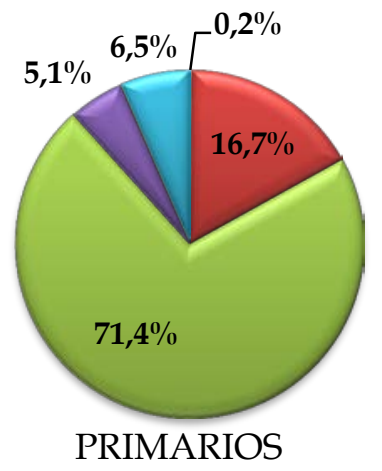

口OBJETIVO

口CONTENIDO

$\triangle$ TAREAS

口REC.TIC

$\square$ REC.NOTIC

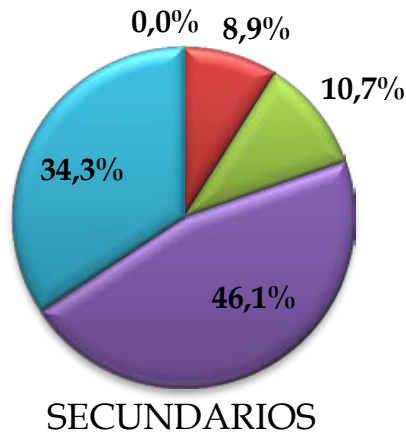

\subsubsection{Organización para salida al recreo}

Se trata en este caso de una actividad muy característica de las etapas de Educación Infantil y primeros cursos de Educación Primaria, donde es importante que las rutinas ayuden a los alumnos a respetar turnos y prepararse para la salida de la clase de manera ordenada. Por tanto, los docentes organizan a los alumnos para la salida al recreo instándoles a que vayan acabando las tareas, ordenando materiales, colocándolos en la fila, cogiendo el abrigo, supervisando si recogen cada uno su almuerzo, etc.

En las acciones instructivas predominan casi por igual la identificación: Ahora, ponerse en la fila (Identifica-Tarea, Caso 6); y la supervisión: Vale venga Enrique despacito (Supervisa-Tarea, Caso 6), suponiendo un porcentaje superior al $85 \%$. Con porcentajes mucho menores le siguen la planificación y la explicación respectivamente. Estos datos los podemos ver recogidos en la figura 7.3 que se muestra a continuación:

Figura 7.3 Organización para la salida al recreo.

Acciones instructivas

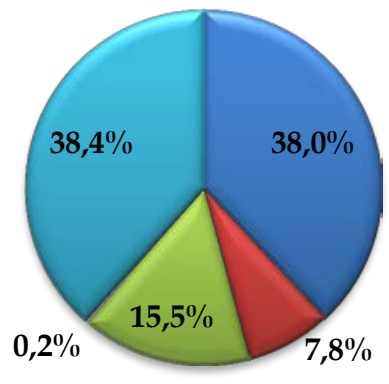

$\square$ IDENTIFICAR

$\square$ EXPLICAR

$\square$ PLANIFICAR

$\square$ RECAPITULAR

$\square$ SUPERVISAR 
Los elementos del curriculum primarios, al igual que ocurría en el caso anterior, tienen en las tareas el mayor número de frecuencias. Por otra parte, los secundarios, en casi la mitad de las ocasiones en que aparecen tienen que ver con los recursos no TIC y en torno a una tercera parte del total con los recursos TIC (figura 7.4).

Figura 7.4 Organización para salida al recreo.

E.Currículum Primarios y Secundarios

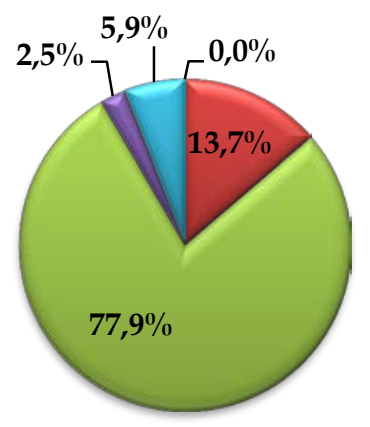

PRIMARIOS

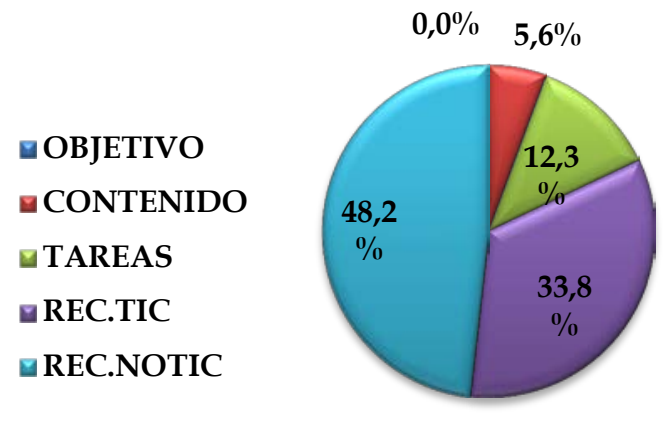

SECUNDARIOS

El número total de apariciones que tiene este ATA en las grabaciones es de 15, las cuales suman un total de 489 acciones, por lo que en comparación con la anterior la media de acciones que el profesor tiene que realizar en cada una de ellas es mayor, teniendo una media de 32,6 acciones instructivas por ATA frente a las 13,2 que veíamos en el ATA anterior.

\subsubsection{Visionado de película con recurso TIC}

El visionado de película con recurso TIC consiste en utilizar el ordenador como reproductor de un archivo de vídeo. Esta actividad se lleva a cabo de forma colectiva, en gran grupo, disponiendo a los alumnos alrededor del pupitre tecnológico con objeto de que todos puedan visionar el monitor. Cuenta con un número bajo de frecuencias ya que a lo largo de las 41 grabaciones sólo ha aparecido en dos ocasiones. Aunque entre las dos suman 159 acciones instructivas, lo que supone una media de 79,5.

En lo referente al tipo de acciones instructivas que predominan en esta ATA, la supervisión ocupa más de un $50 \%$ del total: ¿No ves, cariño? Lo muevo un poquito, ahora ya lo ves, ¿no? (Supervisa-Recurso TIC-Tarea, Caso 2); y el otro $50 \%$ se reparte entre la identificación: Sí, es que es un burrito de cuento (IdentificaContenido-Recurso TIC, Caso 2); la planificación: Siéntate ahí, para ya, a ver, 
ponte ahí, ponte allí. Aquí, aquí tú solo, que aquí lo ves (Planificación-Tarea-Recurso TIC, Caso 6) y la explicación: lo está leyendo muy bien porque o si no, no se puede poner... muy bien (Explica-Recurso TIC-Contenido, Caso 1) (Figura 7.5).

Figura 7.5 Visionado de película con Recurso TIC.

Acciones instructivas.

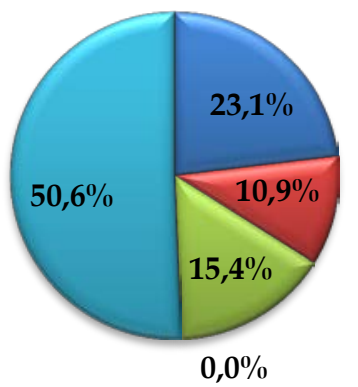

IDENTIFICAR

$\square$ EXPLICAR

$\square$ PLANIFICAR

$\square$ RECAPITULAR

$\square$ SUPERVISAR

Estás acciones recaen sobre los diferentes elementos del curriculum. Destacan entre los elementos de curriculum primarios las tareas, seguidas de los contenidos y en los secundarios de manera muy destacada el recurso TIC, que supone más del 80\% del total (Figura 7.6).

Figura 7.6 Visionado de película con recurso TIC

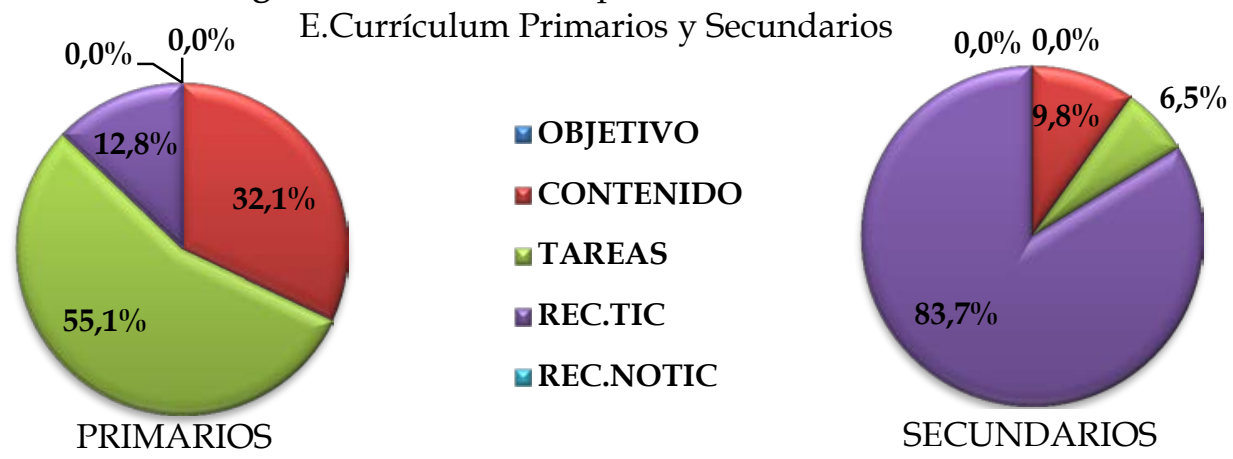

\subsubsection{Pasar lista}

El ATA que hemos denominado "pasar lista" la llevan a cabo, en los casos que hemos estudiado, principalmente los alumnos bajo la supervisión del profesor. Es una de las ATA que marcan el comienzo de la jornada; se convierte, por tanto, en una rutina diaria para profesores y alumnos. A lo largo 
de las 41 grabaciones aparece en 4 ocasiones este tipo de ATA con una media de 9,7 acciones instructivas en cada una de ellas.

La estructura del ATA muestra que casi en un $80 \%$ de las acciones instructivas el profesor supervisa: A sentarse, a ver, Adrián, ¿Quién falta hoy? ¿Todavía falta alguien hoy? (Supervisa-Contenido, Caso 2); e identifica: África, vete pasando lista mi niña (Identifica-Tarea, Caso 4). Explicando: Pablo estaba un poco así ayer y Alejandro tosía mucho, a lo mejor están malitos (Explica-Contenido, Caso 4) y planificando: Sí, ha traído el cuaderno viajero, luego le vamos a ver, tranquilos (Planifica-Tarea-Recurso no TIC), en un porcentaje cercano al $10 \%$ (Figura 7.7)

Figura 7.7 Pasar lista

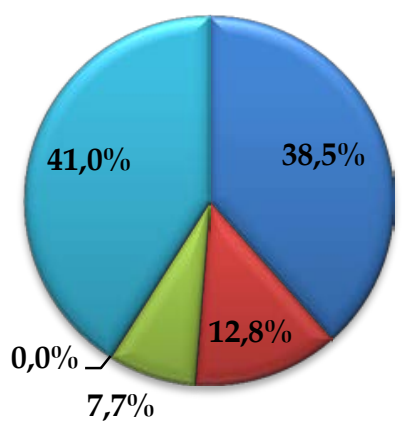

$\square$ IDENTIFICAR

$\square$ EXPLICAR

$\square$ PLANIFICAR

$\square$ RECAPITULAR

$\square$ SUPERVISAR

Como en los casos anteriores las tareas es el elemento del curriculum primario que más destaca seguido del contenido. En cambio en los secundarios que hasta ahora venían los recursos TIC y los recursos no TIC ocupando un papel central, son las tareas las que destacan en los secundarios con un porcentaje superior al 70\% (Figura 7.8)

Figura 7.8 Pasar lista.

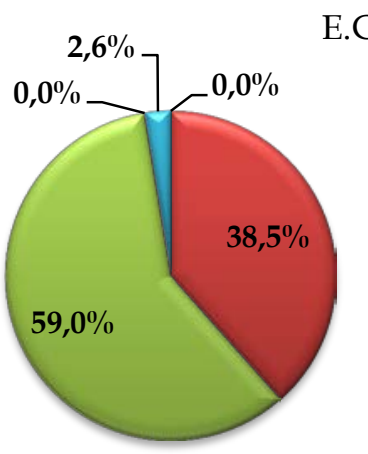

PRIMARIOS

E.Currículum Primarios y Secundarios

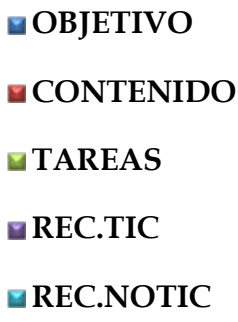

๑OBJETIVO

$\square$ CONTENIDO

$\square$ TAREAS

$\square$ REC.TIC

$\square$ REC.NOTIC

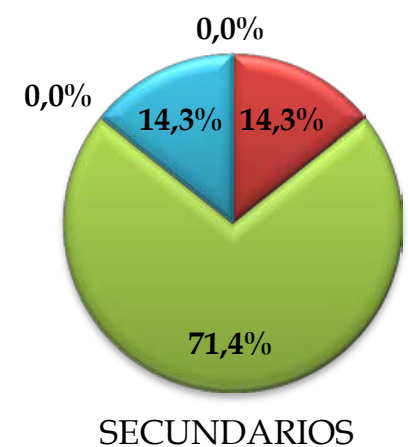




\subsubsection{Fecha y tiempo meteorológico}

$\mathrm{Al}$ igual que ocurre con el ATA de pasar lista, la que hemos identificado como "fecha y tiempo meteorológico" es otra de las rutinas diarias que se realizan al comienzo de la clase. En ella los alumnos bajo la supervisión del profesor identifican qué día es de la semana, qué mes es del año, cuál es el tiempo atmosférico, en qué estación del año están, etc. Del total de ATAs que aparecen en las 41 grabaciones, ésta aparece en 5 ocasiones y la media en cada una es de 20,1 acciones instructivas.

La estructuración de las acciones instructivas dentro del ATA indica que el profesor sobre todo supervisa: ¿Yaiza te acuerdas cómo se llama el día de hoy? (Supervisa-Contenido, Caso 9); e identifica: Bueno, y repasamos los meses del año. Estamos en... (Identifica-Tarea, Caso 4) en más de un 80\% del total (Figura 7.9). Planificar: Vamos a poner la fecha, Yaiza, coges tú la tiza esta y la vamos poniendo a la vez la fecha (Planifica-Tarea-Recurso no TIC, Caso 9) cuenta con algo más de un $11 \%$; mientras que explicar: porque está un poco oscuro, que están las nubes delante (Explica-Contenido), alrededor de un 7\%.

Figura 7.9 Fecha y tiempo meteorológico.

Acciones instructivas.

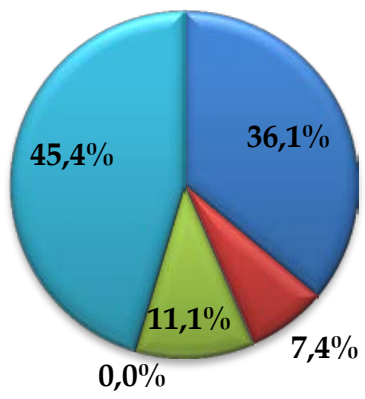

口IDENTIFICAR

IEXPLICAR

$\square$ PLANIFICAR

$\because$ RECAPITULAR

$\square$ SUPERVISAR

Los elementos del curriculum primarios sobre los que se centran las acciones del profesor son dos, el contenido y las tareas. En cuanto a los elementos del curriculum secundarios, los recursos no TIC ocupan casi las tres cuartas partes de los registrados en el ATA, y el resto se reparte entre los contenidos y las tareas (Figura 7.10). Lo cual pone de relieve que en este patrón 
de actividad los recursos TIC no se contemplan, al menos en las grabaciones registradas.

Figura 7.10 Fecha y tiempo meteorológico.

E.Currículum Primarios y Secundarios.

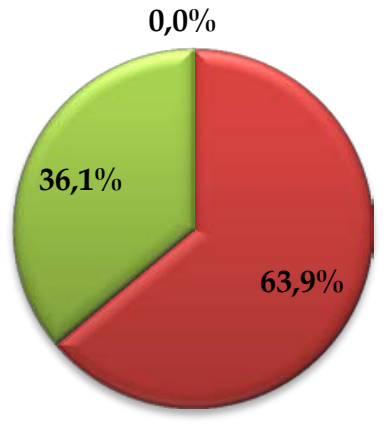

PRIMARIOS
๑OBJETIVO

$\square$ CONTENIDO

$\square$ TAREAS

$\square$ REC.TIC

口REC.NOTIC

SECUNDARIOS

\subsubsection{Explicación de la tarea.}

En todas las etapas educativas los profesores realizan explicaciones de las tareas que se van a llevar a cabo durante la clase. El número de veces que aparece en las grabaciones este patrón de actividad, es de 8, con un total de 263 acciones instructivas entre todas las ATAs de este tipo, lo que muestra una media de 32,7 en cada una. En la etapa de Educación Infantil, debido a la edad de los alumnos, este esquema de acción ha de ser muy directo, sencillo y apoyado en ejemplificaciones prácticas para que los alumnos comprendan qué es lo que tienen que hacer.

En ese sentido, los profesores se basan en la supervisión: ¿Quién es el órgano encargado de hacer la digestión? De los alimentos que comemos (SupervisaContenido-Recurso no TIC, Caso 11) y la identificación: Vale, vale, espera que hay que encender el altavoz (Identifica-Recurso TIC-Tarea, Caso 8) como acciones instructivas predominantes en la actividad de explicación de tarea, quedando la explicación: pues lo único que tenemos que hacer es con mucho, mucho cuidado, con mucho cuidado y picar en el bote que está vacío (Explica-Tarea-Recurso no TIC, Caso 3) en tercer lugar (Figura 7.11). No debemos perder de vista que la acción instructiva de "explicar" supone un desarrollo bastante pormenorizado del contenido objeto de explicación, que no suele utilizarse con niños de estas edades. De tal forma que el discurso se fragmenta y ejemplifica de manera detallada. 
Figura 7.11 Explicación de la tarea.

Acciones instructivas.

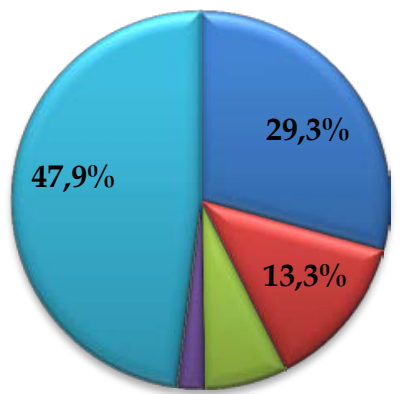

IDENTIFICAR

IEXPLICAR

$\square$ PLANIFICAR

$\square$ RECAPITULAR

$\square$ SUPERVISAR

$2,3 \% 7,2 \%$

Si miramos sobre qué elementos del curriculum inciden las acciones dentro del ATA, los resultados ofrecen un reparto respecto de los primarios con un porcentaje de algo más de la mitad centrado en los contenidos y un porcentaje superior al $40 \%$ en las tareas. En los secundarios prevalecen los recursos no TIC con un $70 \%$ (Figura 7.12 ).

Figura 7.12 Explicación de la tarea.

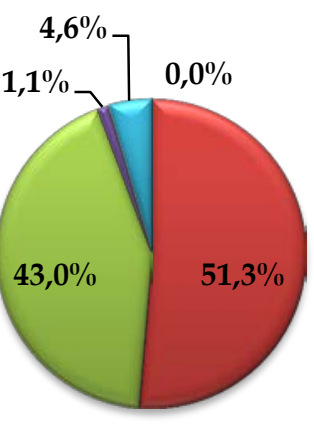

PRIMARIOS $\square$ OBJETIVO

$\because$ CONTENIDO

$\square$ TAREAS

$\square$ REC.TIC

$\square$ REC.NOTIC
$0,0 \% 5,7 \%$

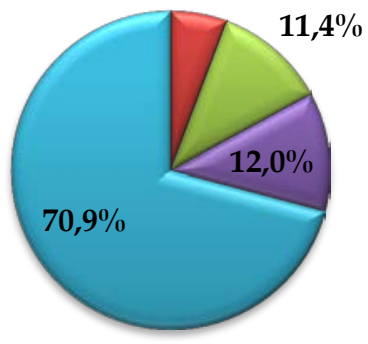

SECUNDARIOS

\subsubsection{Recitado de poesía.}

El ATA de "recitado de poesía" suele ser característica del área del Lenguajes: Comunicación y representación, dentro de la etapa de Educación Infantil. Se trata de que los alumnos aprendan una poesía recitándola por turnos o en grupo con la ayuda del docente. Suele realizarse en gran grupo, mientras el docente señala los turnos en caso de que el procedimiento solicite la intervención sucesiva de los alumnos. Aparece en dos ocasiones a lo largo de todo el tiempo de grabación, teniendo una media de acciones de 48,5 en cada una de ellas. 
El profesor centra su desarrollo en la identificación: Erase una vez un marinero $\_$que hizo un jardin junto al mar (Identifica-Contenido-Tarea, Caso 4), que ocupa más del $50 \%$ del total. Le siguen la planificación: Ahora lo repite... (Alumno: Yo) Víctor ven aquí a repetirlo (Planifica-Tarea, Caso 4); la supervisión: ¿Alguno sabe que es invierno? (Alumnos: ¡Yo!) ¿Y qué canción cantamos en invierno? (Supervisa-Contenido, Caso 2); la recapitulación: Vamos a ver irepetimos todos las poesías? Erase un marinero que hizo un jardín junto al mar y se metió a jardinero estaba el jardín en flor y el marinero se fue por esos mundos de Dios. (RecapitulaTarea, Caso 4); y la explicación: Un árbol. El chamariz en el chopo, el chopo es un árbol (Explica-Contenido, Caso 4) (Figura 7.13).

Figura 7.13 Recitado de poesía.

Acciones instructivas.

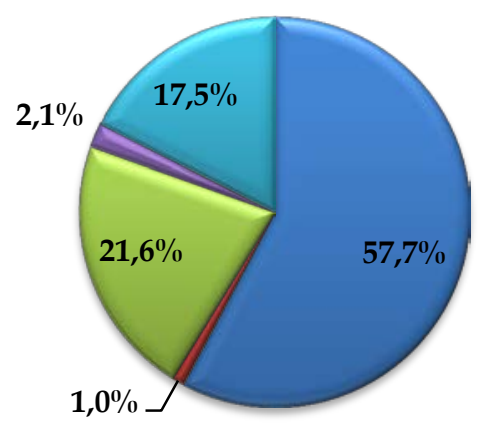

$\square$ IDENTIFICAR

$\square$ EXPLICAR

$\square$ PLANIFICAR

$\square$ RECAPITULAR

$\square$ SUPERVISAR

Los elementos del curriculum primarios sobre los que recaen las acciones son dos: los contenidos y las tareas. Por su parte, los elementos del curriculum secundarios en el caso de que las acciones instructivas se apoyen también en ellos lo hacen principalmente sobre las tareas, con un porcentaje cercano al 90\% (Figura 7.14).

Figura 7.14 Recitado de poesía.

E.Currículum Primarios y Secundarios

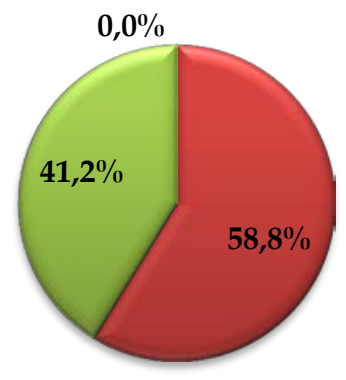

PRIMARIOS
๑OBJETIVO

$\because$ CONTENIDO

$\square$ TAREAS

$\square$ REC.TIC

$\square$ REC.NOTIC

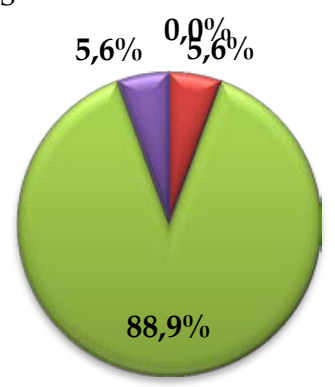

SECUNDARIOS 


\subsubsection{Realización de tareas por rincones.}

El realizar tareas por rincones es una de las ATA característica de la etapa de Educación Infantil, que, asimismo, refleja una metodología de trabajo en el aula de especial interés en esta etapa. En ella el docente dispone la clase dividiéndola en diversos rincones de trabajo por donde los alumnos van rotando, llevando a cabo diversas tareas ajustadas a la naturaleza de cada rincón (de las letras, de los números, del juego simbólico, del ratón...). En las grabaciones encontramos un total de 10 ATAs de realización de tarea por rincones con un total de 3123 acciones instructivas, lo que da una media de 312,3 acciones en cada ATA. En comparación con las ATAs anteriores, ésta ya incorpora un mayor número de acciones por parte del docente, puesto que en torno a ella se desenvuelve una buena parte del tiempo de las sesiones registradas.

La configuración interna de la "realización de tarea por rincones" cuenta con la supervisión: A ver, si hay, si hay maja, lo siento cariño y aqui el dibujo, tienes que leer está frase y aquí el dibujo, y después esta, son dos frases diferentes (Supervisa-Tarea-Recurso no TIC, Caso 5), como la acción más realizada por el profesor seguido de la identificación: En la pizarra, sí. Vale, pues venga, repasamos la letra $F$ (Identifica-Tarea-Contenido, Caso 1). Entre las dos supone más de un $75 \%$ del total (Figura 7.15).

Figura 7.15 Realización de tarea por rincones. Acciones instructivas

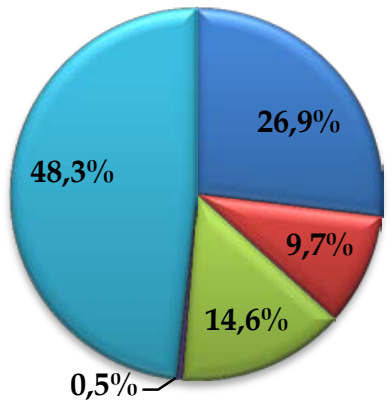

$\because$ IDENTIFICAR

$\square$ EXPLICAR

$\square$ PLANIFICAR

$\square$ RECAPITULAR

$\square$ SUPERVISAR

En este tipo de actividad las acciones instructivas recaen mayoritariamente sobre las tareas, dentro de los elementos primarios del curriculum. El contenido también aparece, aunque de forma mucho menos relevante, ocupando algo más de un cuarto del total y los recursos TIC y no TIC apenas si alcanzan un $10 \%$. Si observamos los resultados que nos ofrecen los elementos del curriculum secundarios, se aprecia una inversión de la tendencia 
respecto de los primarios, de tal forma que los recursos TIC y no TIC ocupan la mayoría de las acciones quedando las tareas y los contenidos con un porcentaje mucho menor que supera escasamente el 15\% (Figura 7.16).

Figura 7.16 Realización de tareas por rincones
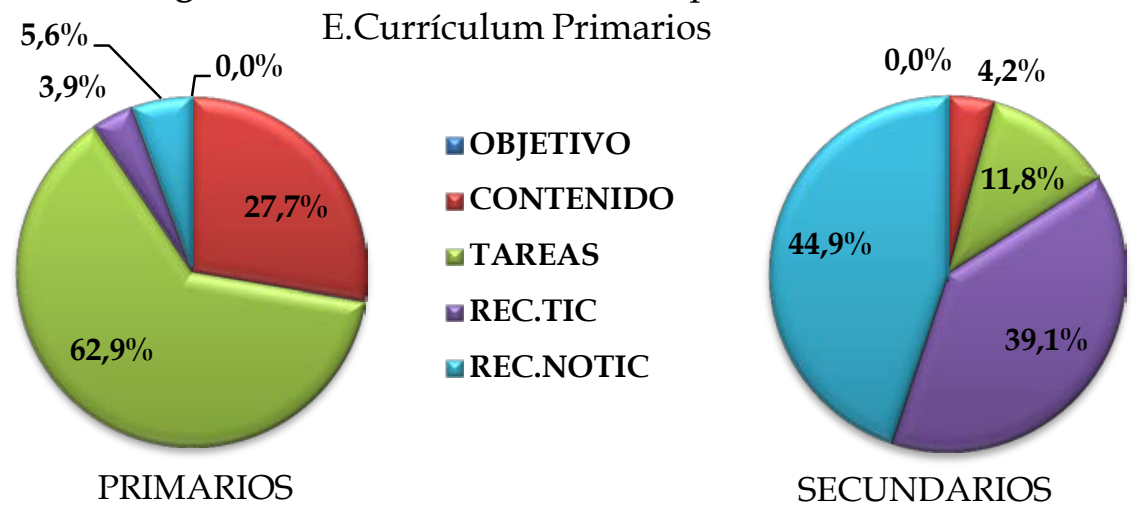

\subsubsection{Realización de tareas con y sin TIC relacionadas.}

La realización de tareas con y sin TIC relacionadas se presenta como un ATA en la que se simultanean dos situaciones de enseñanza: una en la que algunos alumnos están trabajando con recursos no TIC una tarea o contenido y a la vez otros alumnos (habitualmente por parejas) usan el recurso TIC realizando tareas con contenidos similares al resto de los compañeros. A lo largo de los registros recogidos aparece en 15 ocasiones con un total de 2595 acciones instructivas, presentando así una media de 173.

Ese total de acciones instructivas desarrolladas por el profesorado se concentra principalmente en acciones de supervisión: Ainara, déjale que empiece por donde él quiera, con el color que quiera (Supervisa-Tarea-Recurso TIC, Caso 3); e identificación: pues entonces mira a ver que tenemos que coger de aquella caja, para meter en ese conjunto, mira a ver, este (Identifica-Recurso no TIC-Tarea, Caso 7), mostrando un patrón muy similar al visto en la anterior ATA de "realización de tarea por rincones" (Figura 7.17). 
Figura 7.17 Realización de tarea con y sin TIC relacionada. Acciones instructivas.

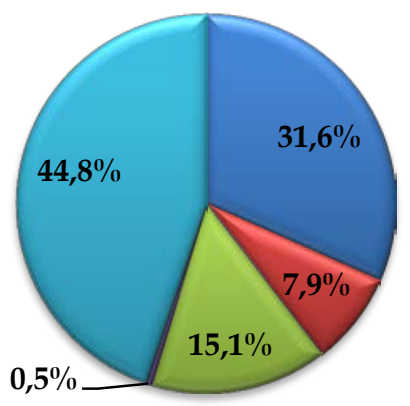

口IDENTIFICAR

EEXPLICAR

$\square$ PLANIFICAR

$\square$ RECAPITULAR

$\square$ SUPERVISAR

Los datos obtenidos sobre los elementos del curriculum nos muestran que respecto de los primarios en este ATA las acciones van dirigidas principalmente a las tareas y en bastante menor medida a los contenidos. Con porcentajes mucho menores aparecen los recursos TIC, los recursos no TIC y los objetivos (prácticamente inexistentes). Los elementos secundarios se reparten de forma bastante equitativa entre los recursos TIC y los recursos no TIC siendo en este caso poco relevantes tanto las tareas como los contenidos y los objetivos (Figura 7.18).

Figura 7.18 Realización de tareas con y sin TIC relacionadas.

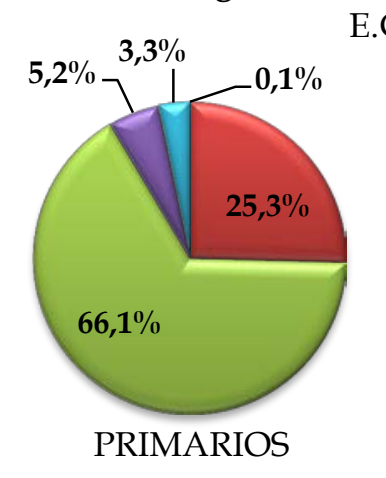

E.Currículum Primarios y Secundarios

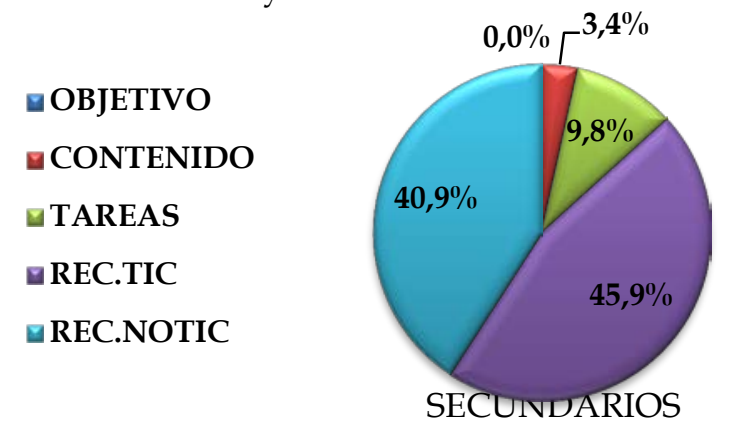

\subsubsection{Realización de tareas con y sin TIC independiente.}

En el caso anterior veíamos que se realizaba de forma simultánea en la clase un doble trabajo tanto con TIC como sin TIC sobre tareas y contenidos comunes. En el caso que nos ocupa ahora, la "realización de tareas con y sin TIC independiente", los alumnos están trabajando en el aula en una actividad que no tiene que ver ni por el tipo de tarea, ni por el contenido con la que 
realizan en el recurso TIC, a donde acuden por turnos, habitualmente en parejas. Este ATA se registra en 16 ocasiones con un total de 3127 acciones instructivas, por lo que cuenta con una media de 195,4 acciones instructivas por ATA.

Las acciones instructivas que más destacan son la supervisión: Hay que formar la pareja ¿verdad? Pues vamos, sino te quito; no juegas al rincón (SupervisaTarea-Recurso TIC, Caso 11); y la identificación: A ver, Iván, haz aquí el tres (Identifica-Tarea-Recurso no TIC, Caso 9), suponiendo entre las dos un $80 \%$ del total. Este porcentaje se completa con una presencia mucho menor de la explicación: Vamos a rodear la estrella, el planeta, el marciano, lo rodeamos con rotu negro que sino no se ve (Explica-Tarea-Recurso no TIC, Caso 1); y la planificación: Recoge, espera, vete a recoger esto y haces esto, Carla ha hecho el tres, ¡Carla! Ven Sergio al sitio, ven, eso, ordénalo en su sitio (Planifica-Tarea-Recurso no TIC, Caso 8). La recapitulación: Os acordáis que os he dicho que tenemos que picar en el bote, no la mancha sino el bote, el bote (Recapitula-tarea-Recurso no TIC, Caso 3) cuenta con menos de un 1\% de las acciones del ATA (Figura 7.19).

Figura 7.19 Realización de tarea con y sin TIC independientes. Acciones instructivas.

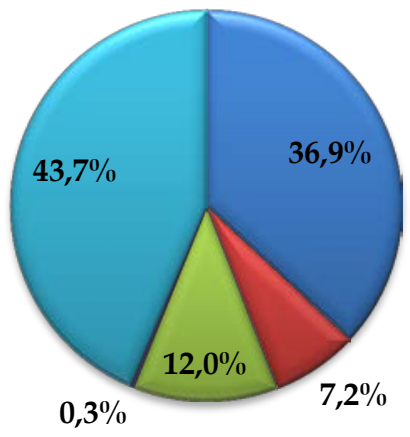

$\square$ IDENTIFICAR

EXPLICAR

$\square$ PLANIFICAR

$\square$ RECAPITULAR

$\square$ SUPERVISAR

Dichas acciones instructivas están ligadas a elementos del curriculum tanto primarios como secundarios, de esta forma, encontramos que en los primarios predominan las tareas con un porcentaje superior al $70 \%$, en menor medida los contenidos y los recursos TIC y no TIC. Si observamos los resultados con respecto a los secundarios vemos que al igual que ocurría en las dos ATAs previas, los recursos tanto TIC como no TIC son los protagonistas y ocupan más del $80 \%$ del total de este ATA (Figura 7.20). 
Figura 7.20 Realización de tareas con y sin TIC independientes.

E.Currículum Primarios y Secundarios

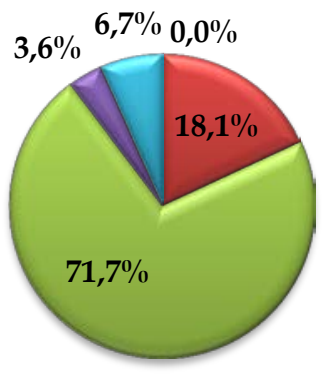

PRIMARIOS

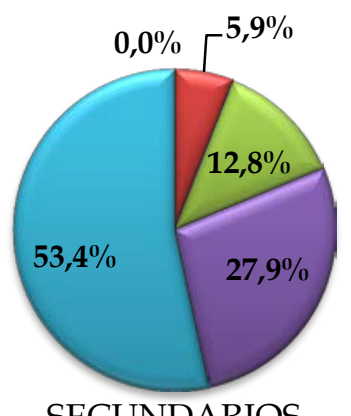

SECUNDARIOS

\subsubsection{Realización de tarea con TIC}

En el ATA de "realización de tarea con TIC" el profesor utiliza el recurso TIC como el soporte básico para llevar a cabo la actividad en cuestión. Es un patrón de actividad en el que el recurso TIC sustituiría a la pizarra tradicional como soporte de presentación de las tareas o contenidos. De tal forma que el profesor presenta la tarea/contenido al grupo clase y va escogiendo a distintos alumnos para que vayan resolviendo pequeñas tareas en el recurso TIC, con la ayuda en muchos casos del resto de la clase. Está actividad cuenta con 11 frecuencias de aparición en las 41 grabaciones y un total de 1898 acciones instructivas, dando una media de 172,5 acciones por ATA.

La forma en que el profesor desenvuelve las acciones instructivas en este ATA se apoya, al igual que las anteriores, en la supervisión: Escúchame un momento cariño, ¿qué quieres hacer? ¿Poner algún adornito alrededor, o quieres que pongamos alguna pegatina de estas de aquí? (Supervisa-Tarea-Recurso TIC, Caso 2) y la identificación: Claro, vamos a esperar a que se cargue (Identifica-TareaRecurso TIC, Caso 5), que suponen más de las tres cuartas partes en el porcentaje total de acciones en este ATA (Figura 7.21).

Figura 7.21 Realización de tarea con TIC.

Acciones instructivas.

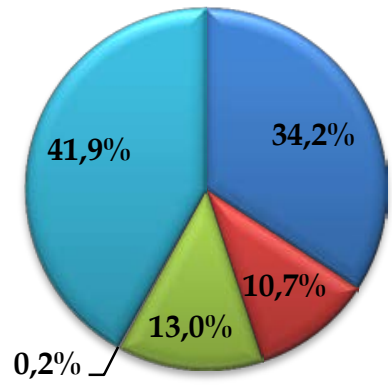

$\square$ IDENTIFICAR

$\square$ EXPLICAR

$\square$ PLANIFICAR

口 RECAPITULAR

$\square$ SUPERVISAR 
Los elementos del curriculum primarios se centran en más de un $50 \%$ en las tareas, mientras que los contenidos y los recursos TIC ocupan la mayoría de las acciones restantes. En cuanto a los secundarios, predominan con un porcentaje superior al $80 \%$ los recursos TIC (Figura 7.22) lo que es lógico dada la naturaleza del ATA.

Figura 7.22 Realización de tarea con TIC.

E.Currículum Primarios y Secundarios
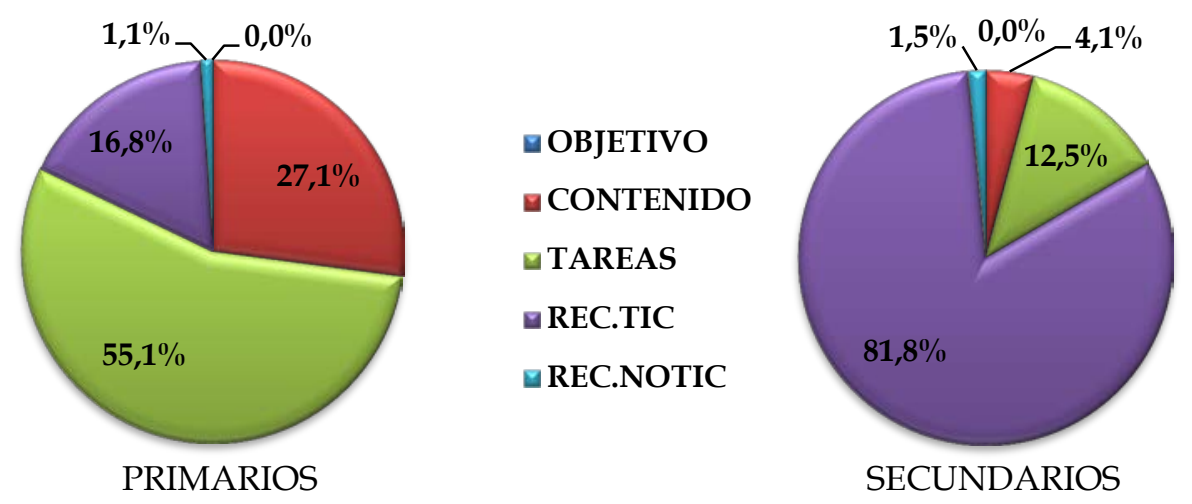

\subsubsection{Realización de tarea sin TIC}

En el ATA de "realización de tarea sin TIC", el recurso TIC no interviene para llevar a cabo la tarea que en cada caso se pueda estar realizando: bien sea ésta una manualidad, usar un punzón sobre un papel, colorear una ficha, escribir en la pizarra, etc. A lo largo de las grabaciones aparecen 10 ATAs de este tipo, que ocupan un total de 416 acciones instructivas, con una media por ATA de 41,6.

En lo referente a las acciones instructivas que desarrollan los profesores en el ATA se mantiene la línea de las anteriores, predominando la supervisión: Mira, se te ha caído el libro, Hansa, porque no lo has hecho bien, vamos (SupervisaTarea-Recurso no TIC, Caso 7); y la identificación: Ya estamos de vuelta al trabajo y hacemos estas letras, ¿Vale? (Identifica-Tarea-Recurso no TIC, Caso 6) como las acciones más frecuentes a lo largo de las sesiones dentro de este ATA, complementadas con la planificación: Yaiza va a poner su nombre, que lo hace muy bien, y sabe ponerlo fenomenal en todas las casillas, ¿verdad Yaiza mi amor? (Planifica-Tarea, Caso 9); y por último la explicación: Eso es, muy bien, Pablo, iban a Bremen, pero en el camino se encontraron a la casa de los ladrones que era muy confortable (Alumno: Eso es lo que he dicho yo) (Explica-Contenido, Caso 2) (Figura 7.23). 
Figura 7.23 Realización de tarea sin TIC.

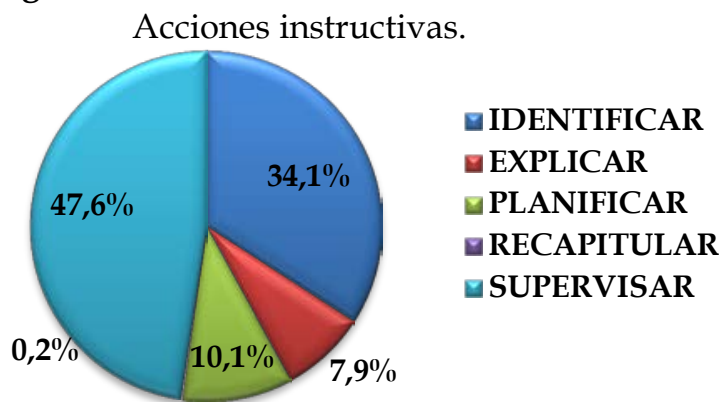

Si analizamos cuáles son los elementos del curriculum que aparecen en este tipo de actividad comprobamos que predominan las tareas y el contenido sumando entre las dos más de un $90 \%$ de los elementos primarios del curriculum, distribuyéndose el resto de los elementos categorizados entre los recursos TIC y los recursos no TIC. En los elementos de curriculum secundarios el recurso no TIC abarca un $80 \%$ del total, y en menor porcentaje las tareas, los contenidos y en algún caso también el recurso TIC (Figura 7.24). Aunque este último dato pueda parecer contradictorio se debe a que en algunas ocasiones el profesor supervisa puntualmente comportamientos relacionados con el ordenador, o bien, identifica contenido visto con anterioridad en el Recurso TIC y que apoyan la realización de tarea sin TIC, un ejemplo sería esta tarea en la que la profesora 1 está preguntando sobre los cuentos:

Profesora: Bueno como ya sabemos de todo el curso, de todo, de todo... hemos dicho que los cuentos... ¿Cómo se pueden? ¿qué formas hay en cuanto a ver?(Supervisa-Contenido-Tarea) Niños: en el libro Profesora: levantamos la mano (Identifica-Tarea) Niños: (levantan la mano) Profesora: en el libo pero los que estamos viendo este año, vale ¿en el libro? (Recapitula-Contenido) Niña: en el ordenador Profesora: en el ordenador (Identifica-Recurso TIC).

Figura 7.24 Realización de tarea sin TIC.

E.Currículum Primarios y Secundarios

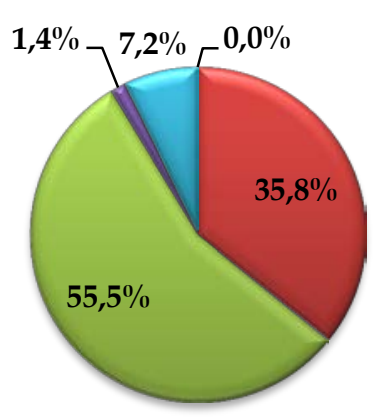

PRIMARIOS

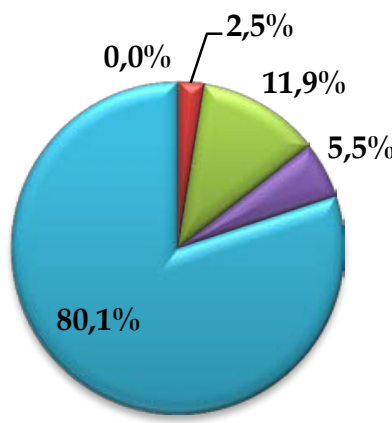

SECUNDARIOS 


\subsubsection{Corrección de trabajos en clase}

Otra de las actividades que los profesores llevan a cabo en ocasiones es la corrección de las tareas realizadas por los alumnos una vez concluidas, lo que suele verificarse mientras los alumnos van pasando de forma ordenada por la mesa del profesor para que les supervise la tarea. Esta ATA aparece en siete ocasiones con una media de 87 acciones instructivas en cada una de ellas.

En relación con las acciones instructivas predomina la supervisión: Vale, ¿y cuál es el tres, qué número es el tres? ¿cómo se pone? ¿Cuál es tres? búscamelo... un gusanito, venga... (Supervisa-Tarea-Recurso no TIC, Caso5); seguida de la identificación: Sí señor, cuéntalos todos, cariño (Identifica-Tarea, Caso 9), suponiendo ambas un porcentaje superior al 80\% (Figura 7.25).

Figura 7.25 Correción de trabajos en clase.

Acciones instructivas.

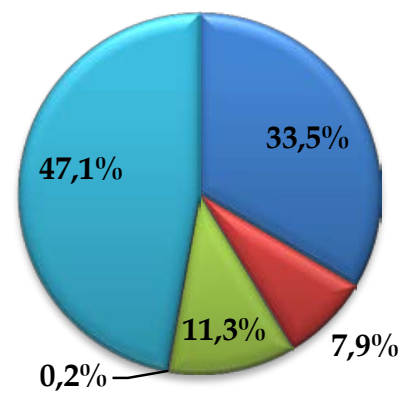

$\square$ IDENTIFICAR

GEXPLICAR

$\square$ PLANIFICAR

$\square$ RECAPITULAR

$\square$ SUPERVISAR

Los elementos del curriculum primarios sobre los que actúan las acciones instructivas son las tareas con un $80 \%$ y los contenidos con un $14 \%$. En cuanto a los secundarios, son los recursos no TIC los que predominan y en menor porcentaje los recursos TIC, las tareas y los contenidos (Figura 7.26).

Figura 7.26 Correción de trabajos en clase.

E.Currículum Primarios y Secundarios
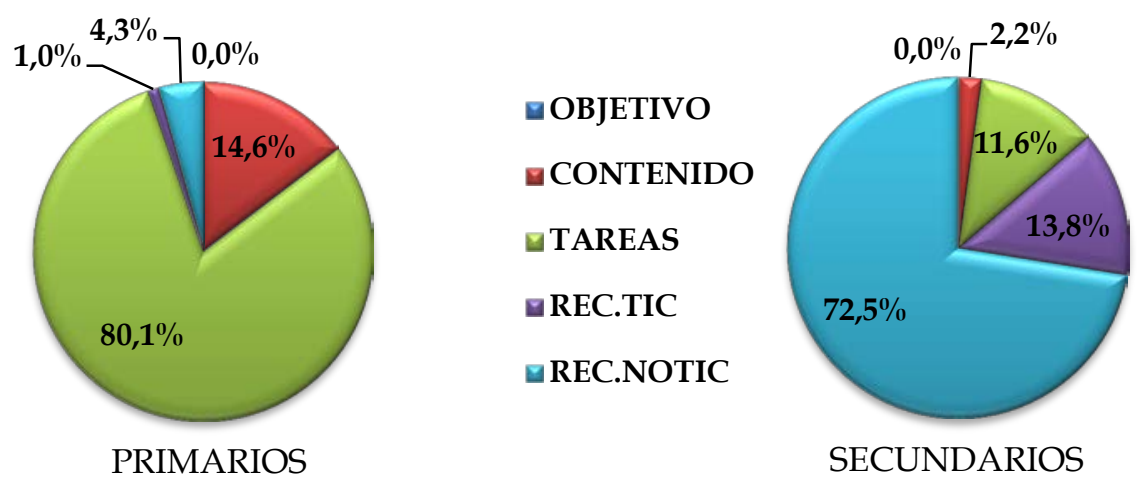


\subsubsection{Organización de vuelta del recreo.}

El ATA de "organización de vuelta del recreo" en la etapa de Educación Infantil se podría también calificar de rutina. Se trata de organizar a los alumnos en el aula una vez que regresan del descanso, para poder retomar las actividades de aula de carácter más académico. En las 41 grabaciones aparece en dos ocasiones, con un total de 33 acciones instructivas lo que otorga una media de 16,5 acciones instructivas por ATA.

La estructuración del ATA cuenta con porcentajes más compensados que en otras ATAs vistas anteriormente. Por ello, la supervisión: Vale chicos, hemos bebido agua, hemos hecho pis, nos hemos lavado las manos (Supervisa-Tarea, Caso 1); la planificación: Bueno pues... chicos, cada uno va a continuar con el trabajo que estábamos haciendo y que no hemos acabado vale... y los niños que ya hayan terminado la nevera van a poder jugar al ordenador, vale... de dos en dos. (PlanificaTarea, Caso 1); la identificación: Bebe un poquito de agua que estás super acalorada, a que sí (Identifica-Tarea, Caso 1) y la explicación: (Alumno: Yo estoy sudando) Porque como ya está haciendo buen tiempo (Explica-Contenido, Caso 1) oscilan entre un $36,4 \%$ del total de acciones la que más porcentaje abarca y un $18,2 \%$ la que menos (Figura 7.27).

Figura 7.27 Organización para vuelta del recreo. Acciones instructivas.

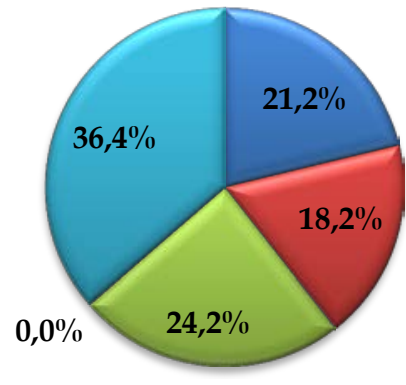

$\square$ IDENTIFICAR

$\square$ EXPLICAR

$\square$ PLANIFICAR

$\square$ RECAPITULAR

$\square$ SUPERVISAR

En cuanto a los elementos del curriculum, al igual que ocurría en la ATA anterior, las tareas destacan significativamente entre los elementos del curriculum primarios con cerca de un $80 \%$ del total. Los elementos secundarios, se distribuyen entre los recursos no TIC y los TIC ocupando éstos tres cuartas partes del total y las restantes acciones instructivas que cuentan con elementos secundarios se apoyan en las tareas (Figura 7.28) 
Figura 7.28 Organización de vuelta del recreo.

E.Currículum Primarios y Secundarios.
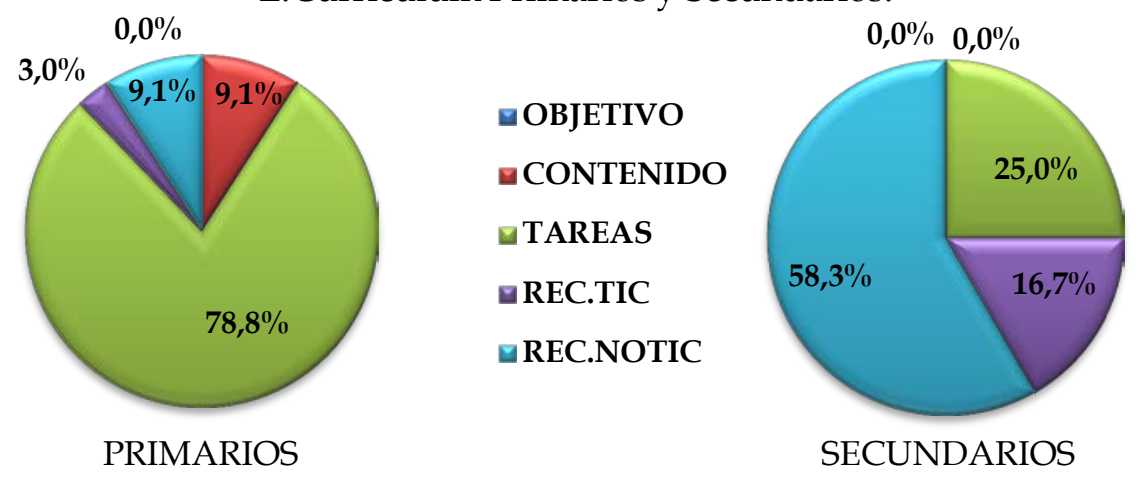

\subsubsection{Juego libre.}

El juego libre es una actividad que predomina en los primeros años de escolarización del alumnado como es el caso de la Educación Infantil. En ella el profesor deja a los alumnos que ya han acabado la tarea un tiempo para que realicen actividades lúdicas dentro de la propia aula, que ellos eligen según sus gustos o preferencias. Cuatro son las veces que están registradas contando con una media de 81,2 acciones por ATA.

Al tratarse de una actividad libre, el profesor sobre todo realiza acciones de supervisión e identificación, las cuales ocupan más de un 90\% del total de las acciones instructivas del ATA quedan relegados a un segundo lugar tanto la explicación como la planificación (Figura 7.29). En el siguiente texto se incluyen referencias a todas estas acciones instructivas dentro del desarrollo de esta ATA para el Caso 10, donde se ofrece a los niños que han acabado poder utilizar el ordenador mientras sus compañeros terminan:

Profesora: venga, Pablo, que te toca, venga, ¿no quieres? ¿quieres, Pablo? ¿quieres? ¿si? ¡Ah! Digo, a lo mejor es que no quiere (Planifica-Tarea-Recurso TIC, Caso 10) Niño: este, quiero... Profesora: venga, vamos a hacer un puzle primero, ¿vale? (Identifica-Tarea-Recurso TIC, Caso 10) ¿Quién va a empezar? Niño: yo Profesora: Adrián. (Planifica-Tarea-Recurso TIC, Caso 10) Adrián coges una pieza y lo arrastramos, esa es una castañera, busca a ver dónde la tienes que colocar, ahí (Explica-Tarea-Recurso TIC, Caso 10). 
Figura 7.29 Juego libre.

Acciones instructivas.

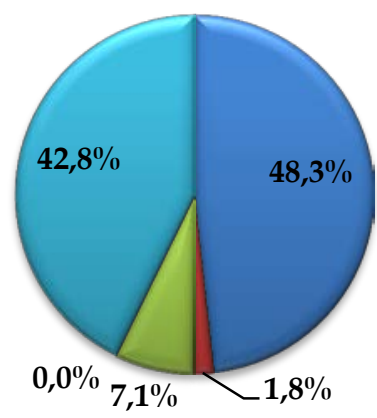

口IDENTIFICAR

口 EXPLICAR

$\square$ PLANIFICAR

$\square$ RECAPITULAR

口SUPERVISAR

Dichas acciones instructivas recaen sobre las tareas y en menor medida sobre el contenido y los recursos TIC y no TIC como elementos del curriculum primarios. En cuanto a aquellas acciones que además se apoyan en elementos del curriculum secundarios observamos que destacan dentro de estos últimos los recursos TIC y los recursos no TIC con más del 85\% del total (Figura 7.30).

Figura 7.30 Juego libre.

E.Currículum Primarios y Secundarios
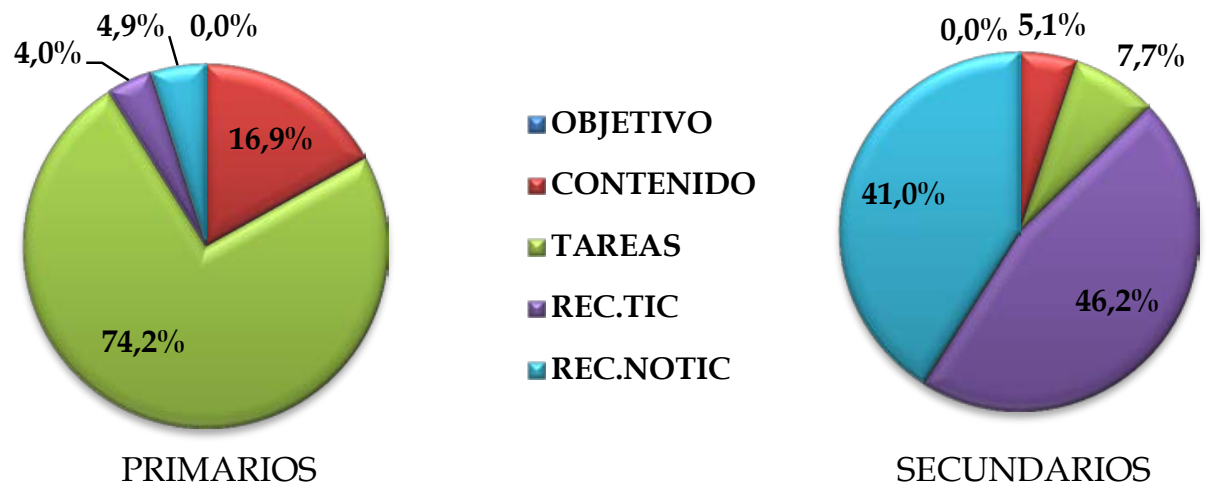

SECUNDARIOS

\subsubsection{Comer el bocadillo.}

Esta actividad se realiza a menudo en la etapa de Educación Infantil dentro del aula, de tal forma que el profesor ayuda y supervisa que los alumnos almuercen a media mañana de forma correcta: masticando despacio, cuidando de no mancharse, ayudándoles a abrir los lácteos... El momento suele coincidir justo antes de la salida al recreo. . Durante las sesiones grabadas ha sido registrada esta actividad en tres ocasiones con una media de 59 acciones instructivas por ATA. 
Esas acciones instructivas que realiza el profesor son mayoritariamente la identificación: María, vete para allí, siéntate, ah, coge el bocata (Identifica-Tarea, Caso 5) y la supervisión: ¿Ya has acabado de almorzar, cariño? (Supervisa-Tarea, Caso 9). Y en menor medida la planificación: Diego, vete y luego te las comes fuera, venga, Diego y Jenifer id los dos, primero Diego, eh, y luego tú, primero Diego y luego Jeni, porque como Jeni es nueva que ha venido hace una semana, ¿verdad?(PlanificaTarea, Caso 5) y la explicación: Puedes jugar, pero ojo con pelear (Explica-Tarea, Caso 9) (Figura 7.31).

Figura 7.31 Comer el bocata.

Acciones instructivas.

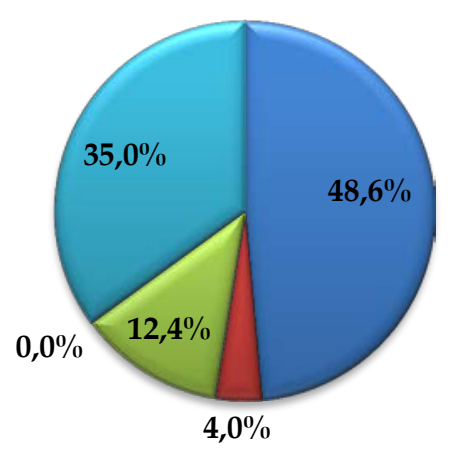

\section{$\square$ IDENTIFICAR}

$\square$ EXPLICAR

$\square$ PLANIFICAR

$\square$ RECAPITULAR

$\square$ SUPERVISAR

Los elementos del curriculum primarios que más destacan son las tareas con casi el 75\% y en menor medida el contenido y los recursos. Si vemos cuáles son los elementos del curriculum secundarios que aparecen en mayor porcentaje vemos que son los recursos TIC y los no TIC con algo más del 85\% (Figura 7.32)

Figura 7.32 Comer el bocata.

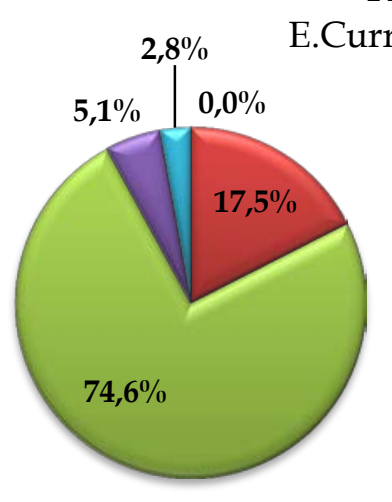

PRIMARIOS $\square$ REC.NOTIC

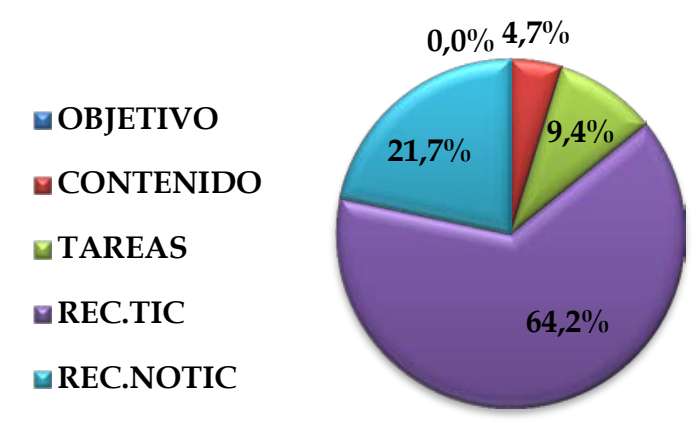

SECUNDARIOS 


\subsubsection{Lectura de imágenes con recurso no TIC.}

En el ATA de lectura de imágenes con recurso no TIC el profesor y los alumnos van construyendo una interpretación sobre qué figura está representada en una lámina que el docente muestra al conjunto de la clase. A través de preguntas, comparaciones, identificación de formas, colores, texturas, se elabora entre todos los participantes una explicación del contenido que transmite la imagen. Este ATA sólo aparece en 1 ocasión y se realiza a través de 79 acciones instructivas.

El profesor desarrolla esta actividad apoyándose en la supervisión: ¿Sabías a qué más se me parece a mí? (Supervisa-Contenido-Recurso no TIC, Caso 7) principalmente como acción instructiva, aunque también ocupan porcentajes relevantes la identificación: yo veo un dibujito ahí que parece otro animal chiquitito, chiquitito, chiquitito (Identifica-Contenido-Recurso no TIC, Caso 7) y la explicación: Pues esa raja es como una raja de las paredes, mira, mira la pared esta, ¿veis esa pared encima de las cortinas que tiene una raja grande? Y alli arriba ¿no veis allí arriba otra raja? pues esas es como una raja de esa pared. Esa pintura está pintada en una pared y esa pintura está pintada hace muchos, muchos, muchos, muchos años... (Explica-Contenido-Recurso no TIC, Caso 7) y, en menor medida, la planificación: vale, ahora vamos hacer otra prueba, vamos a mirar todos a ver desde lejos si veis otra cosa (Planifica-Tarea-Recurso no TIC, Caso 7) (Figura 7.33).

Figura 7.33 Lectura de imágenes con recurso no TIC.

Acciones instructivas.

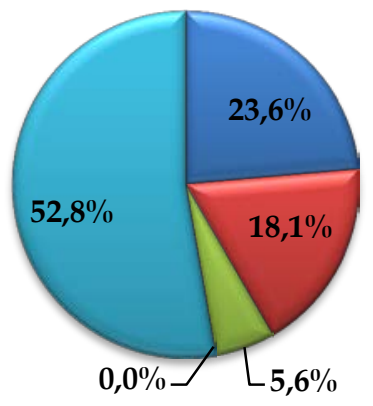

$\square$ IDENTIFICAR

$\square$ EXPLICAR

$\square$ PLANIFICAR

$\square$ RECAPITULAR

$\square$ SUPERVISAR

Los análisis muestran que en este ATA de "lectura de imágenes con recurso no TIC" predomina, en contraste con las mayoría de las ATAs vistas hasta ahora, el contenido con más de un $80 \%$ de las acciones instructivas como elemento del curriculum primario. $\mathrm{Si}$ observamos los registros que hacen referencia a los elementos secundarios del curriculum, prevalece en más de un 
90\% el recurso no TIC, tal como se puede observar en los ejemplos expuestos en el párrafo anterior (Figura 7.34).

Figura 7.34 Lectura de imágenes sin recurso TIC.

E.Currículum Primarios y Secundarios.
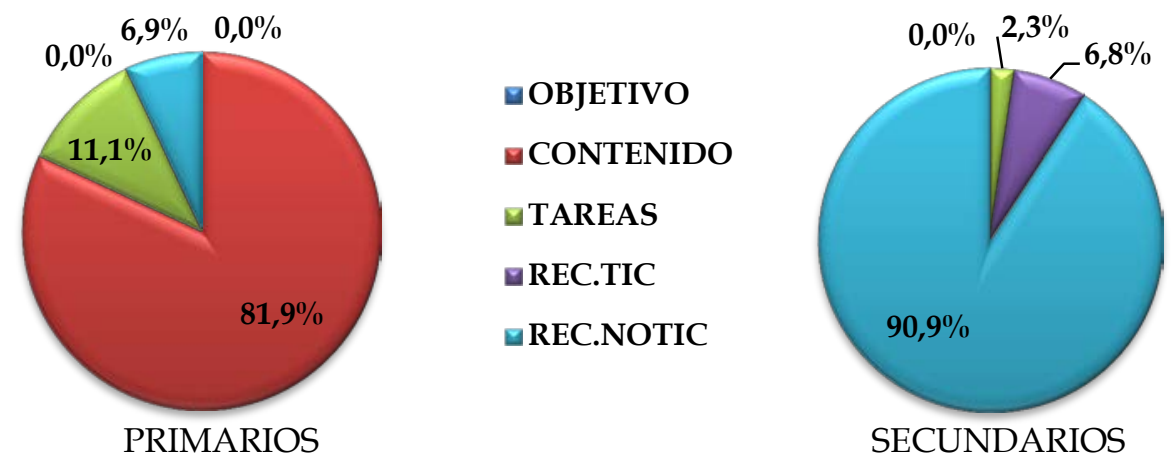

7.1.18. Lectura de imágenes con recurso TIC.

Al igual que en el ATA anterior, el profesor trata de que los alumnos interpreten una imagen sólo que en este caso se apoya en un recurso digital para realizar la actividad. En las 41 grabaciones aparece una vez y cuenta con 29 acciones instructivas.

En lo referente a los tipos de acciones instructivas que la componen, encontramos que son cuatro y se encuentran más repartidos que en lo que hemos visto en la mayor parte de las ATAs anteriores. La que tiene mayor porcentaje lo ocupa la explicación: Ya sabéis que nada que nada más que le deis aquí un poquito en la ruleta vale, a la ruleta que está aquí, la veis la ruleta ios acordáis de la ruleta? le dábamos un poquito a la ruleta $y$ va bajando para abajo ¿veis? Y vamos viendo... (Explica-Tarea-Recurso TIC, Caso 7); le sigue la supervisión: ¿Las veis? Todas estas son pinturas que están hechas ¿en las paredes de dónde? (SupervisaContenido-Recurso TIC, Caso 7) que cuenta con algo más de una cuarta parte; muy próxima a ésta se encuentra la identificación: Y esta otra mira, mira como se ven los animales bien, mira como se ven los animales, uy que chiquitita se ve esta ieh? (Identifica-Contenido-Recurso TIC, Caso 7) y el menor porcentaje de las que aparecen lo tiene la planificación: Ah, y antes de nada, venir, vamos a ver, vamos a ver más pinturas, vamos a ver un momentito para que luego las podáis ver si tenéis tiempo, unas poquitas más de pinturas rupestres (Planifica-Contenido, Caso 7) (Figura. 7.35). 
Figura 7.35 Lectura de imágenes con recurso TIC. Acciones instructivas.

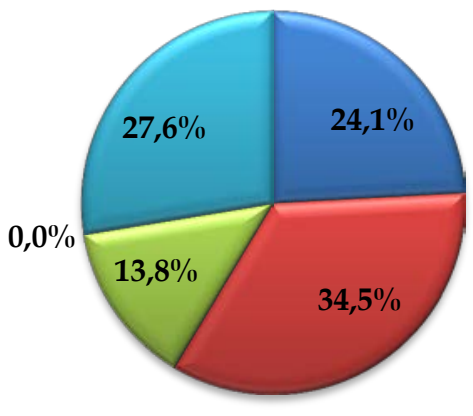

口IDENTIFICAR

口EXPLICAR

$\square$ PLANIFICAR

$\square$ RECAPITULAR

$\square$ SUPERVISAR

El profesor dirige sus acciones instructivas en esta ATA fundamentalmente al contenido, aunque la tarea ocupa un porcentaje superior al $20 \%$ dentro de los elementos del curriculum primarios. En cuanto a los elementos de secundarios, en el $100 \%$ de los casos en los que hay apoyo en la acción instructiva en uno de ellos es en el recurso TIC (Figura 7.36).

Figura 7.36 Lectura de imágenes con recurso TIC.

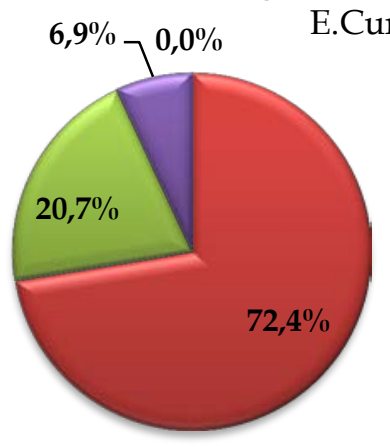

PRIMARIOS $\square$ OBJETIVO

$\square$ CONTENIDO

$\square$ TAREAS

$\square$ REC.TIC

$\square$ REC.NOTIC

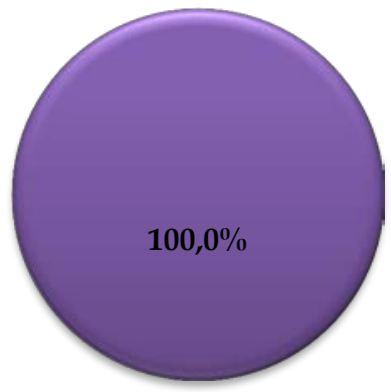

SECUNDARIOS

\subsubsection{Elección de lectura para casa.}

Uno de los rincones que hay en las clases de infantil hace referencia a la lectura, en esta ATA el profesor le indica a los alumnos libros que pueden seleccionar para llevarse a casa y leerlos. La "elección de lectura para casa" sólo apareció en una ocasión en las clases grabadas, que como dato curioso coincidió con un viernes de la semana, y es un tipo de actividad integrado por 24 acciones instructivas. 
Las acciones instructivas que el profesor realiza en el ATA son diversas, aunque predomina la supervisión: ¡Cesar! Ese cuento ya te lo has leído (SupervisaRecurso no TIC-Tarea, Caso 8) y la identificación: O éste, o el de Teo, el de Teo es muy chulo (Identifica-Recurso no TIC-Tarea) que juntas suman más del 80\% del total. Quedando completado por las acciones de planificar: Vamos a ir eligiendo el cuento del fin de semana, ¿vale? Pero nos vamos a sentar todos alli, vale. Marta, vas viniendo, Cesar ponte al lado de Sergio que Abel terminó y dónde... Marta ahí que vas a pasar al ratón, Sergio, para acá (Planifica-Tarea-Recurso no TIC, Caso 8); y por último explicar: Ah, sí, sí, aquí lo pone, cógete otro, coge éste de aquí, de... es una aventura muy diver... este no, mira, si tiene un cocodrilo, hombre (Explica-Recurso no TIC-Tarea, Caso 8) (Figura 7.37).

Figura 7.37 Elección de lectura para casa.

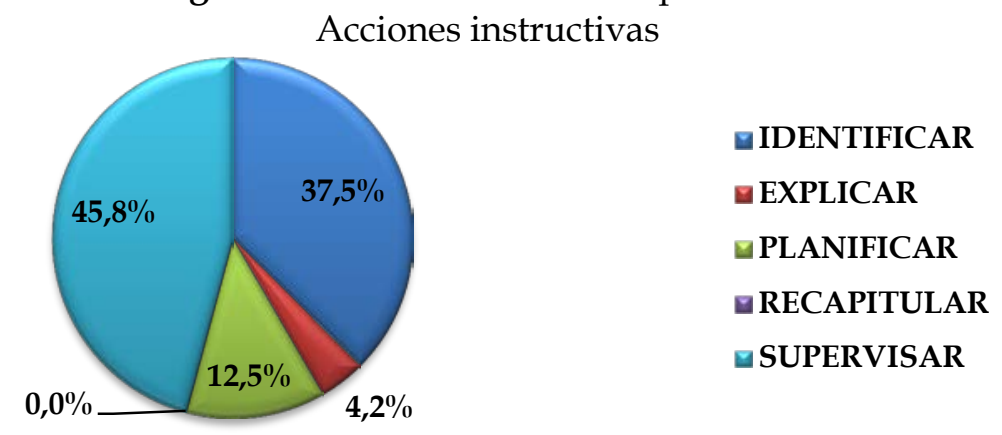

Analizando el ATA apreciamos que las acciones mencionadas se dirigen a los recursos no TIC y a las tareas como elementos del curriculum primarios, y lo mismo ocurre en los secundarios con porcentajes muy similares a los primarios (Figura 7.38).

Figura 7.38 Elección de lectura para casa.

E.Currículum Primarios y Secundarios

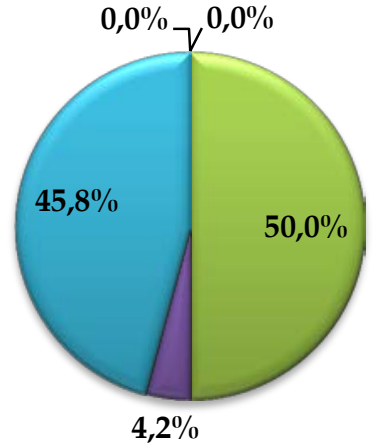

PRIMARIOS

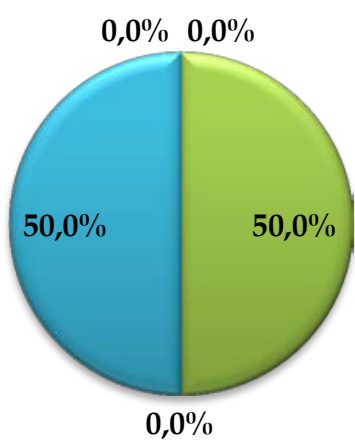

SECUNDARIOS 


\subsubsection{Síntesis comparativa de los datos descriptivos de las diferentes ATAs.}

Los resultados expuestos en los apartados anteriores desmenuzan de forma detallada cómo se trabaja en cada tipo de actividad detectada en los casos estudiados, permitiendo describir y analizar cuál es la naturaleza peculiar de cada una de ellas. Pero también es importante sintetizar estos datos y ofrecer una visión conjunta de los elementos de análisis para completar el estudio de lo que sucede en las ATAs y comparar cómo se distribuyen las acciones instructivas y los elementos del curriculum primario y secundarios en su conjunto.

Así, si miramos el total de los datos que hemos obtenido de la investigación en relación con el sistema de categorías, comprobamos que las acciones instructivas se distribuyen de forma global de la siguiente manera:

- Supervisar, que con 6214 acciones instructivas cuenta con el $44,2 \%$ de las 14.070 totales que han sido categorizadas a través del sistema de análisis.

- Identificar, que supone el 33,1\% del total con 4658 acciones instructivas de los docentes.

- Planificar, con un $13,7 \%$ ocupa el tercer lugar con una frecuencia de 1923 acciones instructivas.

- Explicar, cuenta con 1215 acciones con lo que supone un 8,6\% de las 14070 que componen el total.

- Recapitular, es la que menor representación tiene dentro de las acciones de los docentes con tan sólo un $0,4 \%$ lo que supone 60 acciones instructivas recogidas a lo largo de las 41 grabaciones.

Por lo tanto, encontramos que las Actividades Típicas de Aula analizadas de forma individual repiten un patrón muy similar al que se obtiene cuando se analizan todas en conjunto. De tal forma que las acciones instructivas de identificar o supervisar son las que más desarrolla el profesorado. Sólo se ha constatado una excepción en el ATA de "lectura de imágenes con recurso TIC", donde aunque la identificación y la supervisión aparecen con un porcentaje importante, la acción que más destaca es la de explicación.

Esta afirmación sobre la semejanza del conjunto de las ATAs analizadas respecto a cómo se distribuyen las acciones instructivas, queda reflejada de forma gráfica en la Figura 7.39 que se muestra a continuación: 


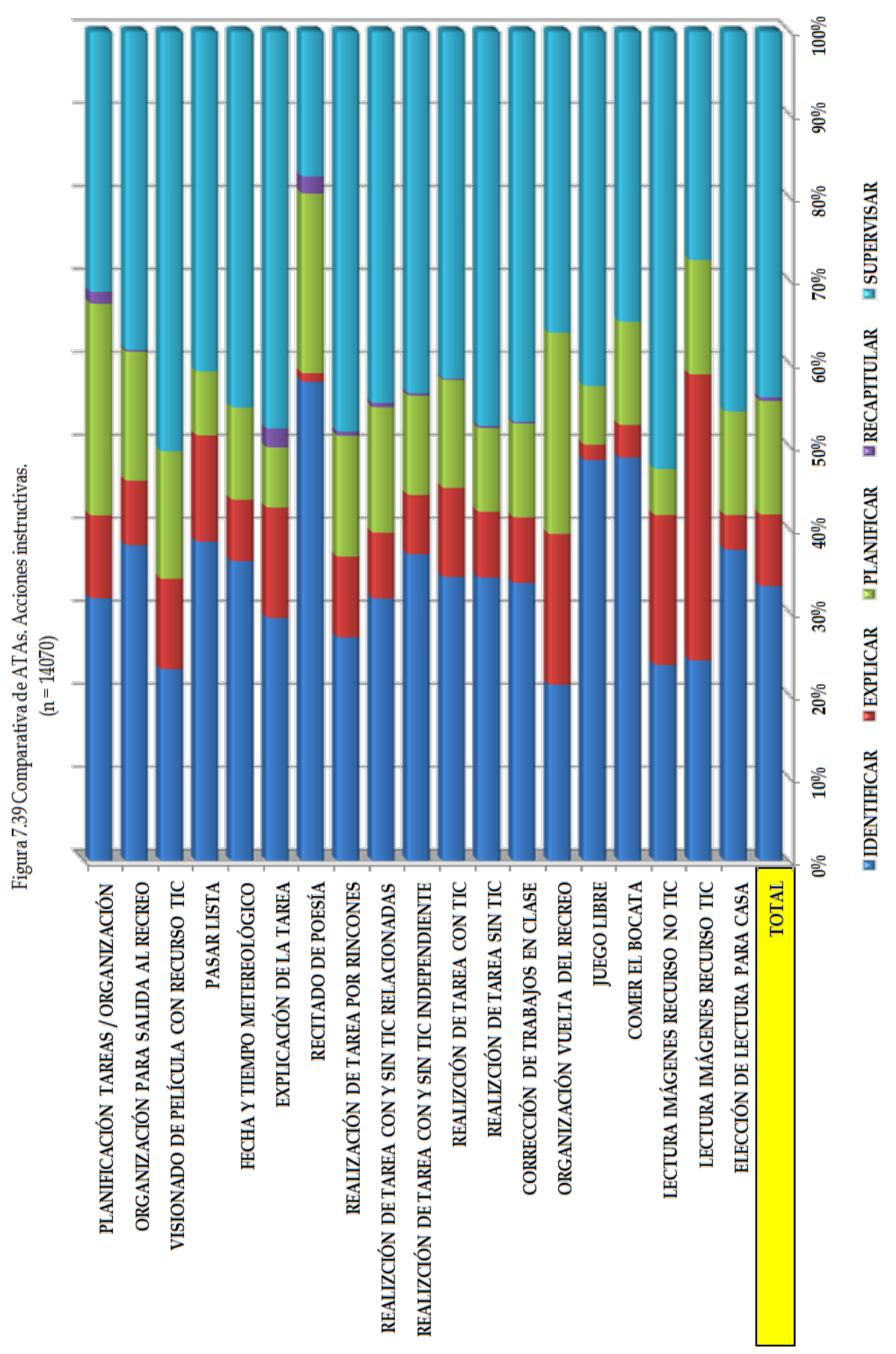


De igual manera que hemos visto que ocurre con las acciones instructivas, los elementos del curriculum primarios se presentan de forma global en el listado a continuación:

- Tareas, que ocupan el $65 \%$ de los 14070 elementos del curriculum primarios, lo que supone una frecuencia de 9139 de este elemento del curriculum primario.

- Contenido, son 3482 las frecuencias de aparición del contenido como elemento primario, lo cual representa un porcentaje del $24,7 \%$.

- Recurso TIC, ocupa el tercer lugar con un porcentaje del 5,6\% del total contando con una frecuencia de 786 .

- Recurso no TIC, muy próximo a los recursos TIC tiene una frecuencia de 658 , lo que supone un porcentaje del $4,7 \%$.

- Objetivo, su frecuencia es insignificante dentro de los datos aportados por la investigación contando con 4 frecuencias del total, lo cual representa un $0,02 \%$ de los 14070 elementos del curriculum primarios.

Por tanto, las tareas predominan sobre el resto de elementos del curriculum primario en el conjunto de los datos. Esta tendencia también se verifica de forma individual en las ATAs. Sin embargo, en cinco de las ATA descritas dicha tendencia no se verifica y es el contenido el elementos del curriculum primario mayoritario - fecha y tiempo meteorológico, explicación de la tarea, recitado de poesía, lectura de imágenes sin recurso TIC y lectura de imágenes con recurso TIC. Por otra parte en el ATA de "Elección de lectura para casa" las tareas están muy pocos puntos porcentuales por encima de los recursos no TIC. El resto de los tipos de actividad registrados verifican la tendencia que señalábamos al principio de este párrafo.

En la Figura 7.40 se aprecia de forma gráfica las excepciones anteriormente mencionadas y puede verse de forma comparada cómo se comportan cada una de las ATAs en función de los elementos del curriculum primarios que definen su estructura. 


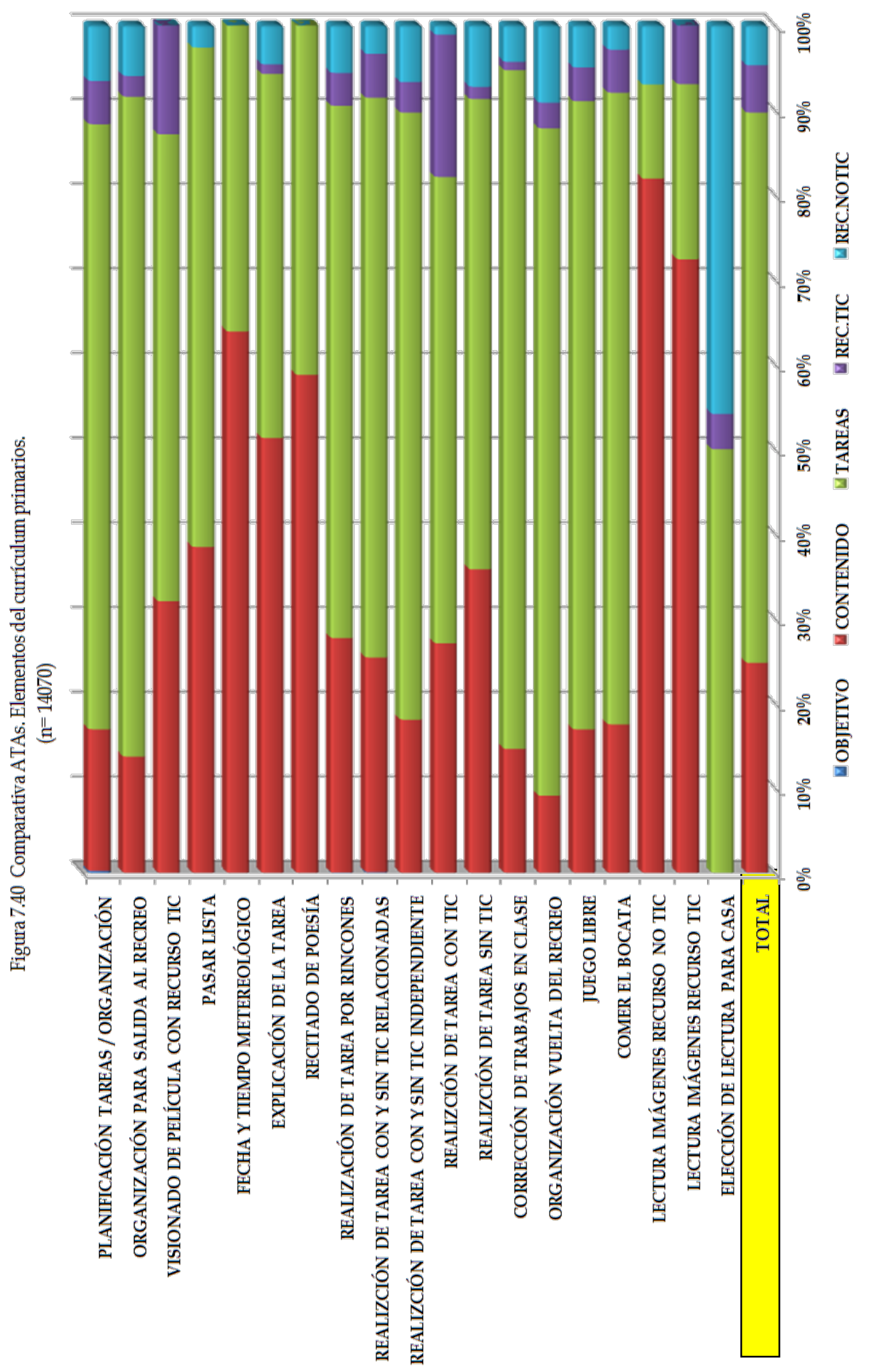


Por último, resta por describir los resultados relativos a los elementos del curriculum secundarios en su conjunto. Tal y como explicamos en el diseño de la investigación, si bien el número de acciones instructivas coincide con el número de elementos del curriculum primarios, no ocurre lo mismo en los secundarios. Los datos obtenidos muestran los siguientes resultados en el total de los 9169 elementos del curriculum secundarios registrados en todas las ATAs:

- Recurso TIC, es el elemento que más aparece de forma secundaria. En concreto un $42 \%$ del total, lo que corresponde a un total de frecuencias de 3852 .

- Recurso no TIC, casi en el mismo nivel que los recursos TIC, supone una suma de 3796 de las 9169 frecuencias totales, lo que representa un $41,2 \%$.

- Tareas, con un porcentaje del $12 \%$ las tareas ocupan el tercer lugar y los datos reflejan un total de frecuencias de 1099.

- Contenido, menos de la mitad de acciones que las tareas -421- son las que tienen como elemento del curriculum secundario el contenido, su porcentaje sobre el total es del $4,6 \%$.

- Objetivo, al igual que ocurría en los elementos del curriculum primarios los objetivos prácticamente no aparecen y en este caso una única frecuencia es la que se ha registrado, dentro de los elementos del curriculum secundarios.

La Figura 7.41, nos muestra el predominio de los recursos TIC y/o los recursos no TIC sobre el resto. Pero también en este caso encontramos algunas excepciones, en las que las tareas juegan un papel relevante como elementos secundario dentro de ATAs tales como: pasar lista, recitado de poesía y elección de lectura para casa. 


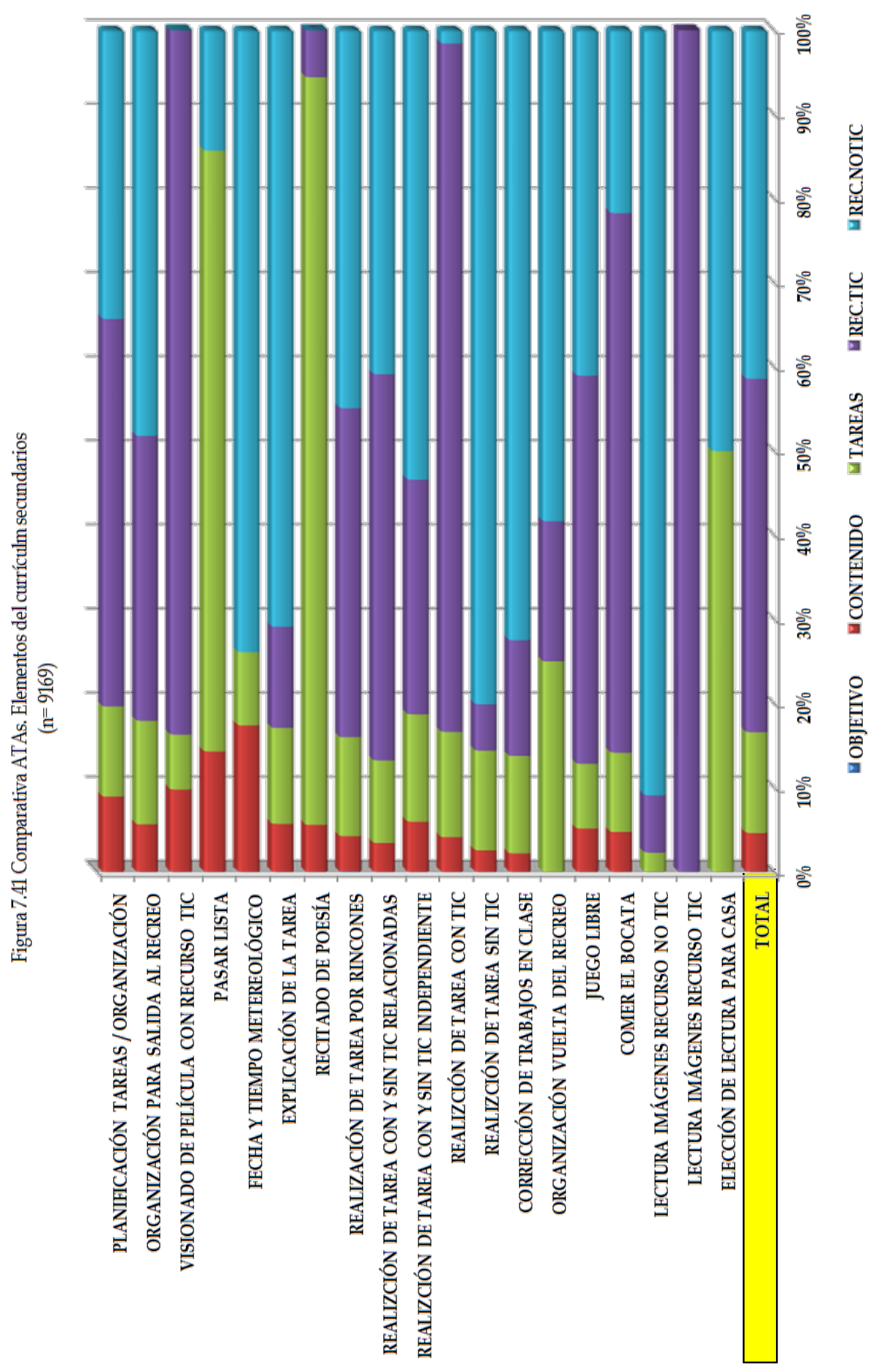


7.2. Datos descriptivos por profesores: Cómo desarrolla las prácticas docentes cada profesor del estudio.

\subsubsection{Caso 1}

En el estudio de caso 1 ( profesora 1), se realizaron un total de 5 grabaciones durante los dos primeros años del proyecto, llevándose a cabo tanto en el centro 1.2 -curso 2009/2010-, como en el centro 1.1 -curso 2010/2011- tal y como recoge la tabla 7.2:

\begin{tabular}{cccc}
$\begin{array}{c}\mathbf{N}^{0} \text { de } \\
\text { grabaciones }\end{array}$ & Año & Curso & $\begin{array}{c}\text { Tiempo de } \\
\text { grabación }\end{array}$ \\
\cline { 1 - 3 } 3 & $2009 / 2010$ & Aula unitaria & \multirow{2}{*}{5 h $4^{\prime} 33^{\prime \prime}$} \\
\hline 2 & $2010 / 2011$ & $3^{\circ}$ de EI & \\
\hline
\end{tabular}

Tabla 7.2 Número de grabaciones, año y curso Caso 1.

Una vez realizados los análisis de las clases nos encontramos con diferente distribución y reparto de ATAS en las sesiones registradas. De esta forma, los resultados muestran que las ATAS que aparecen un mayor número de veces son dos: "Planificación/Organización de Tarea" y "Realización de tarea por rincones" con tres frecuencias de aparición cada una de ellas. Por otro lado, las ATAS que tienen una frecuencia menor son $7 \mathrm{y}$ entre ellas podemos encontrar: "Realización de tarea con TIC", “Explicación de tarea”, ... (Tabla 7.3).

\begin{tabular}{ccc} 
ATA & $\begin{array}{c}\mathbf{N}^{0} \text { de ATA } \\
(\mathbf{f})\end{array}$ & $\begin{array}{c}\mathbf{N}^{0} \text { de Acciones } \\
\text { Instructivas (f) }\end{array}$ \\
\hline Planificación / organización tareas & 5 & 75 \\
\hline Organización para salida al recreo & 1 & 6 \\
\hline Visionado de película con recurso tic & 1 & 61 \\
\hline Explicación de la tarea & 1 & 9 \\
\hline Realización de tarea por rincones & 3 & 315 \\
\hline Realización de tarea con y sin tic relacionadas & 1 & 73 \\
\hline Realización de tarea con y sin tic independiente & 1 & 140 \\
\hline Realización de tarea con tic & 2 & 37 \\
\hline Realización de tarea sin tic & 1 & 18 \\
\hline Corrección de trabajos en clase & 1 & 33 \\
\hline Organización vuelta del recreo & 2 & 1573 \\
\hline TOTAL & 19 & \\
\hline
\end{tabular}

Tabla 7.3 Frecuencia de ATAs y de acciones instructivas por ATA. 
En cuanto al peso que las ATAS tienen en la sesión (tabla 7.3) destacan por encima del resto, aquellas que tienen que ver con la realización de tareas pues representan un $90 \%$ del total de las acciones instructivas que conforman las ATAs.

Para completar estos datos, resulta interesante también mostrar cómo el profesor estructura cada sesión de clase, en definitiva, cómo se configura cada sesión a través de la secuencia de ATAs seguida. Así, el conjunto de sesiones recogidas en la figura 7.42 muestra secuencia cronológica de las ATAS en cada sesión y el peso temporal de cada una de ellas, a través de las acciones instructivas.

Figura 7.42 Estructura de las ATAS por sesión Caso 1

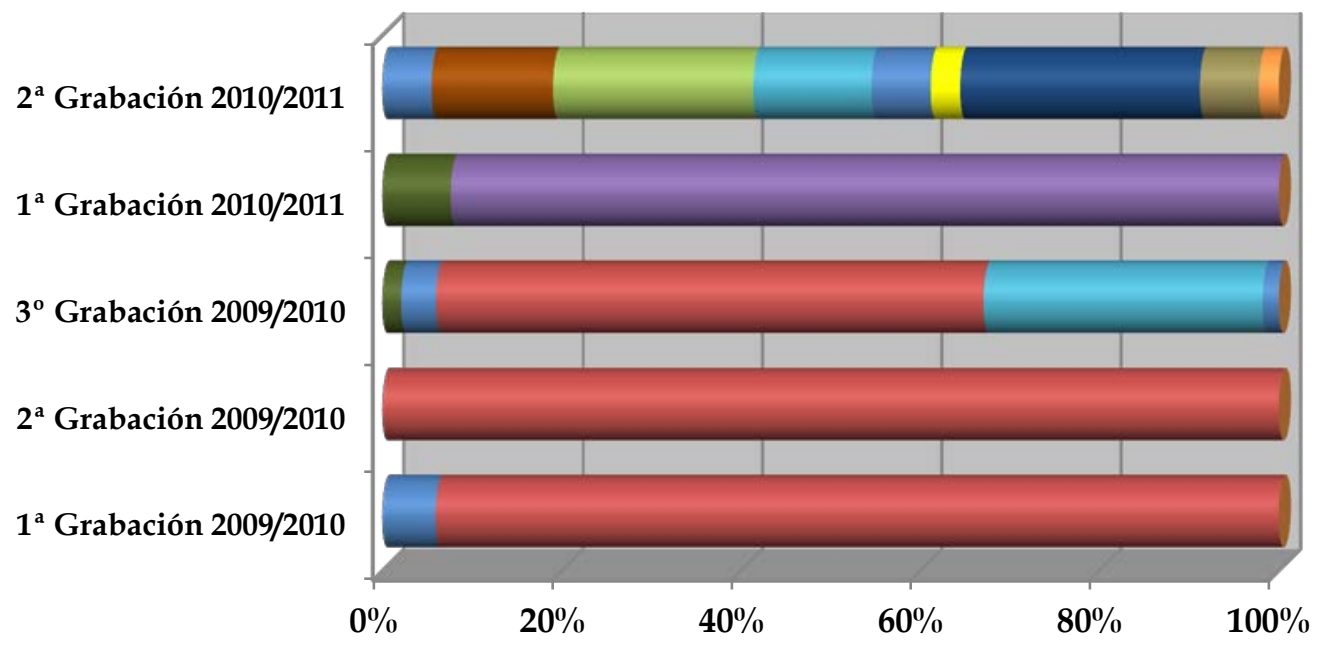

- Planificación/organización tareas

- Visionado de película con recurso tic

- Realización de tarea por rincones

- Realización de tarea con y sin tic independiente

- Realización de tarea sin tic

- Organización vuelta del recreo
- Organización para salida al recreo

Explicación de la tarea

- Realización de tarea con y sin tic relacionadas

- Realización de tarea con tic

- Corrección de trabajos en clase

El desarrollo de la práctica del profesor tomando como referencia las acciones instructivas, pone de relieve que la supervisión y la identificación son las más frecuentes a lo largo de las grabaciones, y en menor medida la planificación (Figura 7.43). 
Figura 7.43 Porcentaje de acciones instructivas Caso 1
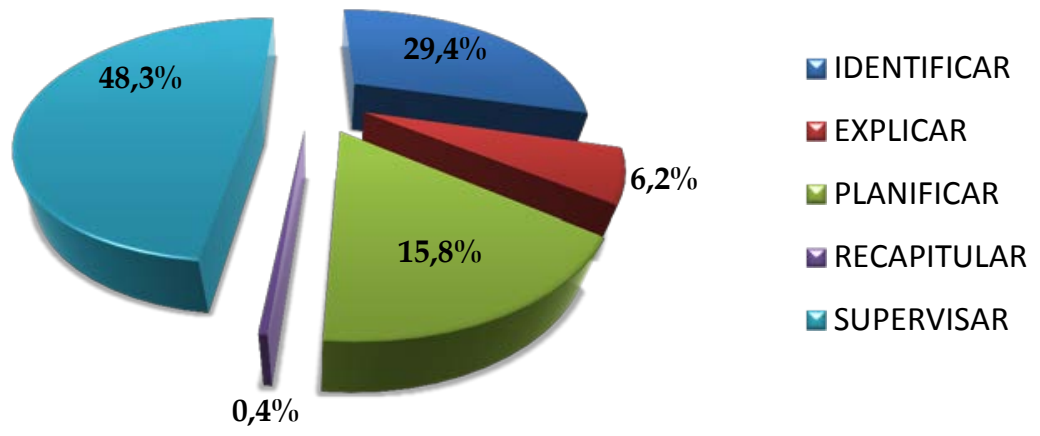

Por último, si atendemos a la configuración de los elementos del curriculum, vemos que entre los primarios destacan las tareas y los contenidos $\mathrm{y}$ en los secundarios encontramos en mayor medida los recursos TIC y los recursos no TIC (Figura 7.44).

Figura 7.44 Elementos del curriculum Caso 1

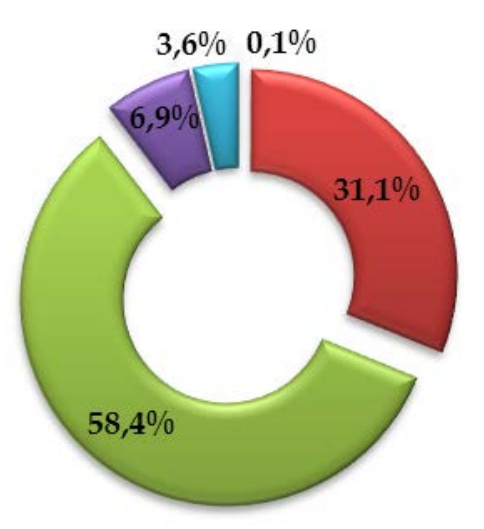

Primarios

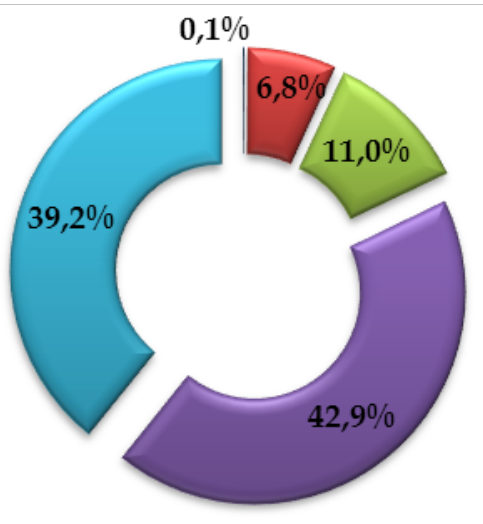

Secundarios

\subsubsection{Caso 2}

En el Caso 2 disponemos de grabaciones de los tres años, aunque en el primero sólo obtuvimos una de las tres posibles, por lo que el total de sesiones que pudimos registrar de la profesora 2 fue de cuatro, que quedan repartidas en función de las ATAS tal y como se muestra a continuación en la tabla 7.4: 


\begin{tabular}{|c|c|c|c|}
\hline $\begin{array}{c}\mathbf{N}^{0} \text { de } \\
\text { grabaciones }\end{array}$ & Año & Curso & $\begin{array}{l}\text { Tiempo de } \\
\text { grabación }\end{array}$ \\
\hline 1 & $2009 / 2010$ & $2^{\circ}$ de EI & \\
\hline 2 & $2010 / 2011$ & $3^{\circ}$ de EI & $3 \mathrm{~h} 55^{\prime} 11^{\prime \prime}$ \\
\hline 1 & $2011 / 2012$ & $1^{\circ}$ de EI & \\
\hline
\end{tabular}

Tabla 7.4 Número de grabaciones, año y curso Caso 2.

Las ATAS que aparecen en las cuatro sesiones analizadas (Tabla 7.5) muestran que las dos predominantes son "Realización de tareas con TIC" y "Planificación/organización de tareas" con 5 y 4 frecuencias respectivamente. Aunque como podemos observar el peso de la última ATA apenas tiene relevancia en proporción al número de acciones instructivas que el profesor ha realizado en ellas. Destaca de manera clara por su peso la "Realización de tareas con TIC" que ocupa un $80 \%$ de las acciones del docente en el total de las sesiones grabadas. El resto de ATAS que se identifican en las clases tiene baja frecuencia, la mayoría están en 1, y el peso en el total es bastante pequeño en comparación con la ATA predominante.

\begin{tabular}{ccc} 
ATA & $\begin{array}{c}\mathbf{N}^{0} \text { de ATA } \\
(\mathbf{f})\end{array}$ & $\begin{array}{c}\mathbf{N}^{0} \text { de Acciones } \\
\text { Instructivas (f) }\end{array}$ \\
\hline Planificación / organización tareas & 4 & 63 \\
\hline Organización para salida al recreo & 1 & 30 \\
\hline Visionado de película con recurso tic & 1 & 10 \\
\hline Pasar lista & $\mathbf{1}$ & 4 \\
\hline Recitado de poesía & 1 & 8 \\
\hline Realización de tarea con y sin tic independiente & 1 & 119 \\
\hline Realización de tarea con tic & 5 & 1387 \\
\hline Realización de tarea sin tic & 2 & 115 \\
\hline TOTAL & 16 & 1736 \\
\hline
\end{tabular}

Tabla 7.5 Frecuencia de ATAs y de acciones instructivas por ATA.

La secuencia cronológica de las ATAs en las diferentes sesiones grabadas en cada uno de los tres años con la profesora 2 se ofrece en la Figura 7.45. De esta forma podemos ver diferentes combinaciones en la gestión de la 
clase, aunque como ya hemos dicho, la realización de tareas con el recurso como centro es lo predominante en este caso concreto.

Figura 7.45 Estructura de las ATAS por sesión Caso 2

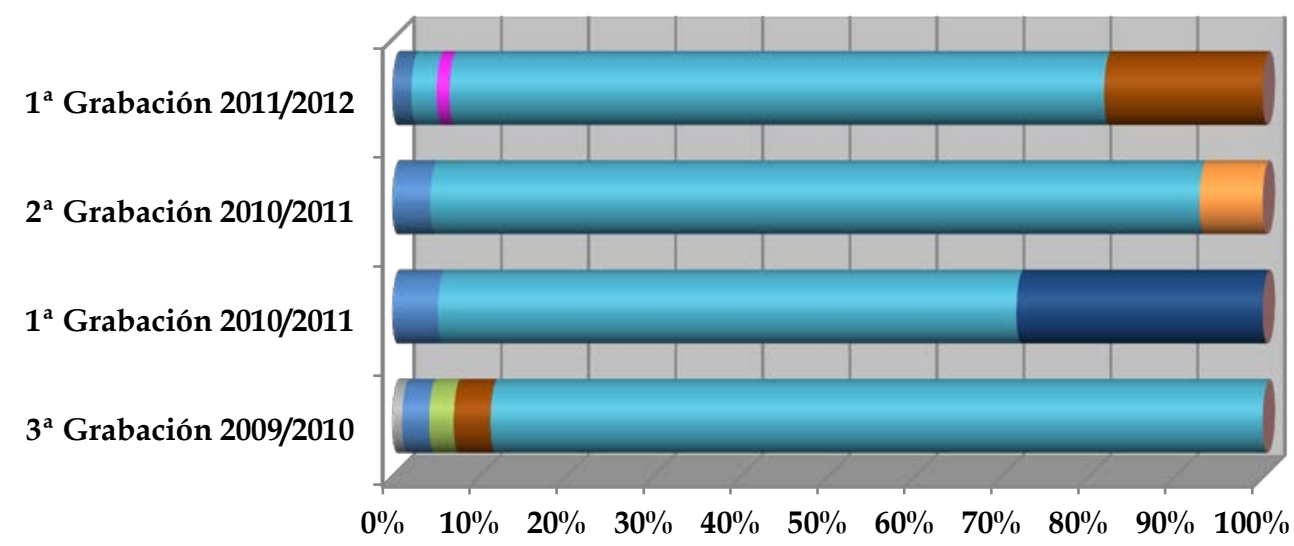

- Planificación tareas/organización

- Visionado de película con recurso tic

- Recitado de poesía

- Realización de tarea con tic

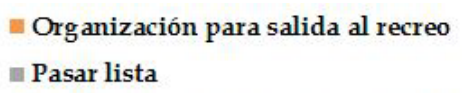

- Organización para salida al recreo

- Pasar lista

- Realización de tarea con y sin tic independiente

- Realización de tarea sin tic

En lo referente a las acciones instructivas en el Caso 2, predomina la supervisión y la identificación ocupando más de las tres cuartas partes del total de acciones instructivas realizadas. La planificación y la explicación quedan en un segundo plano y la recapitulación es, en este caso, inexistente (figura 7.46).

Figura 7.46 Porcentaje de acciones instructivas Caso 2

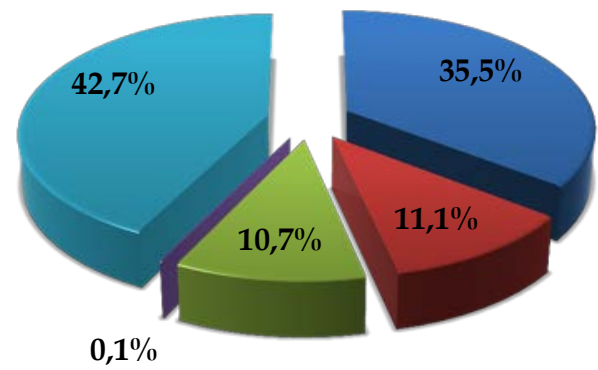
IDENTIFICAR
$\square$ EXPLICAR
$\square$ PLANIFICAR
$\square$ RECAPITULAR
$\square$ SUPERVISAR 
En los elementos del curriculum primarios predominan las tareas que representan más de la mitad del total de elementos sobre los que actúa el profesor. En cuanto a los secundarios, destaca de manera muy significativa el recurso TIC con aproximadamente el $75 \%$ del total de elementos del curriculum secundarios (figura 7.47).

Figura 7.47 Elementos del curriculum Caso 2
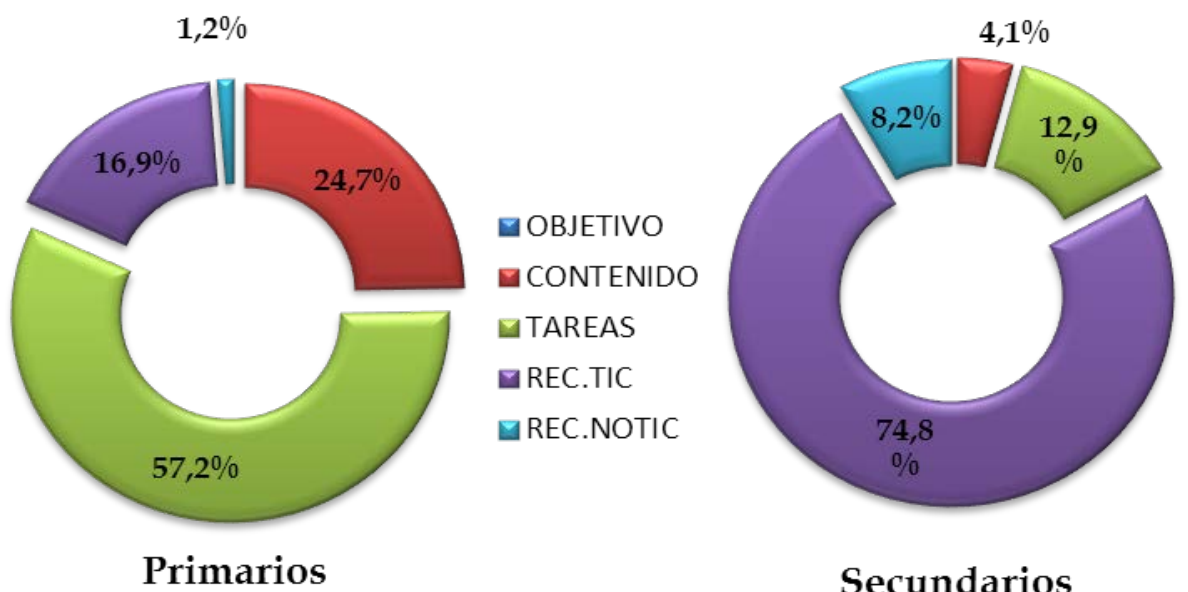

Secundarios

\subsubsection{Caso 3}

El profesor 3 permaneció en el centro 3 durante un año, esta circunstancia hace que sólo dispongamos de grabaciones durante un año académico y en un solo curso (Tabla 7.6).

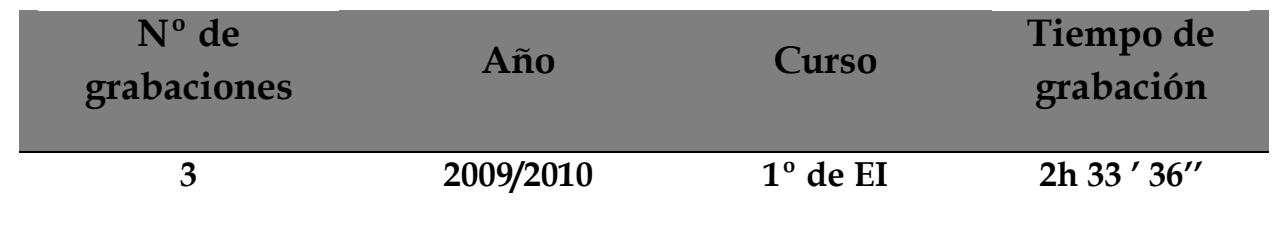

Tabla 7.6 Número de grabaciones, año y curso Caso 3.

El número de ATAS distintas es menor que en los casos anteriores, predominando por su frecuencia de aparición la "Planificación/organización de tarea" (a pesar de que su peso temporal sea reducido (48). La planificación queda registrada en cinco momentos distintos a lo largo de las 3 sesiones. En 
cuanto a la "Realización de tarea con y sin TIC relacionada" y la "Realización de tarea con y sin TIC independiente" son las ATAS que más acciones instructivas tienen con 159 y 477 respectivamente (tabla 7.7)

\begin{tabular}{ccc} 
ATA & $\begin{array}{c}\mathbf{N}^{0} \text { de ATA } \\
(\mathbf{f})\end{array}$ & $\begin{array}{c}\mathbf{N}^{0} \text { de Acciones } \\
\text { Instructivas (f) }\end{array}$ \\
\hline Planificación / organización de tareas & 5 & 48 \\
\hline Explicación de la tarea & 2 & 86 \\
\hline Realización de tarea con y sin TIC relacionada & 1 & 159 \\
\hline Realización de tarea con y sin tic independiente & 2 & 477 \\
\hline TOTAL & 10 & 770 \\
\hline
\end{tabular}

Tabla 7.7 Frecuencia de ATAs y acciones instructivas por ATA en el Caso 3.

Las cuatro ATAS que acabamos de describir se disponen a lo largo de las sesiones con diversa secuencia, combinándose para dar sentido a la planificación del docente, tal como se puede comprobar en la figura 7.48.

Figura 7.48 Estructura de las ATAS por sesión Caso 3

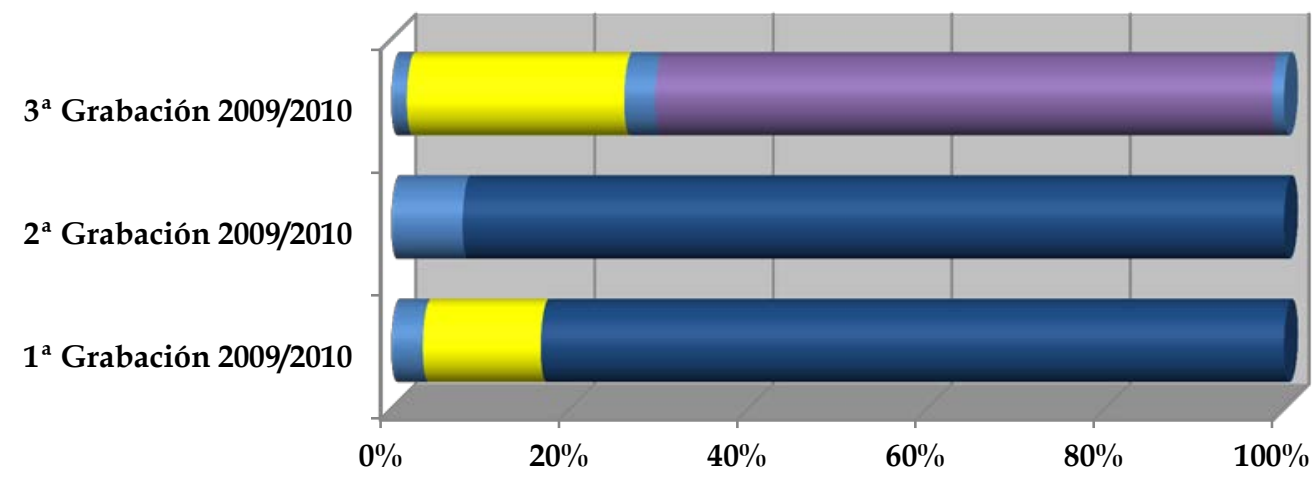

- Planificación tareas/ organización

Explicación de la tarea

- Realización de tarea con y sin tic relacionadas

- Realización de tarea con y sin tic independiente

$\mathrm{Si}$ atendemos a las acciones instructivas a lo largo de las tres grabaciones, el profesor 3 tiende a identificar y supervisar casi en un $75 \%$ de las acciones categorizadas (Figura 7.49), en menor medida planifica, explica y recapitula. 
Figura 7.49 Porcentaje de acciones instructivas Caso 3

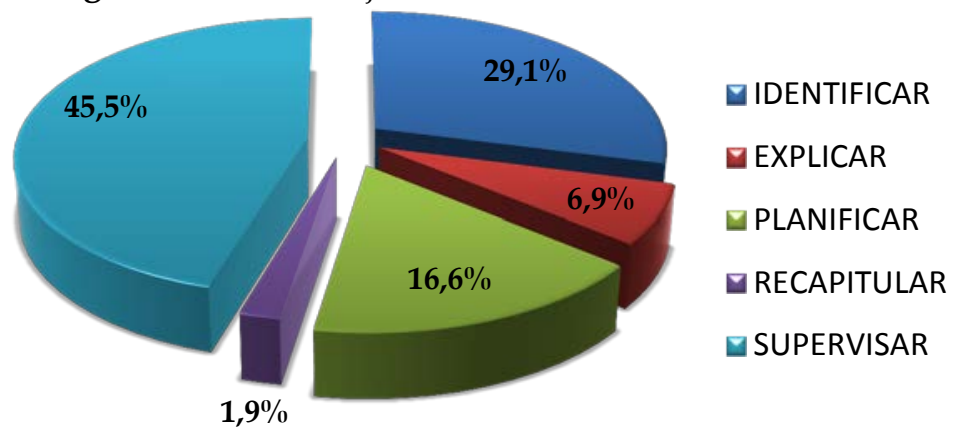

En relación con los elementos del curriculum, las tareas son más relevantes dentro de los primarios con casi el 70\%, que sumado al $20 \%$ de los contenidos dejan para los otros tres un poco más de un 10\% (Figura 7.50). Algo similar ocurre en los secundarios, pero en este caso pasan a ser los recursos TIC y los no TIC los que ocupan más de un $80 \%$ de los elementos secundarios categorizados en las sesiones del profesor 3.

Figura 7.50 Elementos del curriculum Caso 3
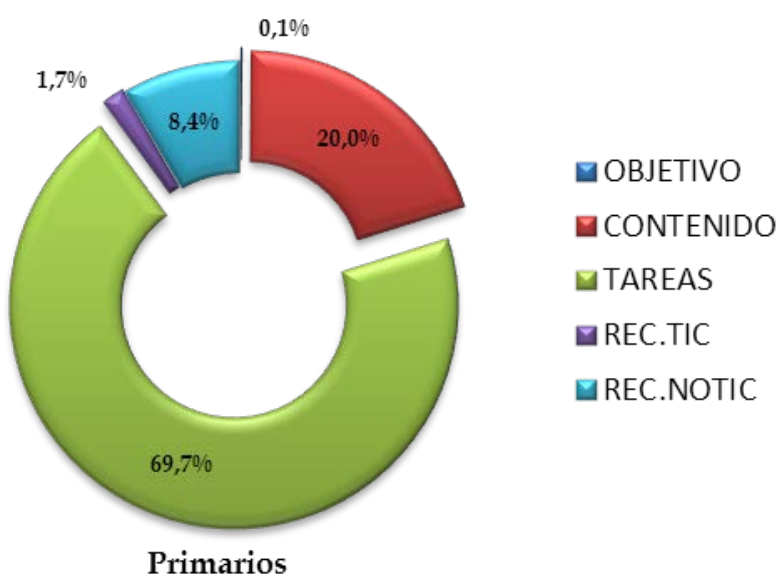

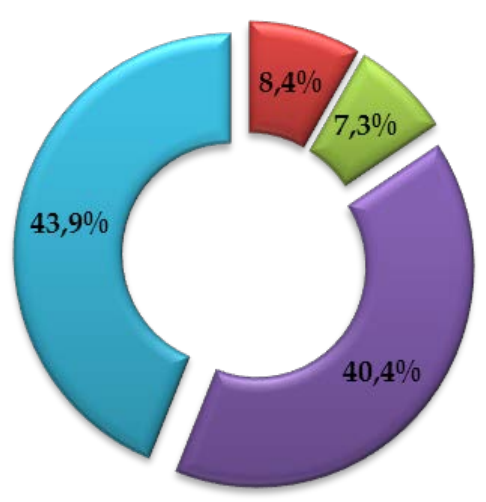

Secundarios

\subsubsection{Caso 4}

En el Caso 4 disponemos de un total de 6 grabaciones que están repartidas durante los tres años que dura la investigación. La profesora 4 además 
imparte docencia en los tres cursos del segundo ciclo de la etapa de EI a lo largo de los tres años de desarrollo de la investigación (Tabla 7.8).

\begin{tabular}{cccc}
$\begin{array}{c}\mathrm{N}^{\mathrm{o}} \text { de } \\
\text { grabaciones }\end{array}$ & Año & Curso & $\begin{array}{c}\text { Tiempo de } \\
\text { grabación }\end{array}$ \\
\hline 3 & $2009 / 2010$ & $2^{\circ}$ de EI & \\
\hline 2 & $2010 / 2011$ & $3^{\circ}$ de EI $17^{\prime} 52^{\prime \prime}$ & \\
\hline 1 & $2011 / 2012$ & $1^{\circ}$ de EI & \\
\hline
\end{tabular}

Tabla 7.8 Número de grabaciones, año y curso Caso 4.

En las seis grabaciones registradas la profesora 4 presenta frecuencias de entre 3 y 6 en diferentes ATAS, de las cuales las más habituales son "Planificación/organización de tareas", "Fecha y tiempo meteorológico" y "Realización de tarea con y sin TIC independiente". Sin embargo, "Explicación de tarea" y "Recitado de poesía" tan sólo aparecen una vez en los tres años de los que tenemos registros. En lo referente al peso de los tipos de ATA, las dos que tienen que ver con realización de tarea suman el mayor número de acciones instructivas, suponiendo más del 80\% del total (tabla 7.9)

\begin{tabular}{ccc} 
ATA & $\begin{array}{c}\mathbf{N}^{0} \text { de ATA } \\
\text { (f) }\end{array}$ & $\begin{array}{c}\mathbf{N}^{0} \text { de Acciones } \\
\text { Instructivas (f) }\end{array}$ \\
\hline Planificación / organización de tareas & 6 & 59 \\
\hline Pasar lista & 3 & 35 \\
\hline Fecha y tiempo meteorológico & 4 & 55 \\
\hline Explicación de tarea & 1 & 29 \\
\hline Recitado de poesía & 1 & 89 \\
\hline Realización de tarea con y sin TIC relacionada & 3 & 710 \\
\hline Realización de tarea con y sin tic independiente & 4 & 671 \\
\hline TOTAL & 22 & 1648 \\
\hline
\end{tabular}

Tabla 7.9 Frecuencia de ATAs y acciones instructivas por ATA en el Caso 4.

Si atendemos a la cronología de las ATAS en función de las diferentes sesiones categorizadas que disponemos, el resultado aparece en la figura 7.51. que ofrece una síntesis del desarrollo temporal de cada sesión registrada. 
Figura 7.51 Estructura de las ATAS por sesión Caso 4

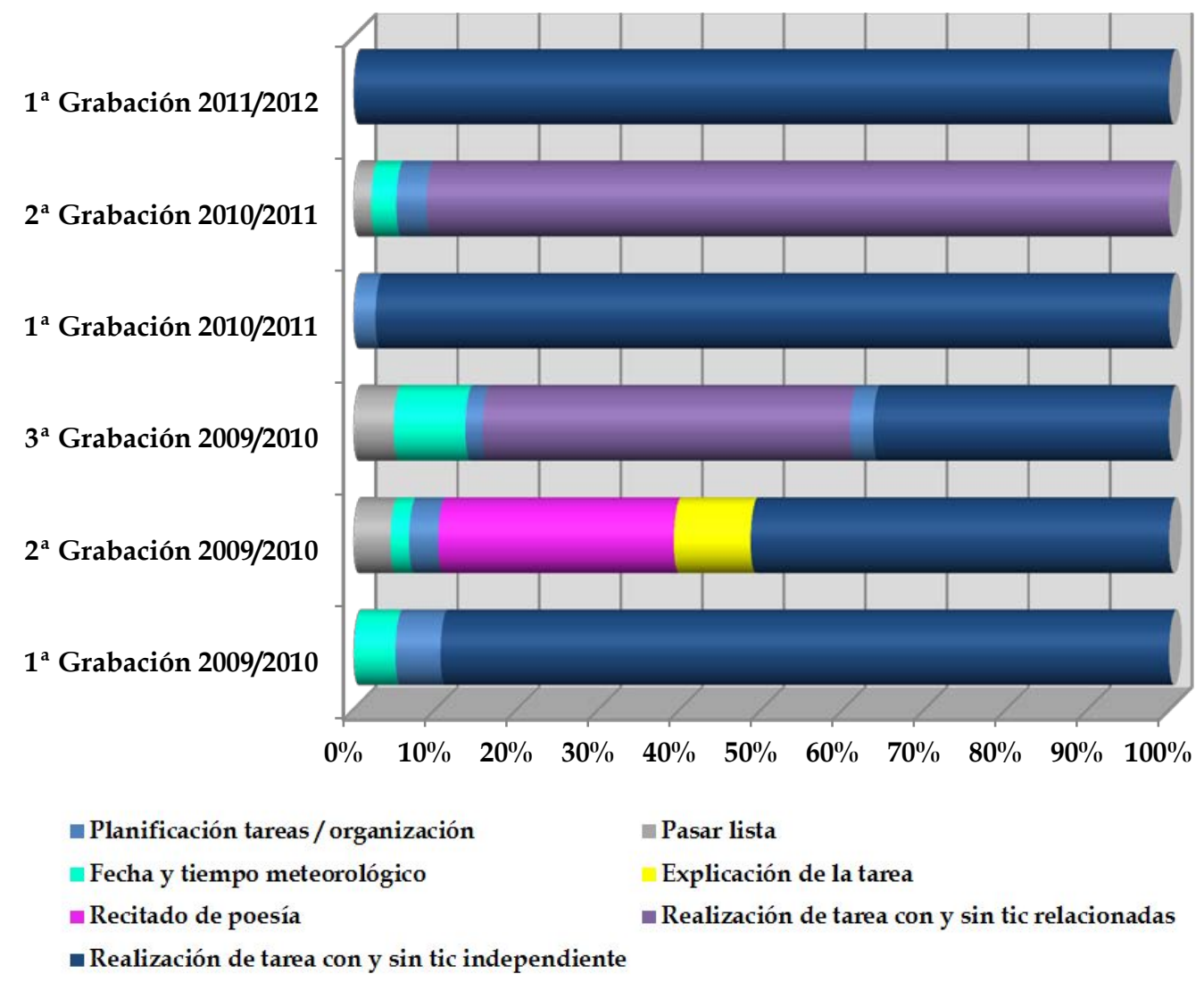

Las acciones instructivas que predominan en la profesora 4 de nuevo son la supervisión y la identificación. La suma de las dos suponen más del 70\% de todas las acciones categorizadas, las restantes se reparten entre la planificación, la explicación y la recapitulación, aunque la presencia de esta última es prácticamente insignificante (Figura 7.52). 
Figura 7.52 Porcentaje de acciones instructivas Caso 4

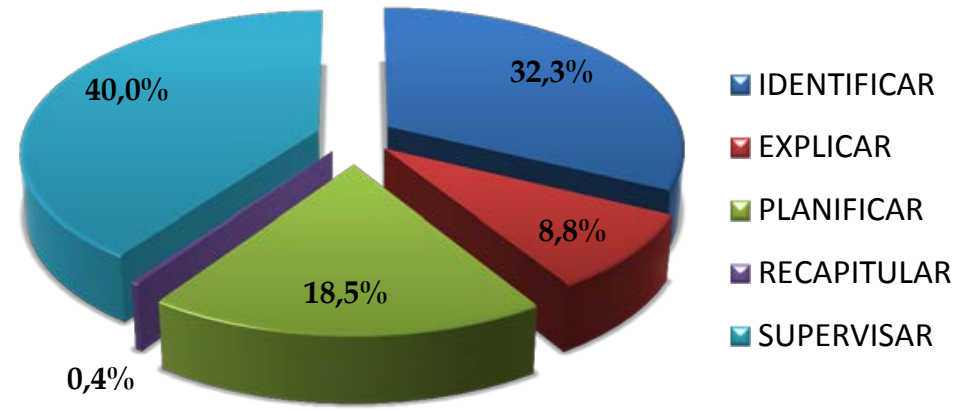

Las acciones instructivas indicadas anteriormente se ejecutan sobre distintos elementos del curriculum. En el Caso 4 son las tareas y el contenido, como viene siendo habitual, las que tienen un mayor número en los elementos del curriculum primario, mientras que en los secundarios predominan de nuevo los recursos TIC y no TIC. Destacar también la ausencia en ambos casos de los objetivos (Figura 7.53)

Figura 7.53 Elementos del curriculum Caso 4

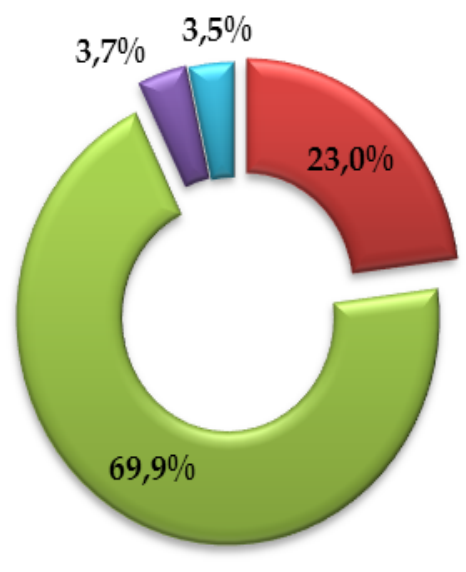

Primarios

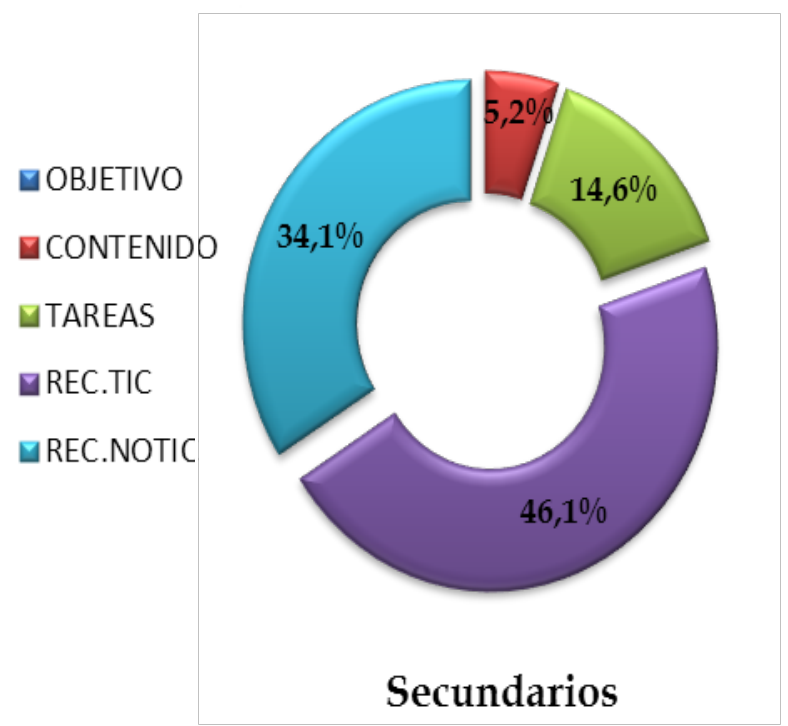




\subsubsection{Caso 5}

La profesora 5 ha participado en el proyecto durante los tres años, por lo que al igual que en el caso anterior contamos también con seis sesiones grabadas para su análisis. En la tabla 7.10 vemos la distribución de grabaciones, años y cursos del Caso 5

\begin{tabular}{cccc}
$\begin{array}{c}\mathbf{N}^{0} \text { de } \\
\text { grabaciones }\end{array}$ & Año & Curso & $\begin{array}{c}\text { Tiempo de } \\
\text { grabación }\end{array}$ \\
\cline { 1 - 2 } 3 & $2009 / 2010$ & $3^{\text {o de EI }}$ & \\
\cline { 1 - 3 } 2 & $2010 / 2011$ & $2^{\text {o de EI }} 25^{\prime} 31^{\prime \prime}$ \\
\cline { 1 - 3 } & $2011 / 2012$ & $3^{\text {o de EI }}$ & \\
\hline
\end{tabular}

Tabla 7.10 Número de grabaciones, año y curso Caso 5.

En cuanto a las ATAS, de los ocho tipos a los que recurre la profesora 5 para estructurar las sesiones, los más repetidos son "Planificación/Organización de tareas" y "Organización para salida al recreo" que cuentan con frecuencias de 5 y 4 en el total. Asimismo, las que menos registros tienen son "Realización de tareas por rincones", "Realización de tarea con y sin TIC independiente" y "Comer el bocadillo". En cuanto al peso, al igual que venimos viendo en los casos anteriores, las que tienen que ver con la realización de tareas son las que computan un mayor número de acciones instructivas por parte de la docente (Tabla 7.11).

\begin{tabular}{ccc} 
ATA & $\begin{array}{c}\mathbf{N}^{0} \text { de ATA } \\
\text { (f) }\end{array}$ & $\begin{array}{c}\mathbf{N}^{0} \text { de Acciones } \\
\text { Instructivas (f) }\end{array}$ \\
\hline Planificación / organización de tareas & 5 & 56 \\
\hline Organización para salida al recreo & 4 & 90 \\
\hline Realización de tarea por rincones & 1 & 158 \\
\hline Realización de tarea con y sin TIC relacionada & 4 & 603 \\
\hline Realización de tarea con y sin tic independiente & 1 & 316 \\
\hline Realización de tarea con TIC & 2 & 144 \\
\hline Corrección de trabajo en clase & 2 & 156 \\
\hline Comer el bocadillo & 1 & 8 \\
\hline TOTAL & 20 & 1531 \\
\hline
\end{tabular}

Tabla 7.11 Frecuencia de ATAs y acciones instructivas por ATA en el Caso 5. 
La estructuración cronológica de las seis sesiones de la profesora 5 es bastante variada. Es más duradera sobre todo la "Realización de tareas con y sin TIC relacionada", como podemos comprobar a través del número de acciones instructivas de la tabla anterior. Pero si nos fijamos de manera concreta en cada una de las sesiones, encontramos diferencias sustanciales entre las mismas.

Así, el orden cronológico que las ATAS presentan en las diferentes clases junto con el peso relativo de cada ATA dentro de las sesiones lo podemos valorar en la figura que se muestra a continuación (Figura 7.54):

\section{Figura 7.54 Estructura de las ATAS por sesión Caso 5}

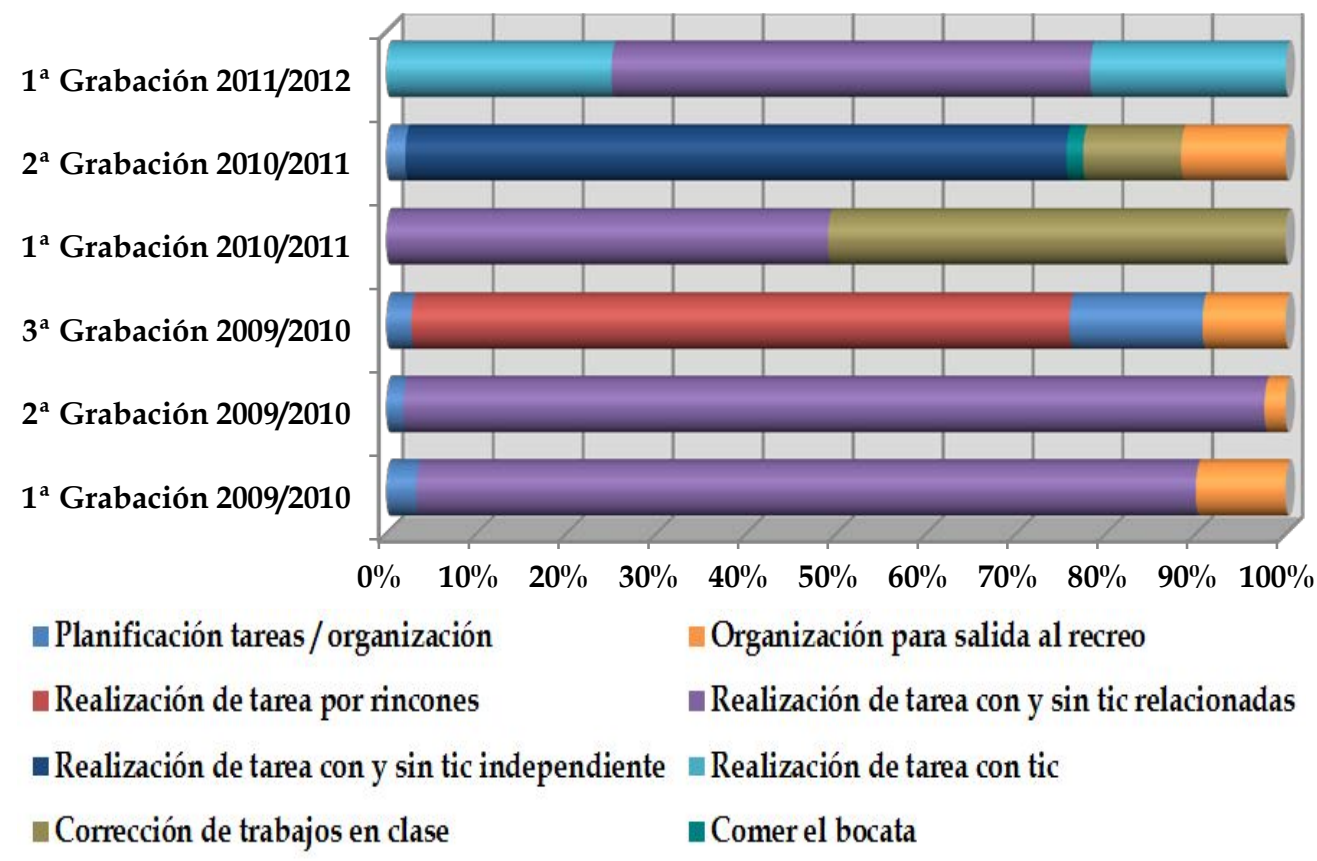

Analizando qué acciones instructivas destacan más durante las clases grabadas, vemos que predominan la supervisión y la identificación, en ese orden, contando con un porcentaje superior al 75\%, seguidas por la planificación con un porcentaje cercano al 20\% (Figura 7.55). 
Figura 7.55 Porcentaje de acciones instructivas Caso 5

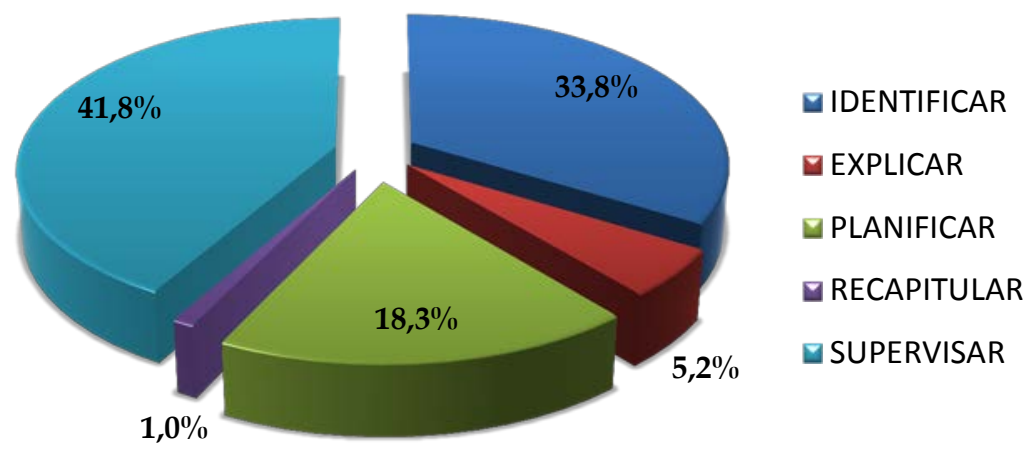

Para finalizar la descripción de los resultados del Caso 5, comprobamos que en lo relativo a los elementos del curriculum y su gestión por parte de la profesora 5, destacan en primer plano las tareas con casi un 75\% de todos los registros, seguido de los contenidos que cuenta con un 23\%; el resto corresponde a los recursos TIC y no TIC. Invirtiendo esta distribución, en los elementos secundarios cobran fuerza los recursos TIC y los recursos no TIC sumando más de un $80 \%$, seguido de las tareas y los contenidos en ese orden respectivamente (Figura 7.56). Tanto en los primarios como los secundarios encontramos una ausencia total de los objetivos.

Figura 7.56 Elementos del curriculum Caso 5

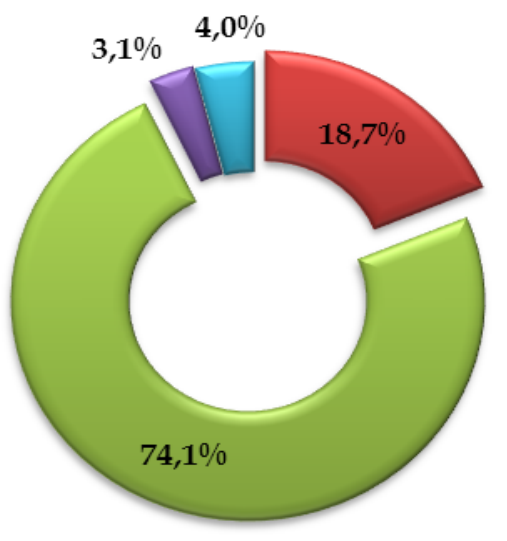

Primarios
口 OBJETIVO

$\square$ CONTENIDO

$\square$ TAREAS

$\square$ REC.TIC

$\square$ REC.NOTIC

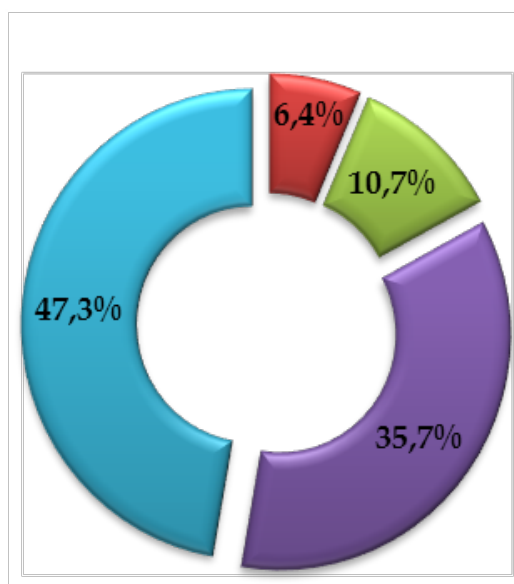

Secundarios 


\subsubsection{Caso 6}

Durante la investigación ha sido posible realizar grabaciones en el caso 6 durante el primer año, por lo que disponemos de 3 grabaciones tal y como recoge la Tabla 7.12.

\begin{tabular}{cccc}
$\begin{array}{c}\mathrm{N}^{\circ} \text { de } \\
\text { grabaciones }\end{array}$ & Año & Curso & $\begin{array}{c}\text { Tiempo de } \\
\text { grabación }\end{array}$ \\
\hline 3 & $2009 / 2010$ & $3^{\circ}$ de EI & $2 \mathrm{~h} \mathrm{20} 5^{\prime \prime \prime}$ \\
\hline
\end{tabular}

Tabla 7.12 Número de grabaciones, año y curso Caso 6 .

Los patrones de actividad que realiza en clase vienen recogidos en la tabla 7.13, en ella observamos que la ATA que aparece con más frecuencia en las sesiones es la de "Realización de tarea con y sin TIC relacionada" que cuenta con cuatro frecuencias a lo largo de las tres sesiones. Además, también tienen el mayor peso en acciones instructivas con un total de 376 acciones. En cuanto a las que menos frecuencia tienen comprobamos que son "Explicación de tarea"

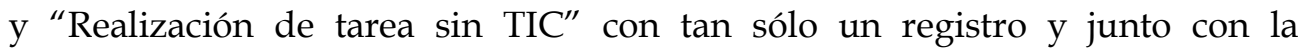
"Planificación/organización de tareas" son las que cuentan con menos peso temporal en el total de las clases grabadas.

\begin{tabular}{ccc} 
ATA & $\begin{array}{c}\mathbf{N}^{0} \text { de ATA } \\
(\mathbf{f})\end{array}$ & $\begin{array}{c}\mathbf{N}^{0} \text { de Acciones } \\
\text { Instructivas (f) }\end{array}$ \\
\hline Planificación / organización de tareas & 2 & 9 \\
\hline Organización para salida al recreo & 2 & 66 \\
\hline Visionado de película con recurso TIC & 2 & 85 \\
\hline Explicación de tarea & 1 & 376 \\
\hline Realización de tarea con y sin TIC relacionada & 4 & 7 \\
\hline Realización de tarea sin TIC & 1 & 560 \\
\hline 2.1 .2 TOTAL & 12 & 376 \\
\hline
\end{tabular}

Tabla 7.13 Frecuencia de ATAs y acciones instructivas por ATA en el Caso 6. 
Atendiendo a las ATAS recogidas en la tabla anterior, las sesiones se van organizando con diferentes distribuciones. En la Figura 7.57 aparecen cada una de las grabaciones registradas con la disposición temporal de las ATAS, indicando el porcentaie de su peso en acciones instructivas.

Figura 7.57 Estructura de las ATAS por sesión Caso 6

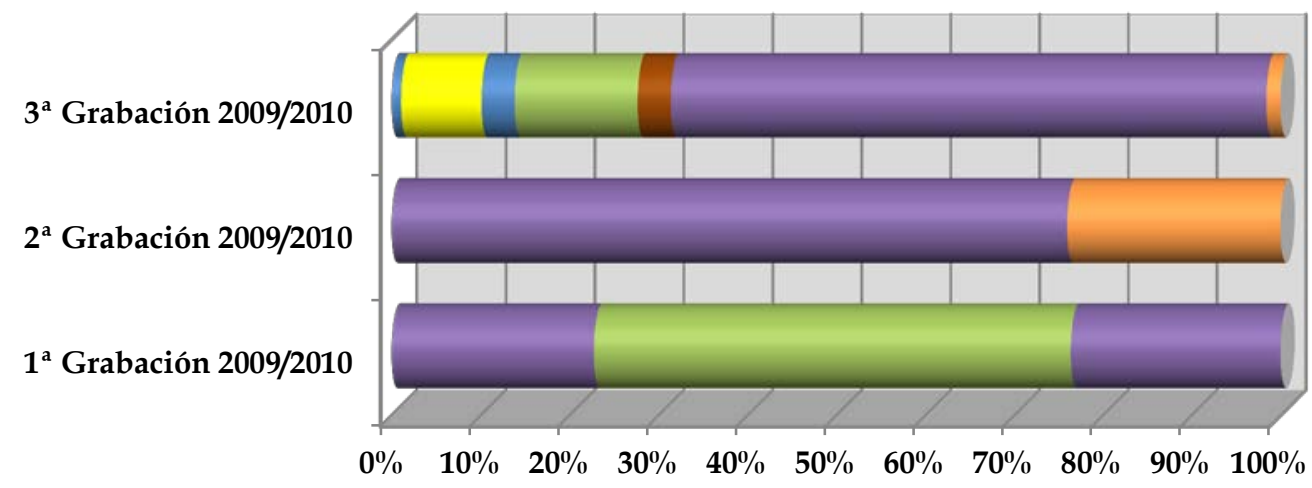

- Planificación tareas / organización

- Visionado de película con recurso tic

- Realización de tarea con y sin tic relacionadas
- Organización para salida al recreo

Explicación de la tarea

- Realización de tarea sin tic

Las acciones instructivas se concentran mayoritariamente en torno a la supervisión y la identificación, aunque la planificación también cuenta con una importante presencia en el Caso 6.

Figura 7.5 Porcentaje de acciones instructivas Caso 6

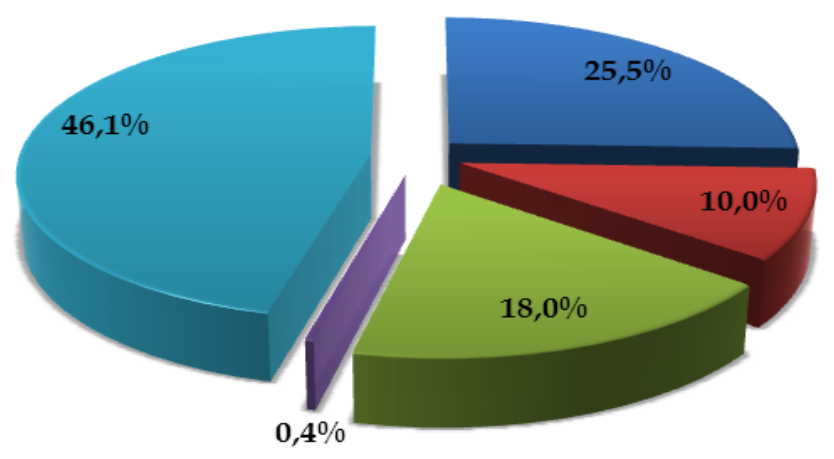

\author{
- IDENTIFICAR \\ $\square$ EXPLICAR \\ $\square$ PLANIFICAR \\ $\square$ RECAPITULAR \\ $\square$ SUPERVISAR
}

Por último, en los elementos del curriculum primario aparecen mayoritariamente las tareas y los contenidos. La profesora 6 dirige sus acciones instructivas hacia estos dos elementos en más del $90 \%$ de las ocasiones. Sin 
embargo, en los elementos secundarios del curriculum el papel protagonista lo desempeñan los recursos TIC y los recursos no TIC con un $44,4 \%$ y un $40,3 \%$ respectivamente. El resto de los elementos del curriculum, tanto en los primarios como en los secundarios, juegan un papel menor dentro del desarrollo de la clase (Figura 7.59).

Figura 7.59 Elementos del curriculum Caso 6

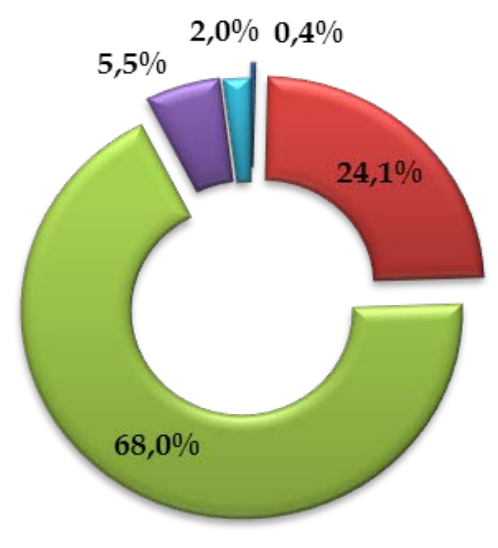

Primarios

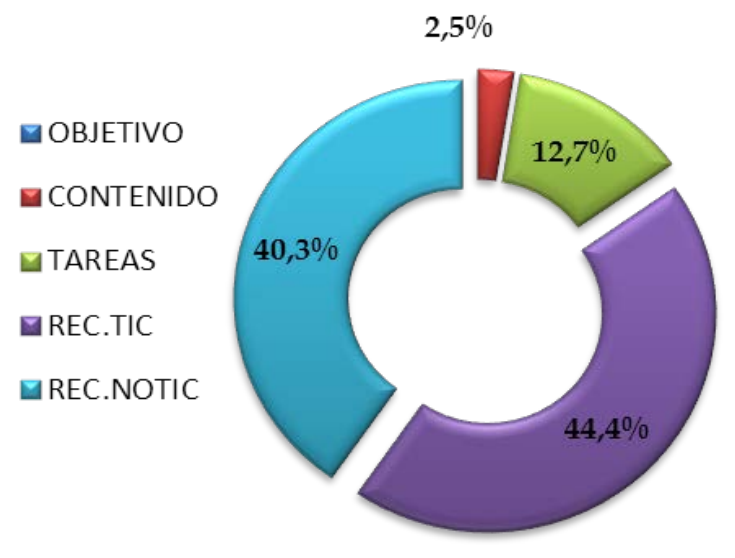

Secundarios

\subsubsection{Caso 7}

El profesor 7 ha estado presente en los tres años de la investigación, de esta forma, al igual que ocurre con los Casos 4 y 5, contamos con el máximo de grabaciones en cada uno de los años (Tabla 7.14).

\begin{tabular}{|c|c|c|c|}
\hline $\begin{array}{c}\mathrm{N}^{\mathrm{o}} \text { de } \\
\text { grabaciones }\end{array}$ & Año & Curso & $\begin{array}{l}\text { Tiempo de } \\
\text { grabación }\end{array}$ \\
\hline 3 & $2009 / 2010$ & $3^{\circ}$ de EI & \\
\hline 2 & $2010 / 2011$ & $1^{\circ}$ de EI & $7 h 51^{\prime} 3^{\prime \prime}$ \\
\hline 1 & $2011 / 2012$ & $2^{\circ}$ de EI & \\
\hline
\end{tabular}

Tabla 7.14 Número de grabaciones, año y curso Caso 7.

De las ocho ATAS distintas que aparecen en 22 ocasiones durante las 6 grabaciones presentan un mayor número de frecuencias (5) la "Planificación/organización de tareas" y la "Realización de tarea por 
Rincones". Por el contrario, tan sólo aparecen una vez la "Lectura de imágenes con recurso TIC", "Lectura de imágenes con Recurso no TIC" y "Corrección de tareas en clase". En cuanto al peso temporal destaca de manera clara la "Realización de tareas por rincones", seguido de la "Realización de tareas con y sin TIC relacionada" aunque esta última con un peso muy inferior (Tabla 7.15).

\begin{tabular}{ccc} 
ATA & $\begin{array}{c}\mathbf{N}^{0} \text { de ATA } \\
\text { (f) }\end{array}$ & $\begin{array}{c}\mathbf{N}^{0} \text { de Acciones } \\
\text { Instructivas (f) }\end{array}$ \\
\hline Planificación / organización de tareas & 5 & $\mathbf{9 2}$ \\
\hline Organización para salida al recreo & 4 & 167 \\
\hline Realización de tarea por rincones & 5 & 1962 \\
\hline Realización de tarea con y sin TIC relacionada & 2 & 432 \\
\hline Realización de tarea sin TIC & 3 & 180 \\
\hline Corrección de trabajos en clase & $\mathbf{1}$ & $\mathbf{1 1 7}$ \\
\hline Lectura de imágenes con recurso no TIC & $\mathbf{1}$ & $\mathbf{7 2}$ \\
\hline Lectura de imágenes con recurso TIC & $\mathbf{1}$ & $\mathbf{2 9}$ \\
\hline 2.1 .3 TOTAL & 22 & 3051 \\
\hline
\end{tabular}

Tabla 7.15 Frecuencia de ATAs y acciones instructivas por ATA en el Caso 7.

Las ATAS que ocupan más tiempo de las sesiones de clase, casi el $90 \%$ del tiempo registrado, son aquellas que tiene que ver con la realización de tareas ya sea con TIC o sin ellas. Si analizamos la figura 7.60, la "Realización de tarea por rincones" y la "Realización de tarea con y sin TIC relacionada" abarcan la mayor parte de las sesiones. La primera de las ATAs mencionadas corresponde a una forma muy concreta de trabajo perteneciente a la etapa de Educación Infantil, el trabajo por rincones que ya mencionábamos en el capítulo 2.

Figura 7.60 Estructura de las ATAS por sesión Caso 7

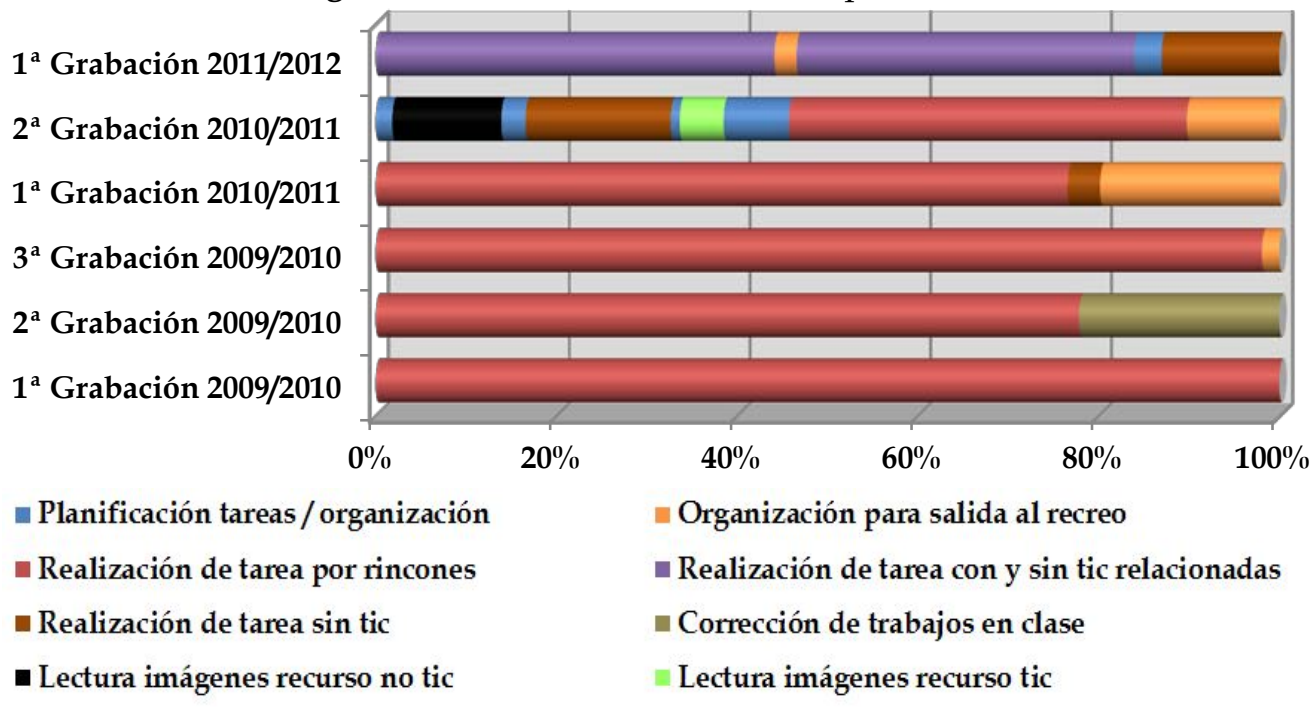


En el Caso 7 predominan por parte del profesor las acciones de supervisión y en menor medida de identificación. Las de planificación y explicación presentan porcentajes similares entre sí, aunque por debajo de los anteriores, por su parte la recapitulación es casi inexistente (Figura 7.61)

Figura 7.61 Porcentaje de acciones instructivas Caso 8

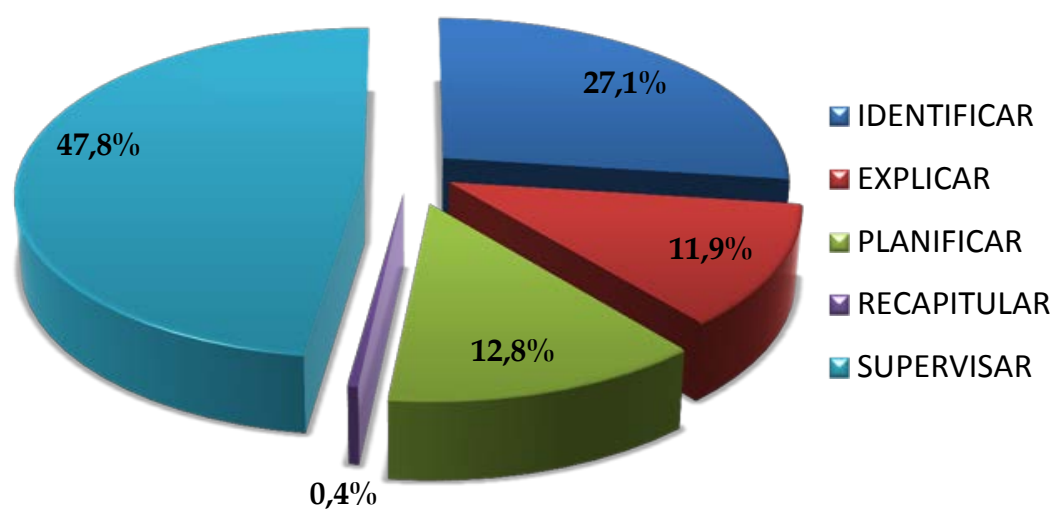

Los elementos del curriculum se mantienen en una línea similar a la de los anteriores casos figurando como elementos primarios destacados las tareas y los contenidos y dentro de los secundarios los recursos TIC y los recursos no TIC (Figura 7.62).

Figura 7.62 Elementos del curriculum Caso 7

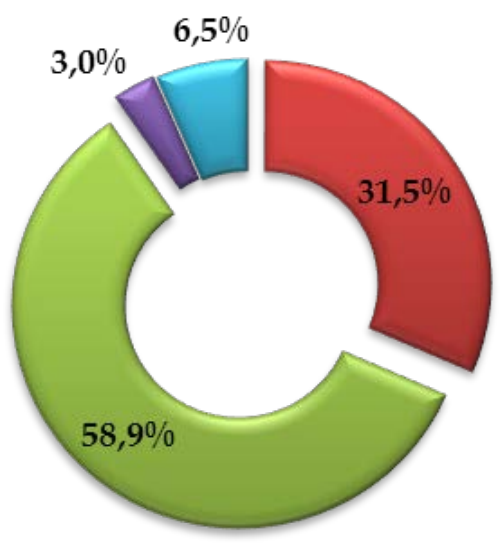

Primarios
๑ OBJETIVO

a CONTENIDO

$\square$ TAREAS

口 REC.TIC

$\square$ REC.NOTIC

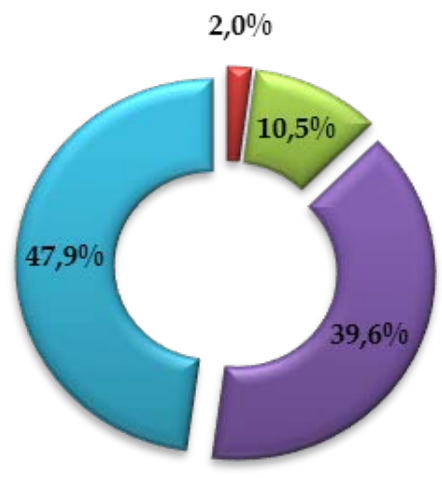

Secundarios 


\subsubsection{Caso 8}

Hemos obtenidos grabaciones de la profesora 8 durante los dos últimos años que ha durado la investigación. Por lo que contamos con 3 registros repartidos en dos años distintos (Tabla 7.16).

\begin{tabular}{cccc}
$\begin{array}{c}\mathbf{N}^{0} \text { de } \\
\text { grabaciones }\end{array}$ & Año & Curso & $\begin{array}{c}\text { Tiempo de } \\
\text { grabación }\end{array}$ \\
\hline 2 & $2010 / 2011$ & $1^{\text {o de EI }}$ & 2 2h $34^{\prime} 23^{\prime \prime}$ \\
\hline 1 & $2011 / 2012$ & $1^{\text {o de EI }}$ & \\
\hline
\end{tabular}

Tabla 7.16 Número de grabaciones, año y curso Caso 8.

Las ATAS que aparecen en las sesiones son variadas. Salvo el caso de "Realización de tarea con y sin TIC independiente" que se repite en dos ocasiones, el resto de ATAS solamente aparece una vez. En cuanto al peso, cuentan con mayor número de acciones instructivas aquéllas que tienen que ver con la realización de algún tipo de tareas (Tabla 7.17)

\begin{tabular}{ccc} 
ATA & $\begin{array}{c}\mathbf{N}^{0} \text { de ATA } \\
(\mathbf{f})\end{array}$ & $\begin{array}{c}\mathbf{N}^{0} \text { de Acciones } \\
\text { Instructivas (f) }\end{array}$ \\
\hline Planificación / organización de tareas & 1 & 11 \\
\hline Explicación de tarea & 1 & 17 \\
\hline Realización de tarea por rincones & 1 & 197 \\
\hline Realización de tarea con y sin TIC independiente & 2 & 331 \\
\hline Realización de tarea con TIC & 1 & 108 \\
\hline Juego libre & 1 & 24 \\
\hline Elección de lectura para casa & 1 & 798 \\
\hline TOTAL & 8 & 110 \\
\hline
\end{tabular}

Tabla 7.17 Frecuencia de ATAs y acciones instructivas por ATA en el Caso 8.

Esta variabilidad también se refleja en la estructura de cada una de las sesiones, que como se puede ver en la figura 7.63 se secuencia de forma bastante diferente con respecto a las ATAs. 
Figura 7.63 Estructura de las ATAS por sesión Caso 8

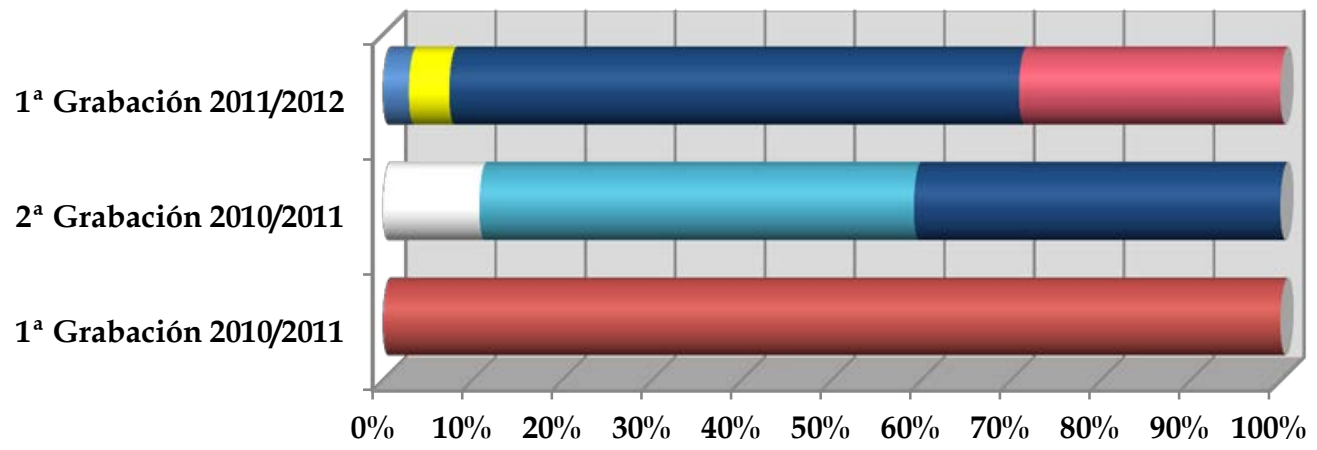

- Planificación tareas/organización

Explicación de la tarea

- Realización de tarea por rincones

- Realización de tarea con y sin tic independiente

- Realización de tarea con tic Juego libre

$\square$ Elección de lectura para casa

La profesora 8 desarrolla sus clases sobre todo identificando y supervisando; ambas acciones suman cerca del 85\% del total (figura 7.64).

Figura 7.64 Porcentaje de acciones instructivas Caso 8

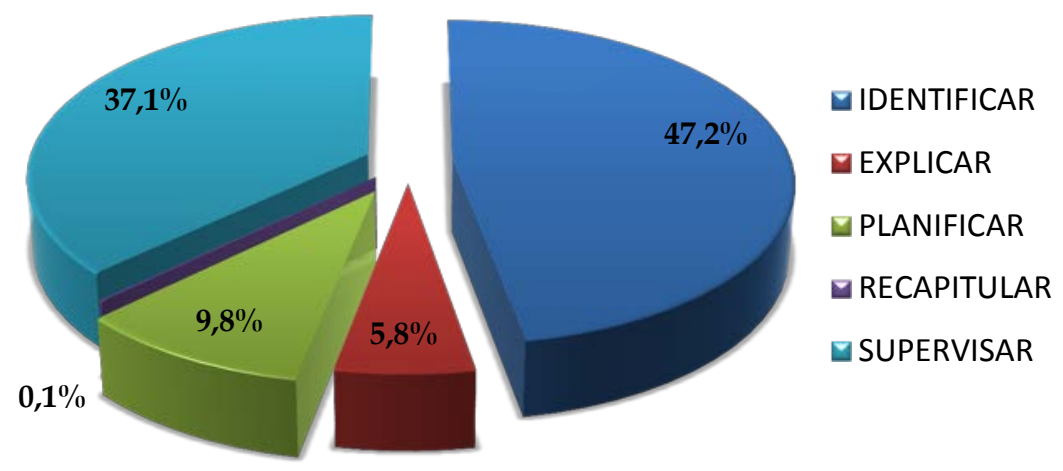

En relación con los elementos del curriculum las tareas predominan con casi el $70 \%$ y le siguen los contenidos algo más de un $17 \%$ dentro de los elementos del curriculum primarios. Los secundarios, al igual que en los casos anteriores muestran un claro protagonismo de los recursos TIC y no TIC. 
Figura 7.65 Elementos del curriculum Caso 8

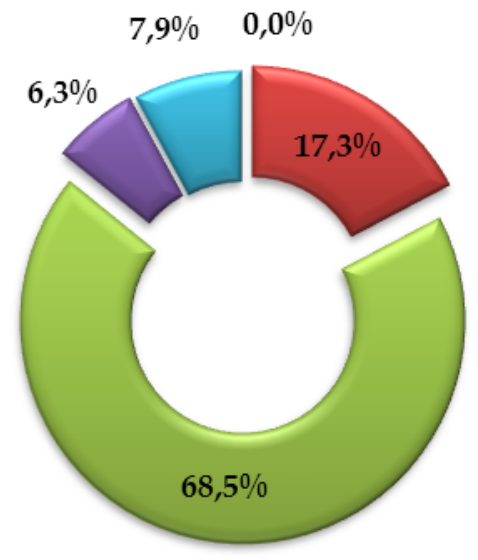

Primarios

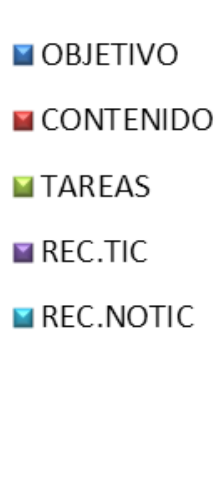

7.2.9. Caso 9

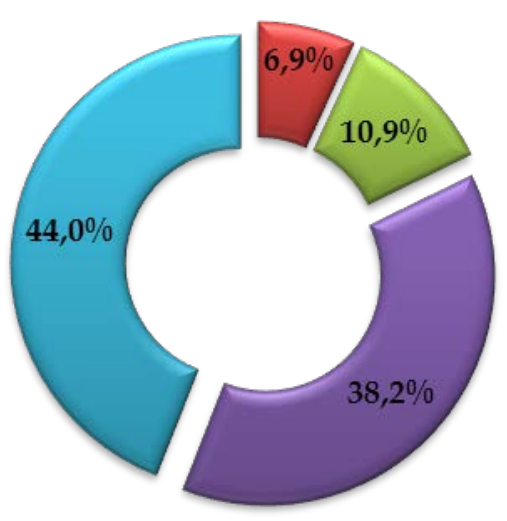

Secundarios

En el Caso 9 nos encontramos con una situación igual a la del caso anterior, ya que la profesora 9 se incorporó al centro 3 y al proyecto en el segundo año de la investigación. Por ello disponemos de tres grabaciones repartidas a lo largo de los dos últimos años del estudio (Tabla 7.18).

\begin{tabular}{cccc}
$\begin{array}{c}\mathbf{N}^{0} \text { de } \\
\text { grabaciones }\end{array}$ & Año & Curso & $\begin{array}{c}\text { Tiempo de } \\
\text { grabación }\end{array}$ \\
\hline 2 & $2010 / 2011$ & $1^{\circ}$ de EI & 2 2h $53^{\prime} 56^{\prime \prime}$ \\
\hline 1 & $2011 / 2012$ & $2^{\circ}$ de EI & \\
\hline
\end{tabular}

Tabla 7.18 Número de grabaciones, año y curso Caso 9.

Destaca dentro de las ATAS la "Realización de tarea con y sin TIC independiente", la "Planificación/organización de tareas", la "Realización de tarea sin TIC" y la "Corrección de trabajos en clase" que aparecen tres veces durante las tres sesiones analizadas. Otras sin embargo como "Fecha y tiempo meteorológico", "Comer el bocadillo", "Explicación de tarea" o "Realización de tarea con $\mathrm{TIC}^{\prime \prime}$ aparecen sólo en una ocasión. En cuanto al peso, como viene ocurriendo hasta ahora, cuentan con mayor número de acciones aquéllas que tienen que ver con la realización de tareas, aunque en este caso la corrección de trabajos también cuenta con un importante número (Tabla 7.19). 


\begin{tabular}{ccc} 
ATA & $\begin{array}{c}\mathbf{N}^{0} \text { de ATA } \\
(\mathbf{f})\end{array}$ & $\begin{array}{c}\mathbf{N}^{0} \text { de Acciones } \\
\text { Instructivas (f) }\end{array}$ \\
\hline Planificación / organización de tareas & 3 & 62 \\
\hline Organización para salida al recreo & 2 & 84 \\
\hline Fecha y tiempo meteorológico & 1 & 53 \\
\hline Explicación de tarea & 1 & 19 \\
\hline Realización de tarea con y sin TIC independiente & 3 & 672 \\
\hline Realización de tarea con TIC & 1 & 718 \\
\hline Realización de tarea sin TIC & 3 & 318 \\
\hline Corrección de trabajos en clase & 3 & 53 \\
\hline Juego libre & 2 & 47 \\
\hline Comer el bocadillo & 1 & 1503 \\
\hline TOTAL & 20 & 79
\end{tabular}

Tabla 7.19 Frecuencia de ATAs y acciones instructivas por ATA en el Caso 9.

Las sesiones grabadas se estructuran de diferentes formas en función de las ATAS y el momento y duración de las mismas. En este sentido, los 10 tipos de ATAS que hemos encontrado y visto en la tabla 7.19 se organizan con diversas secuencias a lo largo de cada sesión (Figura 7.66).

Figura 7.66 Estructura de las ATAS por sesión caso 9

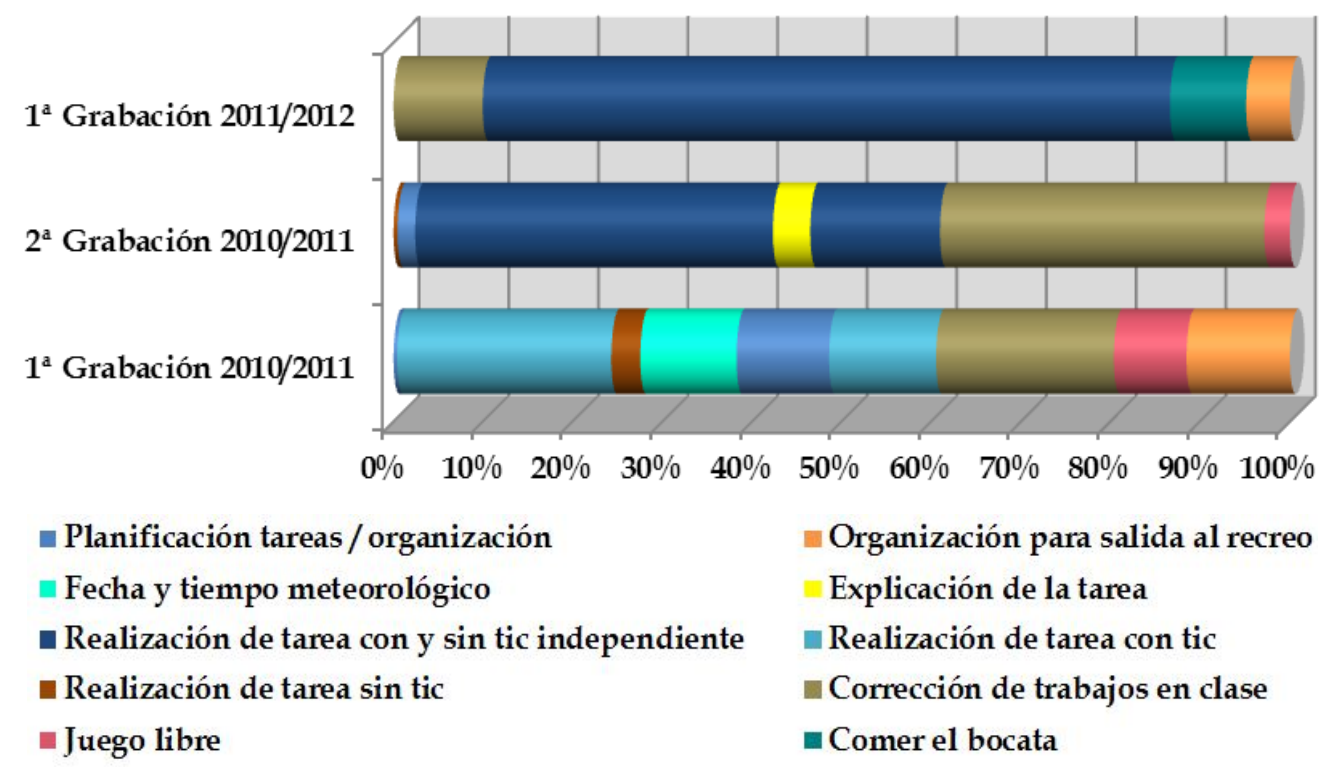


Si atendemos a las acciones instructivas, a lo largo de las grabaciones analizadas observamos que la profesora 9 en más de un $80 \%$ de los casos supervisa e identifica los distintos elementos del curriculum, la recapitulación no cuenta con ningún registro y la explicación y planificación presentan un volumen muy similar de acciones cercano al 20\% (figura 7.67).

Figura 7.67 Porcentaje de acciones instructivas Caso 9

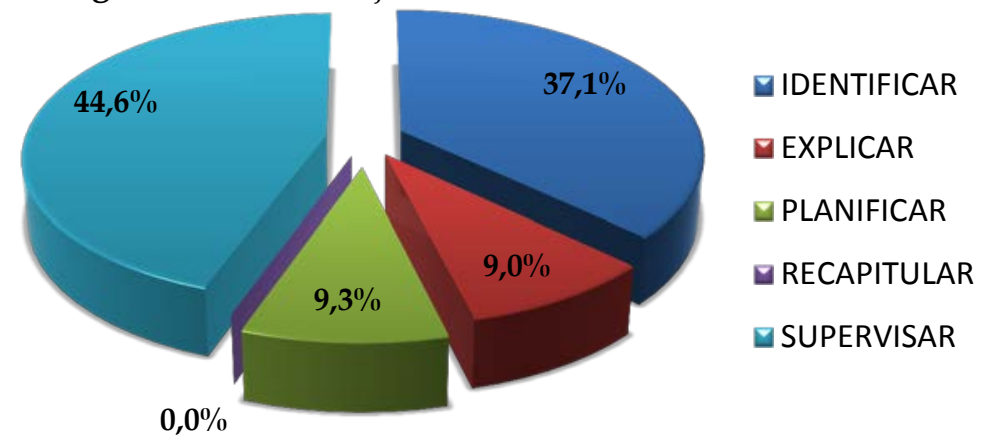

Dichas acciones instructivas se ejecutan sobre los diferentes elementos del curriculum primarios, de los cuales hay que destacar, como viene siendo habitual, las tareas y, en menor medida, los contenidos. En cuanto a los elementos del curriculum secundario predominan de forma muy destacada los recursos no TIC, encontrando en segundo lugar las tareas y en tercero los recursos TIC (Figura 7.68).

Figura 7.68 Elementos del curriculum Caso 9

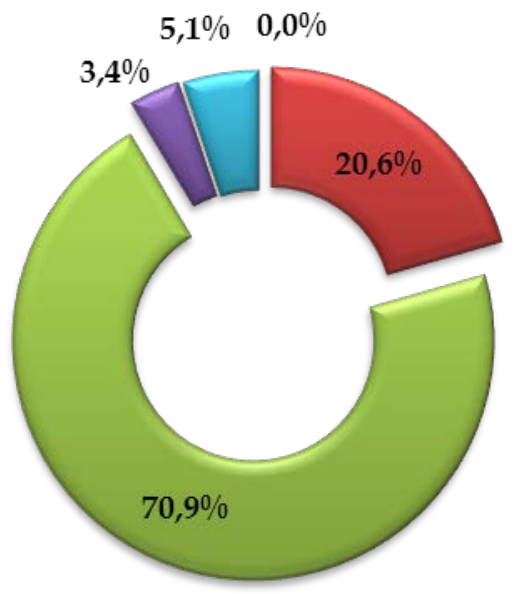

Primarios

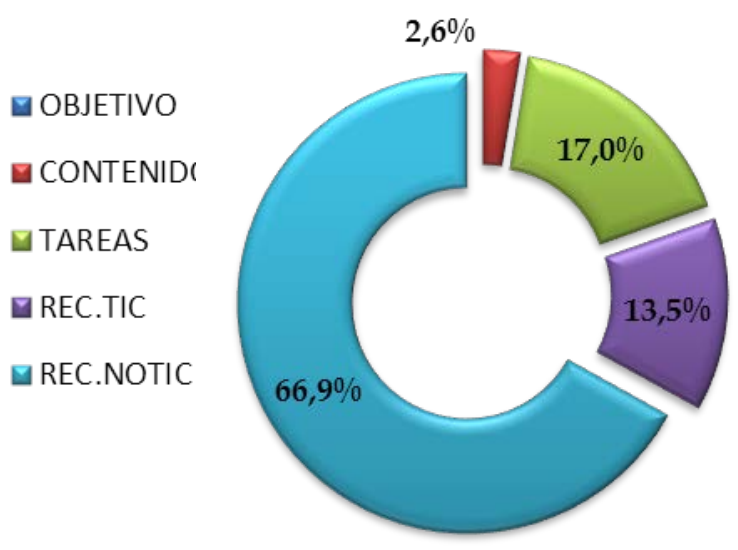

Secundarios 


\subsubsection{Caso 10}

La profesora 10 se incorporó al proyecto en el último año de la investigación, por tanto contamos con una grabación de su clase en el centro 1.2 (Tabla 7.20).

\begin{tabular}{cccc}
$\begin{array}{c}\mathrm{N}^{0} \text { de } \\
\text { grabaciones }\end{array}$ & Año & Curso & $\begin{array}{c}\text { Tiempo de } \\
\text { grabación }\end{array}$ \\
\hline 1 & $2011 / 2012$ & Aula unitaria & $50^{\prime} 24^{\prime \prime}$
\end{tabular}

Tabla 7.20 Número de grabaciones, año y curso Caso 10.

Todas las ATAS presentan una frecuencia de uno. Si miramos el peso que tiene cada ATA dentro de la clase destacan la "Realización de tarea con y sin TIC independiente", "Juego libre” y "Comer el bocadillo" (Tabla 7.21).

\begin{tabular}{ccc} 
ATA & $\begin{array}{c}\mathbf{N}^{0} \text { de ATA } \\
(\mathbf{f})\end{array}$ & $\begin{array}{c}\mathbf{N}^{0} \text { de Acciones } \\
\text { Instructivas (f) }\end{array}$ \\
\hline Planificación / organización de tareas & $\mathbf{1}$ & $\mathbf{1 6}$ \\
\hline Organización para salida al recreo & $\mathbf{4}$ & $\mathbf{1 8 1}$ \\
\hline Realización de tarea con y sin TIC independiente & $\mathbf{1}$ & $\mathbf{1 6 2}$ \\
\hline Juego libre & $\mathbf{1}$ & $\mathbf{1 2 2}$ \\
\hline Comer el bocadillo & $\mathbf{1}$ & 527 \\
\hline TOTAL & 5 & Cas
\end{tabular}

Tabla 7.21 Frecuencia de ATAs y acciones instructivas por ATA en el Caso 10.

La Figura 7.69 muestra la secuencia cronológica de las ATAS anteriores, también ofrece datos relativos al porcentaje de acciones instructivas del total de la sesión que tiene cada una de ellas.

Figura 7.69 Estructura de las ATAS por sesión Caso 10

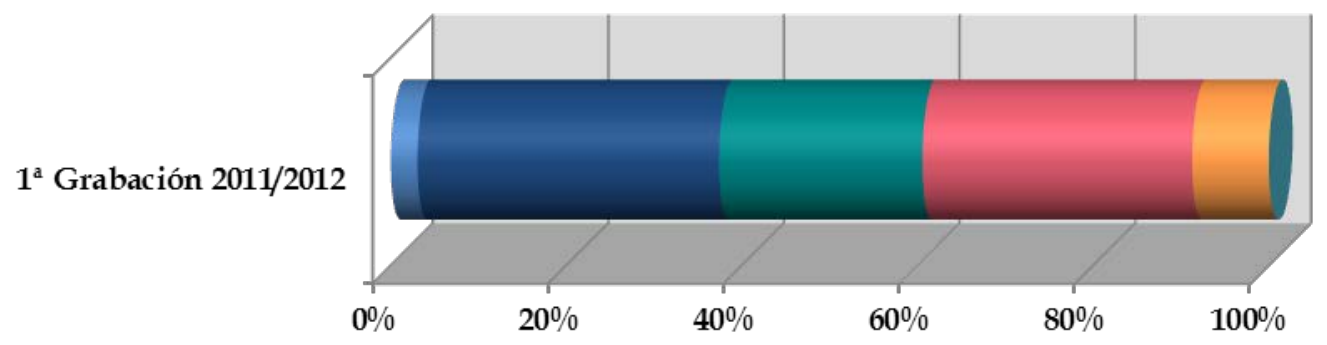

- Planificación tareas/organización

- Realización de tarea con y sin tic independiente

- Comer el bocata
- Organización para salida al recreo - Juego libre 
Las acciones instructivas que cuentan con un porcentaje muy alto son la identificación y la supervisión, que suman más de un 90\% del total. El 10\% restante se distribuye entre planificar y explicar (Figura 7.70).

Figura 7.70 Porcentaje de acciones instructivas Caso 10

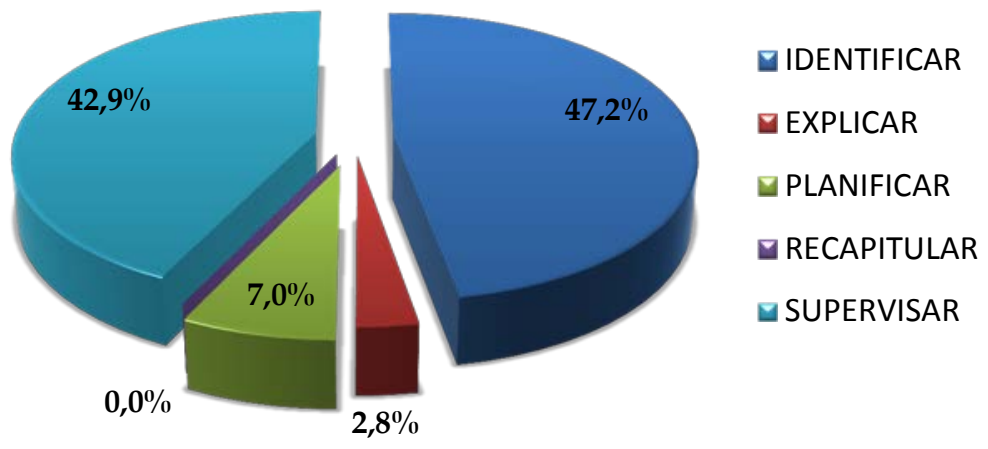

Para finalizar los resultados sobre el Caso 10, los elementos del curriculum primarios se estructuran sobre las tareas y el contenido con un $68,9 \%$ y un $22 \%$ respectivamente. Respecto de los secundarios, predominan los recursos TIC con un 60,5\% y los recursos no TIC con un 22,2\% (Figura 7.71)

Figura 7.71 Elementos del curriculum Caso 10

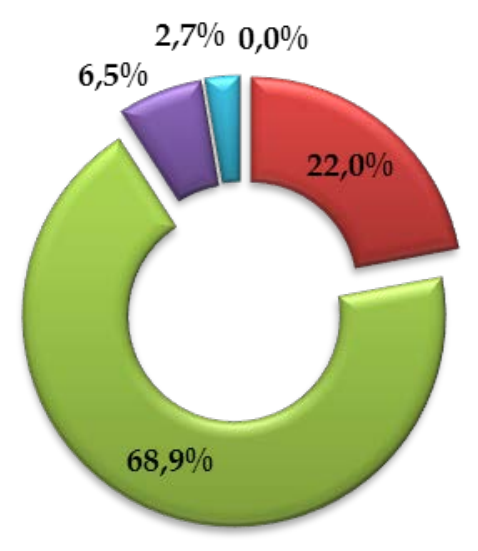

Primarios

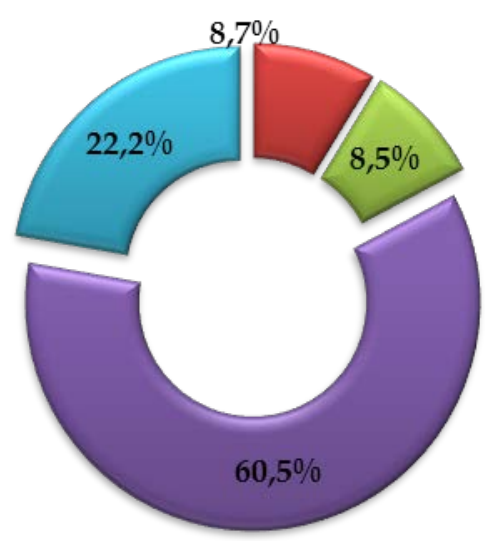

Secundarios 


\subsubsection{Caso 11}

Al igual que en el Caso 10, la profesora 11 se incorporó en el curso 2011/2012 al proyecto de "El Rincón del Ratón" por lo que disponemos de la grabación de una sola sesión (Tabla 7.22).

\begin{tabular}{cccc}
$\begin{array}{c}\mathrm{N}^{0} \text { de } \\
\text { grabaciones }\end{array}$ & Año & Curso & $\begin{array}{c}\text { Tiempo de } \\
\text { grabación }\end{array}$ \\
\hline 1 & $2011 / 2012$ & $3^{\circ}$ EI & 1 h 1' 12" \\
\hline
\end{tabular}

Tabla 7.22 Número de grabaciones, año y curso Caso 11.

Durante la clase se han llevado a cabo dos ATAS, concretamente una "Explicación de tarea" y una "Realización de tarea con y sin TIC independiente" (Tabla 7.23), siendo esta última la de mayor peso en cuanto a las acciones instructivas.

\begin{tabular}{cccc} 
ATA & $\begin{array}{c}\mathbf{N}^{0} \text { de ATA } \\
(\mathrm{f})\end{array}$ & $\begin{array}{c}\mathbf{N}^{0} \text { de Acciones } \\
\text { Instructivas (f) }\end{array}$ \\
\hline Explicación de tarea & 1 & 86 \\
\hline Realización de tarea con y sin TIC independiente & 1 & 287 \\
\hline TOTAL & 2 & 373
\end{tabular}

Tabla 7.23 Frecuencia de ATAs y acciones instructivas por ATA en el Caso 11.

Si miramos la configuración de la clase en la figura 7.72 vemos que en primer lugar se desarrolla la explicación de la tarea y posteriormente la realización de la misma, ocupando esta última en torno al $80 \%$ de la sesión.

Figura 7.72 Estructura de ATAS por sesión Caso 11

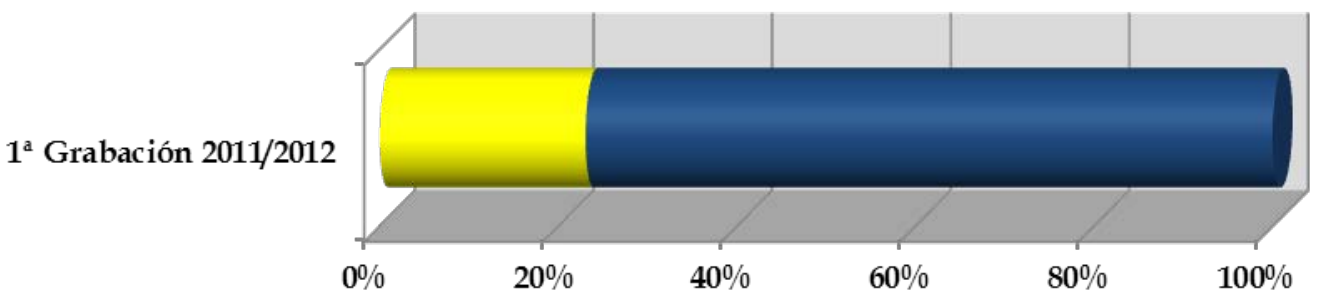

Explicación de la tarea

- Realización de tarea con y sin tic independiente 
En lo relativo a las acciones que desempeña la profesora 11 durante la clase, predominan con porcentajes casi idénticos supervisar e identificar, que suman un $83 \%$ del total (Figura 7.73 ).

Figura 7.73 Porcentaje de acciones instructivas Caso 11
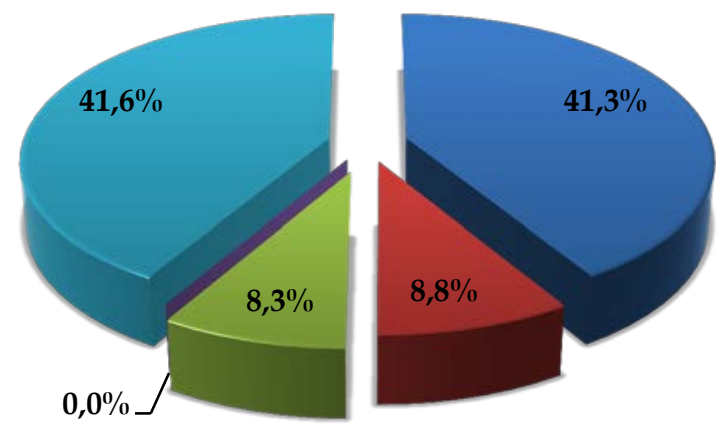

- IDENTIFICAR

$\square$ EXPLICAR

$\square$ PLANIFICAR

$\square$ RECAPITULAR

$\square$ SUPERVISAR

En este último caso, comprobamos que en los elementos del curriculum primarios, tareas y contenidos suman más del $90 \%$ del total de los registros. En cuanto a los secundarios predomina el recurso TIC con casi un $70 \%$ seguido de los recursos no TIC y las tareas que completan hasta el 100\% (Figura 7.74)

Figura 7.74 Elementos del curriculum Caso 11

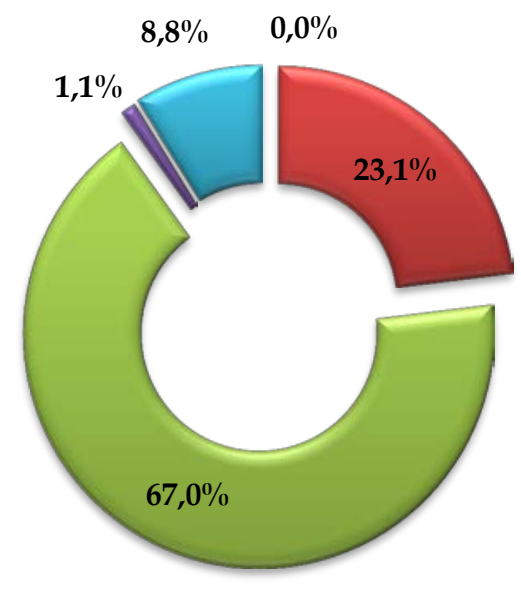

Primarios

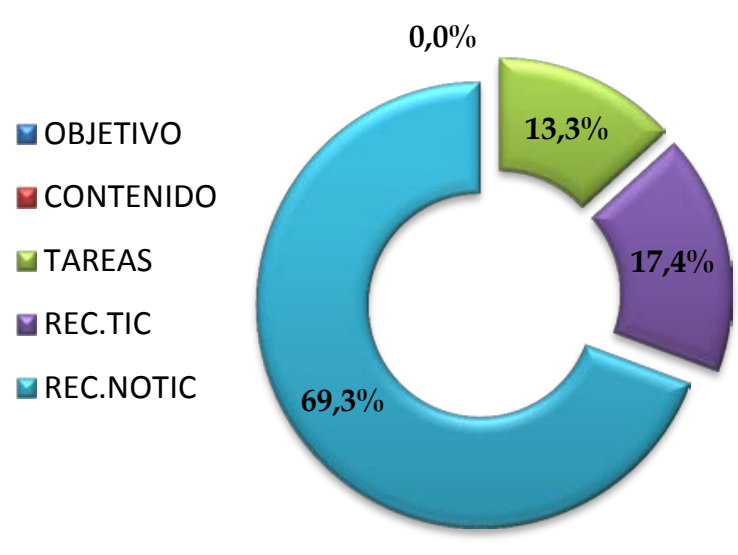

Secundarios 


\subsection{Análisis cruzados}

Los datos expuestos hasta ahora describen en detalle cuáles son los patrones de actividad detectados en las sesiones de clase, su sentido y su configuración interna. Asimismo, dichos datos ofrecen un retrato pormenorizado de cómo cada profesor desarrolla su trabajo en cada una de las grabaciones recogidas. Por tanto, ese conjunto de resultados abre las puertas de cada aula y ofrece un relato de lo que allí sucedió.

A partir de ahora, los resultados que se exponen, profundizan en el estudio de investigación con objeto de buscar relaciones, regularidades y patrones comunes entre los tipos de actividad que se han descrito, los profesores que los ejecutan y los cursos de la etapa de Educación Infantil de donde proceden los datos.

Para presentar estos resultados, utilizaremos tablas de contingencia. Se ha aplicado la prueba de chi cuadrado a los datos de las distintas categorías del sistema de análisis, analizando los residuos tipificados corregidos. Con objeto de refinar el resultado se eliminaron cuando fue preciso las casillas con frecuencias teóricas inferiores a 5, para descartar el tamaño del efecto en los cálculos de la significación.

A continuación se ofrecen los datos cruzados con su correspondiente interpretación.

\subsubsection{Análisis de las relaciones entre ATAs y curso de Educación Infantil.}

Es importante aclarar que los datos que se ofrecen en estos apartados no equivalen al total de lo recogido en todas las sesiones grabadas, puesto que hubieron de retirarse las grabaciones correspondientes a aulas unitarias al no poder distinguir los distintos cursos en dichas aulas. De esta forma se ha trabajado con datos recogidos en 37 de las 41 grabaciones totales.

Como puede comprobarse en la tabla 7.24, las ATAs se distribuyen de forma diferente en cada uno de los tres cursos con los que cuenta el segundo ciclo de Educación Infantil, de hecho se obtiene relación significativa entre 
ATAs y curso $[\chi 2(36, \mathrm{n}=12585)=4618.75, \mathrm{p}<.001, V=.42]$, lo que pone de relieve que los diversos tipos de actividad no aparecen en la misma proporción en los distintos cursos.

Si analizamos los resultados de la tabla, se observa que las ATAs que tienen que ver con Realización de tarea y que incorporan el recurso TIC, son las que más tiempo ocupan del trabajo que se desarrolla en las aulas. La distribución de estos patrones de actividad relacionados con las TIC difiere a lo largo de los cursos. Así, el ATA de Realización de tareas con y sin TIC independiente aparece más frecuentemente en el primer y en el segundo curso frente al tercero. También se aprecia que en el tercer curso adquiere más protagonismo la Realización de tareas con y sin TIC relacionadas. Otra cuestión concerniente a las ATAs que muestran los análisis es que la realización de tareas por rincones aparece en el primer y tercer curso y no cuenta con ningún registro en las grabaciones correspondientes al segundo curso (Tabla 7.24).

Otras ATAs diferentes de las de realización de tarea cuentan con registros diversos. Por ejemplo el ATA de Planificación/organización de tareas está presente en todos los cursos de la etapa, de igual manera que ocurre con la de Organización para salida al recreo, la Explicación de la tarea, Fecha y tiempo meteorológico, etc. (tabla 7.24). Sin embargo, también encontramos otras que, siendo también diferentes de las de realización de tarea, sólo aparecen en alguno de los cursos y de forma anecdótica, entre ellas podemos encontrar la Organización de la vuelta del recreo, el Juego libre, el Comer el bocadillo, la Elección de lectura para casa, la Lectura de imágenes con recurso no TIC o la Lectura de imágenes con recurso TIC (Tabla 7.24). En cualquier caso, en relación a estas últimas es preciso indicar que su aparición o no en la sesión de clase registrada, puede depender en buena medida del momento de la jornada, incluso del día concreto, que se seleccionó para grabar. Se trata de actividades que se registran en horarios o días particulares que no tienen por qué coincidir con el momento de grabación de la sesión determinada para unos u otros casos, es decir, que al acordarse la grabaciones en función de la disponibilidad de los docentes, la elección del día y la hora de grabación obedecía a un criterio bastante aleatorio. 


\begin{tabular}{|c|c|c|c|c|}
\hline ACTIVIDAD TÍPICA DE AULA & $1^{\circ} \mathrm{EI}$ & $2^{\circ} \mathrm{EI}$ & $3^{\circ} \mathrm{EI}$ & TOTAL \\
\hline Planificación / organización de tareas & $\begin{array}{c}209 \\
(4.9 \%)\end{array}$ & $\begin{array}{c}75 \\
(2.6 \%)\end{array}$ & $\begin{array}{c}149 \\
(2.8 \%)\end{array}$ & $\begin{array}{c}433 \\
(3.4 \%)\end{array}$ \\
\hline Organización para salida al recreo & $\begin{array}{c}201 \\
(4.7 \%)\end{array}$ & $\begin{array}{c}90 \\
(3.1 \%)\end{array}$ & $\begin{array}{c}152 \\
(2.8 \%)\end{array}$ & $\begin{array}{c}443 \\
(3.5 \%)\end{array}$ \\
\hline $\begin{array}{l}\text { Visionado de película con recurso } \\
\text { TIC }\end{array}$ & $\begin{array}{c}\mathbf{0} \\
(.0 \%)\end{array}$ & $\begin{array}{c}10 \\
(.3 \%)\end{array}$ & $\begin{array}{c}146 \\
(2.7 \%)\end{array}$ & $\begin{array}{c}156 \\
(1.2 \%)\end{array}$ \\
\hline Pasar lista & $\begin{array}{c}\mathbf{0} \\
(.0 \%) \\
\end{array}$ & $\begin{array}{c}32 \\
(1.1 \%) \\
\end{array}$ & $\begin{array}{c}7 \\
(.1 \%) \\
\end{array}$ & $\begin{array}{c}39 \\
(.3 \%) \\
\end{array}$ \\
\hline Fecha y tiempo meteorológico & $\begin{array}{c}53 \\
(1.2 \%)\end{array}$ & $\begin{array}{c}45 \\
(1.5 \%)\end{array}$ & $\begin{array}{c}10 \\
(.2 \%)\end{array}$ & $\begin{array}{c}108 \\
(.9 \%)\end{array}$ \\
\hline Explicación de tarea & $\begin{array}{c}122 \\
(2.9 \%) \\
\end{array}$ & $\begin{array}{c}29 \\
(1 \%) \\
\end{array}$ & $\begin{array}{c}112 \\
(2.1 \%) \\
\end{array}$ & $\begin{array}{c}263 \\
(2.1 \%) \\
\end{array}$ \\
\hline Recitado de poesía & $\begin{array}{c}8 \\
(.2 \%) \\
\end{array}$ & $\begin{array}{c}89 \\
(3 \%)\end{array}$ & $\begin{array}{c}\mathbf{0} \\
(.0 \%)\end{array}$ & $\begin{array}{c}97 \\
(.8 \%)\end{array}$ \\
\hline Realización de tarea por rincones & $\begin{array}{c}781 \\
(18.3 \%) \\
\end{array}$ & $\begin{array}{c}\mathbf{0} \\
(.0 \%)\end{array}$ & $\begin{array}{c}1536 \\
(28.5 \%) \\
\end{array}$ & $\begin{array}{c}2317 \\
(18.4 \%) \\
\end{array}$ \\
\hline $\begin{array}{l}\text { Realización de tarea con y sin TIC } \\
\text { relacionada }\end{array}$ & $\begin{array}{c}159 \\
(3.7 \%)\end{array}$ & $\begin{array}{c}665 \\
(22.7 \%) \\
\end{array}$ & $\begin{array}{c}\mathbf{1 7 7 1} \\
(32.8 \%)\end{array}$ & $\begin{array}{c}2595 \\
(20.6 \%)\end{array}$ \\
\hline $\begin{array}{l}\text { Realización de tarea con y sin TIC } \\
\text { independiente }\end{array}$ & $\begin{array}{c}1240 \\
(29.1 \%) \\
\end{array}$ & $\begin{array}{c}\mathbf{1 2 2 7} \\
(41.9 \%) \\
\end{array}$ & $\begin{array}{c}479 \\
(8.9 \%) \\
\end{array}$ & $\begin{array}{c}2946 \\
(23.4 \%) \\
\end{array}$ \\
\hline Realización de tarea con TIC & $\begin{array}{c}654 \\
(15.3 \%)\end{array}$ & $\begin{array}{c}315 \\
(10.8 \%)\end{array}$ & $\begin{array}{c}\mathbf{8 2 5} \\
(15.3 \%)\end{array}$ & $\begin{array}{c}\mathbf{1 7 9 4} \\
(14.3 \%)\end{array}$ \\
\hline Realización de tarea sin TIC & $\begin{array}{c}288 \\
(6.8 \%) \\
\end{array}$ & $\begin{array}{c}84 \\
(2.9 \%) \\
\end{array}$ & $\begin{array}{c}44 \\
(.8 \%) \\
\end{array}$ & $\begin{array}{c}416 \\
(3.3 \%) \\
\end{array}$ \\
\hline Corrección de trabajos en clase & $\begin{array}{c}263 \\
(6.2 \%)\end{array}$ & $\begin{array}{c}211 \\
(7.2 \%)\end{array}$ & $\begin{array}{c}135 \\
(2.5 \%)\end{array}$ & $\begin{array}{c}609 \\
(4.8 \%)\end{array}$ \\
\hline Organización vuelta del recreo & $\begin{array}{c}\mathbf{0} \\
(.0 \%)\end{array}$ & $\begin{array}{c}\mathbf{0} \\
(.0 \%)\end{array}$ & $\begin{array}{c}26 \\
(.5 \%)\end{array}$ & $\begin{array}{c}26 \\
(.2 \%)\end{array}$ \\
\hline Juego libre & $\begin{array}{c}163 \\
(1.7 \%)\end{array}$ & $\begin{array}{c}\mathbf{0} \\
(.0 \%) \\
\end{array}$ & $\begin{array}{c}\mathbf{0} \\
(.0 \%) \\
\end{array}$ & $\begin{array}{c}163 \\
(1.3 \%)\end{array}$ \\
\hline Comer el bocadillo & $\begin{array}{c}\mathbf{0} \\
(.0 \%)\end{array}$ & $\begin{array}{c}55 \\
(1.9 \%) \\
\end{array}$ & $\begin{array}{c}\mathbf{0} \\
(.0 \%)\end{array}$ & $\begin{array}{c}55 \\
(.4 \%)\end{array}$ \\
\hline $\begin{array}{l}\text { Lectura de imágenes con recurso no } \\
\text { TIC }\end{array}$ & $\begin{array}{c}72 \\
(1.7 \%)\end{array}$ & $\begin{array}{c}\mathbf{0} \\
(.0 \%)\end{array}$ & $\begin{array}{c}\mathbf{0} \\
(.0 \%) \\
\end{array}$ & $\begin{array}{c}72 \\
(.6 \%)\end{array}$ \\
\hline Lectura de imágenes con recurso TIC & $\begin{array}{c}29 \\
(.7 \%) \\
\end{array}$ & $\begin{array}{c}\mathbf{0} \\
(.0 \%) \\
\end{array}$ & $\begin{array}{c}0 \\
(\%)\end{array}$ & $\begin{array}{c}29 \\
(.2 \%) \\
\end{array}$ \\
\hline Elección de lectura para casa & $\begin{array}{c}24 \\
(.6 \%)\end{array}$ & $\begin{array}{c}\mathbf{0} \\
(.0 \%)\end{array}$ & $\begin{array}{c}0 \\
(\%)\end{array}$ & $\begin{array}{c}24 \\
(.2 \%)\end{array}$ \\
\hline TOTAL & $\begin{array}{c}4266 \\
(100 \%)\end{array}$ & $\begin{array}{c}2927 \\
(100 \%)\end{array}$ & $\begin{array}{c}5392 \\
(100 \%)\end{array}$ & $\begin{array}{c}12585 \\
(100 \%)\end{array}$ \\
\hline
\end{tabular}

Tabla 7.24 Frecuencia y porcentaje de acciones instructivas de ATAs por curso.

$$
(\chi 2(36, \mathrm{n}=12585)=4618.75, \mathrm{p}<.001, V=.42)
$$

El análisis de los datos de las ATAs que incorporan el uso de los recursos TIC, obtiene igualmente relación significativa entre "ATAs TIC" y 
curso $[\chi 2(10, \mathrm{n}=9837)=2918.19, \mathrm{p}<.001, V=.38]$ tal y como se muestra en la Tabla 7.25:

\begin{tabular}{lcccc}
\multicolumn{1}{c}{ ACTIVIDAD TÍPICA DE AULA } & $\mathbf{1}^{\mathbf{0}} \mathrm{EI}$ & $2^{\circ} \mathrm{EI}$ & $3^{\circ} \mathrm{EI}$ & TOTAL \\
\hline $\begin{array}{l}\text { Visionado de película con recurso } \\
\text { TIC }\end{array}$ & $\mathbf{0}$ & $\mathbf{1 0}$ & $\mathbf{1 4 6}$ & $\mathbf{1 5 6}$ \\
\hline Realización de tarea por rincones & $\mathbf{7 8 1}$ & $(.5 \%)$ & $(3.1 \%)$ & $(1.6 \%)$ \\
\hline $\begin{array}{l}\text { Realización de tarea con y sin TIC } \\
\text { relacionada }\end{array}$ & $\mathbf{1 5 9}$ & $\mathbf{0}$ & $\mathbf{1 5 3 6}$ & $\mathbf{2 3 1 7}$ \\
\hline Realización de tarea con y sin TIC & $\mathbf{1 2 4 0}$ & $\mathbf{6 6 5}$ & $(32.3 \%)$ & $(23.6 \%)$ \\
independiente & $(43.3 \%)$ & $\mathbf{1 7 7 1}$ & $\mathbf{2 5 9 5}$ \\
\hline Realización de tarea con TIC & $\mathbf{6 5 4}$ & $\mathbf{3 1 5}$ & $(37.2 \%)$ & $(26.4 \%)$ \\
\hline Lectura de imágenes con recurso TIC & $(22.8 \%)$ & $(14.2 \%)$ & $(10.1 \%)$ & $(29.9 \%)$ \\
\hline \multicolumn{1}{c}{ TOTAL } & $\mathbf{2 9}$ & $\mathbf{0}$ & $\mathbf{8 2 5}$ & $\mathbf{1 7 9 4}$ \\
& $\mathbf{2 8 6 3}$ & $(.0 \%)$ & $(.0 \%)$ & $(18.2 \%)$ \\
\hline
\end{tabular}

Tabla 7.25 Frecuencia y porcentaje de acciones instruc. de ATAs “TIC" por curso.

$$
(\chi 2(10, \mathrm{n}=9837)=2918.19, \mathrm{p}<.001, V=.38)
$$

Si observamos estos tipos de "ATAs TIC" mostrados en la tabla $7.25 \mathrm{y}$ analizamos la distribución por cursos, comprobamos que en $1^{\circ}$ de Educación Infantil predomina la Realización de tarea con y sin TIC independiente (1240), seguida de la Realización de tarea por rincones (781) y la Realización de tarea con TIC (654). En cuanto a $2^{\circ}$ de Educación Infantil también aparece la Realización de tarea con y sin TIC independiente (1227) con más peso, y en segundo lugar la Realización de tareas con y sin TIC relacionadas (665). En el último curso, $3^{\circ}$ de Educación Infantil, el ATA que cuenta con mayor número de acciones instructivas es la Realización de tarea con y sin TIC relacionada (1771), seguida con un resultado similar por la Realización de tarea por rincones (1536). En tercer lugar, en el último curso de Educación Infantil, la Realización de tarea con TIC (825), que suma aproximadamente la mitad de las acciones instructivas de las dos anteriores.

\subsubsection{Análisis de las diferencias entre profesores y tipos de actividad (ATA).}

Si analizamos la distribución de las ATAs con respecto a los diferentes profesores, obtenemos relación significativa entre ambas variables $[\chi 2$ ( 90 , $\mathrm{n}=13335)=23430,126, \mathrm{p}<.001, V=.44]$. Por tanto se verifica que las ATAs no 
aparecen en la misma proporción en todos los profesores. Tras eliminar del análisis las ATAs con frecuencias inferiores a 5, la distribución de las ATAs por profesores se muestra en la figura 7.26

\begin{tabular}{|c|c|c|c|c|c|c|c|c|c|c|}
\hline & 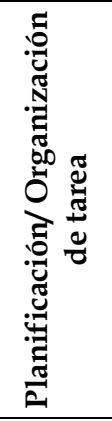 & 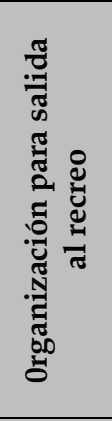 & 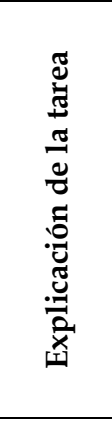 & 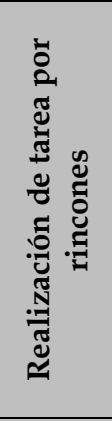 & 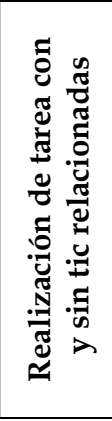 & 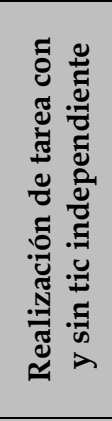 & 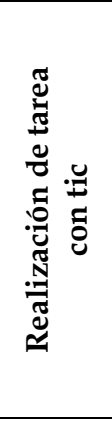 & 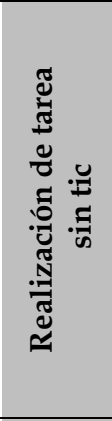 & 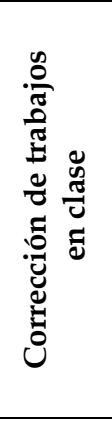 & 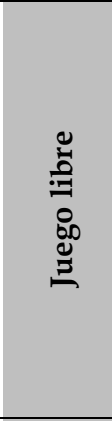 \\
\hline Caso 1 & $15.1 \%$ & $1.2 \%$ & $3.4 \%$ & $25.8 \%$ & $12.1 \%$ & $2.3 \%$ & $7.4 \%$ & $8.9 \%$ & $3.0 \%$ & $.0 \%$ \\
\hline Caso 2 & $12.9 \%$ & $6.1 \%$ & $.0 \%$ & $.0 \%$ & $.0 \%$ & $3.8 \%$ & $73.1 \%$ & $27.6 \%$ & $.0 \%$ & $.0 \%$ \\
\hline Caso 3 & $9.8 \%$ & $.0 \%$ & $32.7 \%$ & $.0 \%$ & $6.1 \%$ & $15.3 \%$ & $.0 \%$ & $.0 \%$ & $.0 \%$ & $.0 \%$ \\
\hline Caso 4 & $12.0 \%$ & $.0 \%$ & $11.0 \%$ & $.0 \%$ & $27.4 \%$ & $21.5 \%$ & $.0 \%$ & $.0 \%$ & $0.0 \%$ & $.0 \%$ \\
\hline Caso 5 & $11.4 \%$ & $18.4 \%$ & $.0 \%$ & $5.1 \%$ & $23.2 \%$ & $10.1 \%$ & $7.6 \%$ & $0.0 \%$ & $25.6 \%$ & $.0 \%$ \\
\hline Caso 6 & $1.8 \%$ & $13.5 \%$ & $6.5 \%$ & $0.0 \%$ & $14.5 \%$ & $.0 \%$ & $.0 \%$ & $1.7 \%$ & $.0 \%$ & $.0 \%$ \\
\hline Caso 7 & $18.8 \%$ & $34.2 \%$ & $.0 \%$ & $62.8 \%$ & $16.6 \%$ & $.0 \%$ & $.0 \%$ & $43.3 \%$ & $19.2 \%$ & $.0 \%$ \\
\hline Caso 8 & $2.2 \%$ & $.0 \%$ & $6.5 \%$ & $6.3 \%$ & $.0 \%$ & $10.6 \%$ & $5.7 \%$ & $.0 \%$ & $.0 \%$ & $33.8 \%$ \\
\hline Caso 9 & $12.7 \%$ & $17.2 \%$ & $7.2 \%$ & $.0 \%$ & $.0 \%$ & $21.5 \%$ & $6.2 \%$ & $18.5 \%$ & $52.2 \%$ & $16.3 \%$ \\
\hline Caso 10 & $3.3 \%$ & $9.4 \%$ & $.0 \%$ & $.0 \%$ & $.0 \%$ & $5.8 \%$ & $.0 \%$ & $.0 \%$ & $.0 \%$ & $49.8 \%$ \\
\hline Caso 11 & $0.0 \%$ & $.0 \%$ & $32.7 \%$ & $.0 \%$ & $.0 \%$ & $9.2 \%$ & $.0 \%$ & $.0 \%$ & $.0 \%$ & $.0 \%$ \\
\hline Total & $100.0 \%$ & $100.0 \%$ & $100.0 \%$ & $100.0 \%$ & $100.0 \%$ & $100.0 \%$ & $100.0 \%$ & $100.0 \%$ & $100.0 \%$ & $100.0 \%$ \\
\hline
\end{tabular}

Tabla 7.26 Porcentaje de observación de las diferentes ATAs en cada caso $(\chi 2(90, \mathrm{n}=13335)=23430,126, \mathrm{p}<.001, V=.44)$

Al observar estos porcentajes comprobamos que todos los tipos de ATAs no son desarrollados por todos los profesores (Tabla 7.27). Además las distribuciones de algunas de estas ATAs son ciertamente diversas. Un ejemplo de ello, lo podemos observar en el ATA de Realización de tarea por rincones, donde de las 3123 acciones instructivas que la constituyen, 2768 corresponden a 
dos profesores que llevan a cabo este ATA (caso 1 y caso 7), distribuyéndose las 355 restantes entre el caso 5 y el caso 8 .

\begin{tabular}{|c|c|c|c|c|c|c|c|c|c|c|c|}
\hline & 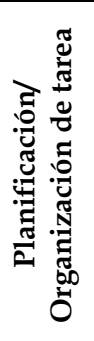 & 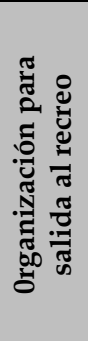 & 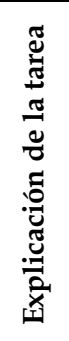 & 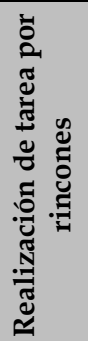 & 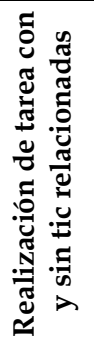 & 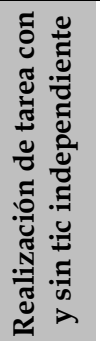 & 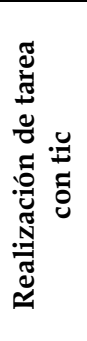 & 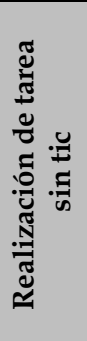 & 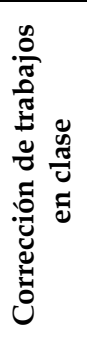 & 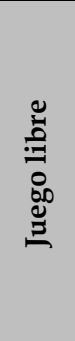 & 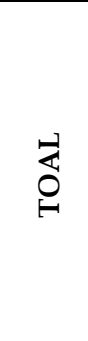 \\
\hline Caso 1 & 74 & 6 & 9 & 806 & 315 & 73 & 141 & 37 & 18 & 0 & 1479 \\
\hline Caso 2 & 63 & 30 & 0 & 0 & 0 & 119 & 1387 & 115 & 0 & 0 & 1714 \\
\hline Caso 3 & 48 & 0 & 86 & 0 & 159 & 477 & 0 & 0 & 0 & 0 & 770 \\
\hline Caso 4 & 59 & 0 & 29 & 0 & 710 & 671 & 0 & 0 & 0 & 0 & 1469 \\
\hline Caso 5 & 56 & 90 & 0 & 158 & 603 & 316 & 144 & 0 & 156 & 0 & 1523 \\
\hline Caso 6 & 9 & 66 & 17 & 0 & 376 & 0 & 0 & 7 & 0 & 0 & 475 \\
\hline Caso 7 & 92 & 167 & 0 & 1962 & 432 & 0 & 0 & 180 & 117 & 0 & 2950 \\
\hline Caso 8 & 11 & 0 & 17 & 197 & 0 & 331 & 108 & 0 & 0 & 110 & 774 \\
\hline Caso 9 & 62 & 84 & 19 & 0 & 0 & 672 & 118 & 77 & 318 & 53 & 1403 \\
\hline Caso 10 & 16 & 46 & 0 & 0 & 0 & 181 & 0 & 0 & 0 & 162 & 405 \\
\hline Caso 11 & 0 & 0 & 86 & 0 & 0 & 287 & 0 & 0 & 0 & 0 & 373 \\
\hline TOTAL & 490 & 489 & 263 & 3123 & 2595 & 3127 & 1898 & 416 & 609 & 325 & 13335 \\
\hline
\end{tabular}

Tabla 7.27 Frecuencia de acciones instructivas de las ATAs en cada caso/profesor $(\chi 2(90, \mathrm{n}=13335)=23430,126, \mathrm{p}<.001, V=.44)$

\subsubsection{Análisis de las diferencias entre los tipos de actividad que desarrollan los profesores en los distintos cursos.}

De la misma manera que encontramos diferencias entre las ATAs en relación con los profesores de forma global, también aparecen estas diferencias significativas cuando analizamos la distribución de los tipos de actividad cruzando profesores y cursos.

Así, para el primer curso obtenemos relación significativa entre ATAs y profesores $[\chi 2(45, \mathrm{n}=4080)=6914,788, \mathrm{p}<.001, V=.58]$. En este primer curso destacan por el peso total que tienen en las sesiones recogidas, las ATAs de Realización de tareas con y sin TIC independiente (1240), la Realización de tarea por rincones (781) y la Realización de tarea con TIC (654). Los datos de la distribución de profesores que imparten en $1^{\circ} \mathrm{EI}$, ofrecen de forma detallada el uso de los distintos tipos de actividad por parte de los profesores de este curso (tabla 7.28). 


\begin{tabular}{|c|c|c|c|c|c|c|c|c|c|c|c|}
\hline & 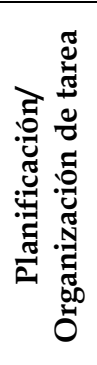 & 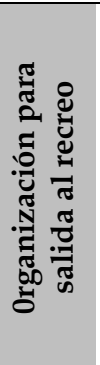 & 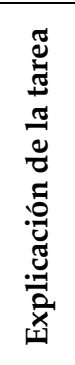 & 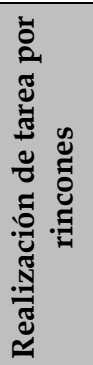 & 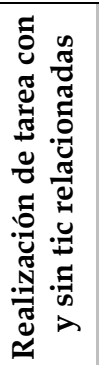 & 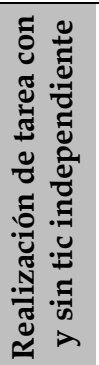 & 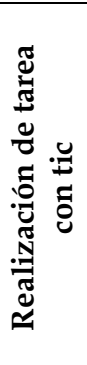 & 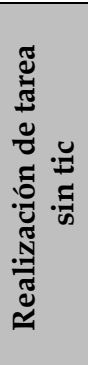 & 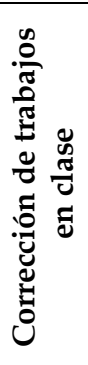 & 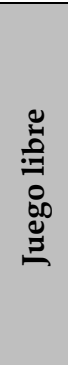 & 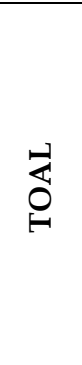 \\
\hline Caso 2 & 12 & 0 & 0 & 0 & 0 & 0 & 428 & 100 & 0 & 0 & 540 \\
\hline Caso 3 & 48 & 0 & 86 & 0 & 159 & 477 & 0 & 0 & 0 & 0 & 770 \\
\hline Caso 4 & 0 & 0 & 0 & 0 & 0 & 184 & 0 & 0 & 0 & 0 & 184 \\
\hline Caso 7 & 76 & 144 & 0 & 584 & 0 & 0 & 0 & 111 & 0 & 0 & 915 \\
\hline Caso 8 & 11 & 0 & 17 & 197 & 0 & 331 & 108 & 0 & 0 & 110 & 774 \\
\hline Caso 9 & 62 & 57 & 19 & 0 & 0 & 248 & 118 & 77 & 263 & 53 & 897 \\
\hline TOTAL & 209 & 201 & 122 & 781 & 159 & 1240 & 654 & 288 & 263 & 163 & 4080 \\
\hline
\end{tabular}

Tabla 7.28 Frecuencia de acciones instructivas de las ATAs en cada caso/profesor en $1^{\circ}$ EI $(\chi 2(45, \mathrm{n}=4080)=6914,788, \mathrm{p}<.001, V=.58)$

Los datos para $2^{\circ}$ EI vuelven a mostrar relación significativa entre ATA y profesor $[\chi 2(36, \mathrm{n}=2856)=5172,473, \mathrm{p}<.001, V=.67]$. De nuevo destaca la Realización de tareas con y sin TIC independiente (1227), seguido de la Realización de tarea con y sin TIC relacionada (665). En este caso la Realización de tarea por rincones no es desarrollada por ninguno de los profesores (tabla 7.29).

\begin{tabular}{|c|c|c|c|c|c|c|c|c|c|c|c|}
\hline & 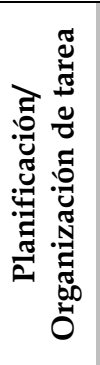 & 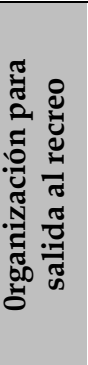 & 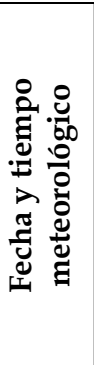 & 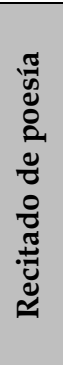 & 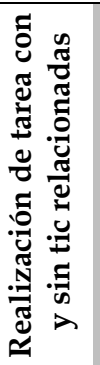 & 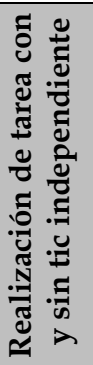 & 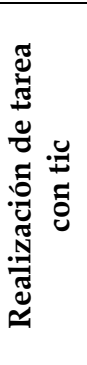 & 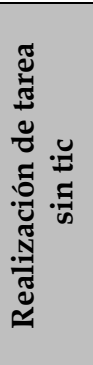 & 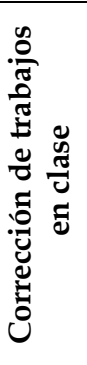 & 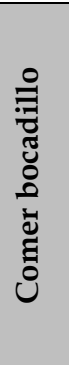 & $\underset{H}{\stackrel{\leftrightarrow}{O}}$ \\
\hline Caso 2 & 11 & 0 & 0 & 0 & 0 & 0 & 315 & 15 & 0 & 0 & 341 \\
\hline Caso 4 & 39 & 0 & 45 & 89 & 128 & 487 & 0 & 0 & 0 & 0 & 788 \\
\hline Caso 5 & 9 & 50 & 0 & 0 & 105 & 316 & 0 & 0 & 156 & 8 & 644 \\
\hline Caso 7 & 16 & 13 & 0 & 0 & 432 & 0 & 0 & 69 & 0 & 0 & 530 \\
\hline Caso 9 & 0 & 27 & 0 & 0 & 0 & 424 & 0 & 0 & 55 & 47 & 553 \\
\hline TOTAL & 75 & 90 & 45 & 89 & 665 & 1227 & 315 & 84 & 211 & 55 & 2856 \\
\hline
\end{tabular}

Tabla 7.29 Frecuencia de acciones instructivas de las ATAs en cada caso/profesor en $1^{\circ}$ EI $(\chi 2(36, \mathrm{n}=2856)=5172,473, \mathrm{p}<.001 V=.67)$ 
Por último, constatamos que vuelve a ser significativa la diferencia entre ATAs y profesor para los datos correspondientes a $3^{\circ}$ EI $[(\chi 2(48, n=5305)=$ $11793,251, \mathrm{p}<.001, V=.40]$. En este caso son protagonistas el ATA de Realización de tarea con y sin TIC relacionadas (1771), junto con la Realización de tarea por rincones (1536). En tercer y cuarto lugar se sitúan la Realización de tarea con TIC (825) y la Realización de tareas con y sin TIC independiente (479) (Tabla 7.30).

\begin{tabular}{|c|c|c|c|c|c|c|c|c|c|c|}
\hline & 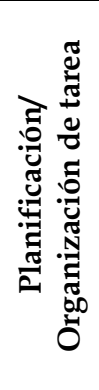 & 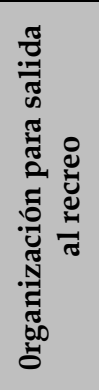 & 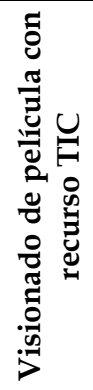 & 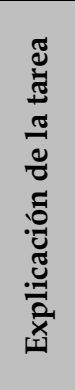 & 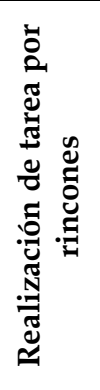 & 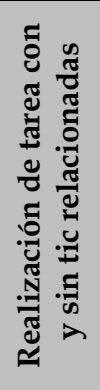 & 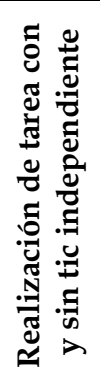 & 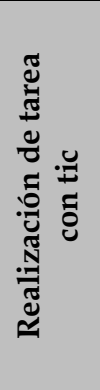 & 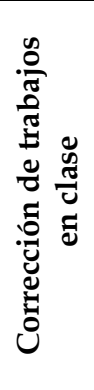 & 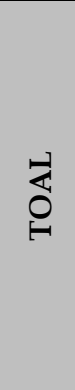 \\
\hline Caso 1 & 33 & 6 & 61 & 9 & 0 & 315 & 73 & 37 & 18 & 552 \\
\hline Caso 2 & 40 & 30 & 0 & 0 & 0 & 0 & 119 & 644 & 0 & 833 \\
\hline Caso 4 & 20 & 0 & 0 & 0 & 0 & 582 & 0 & 0 & 0 & 602 \\
\hline Caso 5 & 47 & 40 & 0 & 0 & 158 & 498 & 0 & 144 & 0 & 887 \\
\hline Caso 6 & 9 & 66 & 85 & 17 & 0 & 376 & 0 & 0 & 0 & 553 \\
\hline Caso 7 & 0 & 10 & 0 & 0 & 1378 & 0 & 0 & 0 & 117 & 1505 \\
\hline Caso 11 & 0 & 0 & 0 & 86 & 0 & 0 & 287 & 0 & 0 & 373 \\
\hline TOTAL & 149 & 152 & 146 & 112 & 1536 & 1771 & 479 & 825 & 135 & 5305 \\
\hline
\end{tabular}

Tabla 7.30 Frecuencia de acciones instructivas de las ATAs en cada caso/profesor en $1^{\circ} \mathrm{EI}$ $\left(\chi^{2}(36, \mathrm{n}=2856)=5172,473, \mathrm{p}<.001, V=.40\right)$

En síntesis, por tanto, encontramos en estos análisis diferencias significativas en la distribución de ATAs por profesor tanto en el conjunto de los tres cursos de Educación Infantil, como en cada uno de ellos por separado.

\subsubsection{Análisis de la relación entre acciones instructivas y elementos del curriculum.}

En el apartado anterior sobre resultados descriptivos del estudio, se han ofrecido datos sobre la distribución de las acciones instructivas referidas a cada tipo de actividad y a cada profesor, así como a cada curso de la etapa. De forma 
similar se procedió con los elementos del curriculum primarios y secundarios para cada patrón de actividad y para cada docente. Se pretendía, de esta forma, completar la descripción sobre la configuración de los patrones de actividad detectados y sobre cómo cada profesor llevaba a cabo cada una de las sesiones grabadas. A continuación trataremos de ofrecer datos que permitan avanzar un paso más en la explicación de cómo trabajan los profesores en las ATAs detectadas, incluyendo el curso de la etapa correspondiente. Por tanto, se expondrán datos sobre la relación entre acciones instructivas que se llevan a cabo en las aulas y elementos del curriculum (primarios y secundarios) sobre los que recaen dichas acciones. Entendemos que ello permitirá profundizar en el análisis de la relación entre ATAs y profesores, añadiendo el curso de la etapa en el que se han recogido los datos.

\subsubsection{Acciones instructivas y elementos del curriculum primarios.}

En relación con los elementos del curriculum primarios y las acciones instructivas obtenemos relación significativa, $[\chi 2(9, \mathrm{n}=14005)=1219,338, \mathrm{p}<.001$, $V=.17]$. Comprobamos que son las tareas a las que mayoritariamente se dirigen las acciones instructivas de los docentes en todos los casos. Como acciones instructivas destacan supervisar, identificar y planificar (Tabla 7.31).

\begin{tabular}{cccccc} 
& Contenido & Tarea & Rec. TIC & Rec. no TIC & Total \\
& & & & & \\
\hline \multirow{2}{*}{ Identificar } & $\mathbf{1 1 9 8}$ & $\mathbf{2 8 2 9}$ & $\mathbf{2 5 7}$ & $\mathbf{3 7 2}$ & $\mathbf{4 6 5 6}$ \\
& $25.7 \%$ & $60.8 \%$ & $5.5 \%$ & $8.0 \%$ & $100.0 \%$ \\
\hline \multirow{2}{*}{ Explicar } & $\mathbf{3 6 5}$ & $\mathbf{6 3 9}$ & $\mathbf{1 5 8}$ & $\mathbf{5 2}$ & $\mathbf{1 2 1 4}$ \\
& $30.1 \%$ & $52.6 \%$ & $13.0 \%$ & $4.3 \%$ & $100.0 \%$ \\
\hline \multirow{2}{*}{ Planificar } & $\mathbf{1 7}$ & $\mathbf{1 8 4 2}$ & $\mathbf{4 7}$ & $\mathbf{1 6}$ & $\mathbf{1 9 2 2}$ \\
& $\mathbf{9} \%$ & $95.8 \%$ & $2.4 \%$ & $0.8 \%$ & $100.0 \%$ \\
\hline \multirow{2}{*}{ Supervisar } & $\mathbf{1 8 8 7}$ & $\mathbf{3 7 8 6}$ & $\mathbf{3 2 3}$ & $\mathbf{2 1 7}$ & $\mathbf{6 2 1 3}$ \\
& $30.4 \%$ & $60.9 \%$ & $5.2 \%$ & $3.5 \%$ & $100.0 \%$ \\
\hline \multirow{2}{*}{ Total } & $\mathbf{3 4 6 7}$ & $\mathbf{9 0 9 6}$ & $\mathbf{7 8 5}$ & $\mathbf{6 5 7}$ & $\mathbf{1 4 0 0 5}$ \\
& $24.8 \%$ & $64.9 \%$ & $5.6 \%$ & $4.7 \%$ & $100.0 \%$ \\
\hline
\end{tabular}

Tabla 7.31 Porcentaje de observación de los diferentes ECP y acciones instructivas $(\chi 2(9, \mathrm{n}=14005)=1219.338, \mathrm{p}<.001, V=.10)$ 
7.3.4.2. Acciones instructivas y elementos del curriculum secundarios.

Si estudiamos esta misma relación respecto de los elementos del curriculum secundario, con una diferencia significativa $[\chi 2(9, \mathrm{n}=9139)=384,804$, $\mathrm{p}<.001, V=.11]$, obtenemos que son el Recurso TIC y el Recurso no TIC los protagonistas. $\mathrm{Y}$ destacan las acciones instructivas de Supervisar, Identificar y Planificar (Tabla 7.32).

\begin{tabular}{cccccc} 
& Contenido & Tarea & Rec. TIC & Rec. no TIC & Total \\
\hline \multirow{2}{*}{ Identificar } & $\mathbf{2 1 4}$ & $\mathbf{4 4 7}$ & $\mathbf{1 1 7 4}$ & $\mathbf{1 2 3 4}$ & $\mathbf{3 0 6 9}$ \\
& $7.0 \%$ & $14.6 \%$ & $38.3 \%$ & $40.2 \%$ & $100.0 \%$ \\
\hline \multirow{2}{*}{ Explicar } & $\mathbf{4 5}$ & $\mathbf{1 5 8}$ & $\mathbf{2 8 6}$ & $\mathbf{3 1 7}$ & $\mathbf{8 0 6}$ \\
& $5.6 \%$ & $19.6 \%$ & $35.5 \%$ & $39.3 \%$ & $100.0 \%$ \\
\hline \multirow{2}{*}{ Planificar } & $\mathbf{3 5}$ & $\mathbf{3 9}$ & $\mathbf{8 2 2}$ & $\mathbf{4 6 5}$ & $\mathbf{1 3 6 1}$ \\
& $2.6 \%$ & $2.9 \%$ & $60.4 \%$ & $34.2 \%$ & $100.0 \%$ \\
\hline \multirow{2}{*}{ Supervisar } & $\mathbf{1 2 4}$ & $\mathbf{4 5 0}$ & $\mathbf{1 5 6 3}$ & $\mathbf{1 7 6 6}$ & $\mathbf{3 9 0 3}$ \\
& $3.2 \%$ & $11.5 \%$ & $40.0 \%$ & $45.2 \%$ & $100.0 \%$ \\
\hline \multirow{2}{*}{ Total } & $\mathbf{4 1 8}$ & $\mathbf{1 0 9 4}$ & $\mathbf{3 8 4 5}$ & 3782 & $\mathbf{9 1 3 9}$ \\
& $4.6 \%$ & $12.0 \%$ & $42.1 \%$ & $41.4 \%$ & $100.0 \%$ \\
\hline
\end{tabular}

Tabla 7.32 Porcentaje de observación de los diferentes ECS y acciones instructivas $(\chi 2(9, \mathrm{n}=9139)=384,804, \mathrm{p}<.001, V=.11)$

\subsubsection{Análisis de la relación entre acciones instructivas y elementos del curriculum en los diferentes cursos.}

Las relaciones estudiadas en el apartado anterior entre las acciones instructivas y los elementos del curriculum también pueden ser observadas en función de los diferentes cursos donde también plantean diferencias significativas, tal y como veremos a continuación, tanto para los elementos del curriculum primarios como para los secundarios.

7.3.5.1. Acciones instructivas y elementos del curriculum primarios en cada uno de los cursos de Educación Infantil.

Si observamos los resultados obtenidos para el primer curso de Educación Infantil, vemos que las diferencias son significativas entre acciones y 
elementos $[\chi 2(9, \mathrm{n}=4246)=268,160, \mathrm{p}<.001, V=.14]$. Destacan como elementos del curriculum primarios la Tarea y el Contenido. Y las acciones instructivas que más se desarrollan por los docentes son Supervisar e Identificar (Tabla 7.33).

\begin{tabular}{cccccc}
\hline \multirow{2}{*}{$\mathbf{1}^{\mathbf{0}} \mathrm{EI}$} & Contenido & Tarea & Rec. TIC & Rec. no TIC & Total \\
\hline \multirow{2}{*}{ Identificar } & $\mathbf{3 2 2}$ & $\mathbf{9 6 6}$ & $\mathbf{6 9}$ & $\mathbf{1 6 1}$ & $\mathbf{1 5 1 8}$ \\
& $21.2 \%$ & $63.6 \%$ & $4.5 \%$ & $10.6 \%$ & $100.0 \%$ \\
\hline \multirow{2}{*}{ Explicar } & $\mathbf{1 1 0}$ & $\mathbf{2 1 3}$ & $\mathbf{1 8}$ & $\mathbf{1 3}$ & $\mathbf{3 5 4}$ \\
& $31.1 \%$ & $60.2 \%$ & $5.1 \%$ & $3.7 \%$ & $100.0 \%$ \\
\hline \multirow{2}{*}{ Planificar } & $\mathbf{6}$ & $\mathbf{4 4 8}$ & $\mathbf{1 0}$ & $\mathbf{9}$ & $\mathbf{4 7 3}$ \\
& $1.3 \%$ & $94.7 \%$ & $2.1 \%$ & $1.9 \%$ & $100.0 \%$ \\
\hline \multirow{2}{*}{ Supervisar } & $\mathbf{5 1 2}$ & $\mathbf{1 2 2 6}$ & $\mathbf{8 2}$ & $\mathbf{8 1}$ & $\mathbf{1 9 0 1}$ \\
& $26.9 \%$ & $64.5 \%$ & $4.3 \%$ & $4.3 \%$ & $100.0 \%$ \\
\hline \multirow{2}{*}{ Total } & $\mathbf{9 5 0}$ & $\mathbf{2 8 5 3}$ & $\mathbf{1 7 9}$ & $\mathbf{2 6 4}$ & 4246 \\
& $22.4 \%$ & $67.2 \%$ & $4.2 \%$ & $6.2 \%$ & $100.0 \%$ \\
\hline
\end{tabular}

Tabla 7.33 Porcentaje de observación de los diferentes ECP y Acciones I. en $1^{\circ}$ EI $(\chi 2(9, \mathrm{n}=4246)=268,160, \mathrm{p}<.001, V=.14)$

En el segundo curso de la etapa vemos que los ECP y las acciones instructivas presentan diferencias significativas $[\chi 2(9, n=2924)=244,448, p<.001$, $V=.16]$. De nuevo, al igual que ocurría en $1^{\circ}$ de EI, la tarea y el contenido se postulan como los ECP con mayor peso. $Y$ en cuanto a las acciones instructivas, son también Supervisar e Identificar las más frecuentes en este segundo curso (Tabla 7.34).

\begin{tabular}{cccccc}
\hline \multirow{2}{*}{$\mathbf{2}^{\circ} \mathrm{EI}$} & Contenido & Tarea & Rec. TIC & Rec. no TIC & Total \\
\hline \multirow{2}{*}{ Identificar } & $\mathbf{2 9 1}$ & $\mathbf{6 3 1}$ & $\mathbf{1 4}$ & $\mathbf{6 4}$ & $\mathbf{1 0 0 0}$ \\
& $29.1 \%$ & $63.1 \%$ & $1.4 \%$ & $6.4 \%$ & $100.0 \%$ \\
\hline \multirow{2}{*}{ Explicar } & $\mathbf{7 2}$ & $\mathbf{1 3 2}$ & $\mathbf{1 3}$ & $\mathbf{1 4}$ & $\mathbf{2 3 1}$ \\
& $31.2 \%$ & $57.1 \%$ & $5.6 \%$ & $6.1 \%$ & $100.0 \%$ \\
\hline \multirow{2}{*}{ Planificar } & $\mathbf{6}$ & $\mathbf{4 1 6}$ & $\mathbf{6}$ & $\mathbf{3}$ & $\mathbf{4 3 1}$ \\
& $1.4 \%$ & $96.5 \%$ & $1.4 \%$ & $.7 \%$ & $100.0 \%$ \\
\hline \multirow{2}{*}{ Supervisar } & $\mathbf{4 1 7}$ & $\mathbf{7 7 1}$ & $\mathbf{3 8}$ & $\mathbf{3 6}$ & $\mathbf{1 2 6 2}$ \\
& $33.0 \%$ & $61.1 \%$ & $3.0 \%$ & $2.9 \%$ & $100.0 \%$ \\
\hline \multirow{2}{*}{ Total } & $\mathbf{7 8 6}$ & $\mathbf{1 9 5 0}$ & $\mathbf{7 1}$ & $\mathbf{1 1 7}$ & $\mathbf{2 9 2 4}$ \\
& $26.9 \%$ & $66.7 \%$ & $2.4 \%$ & $4.0 \%$ & $100.0 \%$ \\
\hline
\end{tabular}

Tabla 7.34 Porcentaje de observación de los diferentes ECP y Acciones I. en $2^{\circ}$ EI $(\chi 2(9, \mathrm{n}=2924)=244,448, \mathrm{p}<.001, V=.19)$ 
En el último curso, los datos analizados demuestran que hay diferencias significativas entre las acciones instructivas y los elementos del curriculum $[\chi 2$ $(9, \mathrm{n}=5355)=616,804, \mathrm{p}<.001, V=.16]$. Al igual que en los dos cursos anteriores predominan la Tarea y el Contenido dentro de los elementos del curriculum primarios, aunque en este caso los Recursos TIC tienen mayor porcentaje con un $8,5 \%$ de las acciones que en cursos anteriores, superando a los Recursos no TIC en proporción. En cuanto a las acciones instructivas, la Supervisión y la Identificación vuelven a ser las destacadas (Tabla 7.35).

\begin{tabular}{cccccc}
\hline \multirow{2}{*}{$\mathbf{3}^{\circ} \mathrm{EI}$} & Contenido & Tarea & Rec. TIC & Rec. no TIC & Total \\
\hline \multirow{2}{*}{ Identificar } & $\mathbf{4 4 8}$ & $\mathbf{9 1 0}$ & $\mathbf{1 3 9}$ & $\mathbf{1 1 6}$ & $\mathbf{1 6 1 3}$ \\
& $27.8 \%$ & $56.4 \%$ & $8.6 \%$ & $7.2 \%$ & $100.0 \%$ \\
\hline \multirow{2}{*}{ Explicar } & $\mathbf{1 7 0}$ & $\mathbf{2 5 5}$ & $\mathbf{1 2 2}$ & $\mathbf{2 4}$ & $\mathbf{5 7 1}$ \\
& $\mathbf{2 9 . 8 \%}$ & $\mathbf{4 4 . 7} \%$ & $21.4 \%$ & $4.2 \%$ & $100.0 \%$ \\
\hline \multirow{2}{*}{ Planificar } & $\mathbf{4}$ & $\mathbf{7 7 0}$ & $\mathbf{2 8}$ & $\mathbf{4}$ & $\mathbf{8 0 6}$ \\
& $\mathbf{5} \%$ & $\mathbf{9 5 . 5 \%}$ & $3.5 \%$ & $.5 \%$ & $100.0 \%$ \\
\hline \multirow{2}{*}{ Supervisar } & $\mathbf{7 1 2}$ & $\mathbf{1 4 0 4}$ & $\mathbf{1 6 6}$ & $\mathbf{8 3}$ & $\mathbf{2 3 6 5}$ \\
& $30.1 \%$ & $59.4 \%$ & $7.0 \%$ & $3.5 \%$ & $100.0 \%$ \\
\hline \multirow{2}{*}{ Total } & $\mathbf{1 3 3 4}$ & $\mathbf{3 3 3 9}$ & $\mathbf{4 5 5}$ & $\mathbf{2 2 7}$ & $\mathbf{5 3 5 5}$ \\
& $24.9 \%$ & $62.4 \%$ & $8.5 \%$ & $4.2 \%$ & $100.0 \%$ \\
\hline
\end{tabular}

Tabla 7.35 Porcentaje de observación de los diferentes ECP y Acciones I. en $3^{\circ}$ EI $(\chi 2(9, \mathrm{n}=5355)=616,804, \mathrm{p}<.001, V=.16)$

En síntesis, vemos que tanto acciones instructivas como elementos del curriculum primarios se distribuyen de forma muy similar en los tres cursos del segundo ciclo de Educación Infantil, donde Supervisar e identificar son los que cuentan con más registros. Asimismo, la tarea y el contenido destacan entre los ECP.

7.3.5.2. Acciones instructivas y elementos del curriculum secundarios en cada uno de los cursos de Educación Infantil.

En cuanto a los datos en relación a las acciones instructivas y los elementos del curriculum secundario en el primer curso de Educación Infantil, encontramos diferencias significativas $\left[\chi^{2}(9, \mathrm{n}=2857)=128,891, \mathrm{p}<.001, V=.12\right]$. 
Dentro de las acciones, la Identificación y la Supervisión siguen siendo las más destacadas. En lo concerniente a los elementos del curriculum secundarios, a diferencia de lo que veíamos en los primarios, los recursos TIC y los Recursos no TIC destacan sobre el resto de elementos (Tabla 7.36).

\begin{tabular}{cccccc}
\hline \multirow{2}{*}{${ }^{\mathbf{0}} \mathrm{EI}$} & Contenido & Tarea & Rec. TIC & Rec. no TIC & Total \\
\hline \multirow{2}{*}{ Identificar } & $\mathbf{8 7}$ & $\mathbf{1 1 6}$ & $\mathbf{3 3 8}$ & $\mathbf{4 6 6}$ & $\mathbf{1 0 0 7}$ \\
& $8.6 \%$ & $11.5 \%$ & $33.6 \%$ & $46.3 \%$ & $100.0 \%$ \\
\hline \multirow{2}{*}{ Explicar } & $\mathbf{2 2}$ & $\mathbf{2 6}$ & $\mathbf{9 7}$ & $\mathbf{1 2 1}$ & $\mathbf{2 6 6}$ \\
& $8.3 \%$ & $9.8 \%$ & $36.5 \%$ & $45.5 \%$ & $100.0 \%$ \\
\hline \multirow{2}{*}{ Planificar } & $\mathbf{2}$ & $\mathbf{7}$ & $\mathbf{2 1 3}$ & $\mathbf{1 2 4}$ & $\mathbf{3 4 6}$ \\
& $.6 \%$ & $\mathbf{2 . 0 \%}$ & $61.6 \%$ & $35.8 \%$ & $100.0 \%$ \\
\hline \multirow{2}{*}{ Supervisar } & $\mathbf{5 3}$ & $\mathbf{1 2 2}$ & $\mathbf{4 5 5}$ & $\mathbf{6 0 8}$ & $\mathbf{1 2 3 8}$ \\
& $4.3 \%$ & $9.9 \%$ & $36.8 \%$ & $49.1 \%$ & $100.0 \%$ \\
\hline \multirow{2}{*}{ Total } & $\mathbf{1 6 4}$ & $\mathbf{2 7 1}$ & $\mathbf{1 1 0 3}$ & $\mathbf{1 3 1 9}$ & $\mathbf{2 8 5 7}$ \\
& $5.7 \%$ & $9.5 \%$ & $38.6 \%$ & $46.2 \%$ & $100.0 \%$ \\
\hline
\end{tabular}

Tabla 7.36 Porcentaje de observación de los diferentes ECS y Acciones I. en $1^{\circ}$ EI $(\chi 2(9, \mathrm{n}=2857)=128,891, \mathrm{p}<.001, V=.12)$

Los datos ofrecidos para el segundo curso, revelan diferencias significativas entre acciones y elementos secundarios $[\chi 2(9, \mathrm{n}=2857)=128,891$, $\mathrm{p}<.001, V=.12]$. De nuevo Supervisar e Identificar se erigen como las acciones protagonistas. Mientras que en los elementos se vuelven a repetir como ocurría en primero los Recursos TIC y los Recursos no TIC como los elementos destacados (tabla 7.37).

\begin{tabular}{cccccc}
\hline \multirow{2}{*}{$\mathbf{2}^{\circ} \mathrm{EI}$} & Contenido & Tarea & Rec. TIC & Rec. no TIC & Total \\
\hline \multirow{2}{*}{ Identificar } & $\mathbf{3 6}$ & $\mathbf{1 4 3}$ & $\mathbf{1 7 9}$ & $\mathbf{2 9 1}$ & $\mathbf{6 4 9}$ \\
& $5.5 \%$ & $22.0 \%$ & $27.6 \%$ & $44.8 \%$ & $100.0 \%$ \\
\hline \multirow{2}{*}{ Explicar } & $\mathbf{5}$ & $\mathbf{3 0}$ & $\mathbf{5 4}$ & $\mathbf{7 1}$ & $\mathbf{1 6 0}$ \\
& $3.1 \%$ & $18.8 \%$ & $33.8 \%$ & $44.4 \%$ & $100.0 \%$ \\
\hline \multirow{2}{*}{ Planificar } & $\mathbf{1 2}$ & $\mathbf{9}$ & $\mathbf{1 6 7}$ & $\mathbf{1 1 8}$ & $\mathbf{3 0 6}$ \\
& $3.9 \%$ & $\mathbf{2 . 9 \%}$ & $54.6 \%$ & $38.6 \%$ & $100.0 \%$ \\
\hline \multirow{2}{*}{ Supervisar } & $\mathbf{1 3}$ & $\mathbf{1 0 0}$ & $\mathbf{2 4 5}$ & $\mathbf{4 5 6}$ & $\mathbf{8 1 4}$ \\
& $1.6 \%$ & $12.3 \%$ & $30.1 \%$ & $56.0 \%$ & $100.0 \%$ \\
\hline \multirow{2}{*}{ Total } & $\mathbf{6 6}$ & $\mathbf{2 8 2}$ & $\mathbf{6 4 5}$ & $\mathbf{9 3 6}$ & $\mathbf{1 9 2 9}$ \\
& $3.4 \%$ & $14.6 \%$ & $33.4 \%$ & $48.5 \%$ & $100.0 \%$ \\
\hline
\end{tabular}

Tabla 7.37 Porcentaje de observación de los diferentes ECS y Acciones I. en $2^{\circ}$ EI $(\chi 2(9, \mathrm{n}=1929)=142,942, \mathrm{p}<.001, V=.15)$ 
Por último, el análisis para el tercer curso de Educación Infantil nos muestra que existen diferencias significativas al igual que en los dos cursos anteriores $[\chi 2(9, \mathrm{n}=3358)=153,904, \mathrm{p}<.001, V=.12]$. Las acciones instructivas más destacadas como viene siendo habitual son la Supervisión y la Identificación. De igual manera los Recursos TIC y los Recursos no TIC, son los que predominan entre los elementos del curriculum, aunque en este caso y a diferencia de los otros dos cursos, los Recursos TIC tienen un porcentaje mayor que los Recursos no TIC (Tabla 7.38).

\begin{tabular}{cccccc}
\hline \multirow{2}{*}{$\mathbf{3}^{\circ} \mathrm{EI}$} & Contenido & Tarea & Rec. TIC & Rec. no TIC & Total \\
\hline \multirow{2}{*}{ Identificar } & $\mathbf{5 1}$ & $\mathbf{1 4 5}$ & $\mathbf{4 8 4}$ & $\mathbf{3 7 7}$ & $\mathbf{1 0 5 7}$ \\
& $4.8 \%$ & $13.7 \%$ & $45.8 \%$ & $35.7 \%$ & $100.0 \%$ \\
\hline \multirow{2}{*}{ Explicar } & $\mathbf{1 3}$ & $\mathbf{9 3}$ & $\mathbf{1 2 0}$ & $\mathbf{1 0 7}$ & $\mathbf{3 3 3}$ \\
& $3.9 \%$ & $27.9 \%$ & $36.0 \%$ & $32.1 \%$ & $100.0 \%$ \\
\hline \multirow{2}{*}{ Planificar } & $\mathbf{9}$ & $\mathbf{2 2}$ & $\mathbf{3 5 1}$ & $\mathbf{1 8 1}$ & $\mathbf{5 6 3}$ \\
& $1.6 \%$ & $3.9 \%$ & $\mathbf{6 2 . 3 \%}$ & $32.1 \%$ & $100.0 \%$ \\
\hline \multirow{2}{*}{ Supervisar } & $\mathbf{2 9}$ & $\mathbf{1 8 2}$ & $\mathbf{6 5 5}$ & $\mathbf{5 3 9}$ & $\mathbf{1 4 0 5}$ \\
& $2.1 \%$ & $13.0 \%$ & $46.6 \%$ & $38.4 \%$ & $100.0 \%$ \\
\hline \multirow{2}{*}{ Total } & $\mathbf{1 0 2}$ & $\mathbf{4 4 2}$ & $\mathbf{1 6 1 0}$ & $\mathbf{1 2 0 4}$ & $\mathbf{3 3 5 8}$ \\
& $3.0 \%$ & $13.2 \%$ & $47.9 \%$ & $35.9 \%$ & $100.0 \%$ \\
\hline
\end{tabular}

Tabla 7.38 Porcentaje de observación de los diferentes ECS y Acciones I. en $3^{\circ}$ EI $(\chi 2(9, \mathrm{n}=3358)=153,904, \mathrm{p}<.001, V=.12)$

Durante los tres cursos podemos ver que los ECS se distribuyen de forma similar en $1^{\circ}$ y $2^{\circ}$ contando con los Recursos no TIC como elemento más destacado seguido de los Recursos TIC. En el tercer curso, sin embargo, hemos podido observar en los datos que son los Recursos TIC los que cuentan con más frecuencias seguidos de los Recursos no TIC.

En estos dos últimos apartados (7.3.5.1 y 7.3.5.2) en los que se analizan las relaciones entre acciones instructivas y elementos del curriculum, debemos de tener en cuenta que los datos obtenidos en la prueba $V$ de Cramer da valores muy bajos, comprendidos entre .10 y .19, lo que significa que las variables analizadas presentan una relación muy baja entre sí, cuestión que no ocurre en el resto de tablas de contingencia que mostramos en el apartado de resultados 7.3. 


\subsubsection{Análisis de la relación entre elementos del curriculum primarios y secundarios}

También es importante ver las conexiones que existen entre los ECP y los ECS, puesto que ayudan a entender cuáles son los elementos del curriculum que protagonizan la acción del profesor y a su vez cuáles son los que sirven de apoyo o refuerzo a dichos protagonistas (Figura 7.39).

Comprobamos que existe una relación significativa entre ECP y ECS $[\chi 2(9, \mathrm{n}=9164)=5170,596, \mathrm{p}<.001, V=.43]$, lo que subraya las diferencias en las relaciones entre ambos. Para obtener los índices de significación ha sido necesario eliminar de la matriz los objetivos (5) por presentar frecuencias teóricas inferiores a 5. Del total de Elementos de Curriculum Primarios el mayor número corresponde a las Tareas (6190), seguidas del Contenido (2260), en tercer lugar los Recursos TIC (405) y en último los Recursos no TIC (309). Esos ECP se apoyan principalmente en los Recursos TIC (3849) y Recursos no TIC (3795). La distribución por cada uno de los elementos podemos observarla en la siguiente Tabla 7.39:

\begin{tabular}{cccccc} 
& $\begin{array}{c}\text { Contenido } \\
\text { ECP }\end{array}$ & $\begin{array}{c}\text { Tareas } \\
\text { ECP }\end{array}$ & $\begin{array}{c}\text { Recurso TIC } \\
\text { ECP }\end{array}$ & $\begin{array}{c}\text { Recurso no } \\
\text { TIC ECP }\end{array}$ & TOTAL \\
\hline Contenido & $\mathbf{0}$ & $\mathbf{3 2 8}$ & $\mathbf{7 0}$ & $\mathbf{2 3}$ & $\mathbf{4 2 1}$ \\
ECS & $.0 \%$ & $5.3 \%$ & $17.3 \%$ & $7.4 \%$ & $4.6 \%$ \\
\hline Tareas & $\mathbf{4 8 3}$ & $\mathbf{0}$ & $\mathbf{3 3 2}$ & $\mathbf{2 8 4}$ & $\mathbf{1 0 9 9}$ \\
ECS & $21.4 \%$ & $.0 \%$ & $82.0 \%$ & $91.9 \%$ & $12.0 \%$ \\
\hline Recurso TIC & $\mathbf{9 7 5}$ & $\mathbf{2 8 7 2}$ & $\mathbf{0}$ & $\mathbf{2}$ & $\mathbf{3 8 4 9}$ \\
ECS & $43.1 \%$ & $46.4 \%$ & $.0 \%$ & $.6 \%$ & $42.0 \%$ \\
\hline Recurso no TIC & $\mathbf{8 0 2}$ & $\mathbf{2 9 9 0}$ & $\mathbf{3}$ & $\mathbf{0}$ & 3795 \\
ECS & $35.5 \%$ & $48.3 \%$ & $.7 \%$ & $.0 \%$ & $41.4 \%$ \\
\hline TOTAL & $\mathbf{2 2 6 0}$ & $\mathbf{6 1 9 0}$ & $\mathbf{4 0 5}$ & 309 & $\mathbf{9 1 6 4}$ \\
& $100.0 \%$ & $100.0 \%$ & $100.0 \%$ & $100.0 \%$ & $100.0 \%$ \\
\hline
\end{tabular}

Tabla 7.39 Frecuencias y porcentajes de ECP y ECS

$(\chi 2(9, \mathrm{n}=9169)=5170,596, \mathrm{p}<.001, V=.43)$

De la misma forma, si buscamos diferencias entre los cursos con respecto a los ECP y los ECS, vemos que en todos los casos obtenemos relaciones significativas en $1^{\circ} \mathrm{EI}[\chi 2(9, \mathrm{n}=2866)=1564.704, \mathrm{p}<.001, V=.42]$, en $2^{\circ} \mathrm{EI}$ $[\chi 2(9, \mathrm{n}=1930)=953.040, \mathrm{p}<.001, V=.40]$ y en $3^{\circ}$ EI $[\chi 2(9, \mathrm{n}=3370)=2257.462$, $\mathrm{p}<.001, V=.4]$ 
7.3.6.1. Análisis de la relación entre elementos del curriculum primarios y secundarios en cada uno de los cursos de Educación Infantil.

En primero de Educación Infantil observamos que son las Tareas y los Contenidos como ECP los que más frecuencias presentan con 2047 y 624 respectivamente, mientras que son los Recursos no TIC y los Recursos TIC los que más registros tienen dentro de los ECS con 1326 y 1103 frecuencias respectivamente.

En cuanto a la relación entre ambos, las Tareas se apoyan mayoritariamente en los Recursos no TIC (1088) y los Recursos TIC (829) como elementos de curriculum secundarios: (En una tarea con plastilina) Vamos a hacer, chicos, un gusanito, vale, a ver quién le sale el gusanito más grande, hacemos la bolita, hacemos la bolita, ya está muy blanda Alejandro, y vamos a ver a quien le sale el gusanito más largo. Venga, el gusanito más largo, Rodrigo, venga si, el gusanito más largo, fuerte, fuerte, fuerte, a ver a quien le sale el más largo (Explica-Tarea-Recurso no TIC, Caso 10). También aunque en menor medida en los Contenidos (130). Por su parte, los Contenidos se apoyan en los Recursos TIC (273) y en los Recursos no TIC (236) como Elementos del curriculum secundarios; y en tercer lugar en las Tareas (115): Vale. Ahora, ¿Qué tenemos que hacer? Ahora, ¿hasta que empecemos a funcionar que tenemos que hacer? ¿por qué no podemos empezar ahora a trabajar? Niño: porque se está cargando (Supervisa-Contenido-Recurso TIC, Caso 5). Estos datos los podemos ver en la Tabla 7.40 que se muestra a continuación.

\begin{tabular}{cccccc}
$\mathbf{1}^{\circ} \mathrm{EI}$ & $\begin{array}{c}\text { Contenido } \\
\text { ECP }\end{array}$ & $\begin{array}{c}\text { Tareas } \\
\text { ECP }\end{array}$ & $\begin{array}{c}\text { Recurso TIC } \\
\text { ECP }\end{array}$ & $\begin{array}{c}\text { Recurso no } \\
\text { TIC ECP }\end{array}$ & TOTAL \\
\hline Contenido & $\mathbf{0}$ & $\mathbf{1 3 0}$ & $\mathbf{2 2}$ & $\mathbf{1 4}$ & $\mathbf{1 6 6}$ \\
ECS & $.0 \%$ & $6.4 \%$ & $20.8 \%$ & $15.7 \%$ & $5.8 \%$ \\
\hline Tareas & $\mathbf{1 1 5}$ & $\mathbf{0}$ & $\mathbf{8 2}$ & $\mathbf{7 4}$ & $\mathbf{2 7 1}$ \\
ECS & $18.4 \%$ & $.0 \%$ & $77.4 \%$ & $83.1 \%$ & $9.5 \%$ \\
\hline Recurso TIC & $\mathbf{2 7 3}$ & $\mathbf{8 2 9}$ & $\mathbf{0}$ & $\mathbf{1}$ & $\mathbf{1 1 0 3}$ \\
ECS & $43.8 \%$ & $40.5 \%$ & $.0 \%$ & $1.1 \%$ & $38.5 \%$ \\
\hline Recurso no TIC & $\mathbf{2 3 6}$ & $\mathbf{1 0 8 8}$ & $\mathbf{2}$ & $\mathbf{0}$ & $\mathbf{1 3 2 6}$ \\
ECS & $37.8 \%$ & $53.2 \%$ & $1.9 \%$ & $.0 \%$ & $46.3 \%$ \\
\hline TOTAL & $\mathbf{6 2 4}$ & $\mathbf{2 0 4 7}$ & $\mathbf{1 0 6}$ & 89 & $\mathbf{2 8 6 6}$ \\
& $100.0 \%$ & $100.0 \%$ & $100.0 \%$ & $100.0 \%$ & $100.0 \%$ \\
\hline
\end{tabular}

Tabla 7.40 Frecuencias y porcentajes de ECP y ECS en $1^{\circ}$ EI $(\chi 2(9, \mathrm{n}=2866)=1564.704, \mathrm{p}<.001, V=.42)$ 
En lo referente al segundo curso de Educación Infantil, los datos muestran un comportamiento muy similar al que se producía en el primer curso. Así, las Tareas y el Contenido cuentan con una frecuencia de 1251 y 560 respectivamente dentro de los ECP, quedando los Recursos TIC y Recursos no TIC en un segundo plano con frecuencias de tan sólo 46 y 73. En los ECS se invierte esta proporción y son los Recursos no TIC y los Recursos TIC los predominantes durante este segundo curso, contando con frecuencias de $936 \mathrm{y}$ 646 respectivamente (Tabla 7.41).

En el análisis de los ECS sobre los que se apoyan los ECP, nos muestra de nuevo cómo los Recursos no TIC (732) y los Recurso TIC (462) predominan como apoyo a las Tareas en las acciones del docente, Vamos a ver. Vamos a hacer... vamos, a ver por favor. Raisa, Raisa... Venga que vamos a jugar al ordenador ¿vale? $Y$ vamos a hacer mientras unos jugamos al ordenador (Planifica-TareaRecurso TIC, Caso 3). Cambia en cierta medida el patrón cuando aparece el Contenido, puesto que además de apoyarse en los Recursos TIC (184) y Recursos no TIC (204) se lleva a cabo, con una frecuencia similar a las de los dos elementos anteriores, sobre las Tareas (172), suponiendo esto último una distinción con lo que hemos visto en el primer curso de Educación Infantil, $A h$, la "C" de Carlos, es que no la hemos trabajado y por eso no la sabía. COME (ExplicaContenido-Tarea, Caso, 6) (Tabla 7.41).

\begin{tabular}{cccccc}
\hline $2^{\circ}$ EI & $\begin{array}{c}\text { Contenido } \\
\text { ECP }\end{array}$ & $\begin{array}{c}\text { Tareas } \\
\text { ECP }\end{array}$ & $\begin{array}{c}\text { Recurso TIC } \\
\text { ECP }\end{array}$ & $\begin{array}{c}\text { Recurso no } \\
\text { TIC ECP }\end{array}$ & TOTAL \\
\hline Contenido & $\mathbf{0}$ & $\mathbf{5 7}$ & $\mathbf{5}$ & $\mathbf{4}$ & $\mathbf{6 6}$ \\
ECS & $.0 \%$ & $4.6 \%$ & $10.9 \%$ & $5.5 \%$ & $3.4 \%$ \\
\hline Tareas & $\mathbf{1 7 2}$ & $\mathbf{0}$ & $\mathbf{4 1}$ & $\mathbf{6 9}$ & $\mathbf{2 8 2}$ \\
ECS & $30.7 \%$ & $.0 \%$ & $89.1 \%$ & $94.5 \%$ & $14.6 \%$ \\
\hline Recurso TIC & $\mathbf{1 8 4}$ & $\mathbf{4 6 2}$ & $\mathbf{0}$ & $\mathbf{0}$ & $\mathbf{6 4 6}$ \\
ECS & $32.9 \%$ & $36.9 \%$ & $.0 \%$ & $.0 \%$ & $33.5 \%$ \\
\hline Recurso no TIC & $\mathbf{2 0 4}$ & $\mathbf{7 3 2}$ & $\mathbf{0}$ & $\mathbf{0}$ & $\mathbf{9 3 6}$ \\
ECS & $36.4 \%$ & $58.5 \%$ & $.0 \%$ & $.0 \%$ & $48.5 \%$ \\
\hline TOTAL & $\mathbf{5 6 0}$ & $\mathbf{1 2 5 1}$ & $\mathbf{4 6}$ & $\mathbf{7 3}$ & $\mathbf{1 9 3 0}$ \\
& $100.0 \%$ & $100.0 \%$ & $100.0 \%$ & $100.0 \%$ & $100.0 \%$ \\
\hline
\end{tabular}

Tabla 7.41 Frecuencias y porcentajes de ECP y ECS en $1^{\circ}$ EI

$$
(\chi 2(9, \mathrm{n}=1930)=953.040, \mathrm{p}<.001, V=.40)
$$

En el tercer curso de Educación Infantil, predomina un patrón muy similar en cuanto a ECP a los dos cursos anteriores, donde las Tareas y los Contenidos vuelven a jugar un papel predominante con 2217 y 825 acciones instructivas respectivamente. La diferencia radica en este caso en los ECS, 
donde se produce una distribución diferente de los Recursos TIC (1611) y los Recursos no TIC (1209) tal como podemos apreciar en la Tabla 7.42, puesto que los recursos TIC pasan a ser protagonistas del plano secundario. Las tareas (447) sí se mantienen constantes, proporcionalmente hablando, con respecto a $1^{\circ}$ EI y $2^{\circ}$ EI.

Por último, de las relaciones entre estas dos variables, vemos que las Tareas como ECP se apoyan con mayor frecuencia en los Recursos TIC (1225), seguido de los Recursos no TIC (908) y en menor medida en el Contenido (84), Dale ahí con el ratón, a ver, dale tú, cariño, ahí, dale ahí al ratón ese, donde salimos al indice (Identifica-Tarea-Recurso TIC, Caso 5). En relación con el Contenido como ECP, predomina también el Recurso TIC (385) frente al Recurso no TIC (300) y al igual que ocurría en $1^{\circ}$ EI, las Tareas (140) juegan un papel menos relevante como ECS en relación con el Contenido, No, perdona, el nombre ahí, el nombre ahí, si señor, el nombre Bruno, por favor aqui, y haz esa, ahí, para que baje (Supervisa-Contenido-Recurso no TIC). En la tabla 7.42 que tenemos a continuación podemos ver algunos datos más sobre la relación entre los elementos del curriculum restantes.

\begin{tabular}{cccccc}
\hline $3^{\circ}$ EI & $\begin{array}{c}\text { Contenido } \\
\text { ECP }\end{array}$ & $\begin{array}{c}\text { Tareas } \\
\text { ECP }\end{array}$ & $\begin{array}{c}\text { Recurso TIC } \\
\text { ECP }\end{array}$ & $\begin{array}{c}\text { Recurso no } \\
\text { TIC ECP }\end{array}$ & TOTAL \\
\hline Contenido & $\mathbf{0}$ & $\mathbf{8 4}$ & $\mathbf{1 6}$ & $\mathbf{3}$ & $\mathbf{1 0 3}$ \\
ECS & $.0 \%$ & $3.8 \%$ & $7.9 \%$ & $2.4 \%$ & $3.1 \%$ \\
\hline Tareas & $\mathbf{1 4 0}$ & $\mathbf{0}$ & $\mathbf{1 8 5}$ & $\mathbf{1 2 2}$ & $\mathbf{4 4 7}$ \\
ECS & $17.0 \%$ & $.0 \%$ & $91.6 \%$ & $96.8 \%$ & $13.3 \%$ \\
\hline Recurso TIC & $\mathbf{3 8 5}$ & $\mathbf{1 2 2 5}$ & $\mathbf{0}$ & $\mathbf{1}$ & $\mathbf{1 6 1 1}$ \\
ECS & $46.7 \%$ & $55.3 \%$ & $.0 \%$ & $.8 \%$ & $47.8 \%$ \\
\hline Recurso no TIC & $\mathbf{3 0 0}$ & $\mathbf{9 0 8}$ & $\mathbf{1}$ & $\mathbf{0}$ & $\mathbf{1 2 0 9}$ \\
ECS & $36.4 \%$ & $41.0 \%$ & $.5 \%$ & $.0 \%$ & $35.9 \%$ \\
\hline TOTAL & $\mathbf{8 2 5}$ & $\mathbf{2 2 1 7}$ & $\mathbf{2 0 2}$ & $\mathbf{1 2 6}$ & 3370 \\
& $100.0 \%$ & $100.0 \%$ & $100.0 \%$ & $100.0 \%$ & $100.0 \%$ \\
\hline
\end{tabular}

Tabla 7.42 Frecuencias y porcentajes de ECP y ECS en $1^{\circ} \mathrm{EI}$ $(\chi 2(9, \mathrm{n}=3370)=2257.462, \mathrm{p}<.001, V=.47)$ 


\section{CAPÍTULO}

Discusión de los resultados 



\section{Discusión de los resultados}

En el apartado que iniciamos ahora, en torno precisamente a los resultados obtenidos, trataremos de ofrecer una interpretación de los mismos organizada a partir de los objetivos formulados y a la luz del corpus teórico elaborado respecto de las preguntas objeto de indagación. Y ello, sin perder de vista, las posibilidades y limitaciones que la metodología elegida plantea como modelo para abordar el análisis de los datos.

Como formulábamos en el objetivo genérico de la investigación, saber cómo los docentes de Educación Infantil desarrollan su práctica profesional ante la introducción de los recursos TIC en el aula exige un trabajo interpretativo de los resultados en la medida que los datos ofrecen una descripción del desempeño práctico del profesorado en el estudio de casos múltiple que se ha presentado en este trabajo. Por lo tanto, y siguiendo la línea que Stenhouse (1985) o Schwab proponen, esta práctica se erige como una aportación fundamental para entrever qué sucede en el proceso de integración de las TIC desde la perspectiva docente. Así, como subraya Fullan (1991) el profesor busca conexiones entre el contenido curricular, los recursos y el alumno. La forma en que se producen estas conexiones se construye en torno a ATAs que permiten regular esas relaciones dentro de la estructura y tiempos lectivos.

Estas ATAs son un elemento de análisis esencial para saber qué ocurre dentro de la clase en el proceso de enseñanza aprendizaje. Por lo que analizar cuáles son las ATAs sobre las que los docentes vertebran sus prácticas (objetivo número 1 de esta investigación) es una tarea ineludible en el marco de este estudio. De esta manera, se han identificado un total de 19 tipos de patrones o estructuras de actividad diferentes en las 41 sesiones analizadas, como queda recogido en el apartado 7.1 del capítulo de resultados. Algunos de estos tipos de ATAs que aparecen están muy vinculados a las características de los alumnos y de la etapa, por ejemplo ATAs como la de Comer el bocadillo, Fecha y tiempo meteorológico, Juego libre, Organización para salida al recreo, Organización de vuelta del recreo o Realización de tarea por rincones. Se trata de patrones de actividad que suponemos que irán desapareciendo paulatinamente a medida que los alumnos van avanzando a través de cursos y etapas a lo largo del 
sistema educativo, lo que puede suceder bien porque se eligen otras metodologías más cercanas a la estructuración académica (Realización de tarea por rincones, Fecha y tiempo meteorológico o Juego libre), o bien porque los alumnos ganan en autonomía y esas actividades se realizan fuera del entorno del aula o sin la supervisión del docente (Comer el bocadillo, Organización para salida al recreo u Organización de vuelta del recreo). Otras de las estructuras o patrones de actividad que aparecen son comunes a todas las etapas educativas, entre ellas ejemplos tales como Planificación/organización de tareas, Explicación de la tarea, Corrección de trabajos en clase, Realización de tarea con TIC, Realización de Tarea sin TIC, Realización de tareas con y sin TIC relacionadas, Realización de tareas con y sin TIC independientes, Recitado de poesía, Elección de lectura para casa, Lectura de imágenes con recurso no TIC y Lectura de imágenes con recurso TIC, que obviamente se modificarán en su contenido, configuración y duración dependiendo de la etapa educativa en la que se desarrollen. Por ejemplo, no es lo mismo el nivel de complejidad ni el tiempo que se dedica a una Explicación de tarea para alumnos de bachillerato que para alumnos de infantil.

Asimismo, para nuestra investigación es importante también identificar cuáles son las estructuras en las que el recurso TIC juega un papel central o activo (objetivo número 2 de esta investigación). Basándonos en este parámetro el número de patrones de actividad se reduce a seis cuando analizamos aquellas que incorporan explícitamente el uso de un recurso TIC: las que podemos denominar como "ATAs TIC", que son Realización de trabajo por rincones, Realización de tareas con y sin TIC independiente, Realización de tareas con y sin TIC relacionadas, Realización de tarea con TIC, Visionado de película con recurso TIC o Lectura de imágenes con recurso TIC. Por tanto, estas 19 diversas formas de ATAs y "ATAs TIC" se entrelazan para organizar y dar sentido instructivo a sesiones temporalizadas y organizadas en la etapa de Educación Infantil, donde el profesor desarrolla su práctica profesional e integra los recursos TIC.

Asimismo, la aparición de ATAs relacionadas con TIC en nuestro estudio, nos lleva a afirmar que el recurso digital se introduce en las aulas y además, se usa incorporándolo al conjunto de acciones habituales del profesor. Pero en consonancia con la idea que Dawes (1999) defiende, esta introducción no se realiza de forma idéntica y equivalente en todos los profesores, sino que cada docente opta por incorporar el recurso atendiendo a cómo concibe su práctica de aula y cuáles son sus esquemas de acción más habituales. Por tanto, los mecanismos que cada profesor pone en marcha para integrar las TIC dependen en gran medida de su conocimiento profesional docente (Shulman, 
1986, 1987) y del sentido que tenga el recurso dentro de su enfoque del desarrollo del curriculum. A su vez, también aparecen otras influencias tanto relativas al entorno (dotación de recursos, número de alumnos en clase, apoyo de la Administración, centro y compañeros, espacios, tiempos, presión curricular, características del alumnado, presión social, entorno familiar del alumno, etc.) como a la idiosincrasia del docente (la edad, las habilidades con los recursos TIC, conocimiento de los recursos, actitudes hacia las TIC, etc.) (Angulo, 1999).

Pese a todas estas posibilidades y variantes mencionadas a lo largo del trabajo sobre las características del entorno, el docente y las estructuras o patrones de actividad que componen y dan lugar a cada uno de los casos concretados en las sesiones de aula, existe un patrón bastante homogeneizado entre el profesorado en relación a las acciones instructivas. En este sentido, los datos muestran una similitud en los esquemas de acción del profesorado, es decir, desde una mirada sintética de todos los casos, los resultados expuestos en el apartado 7.2 destacan en todos los profesores la identificación y la supervisión como acciones predominantes; seguidas de la explicación y la planificación que ocupan un segundo plano (no en términos de importancia, que la tienen, sino en el volumen de acciones y por tanto de tiempo que el profesor dedica en comparación con las anteriores); y por último, en menor medida aparece la recapitulación (prácticamente inexistente a lo largo del conjunto de sesiones).

De esta manera, si nos preguntamos cuál es el papel del profesor en estos patrones de actividad (objetivo número 3 de esta investigación) y el por qué centran mayoritariamente sus acciones instructivas en la identificación y la supervisión, una respuesta plausible aparece a partir de las ideas de Gimeno (1988) y Doyle y Carter (1984), quienes argumentan que las clases se estructuran en torno a las actividades o tareas académicas, siendo éstas las que presentan a los alumnos diferentes formas de asimilar la información y, por tanto, sobre las que los docentes dirigen sus acciones. Así, en el caso que nos ocupa, atendiendo a las características y edad del alumnado, el tipo de contenido y los patrones de actividad que se llevan a cabo, parece bastante lógico que el docente identifique y supervise, puesto que en las actividades de realización de tarea con sus múltiples formas (Realización de tarea por rincones, Realización de tarea con y sin TIC relacionadas, Realización de tareas con y sin TIC independientes, Realización de tarea con TIC, Realización de tarea sin TIC), y que suponen más de un $80 \%$ del total de las acciones instructivas del profesorado, es el alumno quien de manera activa y autónoma lleva a cabo las tareas de una 
$\mathrm{u}$ otra forma dependiendo de las ATAs, mientras que el profesor va supervisando en tiempo real y realizando breves aclaraciones del trabajo que el alumno realiza por si mismo.

Otro dato que ayuda a interpretar el papel del docente en el aula y de la incorporación de las TIC, lo obtenemos en los análisis del apartado 7.3, los cuáles muestran que las acciones instructivas recaen primordialmente en las tareas como elemento del curriculum primario y en menor medida en el contenido. Esto adquiere sentido por lo que acabamos de indicar en relación a que sobre las tareas se desenvuelve el trabajo de clase, a través de acciones procedimentales que son guiadas y evaluadas constantemente por el profesor, mayoritariamente mediante las acciones de identificación y de supervisión. A su vez, estas acciones que inciden sobre los elementos del curriculum primarios, se apoyan en un porcentaje cercano al $70 \%$ sobre los elementos del curriculum secundarios, más concretamente en los recursos TIC y los recursos no TIC. Lo cual indica que estos recursos son una herramienta sobre la que se apoya la acción del profesor y la realización de tareas del alumno en el desarrollo del proceso de enseñanza-aprendizaje. Ambos recursos cuentan con una representación muy similar, siendo los Recursos TIC un $42 \%$ y los Recursos no TIC un $41,4 \%$ del total de los elementos del curriculum secundarios.

Los dos párrafos anteriores recogen datos que nos hacen constatar que el docente de infantil no parece desarrollar un enfoque magistral, sino que sus esquemas de acción se decantan más por un enfoque orientador, de guía, de gestión y/o de supervisión de las actividades y la evolución de cada alumno durante el proceso de enseñanza-aprendizaje, así como de su comportamiento en el aula. De ahí que las acciones de explicación y recapitulación no sean las más relevantes, y sí lo sean las de supervisión e identificación, que además como hemos comprobado se centran en la tarea. Para facilitar esta labor se apoya frecuentemente en los recursos y materiales con los que cuenta en el aula, entre los cuales están los recursos TIC. Pero obviamente orquestar todo esto no es posible si no existiese, por un lado, una planificación previa de la acción que va a desarrollar en la clase a través de las estructuras o patrones de actividad en función de los materiales (Smith y Connolly,1980), el contexto (Popkewitz, 1986) y el contenido a trabajar, y por otro, una experiencia y conocimiento del oficio que lo hace poder responder a las situaciones personales que los alumnos tienen durante el desarrollo de la clase (Yinger, 1987; Angulo 1999; Gimeno 1988; Borko, Roberts y Shavelson 2008). Además observamos que hay determinados patrones o estructuras de actividad que se repiten de una forma 
más o menos constante en los docentes, y que adquieren matices rutinarios en su desempeño dentro del aula. Esto facilita la labor de gestión y desarrollo de las clases en la medida en que el alumno ya conoce la estructura básica de la actividad a desarrollar, aunque cambie el contenido, y el cometido de la misma (Leinhardt, Weidman y Hammond, 1987). Algunos ejemplos en este sentido, serían Pasar lista o Fecha y tiempo meteorológico cuando es la primera hora de la mañana, Organización de vuelta al recreo u Organización de salida al recreo en los momentos posteriores o previos al descanso, Planificación de la tarea o Explicación de la tarea justo antes de comenzar la tarea.

Por otro lado, a la hora de ver los patrones de actividad en relación con la realización de tareas en sus múltiples formas (Realización de tarea por rincones, Realización de tarea con y sin TIC relacionadas, Realización de tareas con y sin TIC independientes, Realización de tarea con TIC, Realización de tarea sin TIC), observamos en los datos aportados en el apartado 7.2 que, en los casos que hay más de una grabación (todos menos el caso 10 y caso 11 que sólo cuentan con una), los docentes repiten un patrón de actividad o ATA de realización de tarea que ya han usado en una clase anterior. De esta manera, vemos que por ejemplo en el caso 1 en tres de las cinco sesiones la Realización de tarea por rincones se repite; en el caso 2 en las cuatro sesiones aparece la Realización de tarea con TIC; en el caso 3 en dos de las tres clases encontramos la Realización de tarea con y sin TIC independiente, y así va sucediendo en todos los casos en los que se analizaron más de una sesión de clase, y se puede ver fácilmente si observamos los diagramas de barras que aparecen en cada caso del apartado 7.2. Esta cuestión pone de manifiesto que entre el $60 \%$ y el 100\% de las sesiones analizadas en cada caso, los profesores repiten una estructura de actividad que incluye la realización de tarea. Dicha afirmación refuerza claramente, por un lado, la importancia que tienen las rutinas (Leinhardt, Weidman y Hammond, 1987) en el desarrollo profesional docente de los profesores de Educación Infantil del estudio, y por otro, que los maestros se adscriben a perfiles de patrones de actividad que suelen repetir con más frecuencia dependiendo de los factores contextuales e idiosincrásicos propios de cada caso (Putnan y Borko, 2000).

Aunque ya hemos hablado de las ATAs y de los elementos del curriculum de una forma global, otro de los puntos que nos interesa resaltar se refiere a qué elementos del curriculum son gestionados y de qué forma en cada uno de los tipos, estructuras o patrones de actividad (objetivo número 4 de esta investigación). Para ello, los análisis descriptivos de las ATAs (apartado 
7.1) nos ofrecen claves sobre cuáles son los elementos del curriculum que destacan en cada una de ellas, como elementos primarios y como elementos secundarios. Atendiendo a los datos obtenidos en cada una de las ATAs sobre los elementos del curriculum primarios, podemos establecer tres grupos distintos de patrones de actividad según qué elementos del curriculum primarios predominan en cada uno de ellos:

1. En un primer grupo podríamos identificar aquellos en los que el elemento del curriculum primario protagonista es la tarea, encontrándose siempre por encima del $60 \%$ de las acciones instructivas realizadas en el ATA. Este grupo lo compondrían un total de nueve ATAs: Planificación/organización de tareas, Organización para salida al recreo, Realización de tarea por rincones, Realización de tareas con y sin TIC relacionada, Realización de tareas con y sin TIC independiente, Corrección de trabajos en clase, Organización de vuelta del recreo, Juego libre y Comer el bocadillo. Todas estas ATAs pueden presentar características relacionadas de forma muy directa con la tarea en dos sentidos: por un lado, se simultanean tareas diversas en varias de ellas como en Realización de tarea por rincones, Realización de tareas con y sin TIC relacionada, Realización de tareas con y sin TIC independiente, Comer el bocadillo o Juego libre; o por otro, porque en sí misma el ATA es tan concreta, puntual y relacionada con acciones particulares, que resulta lógico que las tareas sean lo más común dentro de la actividad, en este caso estarían Planificación/organización de tareas, Organización para salida al recreo, Corrección de trabajos en clase, u Organización de vuelta del recreo.

2. En el segundo grupo se sitúan aquellos patrones o estructuras de actividad donde la tarea es importante pero comparte protagonismo con otro $\mathrm{u}$ otros elementos del curriculum, en este caso, la tarea está por debajo del $60 \%$ de las acciones instructivas del docente. De este grupo formarían parte las cinco siguientes estructuras de actividad: Pasar lista (Tarea y contenido), Visionado de película con Recurso TIC (Tarea, Contenido y Recurso TIC), Realización de tarea con TIC (Tarea, Contenido, y Recurso TIC), Realización de tarea sin TIC (Tarea, Contenido y Recurso no TIC) y Elección de lectura para casa (Tarea y Recurso no TIC).Vemos que en estas ATAs la importancia de cada elemento del curriculum es relativa y varía en función de la naturaleza propia de cada una de ellas. Es decir, parece lógico por ejemplo, que en la Elección de lectura para casa el Recurso no TIC adquiera importancia puesto que se trata de seleccionar 
un recurso no TIC, un libro. O también parece lógico que en la Realización de tarea con TIC sea notable la aparición del Contenido y también del Recurso TIC, puesto que el único soporte para presentar la información es el digital y el profesor lo utiliza como canal para transmitir información sobre el tema que se está trabajando.

3. El tercer grupo contiene aquellos tipos o patrones de actividad en los que el contenido como elemento del curriculum primario ocupa más del $50 \%$ de las acciones instructivas que realiza el profesor. Dentro de estos se encuentran los siguientes 5 tipos de actividad: Fecha y tiempo meteorológico, Explicación de la tarea, Recitado de poesía, Lectura de imagen con recurso no TIC y Lectura de imagen con recurso TIC. En ellas el contenido ocupa el principal elemento del curriculum sobre el que recaen las acciones, lo que tiene lógica si comprobamos que las ATAs van encaminadas a recordar y memorizar (Recitado de poesía y Fecha y tiempo meteorológico), explicar (Explicación de la tarea) o interpretar comprensivamente (Lectura de imagen con recurso no TIC y Lectura de imagen con recurso TIC). En todos estos casos predomina una estructura de actividad en la que el profesor se dedica a transmitir verbalmente una información, un contenido, frente a las estructuras de realización de tareas.

De la misma forma que acabamos de ver con los elementos del curriculum primarios, los secundarios también tienen un comportamiento dentro de cada uno de los tipos o patrones de actividad detectados en la investigación. En este caso los datos nos llevan a reordenar las ATAs en cinco grupos diferentes según cómo se dispongan los elementos del curriculum secundarios, por tanto, la clasificación podría ser la siguiente:

1. El primer grupo estaría formado por aquellas ATAs en las que predomina como elemento del curriculum secundario el Recurso TIC con un porcentaje superior al $60 \%$ de las acciones instructivas del profesor sobre el total de elementos del curriculum secundario del ATA. En este grupo se incluirían las siguientes cuatro estructuras o patrones de actividad: Visionado de película con recurso TIC, Realización de tarea con TIC, Comer el bocadillo y Lectura de imágenes con recurso TIC. Durante la realización de estas ATAs el recurso TIC es la principal herramienta en la que se apoya el docente para desarrollar la actividad, ya sea ver una película, trabajar una tarea en gran grupo o analizar imágenes. El caso 
de Comer el bocadillo es singular, ya que la aparición del recurso TIC está relacionado con supervisiones que hace el profesor centradas en que se apague el recurso TIC o se finalicen las últimas tareas de los alumnos en él, antes de empezar el bocadillo.

2. Un segundo grupo recogería aquellos que cuentan con el Recurso TIC y el Recurso no TIC como principales elementos del curriculum secundario, pero utilizando el criterio de que entre ambos sumen al menos el 75\% de los elementos secundarios del ATA, sin que en ningún caso superen el 50\% cada uno individualmente. Los patrones de actividad que encajan en este grupo serían: Planificación/organización de tareas, Organización para salida al recreo, Realización de tareas por rincones, Realización de tareas con y sin TIC relacionadas y Juego libre. En ellas tanto Recurso TIC como Recurso no TIC conviven durante la realización de la misma en un grado similar de importancia dentro de las acciones del profesor.

3. El tercer grupo, cuenta con las tareas como elemento del curriculum secundario central. En este grupo se incluirían las dos ATAs siguientes: Pasar lista y Recitado de poesía, que se caracterizan a su vez por ser patrones de actividad en los que la comunicación oral de información juega un papel fundamental y, por tanto, el contenido es bastante relevante como elemento del curriculum primario. Ello explica que la tarea en sí quede en un segundo plano o de apoyo a la transmisión verbal entre profesor y alumno.

4. Un cuarto grupo, sería aquel en que el Recurso no TIC es el protagonista de al menos un porcentaje cercano al $60 \%$ de las acciones instructivas que recaen sobre los elementos del curriculum secundario en las ATAs. En este caso encontramos 5 estructuras o patrones de actividad que formarían parte de este grupo: Realización de tareas con y sin TIC independiente, Realización de tarea sin TIC, Corrección de trabajos en clase, Organización de vuelta del recreo y Lectura de imágenes sin recurso TIC. Tal y como se aprecia, al igual que ocurría en el grupo del Recurso TIC, en este caso las ATAs se desarrollan mayoritariamente sobre los recursos no TIC, aunque hay que destacar dos casos, uno el de Realización de tarea con y sin TIC independiente, que cuenta con un $53 \%$ de acciones dirigidas a los Recursos no TIC como elementos secundarios, por lo que podría estar entre el grupo 2 y éste. Y la Organización de vuelta del recreo, que 
también depende un poco de los recursos que el profesor decida utilizar justo antes del comienzo del ATA, lo que hace que sea más de organización que de realización de tarea pudiendo al igual que la anterior situarse en el grupo 2.

5. El último grupo tan sólo cuenta con un ATA ya que es un poco peculiar el resultado de los datos en torno a los elementos del curriculum secundarios, se trata de la Elección de lectura para casa, que cuenta con los recursos no TIC y los recursos TIC a partes iguales en cuanto a acciones instructivas, aunque también hay que aclarar que sólo se da una vez a lo largo de las 41 grabaciones. Es preciso indicar que durante el desarrollo de este ATA, en el aula estaban organizándose para seleccionar la lectura del fin de semana y por parejas iban pasando por el ordenador para turnarse en el rincón del ratón.

Uno de los últimos objetivos de nuestra investigación era poder delimitar si entre los elementos analizados en el sistema de categorías existían diferencias que pudieran ser atribuidas al curso de Educación Infantil (objetivo número 5 de esta investigación) en que se desarrollaban las prácticas de aula registradas. Esta visión de los datos, podría ayudar a detectar diferencias en el desarrollo de los docentes dependiendo del curso en el que se encuentre el alumno.

Comenzando por la distribución de las ATAs, el análisis de los datos pone de relieve que dicha distribución no obedece al azar, sino que aparecen diferencias significativas entre los 19 patrones de actividad encontrados. En una visión general las ATAs de realización de tareas eran las que sumaban el mayor número de acciones instructivas, predominando aquellas que en su desarrollo incluían el uso combinado de los Recursos TIC y los Recursos no TIC. Éstas serían la Realización de tarea por rincones, Realización de tareas con y sin TIC relacionada, Realización de tarea con y sin TIC independiente, a las que si sumamos la Realización de tarea con TIC, obtenemos un total de un $75 \%$ de las acciones instructivas realizadas por el profesor. Pero al buscar diferencias en función del curso, de nuevo encontramos que la distribución no se debe al azar y que existen diferencias significativas en cada uno de los cursos. En este caso nuevamente las ATAs de realización de tareas previas son las que suman más acciones por parte del profesor, con particularidades en cada uno de los cursos. De esta forma en el $2^{\circ}$ curso de EI desaparece la Realización de tarea por rincones; en $3^{\circ}$ de EI es más relevante la Realización de tareas con y sin TIC relacionadas; o en 
el $3^{\circ}$ curso de EI es menor el uso del ATA de Realización de tareas con y sin TIC independiente que en $1^{\circ}$ y $2^{\circ}$ de EI. Lo mismo ocurre con otras ATAs que cuentan con menos acciones instructivas, que van desapareciendo o apareciendo en unos cursos u otros. Esta distribución de ATAs en los diferentes cursos de la etapa, las aparición de unas o la desaparición de otras, no se puede atribuir exclusivamente a la influencia del curso en el que se desarrollen, debido a las limitaciones de nuestra muestra. Sólo en el caso de la Realización de Tareas con y sin TIC independiente $\left(1^{\circ}\right.$ y $2^{\circ}$ curso) y la Realización de Tareas con y sin TIC relacionada $\left(3^{\circ} \mathrm{curso}\right)$ puede estar conectado con otros resultados obtenidos en el proyecto respecto de la adquisición por parte de los alumnos de diversos niveles de competencia digital a lo largo de la etapa (Ramírez, Martín, Orgaz y Cañedo, 2012). En esa parte del proyecto comprobamos cómo los alumnos van adquiriendo progresivamente las habilidades multimedia a medida que avanzan en la etapa de infantil, de tal forma que en tercer curso esas competencias necesarias para desenvolverse con el recurso digital son dominadas de forma autónoma casi por el $100 \%$ de los alumnos. Ello podría explicar que el primer y segundo curso los profesores dedicaran más tiempo a la enseñanza independiente de habilidades multimedia en patrones de actividad como Realización de tarea con y sin TIC independiente, mientras que en $3^{\circ}$ curso, adquiridas las habilidades, la integración curricular del recurso se facilitaría (Realización de tarea con y sin TIC relacionada). Ahora bien, esta explicación se encuentra aún sujeta a exploraciones más sistemáticas.

Por ello, siguiendo la relación con las ATAs e introduciendo la variable del profesor para tratar de explicar la distribución desde una perspectiva mediada por el docente en los diferentes cursos, encontramos que de nuevo estos análisis son significativos. Dichos resultados ponen de manifiesto que los profesores trabajan de formas diversas dentro del aula y no existe un patrón común uniforme al que los docentes de la etapa se adscriban por igual. Esta idea, puesta ya de relieve anteriormente a lo largo de esta discusión cuando analizamos la importancia de la idiosincrasia del docente y el papel que desempeña (objetivo número 3 ), hace que se refuerce la idea de la diversidad de prácticas. Así, si encontramos un número desigual de cada ATA en los diferentes cursos, lo que podría a priori atribuirse al nivel educativo de cada curso, parece deberse en nuestro caso que dicha distribución de las ATAs se produce más por aspectos tales como el momento en que desarrolle la sesión, el contenido que se trabaje en la clase durante la sesión, los profesores que cuentan con grabaciones en ese curso y/o el número de sesiones que haya en 
ese curso de cada profesor. Ejemplos de esta afirmación lo vemos en el ATA de Pasar lista que sólo se realiza durante el comienzo de la jornada de clase; en la Organización para salida al recreo y Organización de vuelta de recreo, que se producen en las sesiones inmediatamente anterior y posterior al recreo; en la actividad de visionado de película donde la estructura no permite otra ATA que Visionado de película con recurso TIC; en la Lectura de imágenes con recurso TIC o Lectura de imágenes con recurso no TIC donde el contenido a trabajar es muy específico y puntual más que rutinario; etc. También podemos ver esto en las ATAs de realización de tarea como puede ser la Realización de tarea por rincones, que aparece en $1^{\circ}$ y $3^{\circ}$ de EI y no la encontramos en $2^{\circ}$ de EI, donde el profesor que más uso realiza de esta ATA (Caso 7) presenta en $2^{\circ}$ de EI un menor número de grabaciones (tan sólo una).

Una vez analizadas la relación entre cursos con respecto a las ATAs y ATAs incorporando también al profesor, estudiamos cuál era la distribución de las acciones instructivas en cada uno de los cursos. En este sentido lo que se deduce de los datos, es que este elemento de análisis que son las acciones instructivas se configura de forma diferente atendiendo a los elementos del curriculum sobre los que actúa. Al igual que ocurría con las ATAs, esto se verifica tanto para los análisis del conjunto de registros, como para los análisis de las acciones en cada curso. Reforzando afirmaciones anteriores, Identificar y Supervisar son las acciones instructivas más relevantes y se dirigen a las tareas y el contenido de forma mayoritaria como elementos del curriculum primarios, y a los Recursos TIC y Recursos no TIC como elementos del curriculum secundarios. A este respecto sólo cabe hacer una matización en relación con los cursos, ya que es en $3^{\circ}$ de EI donde se produce una diferencia con los cursos anteriores y en el total del conjunto. Esta diferencia estriba en que si bien en los cursos de $1^{\circ}$ y $2^{\circ}$ de EI, así como en el total, los Recursos no TIC ocupan un mayor número de acciones, en $3^{\circ}$ de EI los Recursos TIC cuentan con un mayor número de acciones instructivas por parte del profesor. Esto puede explicarse por dos razones. Por un lado, el docente dirige las acciones instructivas al Recurso TIC en mayor número en $3^{\circ}$ de EI por las ATAs que se realizan en ese curso. Y por otro lado, porque este reparto de acciones se debe a los profesores que cuentan o no con grabaciones en este curso. Analizando los resultados de los casos y su distribución en cada una de las sesiones, nos decantamos porque esas variaciones entre cursos de los Recursos TIC y los Recursos no TIC son atribuibles a los docentes que participan en cada curso. De esta forma, el Caso 9, en el que predomina el Recurso no TIC, no cuenta con grabaciones en $3^{\circ}$ de EI. A ello hay 
que sumar que el Caso 2, en el que la profesora incide mayoritariamente en el Recurso TIC, sí cuenta con grabaciones en ese curso. Esto explicaría por qué la variación de esos dos elementos del curriculum secundarios está en función de los profesores y no del nivel o curso educativo.

Por último, los análisis que se realizaron también de forma global y por cursos entre la relación de elementos del curriculum primarios y secundarios, que también muestran relación significativa, viene a reforzar lo dicho en el anterior punto, puesto que los elementos primarios más destacados que son las tareas y los contenidos se apoyan principalmente en los Recursos TIC y los Recursos no TIC. Así, como es lógico puesto que son los mismos datos, los Recursos TIC y los Recurso no TIC vuelven a presentar diferencias en función de los cursos, estando los Recursos TIC más presentes en $3^{\circ}$ de EI, y los Recursos no TIC en $1^{\circ}$ y $2^{\circ}$ EI. De nuevo los datos permiten afirmar, al igual que señalábamos en el párrafo anterior, que los motivos de esta variación están ligado más al modo de actuar del docente y su gestión de las ATAs que al curso educativo en el que se desarrollan las prácticas de aula.

En síntesis de lo aportado en esta discusión, comprobamos que los datos nos permiten interpretar qué sucede en el aula de forma coherente con los presupuestos teóricos sobre los que se sustenta la investigación. A lo largo de la exposición de los distintos resultados se aprecia de forma evidente cómo los profesores desarrollan su práctica profesional e introducen el uso de las TIC en el aula. Además, queda patente que cada profesor incorpora las TIC en un modelo propio de desarrollo de las clases, lo que viene a ratificar la idea de Shulman $(1986,1987)$ en lo relativo al pensamiento profesional docente. Es por ello, que podemos afirmar que el uso y secuenciación de los distintos tipos de ATAs para gestionar la clase depende en un alto porcentaje de cada docente, que escoge unas ATAs y no otras porque se ajustan mejor a su manera de entender y desarrollar la práctica educativa en la clase. Asimismo, encontramos diferentes tendencias en el uso de los Recursos TIC y Recursos no TIC como elementos del curriculum secundarios, condicionado por los tipos de patrones de actividad que se realizan, y por tanto como ya hemos comentado, de forma directa con la idiosincrasia de cada profesor. 


\section{CAPÍTULO}

\section{Conclusiones}





\section{Conclusiones}

En el trabajo que hemos desarrollado se ha tratado de estudiar, de forma explícita, cómo los docentes de Educación Infantil integran los recursos TIC en su práctica profesional en las aulas. Es por ello que el análisis de cómo se configuran dichas prácticas se ha erigido como la pieza fundamental sobre la que se sustenta esta investigación. Así estudiar al maestro, su discurso, sus acciones, su conocimiento, la forma de gestionar los recursos, el tiempo y las actividades nos ha permitido desmenuzar la realidad de nuestro objeto de investigación aportando explicaciones fundamentadas de cómo los docentes de la etapa de Educación Infantil de nuestro estudio afrontan y resuelven el desafío de dar sentido a las TIC dentro de sus prácticas de clase.

Aunque el propósito central de esta investigación obedecía al interés de elaborar explicaciones sobre qué papel desempeñan las TIC en las aulas de Educación Infantil del estudio, el acceso a las prácticas directas ha permitido aportar conocimiento no sólo respecto de este elemento central, sino también de otros elementos que participan en los procesos de enseñanza reales. Ello se explica en buena medida, como señalábamos en el marco teórico, por la pluridimensionalidad de las prácticas de enseñanza y, por supuesto, por las decisiones metodológicas tomadas en este estudio encaminadas a reflejar la riqueza de dichas situaciones prácticas. Este rasgo del trabajo que hemos presentado constituye una de las aportaciones más significativas y novedosas al estado de conocimiento sobre el tema, puesto que tal y como mencionábamos en las revisiones del marco teórico inicial, no abundan en la etapa educativa que nos ocupa enfoques de investigación que aborden de una forma tan directa y minuciosa nuestro objeto de estudio, puesto que el interés se ha enfocado hacia indagaciones sobre aspectos más relacionados con el pensamiento lógicomatemático o sobre enseñanza de la lectura, siendo escasos los estudios sobre contextos reales de la práctica.

En este sentido, la metodología y el sistema de análisis utilizados han servido para recoger, organizar y examinar datos acerca de cuál es el papel de los docentes en el desarrollo de la clase; qué estructuras, patrones o tipos de actividad usan; cómo organizan las sesiones en función de dichos patrones o tipos de actividad; y cuáles son los elementos del curriculum sobre los que el docente dirige sus acciones en cada una de las actividades de aula. Aunque el análisis del discurso del profesor ha sido el eje central de la investigación, es 
preciso subrayar la aportación que el uso de las filmaciones supone para conseguir un registro más fiel de qué es lo que acontece en cada momento en el aula. El registro de los datos a través del vídeo permite solventar algunas de las ambigüedades que surgen al trabajar con textos transcritos que no captan con absoluta fidelidad la riqueza de las situaciones reales. De forma especial, en ambientes donde los participantes, por su nivel evolutivo, utilizan recursos muy diversos en la comunicación que no se limitan, en abundantes ocasiones, al lenguaje verbal oral.

Al hacer balance sobre algunos de los interrogantes a los que ha contestado esta investigación, resulta especialmente relevante, por lo que supone de aportación al corpus de conocimiento sobre el enfoque del "conocimiento profesional del docente", las conclusiones obtenidas sobre el papel que los maestros desempeñan en el transcurso de la clase, dado que estas conclusiones contribuyen a definir lo que constituiría parte del conocimiento práctico del docente de Educación Infantil.

La discusión de los datos obtenidos en los 11 casos revelan una clara tendencia de los profesores para llevar a cabo tareas de supervisión y de identificación en las acciones de enseñanza de sus clases. Este resultado es coherente con, por un lado, las características de la etapa y, por otro, las características de los alumnos. Los profesores parecen en general permitir un grado de autonomía importante en sus alumnos lo cual exige, en contrapartida, una supervisión en tiempo real continuada de las tareas que se desenvuelven en las jornadas escolares. Asimismo, las puntualizaciones concretas sobre la tarea abundan en la interacción puesto que en la etapa predomina el trabajo sobre contenidos procedimentales, bien delimitados, más que el desarrollo de explicaciones de carácter académico y conceptual. De forma coincidente con lo que se exponía en el marco teórico, los rasgos peculiares de la etapa y de los alumnos que explicarían estas actuaciones docentes tales como: metodologías de trabajo dinámicas y adaptadas a la autonomía y necesidades de los alumnos; actividades variadas y lúdicas; diferencias madurativas mayores que en otras etapas entre los alumnos de un mismo curso; importancia de los recursos en el desarrollo de las actividades; uso del juego en el proceso de enseñanzaaprendizaje; peculiaridades de los tiempos y espacios; o el enfoque menos academicista que se le otorga al curriculum, que en cierta medida está relacionado con la no obligatoriedad de la etapa. De ahí que los usos docentes en esta etapa no se apoyan tanto en estrategias de enseñanza de carácter magistral, explicativo o expositivo; sino, por el contrario, en otras donde el 
papel activo del alumno como protagonista de su propio proceso de aprendizaje a través de las actividades propuestas suele ser más habitual. Hemos descubierto, por tanto, a un profesor que gestiona el ambiente del aula desarrollando las condiciones que permitan al alumno trabajar en gran medida de forma autónoma.

¿Y cómo resuelven nuestros maestros esta gestión? En la búsqueda de respuestas a esta pregunta, se han encontrado 19 tipos distintos de gestionar la actividad del aula en las sesiones registradas. La discusión e interpretación de estos resultados ha permitido sistematizar, organizar, estudiar y evaluar cómo se manejan las actividades a lo largo de las jornadas escolares. En definitiva, se ha obtenido un repertorio de diferentes patrones organizativos y curriculares de la acción docente en la etapa de infantil, explicando su configuración y sentido dentro del desarrollo curricular. Cada tipo de actividad detectado tiene su propia identidad, lo cual no significa que no se puedan agrupar en función de similitudes que contribuyan a la interpretación y análisis exhaustivo de lo que ocurre en las clases. Dicho con otras palabras, que tengamos 19 tipos diferentes no significa que cada una busque un fin distinto, sino que pueden aparecer patrones de actividades que aunque distintos en su estructura y organización, persigan un mismo objetivo curricular. Un ejemplo de esto serían aquellas ATAs que tienen como fin la realización de una tarea con el uso de los recursos disponibles y en las que se pueden amoldar unos $\mathrm{u}$ otros contenidos: Visionado de película con recurso TIC, Realización de tarea por rincones, Realización de tarea con y sin TIC relacionada, Realización de tarea con y sin TIC independiente, Realización de tarea con TIC y Realización de tarea sin TIC, Lectura de imágenes con recurso TIC o Lectura de imágenes sin recurso TIC. Otras aunque se presten también a la realización de una tarea, sin embargo, no se utilizan tanto como estructuras flexibles respecto del contenido, sino que obedecen a un fin mucho más específico e identificable: Fecha y tiempo meteorológico, Pasar lista, Recitado de poesía, Comer el bocadillo o Elección de lectura para casa.

Aunque el criterio de finalidad curricular, pueda permitir agrupar los tipos de actividad para comprender mejor por qué los profesores eligen unas $u$ otras estructuras en las sesiones de clase, no es el único criterio que contribuye a la interpretación de lo que ocurre en las prácticas. Otros ejemplos de criterios que pueden clasificar este elemento y que ha mostrado el estudio serían las siguientes:

Diferenciar entre tipos de actividad que tendrían valor en cualquier etapa educativa frente a aquéllas más circunscritas a la etapa de Educación 
Infantil. Ejemplos de las primeras pueden ser Planificación/organización de la tarea, Explicación de Tarea, Corrección de trabajos en clase, Visionado de película con Recurso TIC, Realización de tarea sin TIC, Realización de tarea con TIC o Pasar lista.

Otras estructuras o patrones de actividad que presentan un matiz idiosincrásico en relación con la etapa y la edad de los alumnos de Educación Infantil serían las de Realización de tarea por rincones puesto que se trata de una metodología característica de Educación Infantil; Comer el bocadillo ya que la adquisición de hábitos en este tipo de actividades es un asunto de interés educativo en esta etapa; Fecha y tiempo meteorológico que es una rutina típica que los docentes utilizan para trabajar contenidos como el tiempo, estaciones, días, meses, etc.; Organización de salida al recreo y Organización para la vuelta del recreo, que son momentos del día que permiten trabajar contenidos actitudinales como respetar turno, guardar silencio, mantener el orden,... y rutinas como ponerse o quitarse el abrigo, recoger o sacar los materiales, colocar la silla, sentarse o levantarse...; o Juego libre que los profesores de infantil utilizan, además de para intercalar momentos de descanso y momentos más académicos, para ir ajustando los diferentes ritmos individuales simultaneando en el aula la finalización de las tareas y la actividad lúdica.

Se han detectado también otros patrones de actividad que aparecen de forma puntual y están directamente relacionadas con un trabajo concreto que el profesor realiza de forma menos habitual. Dentro de este tipo estarían Elección de lectura para casa, Lectura de imágenes con recurso TIC, Lectura de imágenes con recurso no TIC o Recitado de poesía.

Por último, la gestión del ambiente de clase contempla, entre otros, la gestión de los recursos TIC, que es el núcleo central de este trabajo. La respuesta a cómo nuestros profesores dan sentido al uso de las TIC, se explica en buena medida, a través de los seis patrones de actividad detectados que están relacionadas directamente con la integración del Recurso TIC en el aula. Dichos patrones de actividad son Realización de trabajo por rincones, Realización de tareas con y sin TIC independiente, Realización de tareas con y sin TIC relacionadas, Realización de tarea con TIC, Visionado de película con recurso TIC y Lectura de imágenes con recurso TIC. Es en ellos donde, de una forma u otra, el recurso juega un papel relevante tanto en el contenido como en las acciones de enseñanza que desarrolla el profesor. Al identificar estos patrones, se ha puesto de manifiesto que los profesores usan las TIC de maneras diferentes y además, esos tipos de actividad en los que el recurso se integra aparecen de forma constante en cada caso analizado, confirmando así que cada docente incorpora 
el uso de las tecnologías a los patrones de actividad en los que se encuentra cómodo, a los que está más habituado o que considera apropiados en relación a su enfoque de enseñanza.

Otro de los aspectos sobre los que esta investigación ha establecido conclusiones tiene que ver con la dimensión temporal en la interpretación de los resultados. En otras palabras, cómo se suceden temporalmente los tipos de actividad en las sesiones registradas y qué peso ejerce cada curso de la etapa de infantil en el uso que los profesores hacen de los distintos tipos de actividad.

De forma global, los patrones de actividad que más tiempo ocupan son los relacionados con la realización de tareas, lo cual es coherente con el sentido curricular y escolar de las actuaciones que se llevan a cabo en los procesos de enseñanza analizados. En la mayor parte de los casos estas actividades de realización de tareas suelen venir precedidas de las de Planificación/organización de tareas y luego complementadas con otras que dependen de diversos factores como pueden ser el contenido a trabajar, el periodo del año, la hora de la grabación, etc.

El análisis de los datos ratifica el que hay diferencias y semejanzas entre cada una de las sesiones. Directamente relacionado con esto, una de las hipótesis con las que trabajábamos era que podrían aparecer unos u otros patrones en función del curso de Educación Infantil en el que impartía cada profesor. En este sentido, no podemos afirmar que existan tales diferencias marcadas por el curso, pero dadas las similitudes encontradas en los casos de los que teníamos grabaciones más continuadas y regulares, podemos atribuir mayor peso al docente que al curso en la configuración y distribución de los distintos tipos de actividad. Es decir, que son los profesores los que explican a través de sus enfoques de enseñanza el que se desarrollen unos tipos de actividad $\mathrm{u}$ otros independientemente del curso en el estén impartiendo docencia.

Pero lo que el profesor hace en las aulas, la forma en que gestiona el ambiente de clase con fines educativos, afecta por último, a los elementos del curriculum sobre los que el profesor actúa, tanto en el conjunto de sus clases como en cada uno de los tipos de actividades que se desarrollan. El análisis de cómo se lleva a cabo esta actuación ha permitido concluir que el elemento central de curriculum para el profesor de infantil son las tareas, seguidas en mucha menor medida por los contenidos, mientras que los recursos TIC y los 
recursos no TIC adoptan un papel subsidiario de apoyo en la ejecución de las tareas y en el desarrollo de los contenidos.

Esta importancia de las tareas conecta perfectamente con las conclusiones expuestas anteriormente sobre el papel activo del alumno y el rol del docente en el aula. En las clases se ejecutan tareas apoyándose en distintos recursos materiales. $\mathrm{Y}$ esos recursos materiales se diversifican en las aulas de nuestro estudio como es tradicional en la etapa de Educación Infantil donde habitualmente se combinan materiales académicos y otros de carácter artístico, artesanal o lúdico. La riqueza de los materiales didácticos de esta etapa es uno de sus rasgos diferenciadores respecto a etapas posteriores y una posibilidad a tener en cuenta al plantear el diseño de soportes TIC en este nivel. Como se puede corroborar en los resultados obtenidos en este trabajo, los recursos TIC están entrando en las aulas de infantil, pero sin desplazar a otros soportes ya existentes.

Es necesario, en cualquier caso subrayar, que el sistema de categorías se ha revelado como un instrumento útil que ha permitido establecer de forma coherente las relaciones entre lo que el profesor lleva a cabo para desarrollar su enseñanza en los marcos de actividad en los que aquella se inscribe y los elementos del curriculum sobre los que se desenvuelven las prácticas docentes encaminadas al logro de las finalidades educativas en la fase de desarrollo del curriculum.

Todo lo anterior contribuye a clarificar el panorama de la integración de los recursos TIC en las aulas de infantil, desde un enfoque que, basado en el estudio de la práctica, ha intentado analizarla partiendo de enfoques teóricos rigurosos y procedimientos metodológicos contrastados. Lo cual legitima el que se pueda concluir que el uso de los recursos TIC no ocupa para los docentes un papel central o protagonista en las aulas, sino que se utilizan en el contexto de la clase, al igual que muchos otros recursos, como herramientas que el docente emplea cuando, estando disponibles, facilitan la ejecución de las tareas y el desarrollo de los contenidos y se adaptan a los diversos estilos de desarrollo del curriculum en la práctica.

Como proyecto de futuro y desde los marcos de actividad que se han detectado en este trabajo, se plantean otros retos de investigación que aparecen ligados al fenómeno estudiado. Cuestiones tales como la estructura de las tareas de las que se nutren los patrones de actividad detectados, se constituyen en próximas líneas de investigación. Se trataría de seguir profundizando en el 
análisis del conocimiento práctico de los docentes por medio del estudio de la estructura de las tareas asociadas a los distintos patrones de actividad; pero también a diversos contenidos y recursos, pudiendo distinguir entre recursos digitales y analógicos. Otra línea de trabajo que surge de los resultados de esta investigación, se encaminaría a abordar otras etapas educativas como Primaria y Secundaria, tratando de investigar qué patrones de actividad surgen de las prácticas de aula cuando se incorpora el uso de las TIC, dado que suponemos que existen diferencias en las culturas metodológicas de los profesores que pueden ir ligadas a las etapas educativas donde desarrollan su trabajo. De la misma manera que podemos prever diferencias en las líneas o culturas metodológicas de los docentes asociadas a las especialidades científicas que imparten (esta cuestión más vinculada a la etapa de educación secundaria). 


\section{BIBLIOGRAFÍA}





\section{Bibliografía}

Abrami, P. C., Savage, C., Wade, C. A., Hipps, G., \& Lopez, M. (2008). Using Technology to Assist Children Learning to Read and Write. In T. Willoughby \& E. Wood (Eds.), Children's learning in a digital world (pp. 129-172). Oxford, UK: Blackwell Publishing.

Aesaert, K., Vanderlinde, R., Tondeur, J., \& van Braak, J. (2013) The content of educational technology curricula:a cross-curricular state of the art. Educational Technology Research and Development, 61 (1), 131-151.

Ajlouni, K., \& Aljarrah, A. (2011). The Impact of Using the KidSmart Program on Facilitating Children's Access and Use of ICT Tools According to Jordanian Public Kindergarten Teachers' Viewpoint. Education, 132 (2), 241-261.

Angulo, J. F. y Blanco, N. (1994) Teoría y desarrollo del curriculum. Archidona: Aljibe.

Angulo, J. F., Barquín, J. y Pérez, Á. I. (1999). Desarrollo profesional del docente: Política, investigación y práctica. Madrid: Akal.

Antón, M. (2007). Planificar la etapa 0-6 : Compromiso de sus agente y práctica cotidiana. Barcelona: Graó.

Area, M. (2008). Innovación pedagógica con TIC y el desarrollo de las competencias informacionales digitales. Investigación en la escuela, 64, 5-18.

Area, M. (2010). El proceso de integración y uso pedagógico de las TIC en los centros educativos. Un estudio de casos. Revista de Educación, 352, 77-97.

Ashburn, E. A. y Floden, R. E. (eds.) (2006), Meaningful learning using technology. New York: Teachers College Press.

Attewell, P. A., Suazo-García, B., \& Battle, J. (2003). Computers and Young Children: Social Benefit or Social Problem? Social Forces, 82 (1), 277-296 DOI: 10.1353 /sof.2003.0075

Ausubel, D. P., \& Sullivan, E. V. (1983). El desarrollo infantil (1a caellana ed.).

Barcelona etc.: Paidós.

Baek, Y., Jung, J., \& Kim, B. (2008). What makes teachers use technology in the classroom? Exploring the factors affecting facilitation of technology with a Korean sample. Computers and Education, 50 (1), 224-234 DOI:

10.1016/j.compedu.2006.05.002.

Barba, M. N., Cuenca, M. y Gómez, A. (2007). Piaget y L.S. Vigotsky en el análisis de la relación entre educación y desarrollo. Revista Iberoamericana de Educación, 42 (7), 1-12.

Barrantes, G., Casas, L.M. y Luengo, R. (2011). Obstáculos percibidos para la integración de las TIC por los profesores de infantil y primaria en Extremadura. Píxel-bit. Revista de Medios y Educación, 39, 83-94. 
Bawden, D. (2008). Origins and concepts of digital literacy. In C. Lankshear \& M. Knobel (Eds.), Digital literacies: Concepts, policies an paradoxes (pp. 15-32). New York: Peter Lang.

Becker, H. J. (1985). How schools use microcomputers: Results from a national survey. En M. Chen y W. Paisley, (eds.), Children and microcomputers: Research on the newest medium (pp. 87-107). Beverly Hills, CA: Sage.

Bejarano, J. (2010). El curriculum en la Educación Infantil. En J. Gimeno Sacristán (Ed.). Saberes e incertidumbres sobre el curriculum (399-420). Madrid: Morata.

Beker, H. J. (2001). How are teacher using computers in instruction? Paper presented at the Annual Meeting of the American Educational Research Association, Seattle, WA.

Bobbitt, J. F. (1918). The curriculum. Boston: Houghton Mifflin.

Bobbitt, J. F. (1924). How to make a curriculum. Boston: Houghton Mifflin.

Bolstad, R. (2004). The role and potential of ICT in early childhood education: A review of New Zealand and international literature. Wellington: New Zealand Council of Educational Research.

Borko, H., Roberts, S. A., \& Shalvenson, R. (2008). Teachers' Decision Making: from Alan J. Bishop to Today. In P. Clarson, \& N. Presmeg (Eds.) Critical Issues in Mathematics Education. Springer.

Brown, M., Askew, M., Rhodes, V., Denvir, H., Ranson, E. \& Wiliam, D. (2001). Magic Bullets or Chimeras? Searching for Factors Characterising Effective Teachers and Effective Teaching in Numeracy, British Educational Research Association Annual Conference Symposium on Pedagogy and Educational Policy: modernising teaching or narrowing the agenda? University of Leeds.

Burnett, C. (2010). Technology and literacy in early childhood educational settings: A review of research. Journal of Early Childhood Literacy, 10, 247-270. DOI: $10.1177 / 1468798410372154$

Burniske, R.W. y Monke, L. (2001). Breaking Down the Digital Walls.Learning to Teach in a Post-Modem World. Albany, New York: State University of New York Press.

Burns, R. B., \& Anderson, L. W. (1987). The Activity of Lesson Segments. Curriculum Inquiry, 17(1), 31-53.

Calero, J. y Escardibul, J. O. (2007). Evaluación de servicios educativos: el rendimiento en los centros públicos y privados medido en PISA 2003. Hacienda Pública Española, 83, 33-66.

Carr, W. y Kemmis, S. (1983). Becoming critical: Knowing through action research. Victoria: Deakin University.

Castells, M. (1996). La era de la información: Economía, sociedad y cultura. Vol. 1.

Madrid: Alianza.

Castells, M. (2006). La sociedad red, una visión global. Madrid: Alianza. 
Chen, J. Q., \& Chang, C. (2006). Prueba del planteamiento Whole Teacher hacia el desarrollo profesional. Estudio de esfuerzos por mejorar la competencia tecnológica de maestros de niños pequeños. Early Childhood Research and Practice, 8 (1). Disponible en: http://ecrp.uiuc.edu/v8n1/chen-sp.html

Clark, R. E. (1987). Which technology for what purpose? The state of the argument about research on learning from media. Paper presented at the Annual Convention of the Association for Educational Communications and Technology. Atlanta, GA. February 21-March.

Clark, R. E. (1994). Media will never influence learning. Educational Technology Research and Development, 42 (2), 21-29.

Clark, R.E. (1983). Reconsidering research on learning from media.Review of Educational Research, 53 (4), 445-460.

Clemente, M. (2010). Diseñar el curriculum. Prever y representar la acción. En J. Gimeno Sacristán (Ed.). Saberes e incertidumbres sobre el curriculum (269-293). Madrid: Morata.

Clements, D.H. (2000) From Exercises and Tasks to Problems and Projects - unique contributions of computers to innovative mathematics education, Journal of Mathematical Behavior, 19, 9-47.

Cole, M., Hood, L., \& Mcdermott, R.P. (2002). Conceptos de validez ecológica. En Cole, M., Engeström, Y., \& Vásquez, O. (Coord.) Mente, Cultura y actividad. México: Oxford University Press.

Coll, C., Onrubia, J. y Mauri, T. (2007). Tecnología y prácticas pedagógicas: las TIC como instrumentos de mediación de la actividad conjunta de profesores y estudiantes. Anuario de Psicología, 38 (3), 377-400.

Colmenar, C. (2010). La introducción de los jardines de infancia en España. Apotaciones de Pedro Alcántara García y Eugenio Bartolomé y Mingo. En C. Sanchidrián y J. R. Ruiz (Coords,), Historia y perspectiva actual de la educación infantil (1 $1^{\mathrm{a}}$ ed.) (133-152). Barcelona: Graó.

Comenius, J. A. (1971). Didáctica magna (2a ed.). Madrid: Reus.

Contreras, J. (1990). Enseñanza, curriculum y profesorado. Introducción crítica a la didáctica. Madrid: Akal.

Crook, C. (1998) Children as Computer Users: the case of collaborative learning, Computers \& Education, 30, 237-247.

Crook, C. (1998). Ordenadores y aprendizaje colaborativo. Madrid: MEC y Morata

Crowder, N. A. (1959).Automatic tutoring by means of intrinsic programming. En E.H. Galanter (ed.) Automatic teaching: the State of the art, (pp.109-116). New York: Wiley.

Cuban, L. (2001). Oversold and Underused: Computers in the Classroom. Cambridge, MA: Harvard UniversityPress. 
D.P.P, \& Luzuriaga, L. (1992). Pestalozzi:Vida y obras. Madrid: Ciencias de la Educación Preescolar y Especial.

Daniels, H. (2003). Vygotsky y la pedagogía. Barcelona: Paidós Ibérica.

Dawes, L. (1999). Chalky and the Interactive Whiteboard: media representation of teachers and technology. Paper presented to the British Educational Research Association, London, March.

Decreto 122/2007, de 27 de diciembre, por el que se establece el currículo del segundo ciclo de la Educación Infantil en la Comunidad de Castilla y León. Boletín Oficila de Castilla y León, 2 de enero de 2008, España. Disponible en: www.educa.jcyl.es/es/resumenbocyl/decreto-122-2007-27-12-establece-curriculosegundo-ciclo-ed.ficheros/110049-curriculo\%20infantil.pdf

Dede, C., Honan, J.P., y Peters, L.C. (Eds.) (2005). Scaling up success. Lessons from technology-based educational improvement. San Francisco: Jossey-Bass.

Dewey, J. (1998). Democracia y educación:Una introducción a la filosofía de la educación $\left(1^{\mathrm{a}}, 2^{\mathrm{a}}\right.$ reimpresión editorial.). Madrid: Morata.

Díaz-Barriga, F. (2010). Los profesores ante las innovaciones curriculares. Revista Iberoamericana de Educación Superior (RIES), 1 (1), 37-57. Disponible en: http://ries.universia.net/index.php/ries/article/view/35

Doyle, W. (1979). Classroom tasks and students' abilities. En Peterson, P. y Walberg, H. Research on teaching. pp. 183-209. Berkeley McCutchan Pub Co.

Doyle, W., \& Carter, K. (1984). Academic Task in Classrooms. Curriculum Inquiry, 14(2), 129-149.

Drent, M., y Meelissen, M. (2007). Which factors obstruct or stimulate teacher educatorsto use ICT innovatively? Computers $\mathcal{E}$ Education.

doi:10.1016/j.compedu.2007.05.001.

Elliot, J. (1988). Teachers as researchers. In J. P. Keeves (Ed.), Educational research, methodology, and measurement: An international handbook (pp. 78-81). Oxford:

Pergamon.

Ertmer, P. A., \& Ottenbreit-Leftwich, A. T. (2010). Teacher technology change: how knowledge, beliefs, and culture intersect. Journal of Research of Technology in

Education, 42, 255-284.

Ertmer, P. A., Gopalakrishnan, S., \& Ross, E. M. (2001). Technology-using teachers: comparing perceptions of exemplary technology use to best practice. Journal of Research on Computing in Education, 32 (1), 54-72.

Ertmer, P.A. (1999). Addressing first -and second- barriers to change: strategies for technology integration. Educational Technology Research and Development, 47 (4), 4761. 
Ertmer, P.A., Ottenbreit-Leftwich, A. T., Sadik, O., Sendurur, E., \& Sedurur, P. (2012). Teacher beliefs and technology integration practices: A critical relationship. Computers and Education, 59, 423-435.

Flick, U. (2007). Introducción a la investigación cualitativa (2a ed.). Madrid: Morata.

Freire, P. (1974). Concientización:Teoría y práctica de la liberación (3a ed.). Bogotá: Asociación de Publicaciones Educativas.

Fuchs, T., \& Wossmann, L. (2004). Computers and student learning: bivariate and multivariate evidence on the availability and use of computers at home and at school. Brussels Economic Review, 47 (3-4), 359-386.

Fullan, M.G. (1991). The new meaning of educational change, London: Cassel Educational Limited.

Gandini, L. (1993). Principios básicos de la propuesta de Reggio Emilia para la educación preescolar. Young Children, 49(1), 4-8

García, J. A., Gutiérrez, F., \& Carriedo, N. (2002). Psicología evolutiva II: Desarrollo cognitivo y lingüístico ( $1^{\mathrm{a}}$ ed.). Madrid: Universidad Nacional de Educación a Distancia.

García, M. L. (1996). Organización de la escuela infantil. Madrid: Escuela Española.

Gardner, H. (1998). Foreword: Complementary Perspectives on Reggio Emilia. In C. Edwards, L. Gandini, \& G. Forman (Eds.) The Hundred Languages of Children: The Reggio Emilia Approach. Advanced Reflections (Second Edition) (pp. xv-xviii). USA: Ablex Publishing Corporation.

Gervilla, A. (2006). Didáctica Básica de la Educación Infantil: conocer y comprender a los más pequeños. Madrid: Narcea.

Gialamas, V. \& Nikolopoulou, K. (2010). In-service and pre-service early childhood teachers' views and intentions about ICT use in early childhood settings: A comparative study. Computers and Education, 55, 333-341.

Gilster, P. (1997). Digital literacy. New York: John Wiley

Gimbert, B. \& Cristol, D. (2004). Teaching curriculum with technology: Enhancing children's technological competence during Early Childhood. Early Childhood Education Journal 31(3), 207-216.

Gimeno, J. (1988). El curriculum: una reflexión sobre la práctica. Madrid: Morata.

Gimeno, J. (2008). Educar por competencias. ¿Qué hay de nuevo? Morata: Madrid

Gimeno, J. (2010). Saberes e incertidumbres sobre el curriculum. Madrid: Morata.

Gimeno, J. (2012). En busca del sentido de la educación. Madrid: Morata.

Gimeno, J., Pérez, Á. I., y Bourdieu, P. (1985). La enseñanza :Su teoría y su práctica (2a ed.). Torrejón de Ardoz: Akal. 
Gobbo, C., y Girardi, C. (2001). Teachers' beliefs and integration of information and communications technology in Italian schools. Journal of Information Technology for Teacher Education, 10 (1\&2).63-85.

Goldberg, A., Russell, M., \& Cook, A. (2003). The Effect of Computers on Student Writing: A Meta-analysis of Studies from 1992-2002. The Journal of Technology, Learning, and Assessment, 2 (1), 2-51.

Grabowski, B.L. (2004). Needs Assessment-Informing Instructional Decision Making in a Large Technology-Based Project. En Seel, N. M. y Dijkstra, S. (Eds.). Curriculum, plans and processes in instructional design (pp. 171-192). Mahwah, New Jersey: Lawrence Erlbaum Associates, Publishers.

Greenfield, P.M. (1984). Mind and media: The effects of television, video games and computers. Cambridge, MA: Harvard University Press.

Grimmet, P. y MacKinnon, A. (1992). Craft Knowledge and education of Teachears en G. Grant (com.) Review of research education, 18, 385-456.

Grossman, P. L. (1989). Learning to teach without teacher education. Teachers College Record, 91, 191-207

Grossman, P. L., Wilson, S. M. y Shulman, L. S. (1989). Teachers of substance: Subject matter knowledge for teaching. En M. C. REYNOLDS (Ed.). Knowledge Base for the Beginning Teacher (pp: 23-36). Oxford, Pergamon Press.

Grossman, P., \& Thompson, C. (2008). Learning from curriculum materials: Scaffolds for new teachers? Teaching and Teacher Education, 24, 2014-2026.

Hadley, M. \& Sheingold, K. (1993).Commonalities and Distinctive Patterns in Teachers' Integration of Computers. American Journal of Education, 101 (3), 261-315.

Haertel, G. D., \& Means, B. (2003). Evaluating educational technology: Effective research designs for improving learning. New York: Teachers College Press

Hardwood, D., Klopper, A. Osayin, A., \& Vanderlee, M. L. (2013). It's more than care: early childhood educators' concepts of professionalism. Early Years, 33 (1), 417. DOI: 10.1080/09575146.2012.667394

Hay McBer (2000) Research into Teacher Effectiveness: a model of teacher effectiveness. Report by Hay McBer to the Department for Education and Employment. London: Department for Education and Employment.

Healy, J. M. (1998). Failure to connect: How computers affect our children's minds - for better and worse. New York: Simon \& Schuster.

Hennessy, S., Ruthven, K., y Brindley, S. (2005). Teacher perspectives on integrating ICT into subject teaching: commitment, constraints, caution and change. Journal of Curriculum Studies, 37 (2), 155-192.

Hermans, R. ,Tondeur, J. van Braak,J., y Valcke, M. (2008). The impact of primary school teachers' educational beliefs on the classroom use of computers. Computers $\mathcal{E}$ Education, 51, 1499-1509. 
Hinostroza, E., Labbé, C., Brun, M., y Matamala, C. (2011). Teaching and learning activities in Chilean classrooms: Is ICT making a difference? Computers $\mathcal{E}$ Education, DOI: 10.1016/j.compedu.2011.01.019.

Hlebowisth, P. S. (2005). Generational ideas in Curriculum: A historical triangulation. Curriculum Inquiry, 35 (2), 73-87.

Hogan, T. M., Rabinowitz, M., \& Craven, J. (2003). Problem representation in teching: Inferences from research of expert and novice teachers. Educational Psychologist, 38, 235-247.

Ibáñez Sandín, C. (2003). El proyecto de educación infantil y su práctica en el aula (Edición revisada y actualizada, $15^{\mathrm{a}}$ ed.). Madrid: La Muralla.

Inan, F. A., y Lowther, D. (2009). Factors affecting technology integration in K-12 classrooms: a path model. Educational Technology Research \& Develpment. DOI 10.1007/s11423-009-9132-y

Informe sobre el estado del sistema educativo español 2012. Ministerio de Educación Cultura y Deporte. España: Secretaría General Técnica. Disponible en:

http:/ / www.mecd.gob.es/dctm/cee/informe2012/i2012cee.pdf?documentId=0901 $\underline{\mathrm{e} 72 \mathrm{~b} 8145 \mathrm{~b} 4 \mathrm{f} 2}$

Judson, E. (2006). How teachers integrate technology and their beliefs about learning: is there a connection? Journal of Technology and Teacher Education, 14 (3), 581-597.

Kafai, Y.B., y Giang, M. T. (2008) Virtual Playgrounds: Children's Multi-User Virtual Environments for Playing and Learning with Science. In T. Willoughby \& E. Wood (Eds.), Children's learning in a digital world (pp. 196-217). Oxford, UK:

Blackwell Publishing.

Kant, I. (1983). Pedagogía [Über pädagogik.Español]. Madrid: Akal.

Kardos, S. M., Johnson, S. M. (2007). On Their Own and Presumed Expert: New Teachers' Experience with Their Colleagues. Teacher College Record, 109 (9), 20832016.

Koehler, M.J., \& Mishra, P. (2008). Introducing TPCK. En AACTE Committee on Innovation and Technology (ed.). Handbook of Technological Pedagogical Content Knowledge (TPCK) for Educators (pp.3-30). New York: Routledge.

Kozma, R. B. (2008). Comparative analysis of policies for ITC in education. En J. Voogt y G. Knezed (Eds.), International Handbook of information technology in primary and secondary education. New York: Springer.

Kozma, R., y Anderson, R. (2002). Qualitative case studies of innovative pedagogical practices using ICT. Journal of Computer Assisted Learning, 18, 4 387-394.

Labbo, L. D., Love, M. S., \& Ryan, T. (2007). A vocabulary flood: Making words "sticky" with computer-response activities. The Reading Teacher, 60, 6, 582-588 
Lankshear, C., y Knobel, M. (Eds.) (2008). Digital literacies: Concepts, policies an paradoxes (pp. 15-32). New York: Peter Lang.

Latorre, A. (2004) La investigación acción. En R. Bisquerra (Coord.) Metodología de la investigación educativa. pp. 379-394. Madrid: La Muralla.

Law, N. (2009). Mathematics and science teachers' pedagogicalorientations and their use of ICT in teaching. Education and Information Technologies, 14 (4), 309-323.

Lawless, K. A. y Pellegrino, J. W. (2007). Professional Development in Integrating Technology Into Teaching and Learning: Knowns, Unknowns, and Ways to Pursue Better Questions and Answers. Review of Educational Research, 77 (4), 575-614. DOI: 10.3102/0034654307309921

Le Boulch, J. (1995). El desarrollo psicomotor desde el nacimiento a los seis años: Consecuencias educativas ( $1^{\text {a }}$ de Paidos ed.). Madrid: Paidos.

Lee, K., \& Choi, I. (2008). Learning Classroom Management Through Web-Based Case Instruction: Implications for Early Childhood Teacher Education. Early Childhood Education Journal, 35, 495-503.

Leinhardt, G., \& Greeno, J.G. (1986). The cognitive skill of teaching, Journal of Educational Psychology, 78, April, 75-95.

Leinhardt, G. (1990). Capturing craft knowledge in teaching. Educational Researcher, 19 (2), 18-25.

Leinhardt, G., Weidman, C., \& Hammond, K. M. (1987). Introduction an integration of classroom routines by expert teachers. Curriculum Inquiry, 17(2), 135-176.

Levie, H. W., \& Dickie, K.E. (1972). The Analysis and Application of Media. En Travers, R.M.W. (ed.). The Second Handbook of Research on Teaching (pp. 858-882), Chicago: Rand MacMillan.

Lewin, C., Somekh, B., \& Steadman, S. (2008). Embedding interactive whiteboards in teachingand learning: The process of change in pedagogic practice. Education and Information Technologies, 13, 291-303.

Ley 14/1970, de 4 de agosto, General de Educación y Financiamiento de la Reforma Educativa. Boletín Oficial del Estado, no 189, 6 de agosto de 1970, España.

Disponible en: http://www.boe.es/boe/dias/1970/08/06/pdfs/A12525-12546.pdf

Ley de Educación Primaria, de 17 de julio. Boletín Oficial del Estado, nº 199, 18 julio de 1945, España. Disponible en: http:/ / legislacion.educa-

alv.es/archivos/b2/b2.358.pdf

Ley de instrucción pública, de 9 de septiembre 1857. Disponible en: http://personal.us.es/alporu/historia/ley_moyano_texto.htm

Ley Orgánica 1/1990, de 3 de octubre, de Ordenación General del Sistema Educativo. Boletín Oficial del Estado, $n^{0} 238,4$ de octubre, España. Disponible en: http://www.boe.es/boe/dias/1990/10/04/pdfs/A28927-28942.pdf 
Ley Orgánica 2/2006, de 3 de mayo, de Educación. Boletín Oficial del Estado, n 106, 4 de mayo de 2006, España. Disponible en:

http://www.boe.es/boe/dias/2006/05/04/pdfs/A17158-17207.pdf

Lin, C.H. (2012). Application of a Model for the Integration of Technology in Kindergarten: An Empirical Investigation in Taiwan. Early Childhood Education Journal, 40, 5-17.

Linn, M.C. \& Hsi, S. (2000) Computers, Teachers, Peers: science learning partners.

London: Erlbaum.

Loveless, A. M. (2003). The interaction between Primary Teachers' Perceptions of ICT and Their Pedagogy. Education and Information Technologies, 8 (4), 313-326.

Malaguzzi, L. (1998). History, Ideas, and Basic Philosophy. An Interview with Lella Gandini. In C. Edwards, L. Gandini, \& G. Forman (Eds.) The Hundred Languages of Children: The Reggio Emilia Approach. Advanced Reflections (Second Edition) (pp. 4897). USA: Ablex Publishing Corporation.

Martín, L., Thió de Pol, C. (2007). La escuela de la infancia. En M. Antón (coord.) Planificar la etapa de 0-6: Compromiso de sus agentes y la práctica cotidiana (pp.13-34). Barcelona: Graó.

McCrory Wallace, R. (2004). A framework for understanding teaching with the internet, American Educational Research Journal, 41 (2), 447-448.

McDougall, A., \& Squires, D. (1997). A Framework for Reviewing Teacher Professional Development Programmes in Information Technology. Journal of Information Technology for Teacher Education, 6, 115-126.

Means, B. (2008). Technology's role in curriculum. In F. M. Connelly, M. F. He, \& J. Phillion (Eds.), Sage handbook of curriculum and instruction (pp. 123-144). Thousand Oaks, CA: Sage.

Mercer, N., Littleton, K., \& Wegerif, R. (2004). Methods for studying the processes of interaction and collaborative activity in computer-based educational activities. Technology, Pedagogy and Education, 13(2), 195-212. DOI: 10.1080/14759390400200180

Merchant, G. (2009).Literacy in virtual words. Journal of Research in Reading, 32 (1), $38-56$.

Mishra, P., y Koehler, M. J. (2006). Technological pedagogical content knowledge: A framework for teacher knowledge. Teachers College Record, 108(6), 1017-1054.

Montessori, M., \& Sanchidrián Blanco, C. (2003). El método de la pedagogía científica: Aplicado a la educación en la infancia. Madrid: Biblioteca Nueva.

Moreno, P.L. (2010). El método Decroly. En C. Sanchidrián y J. R. Ruiz (Coords.), Historia y perspectiva actual de la educación infantil (1 ${ }^{\mathrm{a}}$ ed.) (pp. 225-244). Barcelona: Graó. 
Moreu, A. C. (2010). La escuela de Ginebra: Claparède, Piaget, Ademars y Lafendel. En C. Sanchidrián y J. R. Ruiz (Coords,), Historia y perspectiva actual de la educación infantil (1 ${ }^{\mathrm{a}}$ ed.) (267-292). Barcelona: Graó.

Moseley, D., \& Higgins, S. (1999). Ways Forward with ICT: effective pedagogy using information and communications technology for literacy and numeracy in primary schools. London: Teacher Training Agency.

Mueller, J., Wood, E. \& Willoughby, T. (2008). The integration of computer technology in the classroom. In T. Willoughby \& Wood, E. (eds.) Children's learning in a Digital World (pp. 272-298). Malden, MA: Blackwell Publishing, Ltd.

Mueller, J., Wood, E., Willoughby, T., Ross, C., y Specht, J. (2008). Identifying discriminating variables between teachers who fully integrate computers and teachers with limited integration. Computers $\mathcal{E}$ Education, 51, 1523-1537.

Mumtaz, S. (2000). Factors Affecting Teachers' Use of Information and Communications Technology: a review of the literature. Journal of Information Technology for Teacher Education, 9 (3), 319-342.

Munro, A., Surmon, D., y Pizzini, Q. (2006). Teaching Procedural Knowledge in Distance Learning Environments. In H.F. O'Neill and R. S. Perez (eds.). Web-Based Learning. Theory, Research and Practice (pp. 255-278). Mahwah, N. J.: Lawrence Erlbaum Asssociates.

Nesbit, J. C., \& Winne, P. H. (2008). Tools for learning in an information society. In T. Willoughby \& E. Wood (Eds.), Children's learning in a digital world (pp. 173-195). Oxford, UK: Blackwell Publishing.

Niederhauser, D.S., y Stoddart, T. (2001). Teachers' instructional perspectives and use ofeducational software. Teaching and Teacher Education, 17, 15-31.

Null, J.W. (2008).Curriculum development in historical perspective.En Connelly, F. M., Fang, M. yPhillion, J.A. (eds.). The Sage handbook of Curriculum and Instruction (pp. 478-490). California: Sage Publications, Inc.

Olaya Villar, M. D. (1996). Los documentos del plan experimental de educación infantil. Revista Interuniversitaria De Formación Del Profesorado, 25, 167-174.

Olkinuora,E., Mikkilä-Erdmann, M. y Nurmi, S. (2004). Evaluating the Pedagogical Value of Multimedia Learning Material: An Experimental Study in Primary School.En Seel, N.M. y Dijkstra, S. (eds.). Curriculum, Plans, and Processes in Instructional Design (pp. 331-352). Mahwah, New Jersey: Lawrence Erlbaum Associates, Inc.

Olson, D.R. (ed.) (1974). Media and Symbols: the Forms of Expression, Communication and Education. Chicago: Chicago University Press.

Ortega Sebastián, E., \& Blázquez Sánchez, D. (1991). La actividad motriz en el niño de 3 a 6 años (5a reimp ed.). Madrid: Cincel.

Pablos, J. de, Area, M., Valverde, J. y Correa, J.M. (coords.) (2010). Políticaseducativas y buenasprácticas con TIC. Barcelona: Graó. 
Padron, Y. N., Waxman, H. C., Lee, Y-H., Lin, M-F, Michko, G. M. (2010).

Classrooms Observations of Teaching and Learning with Technology in Urban Elementary School Mathematics Classrooms Serving English Language Learners. International Journal of Instructional Media, 39 (1), 45-54.

Papert, S. (1996). Computers in the Classroom: Agents of Change. Washington: The Washington Post Education Review, 27 de Octubre de 1996.

Paraskeva, F., Bouta, H., \& Papagianni, A. (2008). Individual characteristics and computer self-efficacy in secondary education teachers to integrate technology in educational practice. Computers E Education, 50 (3), 1084-1091.

Parette, H. Stoner, J. Watts, E. (2009). Assistive Technology User Group Perspectives of Early Childhood Professionals. Education and Training in Developmental Disabilities, 2009, 44 (2), 257-270.

Pedretti, J.E., Mayer-Smith, J. \& Woodrow, J. (1998) Technology, Text, and Talk: students' perspectives on teaching and learning in a technology-enhanced secondary science classroom, Science Education, 82, 569-590.

Pérez Gómez, A. (2012). Educarse en la era digital. Madrid: Morata.

Pestalozzi, J. H. (1936). Cómo enseña Gertrudis a sus hijos. Madrid: Espasa-Calpe.

Pestalozzi, J. H. (1988). Cartas sobre educación infantil. Madrid: Tecnos.

Plomp, T., y Pelgrum, W.J. (1991). Introduction of computers in education: State of the art in eight countries. Computers $\mathcal{E}$ Education, 17 (3), 249-258.

Popkewitz, T. (1986). The social context of schooling, change and educational research. En Taylor, Ph. (Ed), Recent developments in curriculum studies. pp. 205-232. Windsor. NFER-Nelson.

Prensky, M. (2001). Digital Natives, Digital Immigrant. On the Horizon, 9 (5), 1-6.

Putnam, R. T. \& Borko, H. (2000). What do new views of knowledge and thinking have to say about research on teacher learning? Educational Researcher, 29 (1), 4-15.

Ramírez, E. (1996). La evolución de las concepciones de la tecnología educativa en el desarrollo del curriculum. Revista de Educación, 309, 335-329.

Ramírez, E. (2005). Selección de software educativo: Dos ejemplos de evaluación de material didáctico en soporte CD-Rom. Cultura y Educación, 17 (2), 131-146.

Ramírez, E., Cañedo, I. y Clemente, M. (2012). Las actitudes y creencias de los profesores de secundaria sobre el uso de Internet en sus clases. Revista Comunicar, 38 (19), 147-155.

Ramírez, E., Cañedo, I., Clemente, M., Jiménez, J. y Martín, J. (2011). Un estudio sobre internet en las aulas. ¿Qué nos dicen los profesores de secundaria sobre el uso de estos recursos en sus prácticas? Revista iberoamericana de educación (versión digital), 56 (1), http:// www.rieoei.org/deloslectores/3971Ramirez.pdf 
Ramírez, E., Martín, J., Orgaz, B. y Cañedo, I. (2012). Assessing Digital Skills in Early Childhood Education: A Classroom-Based Practices Approach. Paper presented to the European Conference on Educational Research (ECER), Cádiz, 18-21 September.

Ramos, S. (2010). Un método educativo para la infancia: el de Fröbel. En C.

Sanchidrián y J. R. Ruiz (Coords,), Historia y perspectiva actual de la educación infantil

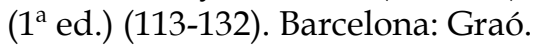

Real Decreto 1630/2006, de 29 de diciembre, por el que se establecen las enseñanzas mínimas del segundo ciclo de Educación Infantil. Boletín Oficial del Estado, 4 enero de 2007, nº 4, España. Disponible en:

http://www.boe.es/boe/dias/2007/01/04/pdfs/A00474-00482.pdf

Rosen, L. S., \& Weil, M. M. (1995). Computer Availability, Computer Experience, And Techonophobia Among Public School Teachers. Computers in Human Behavior, 11, 9-31

Ross, V., Haith, M. M., \& Miller, S. A. (2001). Psicología infantil. Barcelona: Ariel.

Rousseau, J. (1964). Emilio o de la educación [Émile ou De l'éducation.Español].

Madrid: Edaf.

Rousseau, J., \& Armiño, M. (1980). Ensayo sobre el origen de las lenguas. Madrid: Akal.

Ruthven, K., Hennessy, S. \&Deaney, R. (2005). Incorporating internet resources into classroom practice: pedagogical perspectives and strategies of secondary-school subject teachers. Computers $\mathcal{E}$ Education, 44, 1-34.

Salomon, G. (1981). Interaction of Media, Cognition and Learning.San Francisco: Jossey Bass Publishers.

San Martín, A. (2010). La transferencia tecnológica como desafío para la didáctica de los contenido 2.0. En J. Peirats y A. San Martín, Tecnologías educativas 2.0.

Didáctica de los contenidos digitales (pp. 186-204). Madrid: Pearson.

Sánchez Blanco, C. (2001). De la educación infantil y su crítica :Reforma, investigación e innovación y formación del profesorado ( $1^{\mathrm{a}}$ ed.). Morón, Sevilla: M.C.E.P.

Sánchez, E., Rosales, J. \& Cañedo, I. (1999). Understanding and communication in expositive discourse: an analysis of the strategies used by expert and preservice teachers. Teaching and Teacher Education, 15, 37-58.

Sánchez, E., Rosales, J., \& García, R. (2010). La lectura en el aula: Qué se hace, qué se debe hacer y qué se puede hacer. Barcelona: Graó.

Sanchidrián, C., y Ruiz Berrio, J. (2010). Historia y perspectiva actual de la educación infantil (1a ed.). Barcelona: Graó.

Santín, D. (2006). La medición de la eficiencia de las escuelas: una revisión crítica. Hacienda Pública Española, 177, 57-82.

Savage, R.S. ,Erten, O., Abrami, P., Hipps, G. , Comaskey, G. , van Lierop, D. (2010). ABRACADABRA in the hands of teachers: The effectiveness of a web-based 
literacyintervention in grade 1 language arts programs. Computers $\mathcal{E}$ Education, 55, 911-922.

Schank, R. (1997). Virtual learning: A revolutionary approach to building a highly skilled workforce. New York: McGraw-Hill.

Schoenfeld, A. H. (1998). Toward a theory of teaching-in-context. Issues in Education, 4 (1), 1-94.

Schwab, J. (1985). Un enfoque práctico como lenguaje para el curriculum. En Gimeno Sacristán, J., Pérez Gómez, Á. I. y Bourdieu, P. (Comp.), La enseñanza: Su teoría y su práctica (2a ed.). Torrejón de Ardoz: Akal.

Selwyn, N. (2010).Looking beyond learning: notes towards the critical study of educational technology.Journal of Computer Assisted Learning, 26 (1), 65-73.

Selwyn, N. (2012). Ten suggestions for improving academic research in educationand technology. Learning, Media and Technology,

DOI:10.1080/17439884.2012.680213.

Shavelson, R. J. (1986). Toma de decisiones interactiva: algunas reflexiones sobre los procesos cognoscitivos de los profesores. En L. M. Villar Angulo (Ed.) Pensamiento de los profesores y toma de decisiones (pp. 164-184). Sevilla: Publicaciones Universidad de Sevilla.

Shulman, L. S. (1986). Those Who Understand: Knowledge Growth in Teaching. Educational Research, 15 (4), 4-14.

Shulman, L. S. (1987). Knowledge and Teaching: Foundations of the New Reform. Harvard Educational Review, 57 (1), 1-22.

Simons, H. (2011). Estudio de caso :Teoría y práctica. Madrid: Morata.

Siraj-Blatchford, I. \& Siraj-Blatchford, J. (2006). A guide to developing the ICT curriculum for Early Childhood Education. Sttafordshire, UK: Trentham Books Limited.

Smeets, E. (2005). Does ICT contribute to powerful learning environments in primary education? Computers $\mathcal{E}$ Education, 44, 343-355.

Smith, P. y Connolly, K. (1980). The ecology of preschool behavior. Cambridge: Cambridge University Press.

Specht, J., Wood, E., \& Willougby, T. (2002). What Early Childhood Educators Need to Know About Computers in Order to Enhance the Learning Environment.

Canadian Journal of Learning and Technology, 28 (1). Disponible en: http://www.cjlt.ca/index.php/cjlt/article/view/1/1

Spector, J. M. (2004). Multiple Uses of Information and Communication Technology in Education. En Seel, N.M. y Dijkstra, S. (eds.). Curriculum, Plans, and Processes in Instructional Design (pp. 271-288). Mahwah, New Jersey: Lawrence Erlbaum Associates, Inc.

Stake, R. E. (1998). Investigación con estudio de casos. Madrid: Morata. 
Stake, R. E. (2006). Evaluación comprensiva y evaluación basada en estándares (1a ed.). Barcelona: Graó.

Stenhouse, L. (1985). Investigación y desarrollo del curriculum. Madrid: Morata.

Suárez, J.M., Almerich, G., Gargallo, B y Aliaga, F. M. (2013). Las competencias del profesorado en TIC: estructura básica. Educación XX1, 16 (1), 39-62. DOI:

10.5944/educXX1.16.1.716

Tójar Hurtado, J. C. (2006). Investigación cualitativa :Comprender y actuar. Madrid: La Muralla.

Trigueros, F. J., Sánchez, R. y Vera, M. I. (2012). El profesorado de Educación Primaria ante las TIC: realidad y retos. Revista Electrónica de Formación del Profesorado, 15 (1), 101-112. Disponible en:

http:/ / www.redalyc.org/articulo.oa?id $=217024398008$

UNESCO (2008). ICT Competency Standards for Teachers: Implementation Guidelines. París: UNESCO. Disponible en: http://unesdoc.unesco.org/images/0015/001562/156209E.pdf

UNESCO (2011). Transforming Education: The Power of ICT Policies. París: UNESCO. Disponible en: http:// unesdoc.unesco.org/images/0021/002118/211842e.pdf

Valverde, J., Fernández, M. R. y Revuelta, F. I. (2013). El bienestar subjetivo ante las buenas prácticas educativas con TIC: su influencia en profesora innovador.

Educación XX1, 16 (1), 255-280. DOI: 10.5944/educxx1.16.1.726

Vanderlinde, R., Dexter, S., y van Braak, J. (2011). School-based ICT policy plans in primary education: Elements, typologies and underlying processes, British Journal of Educational Technology, doi:10.1111/j.1467-8535.2011.01191.x.

Vasta, R., Haith, M. M., \& Miller, S. A. (2001). Psicología infantil (2a ed.). Barcelona: Ariel.

Vicente Villena, Ma P. de (2001). La génesis social de las escuelas infantiles. Pedagogía Social. Revista Interuniversitaria, (6-7), 321-329.

Vygotsky, L. S., \& Piaget, J. (1977). Pensamiento y lenguaje: Teoría del desarrollo cultural de las funciones psíquicas. Buenos Aires: La Pléyade.

Vygotsky, L. S., Blanck, G., Van der Veer, R., \& Carretero, M. (2001). Psicología pedagógica :Un curso breve (1a ed.). Buenos Aires: Aique.

Vygotsky, L. S., Cole, M., \& Luriia, A. R. (1979). El desarrollo de los procesos psicológicos superiores. Barcelona: Crítica.

Ward, L., y Parr, J. M. (2010). Revisiting and reframing use: Implications for the integration of ICT, Computers \& Education, 54, 113-122.

Waxman, H. C., Lin, M., Michko, G.M. (2003). A Meta-Analysis of the effectiveness of Teaching an Learning With Technology on Student Outcomes. Illinois: Learning Point Associates. Revisado de:

http:/ / treeves.coe.uga.edu/edit6900/metaanalysisNCREL.pdf 
Webb, M. \& Cox, M. (2004). A review of pedagogy related to information and communications technology. Technology, Pedagogy and Education, 13 (3), 235-286

Webb, M. (2011) Changing models for researching pedagogy with information and communications technologies. Journal of Computer Assisted Learning, 27 (6), 1-15.

Wenglinsky, H. (2005). Using technology wisely. The keys to success in schools. New York: Teachers College Press.

Windschitl, M. (2004). What types of knowledge do teachers use to engage learners in "doing science"? Paper commissioned by the National Academy of Sciences. Washington, DC: Board of Science Education .Consultado en diciembre, 2010, de http://www7.nationalacademies.org/bose/mwindschitl_comissioned_paper_6_03 04_hslabs_mtg.pdf.

Wood, E., Gottardo, A., Grant, A., Evans, M. A., Phillips, L., \& Savage, R. (2012). Developing tools for assessing and using commercially available reading software programs to promote the development of early reading skills in children. NHSA Dialog: A research-to-Practice Journal for the Early Childhood Field, 15(4), 350-354.

Yang, H. (2012). ICT in English schools: transforming education? Technology, Pedagogy and Education, 21(1), 101-118.

Yinger, R. J. (1987). Learning the Language of Practice. Curriculum Inquiry, 17(3), 293-318.

Zhao, Y. (2003). What teachers need to know about technology? Framing the Question. En Zhao, Y. (ed.). What should teachers know about technology? Perspectives and Practices (pp. 1-14). Greenwich, Connecticut: Information Age Publishing.

Zhao, Y., Frank, K. A. y Ellefson, N.C. (2006), Fostering meaningful teaching and learning with technology: characteristics of effective professional development, en E.A. Ashburn y R. E. Floden (eds): Meaningful learning using technology. What educators need to know and do. New York: Teachers College Press, 161-179.

Zhao, Y., Yan, B. \& Lei, J. (2008). The logic and logic model of technology evaluation. In J. Voogt \& G. Knezek (eds.). Intenational Handbook of Information Technology in Primary and Secondary Education (pp. 633-653). New York: Springer 


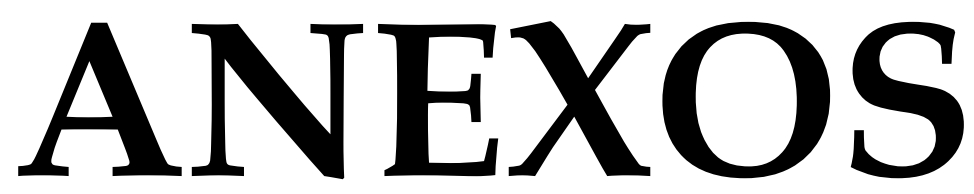



ANEXO I 



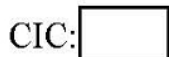

Estimado/a director/a:

Nos ponemos en contacto con usted para solicitar su colaboración. Somos un grupo de profesores de la Universidad de Salamanca que estamos Ilevando a cabo una investigación financiada por el Ministerio de Ciencia e Innovación en colaboración con el CITA, sobre las prácticas de los profesores de Infantil con el Rincón del Ratón. Nos interesa conocer algunos aspectos del contexto de su centro para entender mejor cómo se desarrollan las prácticas con este recurso informático, de ahí que solicitemos su colaboración

Por favor, a continuación, tache la casilla que corresponda

\section{A.- ESTRUCTURA Y ORGANIZACIÓN DEL CENTRO}

1.- Tipo de centro:

Público

Concertado/Privado

3.- Total de alumnos en el centro

4.- Número de profesores en su centro en las en las siguientes categorías:

- Definitivo

- Interino

- Expectativa de destino

- En prácticas
2.- Etapas educativas

$\square$ Infantil

Infantil+Primaria

$\square$ Infantil+Primaria+Secund. ( $1^{\circ}$ ciclo)

$\square$ Infantil+Primaria+Secund. $\left(1^{\circ}\right.$ y $2^{\circ}$ Ciclo $)$

Infantil+Primaria+Secund.+Bachillerato

5.- Número de profesores de Infantil de su centro en las siguientes categorías:

- Definitivo

- Interino

Expectativa de destino

- En prácticas

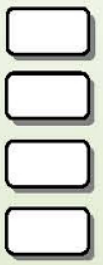

\section{B.- UBICACIÓN Y USO DE RECURSOS INFORMÁTICOS}

6.- ¿Dónde están ubicados los ordenadores del centro y de qué cantidad de ordenadores se dispone? (Señale todas las opciones posibles):

Aula de informática

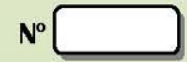

Aulas ordinarias

Infantil
Primaria
profesores
Tecnologia
spacios:

ESO

Bachillerato

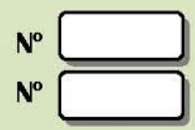

$\mathbf{N}^{\circ}$

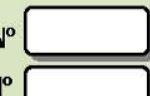

$\mathbf{N}^{\circ}$

$\mathbf{N}^{\circ}$

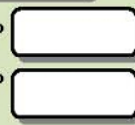

Otros espacios: 
7.- đQuiénes usan los ordenadores en el centro escolar y para qué los usan? ¿Quiénes?

¿Para qué?

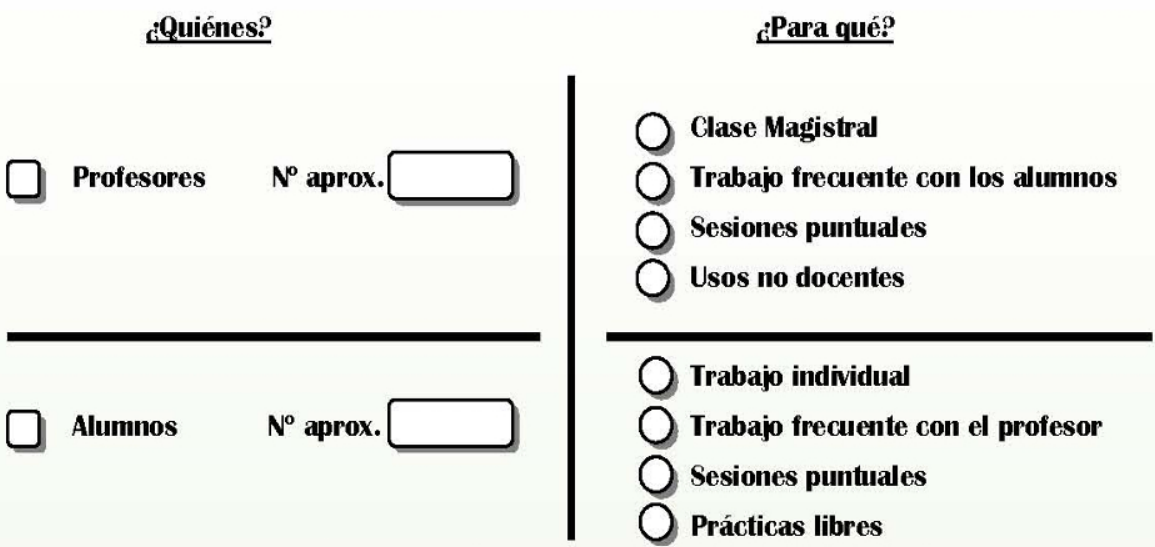

Otros:

8.- ¿Dónde están ubicados las pizarras digitales en el centro y de qué número de pizarras se dispone? (Señale todas las opciones posibles):

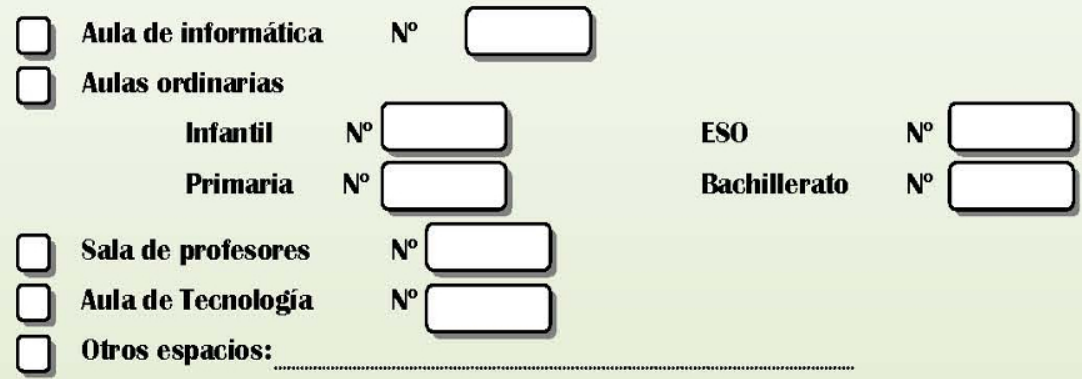

9.- ¡Quiénes usan las pizarras digitales en el centro escolar y para qué las usan?

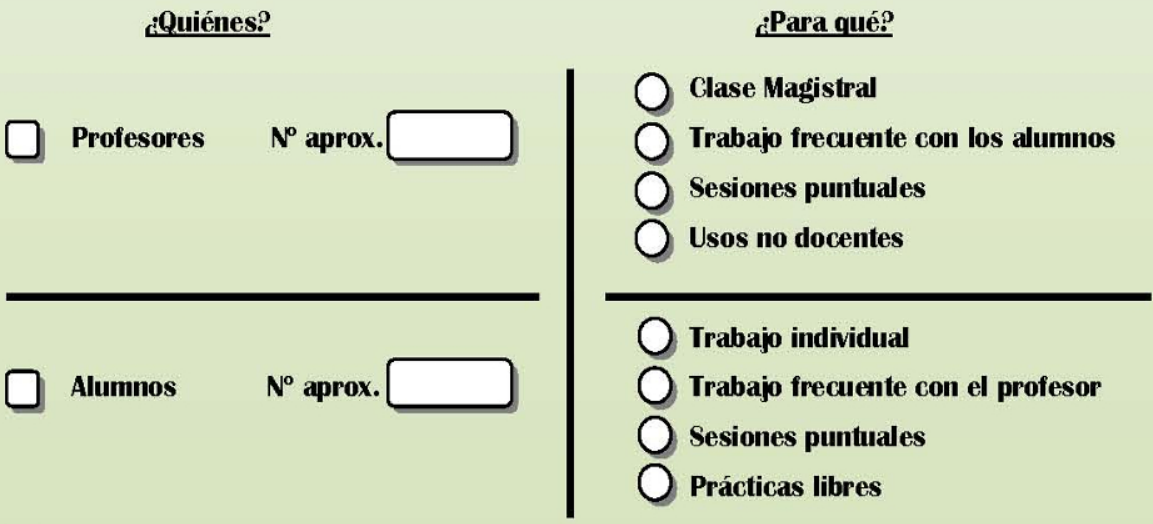

Otros: 
10.- ¿Dónde existe conexión a Internet en el centro y cuántos ordenadores disponen de conexión en cada espacio? (Señale todas las opciones posibles):

$\square$ Aula de informática $\mathbf{N}^{\circ} \square$

Aulas ordinarias

Infantil

Primaria

$\mathbf{N}^{\circ}$

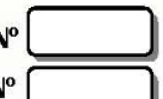

Sala de profesores

Aula de Tecnología

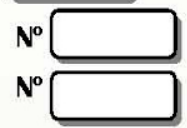

$\square$ Otros espacios:

ESO

Bachillerato
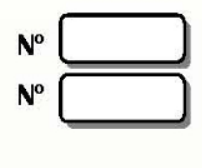

11.- ¿Quiénes usan la conexión a Internet en el centro escolar y para qué la usan?

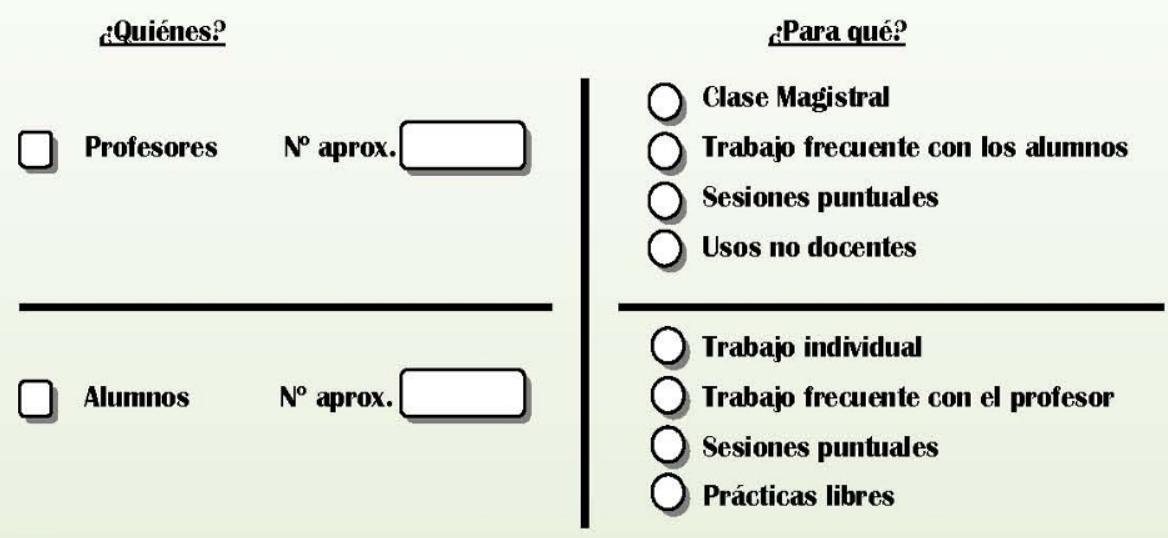

Otros:

12.- ¿Dónde están ubicados los cañones de proyección en el centro y de qué número de cañones se dispone? (Señale todas las opciones posibles):

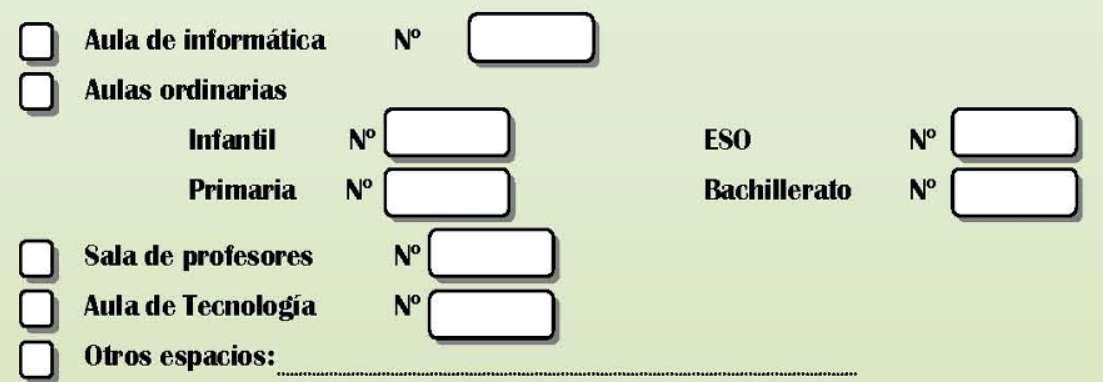

\section{C.- ASESORAMIENTO TÉCNICO Y DISPONIBILIDAD DE MATERIALES DIDÁCTICOS}

13.- ¿Cuáles de los siguientes servicios de mantenimiento están disponibles en su centro? (Señale todas las opciones posibles):

Técnico especialista en informática del centro.

Profesor coordinador TIC liberado de horas lectivas.

Profesor coordinador TIC liberado de horas de permanencia en el centro.

Contrato de mantenimiento con empresas informáticas externas.

Otros: 


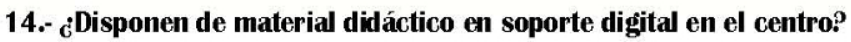

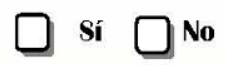

15.- ¿Cuáles son las fuentes más habituales de obtención de material didáctico en soporte digital para la docencia en el centro?

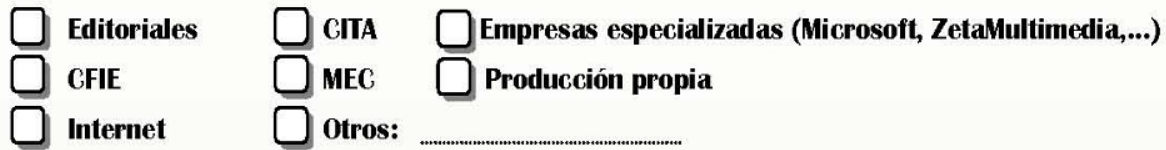

\section{D.- CULTURA DE INNOVACIÓN}

16.- ¿Ha participado su centro en los últimos cinco años en algín proyecto de innovación?

$\square$ Sí Temática: OTecn. de la Inform. y la Comunicación

Ootros:

$\square$ No

17.- ¿Han participado los profesores de su centro en los últimos cinco años en experiencias de formación por iniciativa del centro?

$\square$ Sí Temática: $\begin{aligned} & \text { OTecn. de la Inform. y la comunicación } \\ & \text { Ootros: }\end{aligned}$
$\square$ No

18.- ¿Qué medidas facilitadoras toma el centro cuando los profesores participan en experiencias de formación?

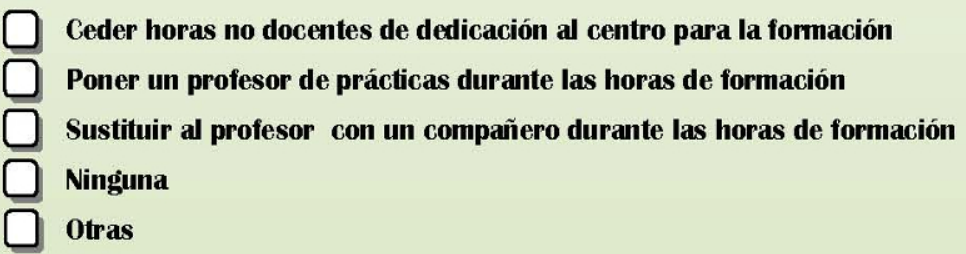

19.- ¿Dónde se han desarrollado esas experiencias de formación?

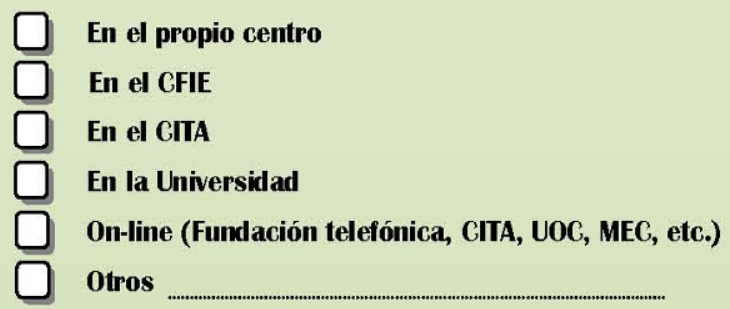


ANEXO II 

Estimados padres: Como sabéis en el aula de Educación Infantil de vuestro hijo, el CITA ha incorporado un nuevo recurso, el Rincón del Ratón. Dicho recurso va asociado a un proyecto de investigación en colaboración con la Universidad de Salamanca para estudiar cómo se está desarrollando el proceso. Entre las acciones asociadas al proyecto se incluye el siguiente cuestionario sobre el uso que las familias hacen de las tecnologías en el hogar. Por ello agradeceríamos que contestasen las preguntas a continuación y devuelvan el cuestionario rellenado al profesor de su hijo, en el plazo de una semana a partir del momento de su recepción.

El cuestionario es totalmente anónimo, y para uso exclusivo de esta investigación. Gracias de antemano por su colaboración. Un saludo

1- Número de hijos en su familia:

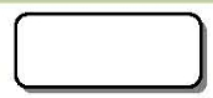

2- Curso de Educación Infantil que realiza su hijo:

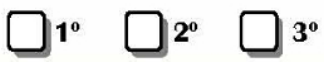

3- Nivel de estudios del padre:

4- Nivel de estudios de la madre:

$\square$ Graduado Escolar/ESO
$\square$ Bachillerato
$\square$ Formación Profesional
$\square$ Diplomatura
$\square$ Licenciatura
$\square$ Otro:

$\square$ Graduado Escolar/ESO
$\square$ Bachillerato
$\square$ Formación Profesional
$\square$ Diplomatura
$\square$ Licenciatura
$\square$ Otro:

5- Ámbito profesional del padre (P) y de la madre (M):

\section{Gestión/Administración}

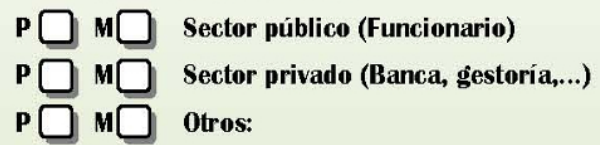

\section{Transporte}

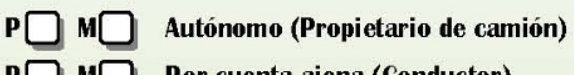

P $\square$ M Por cuenta ajena (Conductor)

Agricultura/Ganadería

Sanidad/Salud

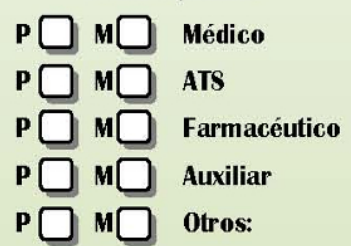

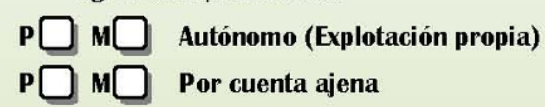

Construcción

$\mathrm{P} \square \mathrm{M} \square$ Autónomo (Construc., pintor,...)

$\mathbf{P} \mathrm{M} \square$ Por cuenta ajena (Peón, oficial,...)

Sector servicios

P $\square \square$ Autónomo (Negocio propio)

P $\square \square$ Por cuenta ajena (Hostelería,

limpieza, comercio,...)

Tareas Domésticas

$\mathbf{p} \mathrm{M} \square$ Sus labores

Otros: 
6- Señale todos los medios tecnológị cos de los que disponga en su casa:

$\begin{array}{ll}\square \text { Televisor-TDT-DVD } & \square \text { Teléfono móvil-Cámara fotogiráfica } \square \text { Ordenador: } \\ \square \text { Internet } & \square \text { Otros }\end{array}$

7- ¿Para qué usa los medios tecnológicos de los que dispone?

$\square$ Ocio y tiempo libre
$\square$ Uso Laboral
$\square$ Informativo

8- ¿Señale todos los medios tecnológicos que utiliza su hijo en casa?

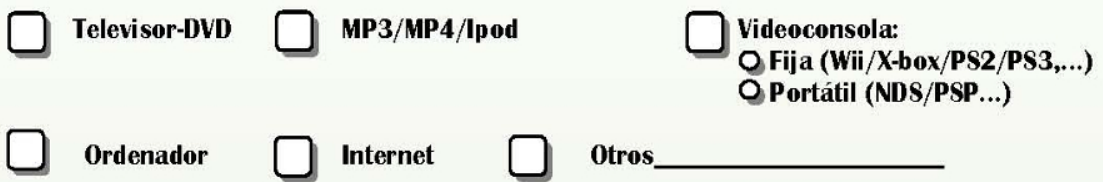

9- Cuando su hijo usa los medios tecnológicos en su casa, lo hace:

De forma individual (sole)

En compañía de la madre/padre

En compañía de un hermano/a

En compañía de amigos

10- Le limita a su hijo el número de horas de uso de estos medios tecnológicos:

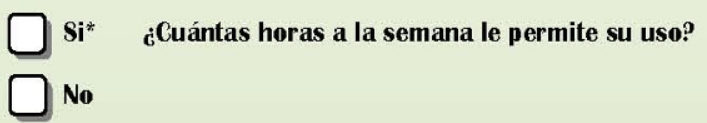

11- ¿Con qué frecuencia acude su hijo a las actividades progiramadas por el CITA?

$\begin{array}{ll}\square \text { Diariamente } & \square \text { Quincenalmente } \square \text { Trimestralmente } \\ \square \text { Semanalmente } & \square \text { Mensualmente }\end{array}$

12- ¿Señale en qué grado está de acuerdo con que se dedique tiempo al uso de las tecnologías en el ámbito escolar?

$\square_{\text {de acuerdo }}^{\text {Totalmente }} \square_{\text {de acuerdo }}^{\text {Bastante }} \square$ Indiferente $\square_{\text {en desacuerdo }}^{\text {Bastante }} \square_{\text {en desacuerdo }}^{\text {Totalmente }}$


ANEXO III 



\section{Fundación Germán Sánchez Ruipérez-}

Universidad de Salamanca.

Plantilla de la entrevista inicial para

profesores participantes en el proyecto "El

Rincón del Ratón"

Curso 2011-12 
Estimado/a profesor/a: Con las preguntas que incluimos a continuación, nos gustaría poder conocer cuáles son las ideas, concepciones, creencias que explican tu posición ante el uso del proyecto educativo "el Rincón del Ratón" para la etapa de Educación Infantil propuesto por el CITA. Nos interesa conocer los aspectos más sobresalientes que te motivaron a trabajar con este recurso en tu aula, así como otros más concretos sobre cómo y para qué lo estás utilizando en relación con la organización y planificación de la enseñanza-aprendizaje del currículo de Infantil. Las preguntas están formuladas de manera abierta con algunas pautas que pueden orientarte, de tal forma que te permitan expresar tus ideas sobre el tema. Como vas a poder disponer de estas preguntas durante un mes, puedes contestar primero a las cuestiones del apartado 1 y 2 , referidas, respectivamente, a tu motivación para trabajar con el programa y la implantación y dejar para más adelante, cuando hayas trabajado durante más tiempo con el recurso, las cuestiones del apartado 3, referidas al uso docente. El apartado 4 sobre cuestiones generales se puede contestar en cualquier momento.

No obstante, estaríamos encantados de que cualquier asunto que desees comentar al respecto durante ese periodo puedas hacerlo dirigiéndote o bien a la asesora del CITA o a los siguientes correos electrónicos: ero@usal.es, jorgemd $($ usal.es

Género:

$\square$ Hombre
$\square$ Mujer

Años de experiencia docente:

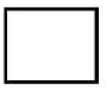

Curso:

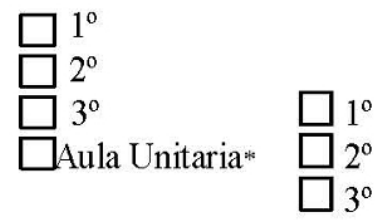

Años de antigüedad en el centro:

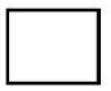

Experiencia previa con El Rincón del Ratón:

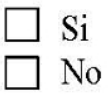




\section{Sobre tu motivación para trabajar con el proyecto:}

1.1. ¿QUÉ MOTIVOS TE HAN ANIMADO A PARTICIPAR EN EL PROYECTO DEL RINCÓN DEL RATÓN?

1.2. ¿QUÉ PAPEL PIENSAS QUE JUEGAN O JUGARÁN LAS TECNOLOGÍAS EN EL TRABAJO DE TU CLASE? (Si crees que mejoraran el proceso de enseñanza, el aprendizaje de los alumnos, su motivación) 
2.- Sobre la formación para la puesta en marcha en el aula

2.1. ¿CÓMO VALORAS TU FORMACIÓN PREVIA EN TIC, INDEPENDIENTEMENTE DEL PROYECTO DEL RINCÓN DEL RATÓN? (Por ejemplo: si has recibido cursos de formación en los CFIEs, en el CITA, en tu formación inicial...Si esa formación es más de carácter didáctico o técnico..., incluso el grado de especialización de esa formación)

2.2. ¿CÓMO HA SIDO LA INFORMACIÓN QUE HAS RECIBIDO PARA LA INTRODUCCIÓN DE ESTE RECURSO EN LAS AULAS?: (Por ejemplo: sobre la explicación ofrecida en la clase cuando se presentó el recurso tecnológico)

2.3. ¿CÓMO HA SIDO LA FORMACIÓN QUE HAS RECIBIDO PARA LA INTRODUCCIÓN DE ESTE RECURSO EN LAS AULAS? (Por ejemplo: sobre la ayuda de la orientadora tecnológica del CITA para apoyar y asesorar en la implantación del nuevo rincón. Sobre la formación ofrecida por los profesionales del CITA con los programas y los materiales del recurso. Concretamente, si la formación se ha centrado en los aspectos técnicos de los programas y la tecnología, en propuestas para integrar el Rincón en las prácticas concretas con los contenidos de Infantil, en cómo resolver problemas del aula...) 
2.4. ¿EXISTEN MEDIDAS DE APOYO EN CASO DE PROBLEMAS TÉCNICOS CON EL RINCÓN DEL RATÓN? ¿SI ES ASÍ, DE DÓNDE PROCEDEN DE TU CENTRO O DEL CITA?

2.5. ¿HAS ENCONTRADO APOYOS Y COBERTURA PARA LA INTRODUCCIÓN DEL RINCÓN DEL RATÓN POR PARTE DEL EQUIPO DIRECTIVO DEL CENTRO? ¿Y ENTRE TUS COMPAÑEROS DEL CENTRO? 


\section{Sobre el uso del recurso en relación con el currículo de infantil:}

3.1. ¿QUÉ OBJETIVOS QUIERES CONSEGUIR USANDO EL RINCÓN EN TUS CLASES?

3.2. ¿SE PUEDEN TRABAJAR TODOS LOS CONTENIDOS DE LAS TRES ÁREAS CURRICULARES A TRAVÉS DE LOS DISTINTOS PROGRAMAS QUE PROPONE EL RECURSO?¿QUÉ CRITERIOS HAS SEGUIDO PARA LA SELECCIÓN?

3.3. ¿TRABAJAR CON ESTOS MATERIALES IMPLICA PLANTEAR LAS ACTIVIDADES EN EL AULA DE FORMA DISTINTA? (Puedes poner algún ejemplo respecto algún programa y actividad) 
3.4. ¿QUÉ TIPO DE APRENDIZAJE Y MOTIVACIÓN GENERA EN LOS ALUMNOS DE TU CLASE TRABAJAR CON LOS DISTINTOS PROGRAMAS? ¿HAS NOTADO MEJORES RESULTADOS? ¿Y EN RELACIÓN CON OTROS RINCONES DE TRABAJO EN EL AULA? (Puedes poner algún ejemplo respecto algún programa y contenido)

3.5. ¿QUÉ CAMBIOS EN LA ORGANIZACIÓN CONCRETA DE TU AULA EXIGE LA UTILIZACIÓN DE ESTE RECURSO? ¿Y DEL CENTRO?

3.6. ¿TE ESTÁ SUPONIENDO MUCHO ESFUERZO INTRODUCIR EL USO DEL RECURSO EN LA DINÁMICA DE TU TRABAJO? 
3.7 ¿LA INTRODUCCIÓN DE ESTE RECURSO EN EL AULA AFECTA A TU FORMA HABITUAL DE EVALUAR A LOS ALUMNOS? 


\section{Sobre otras cuestiones generales:}

4.1.- ¿QUÉ VISIÓN TIENES SOBRE EL PAPEL QUE JUEGA EL PROFESOR EN LA EDUCACIÓN INFANTIL?

4.2.- ¿CUÁL ES EL PAPEL DEL ALUMNO EN EL APRENDIZAJE EN EDUCACIÓN INFANTIL?

4.3.- ¿CREES QUE ALGUNA TEORÍA DEL APRENDIZAJE EN ESPECIAL EXPLICA MEJOR CÓMO SE APRENDE Y CÓMO DEBE ENSEÑARSE? 